\title{
A Comparative Assessment of Alternative Combustion Turbine \\ Inlet Air Cooling Systems
}

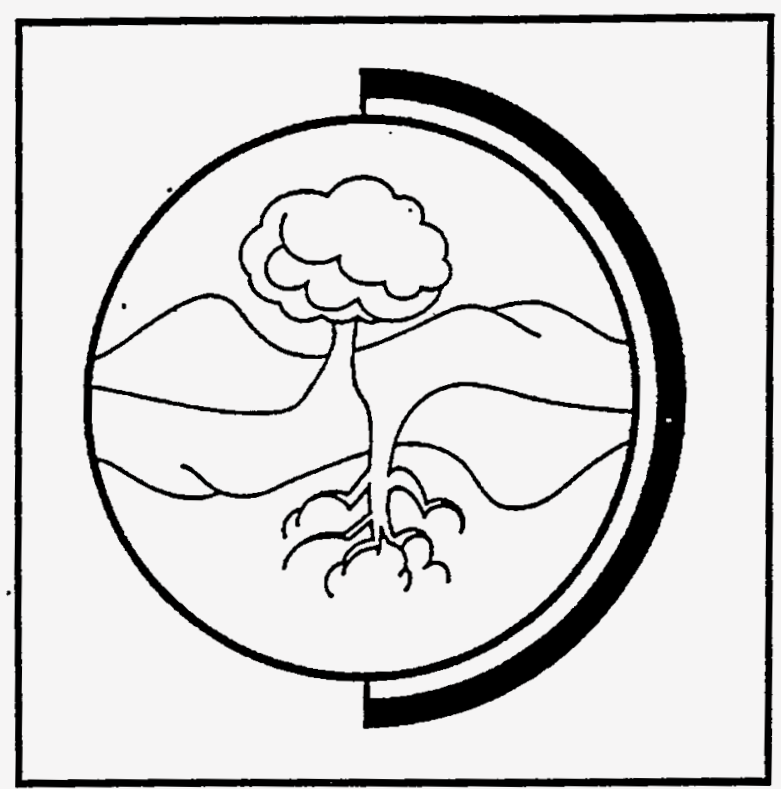

February 1996

Prepared for the U.S. Department of Energy under Contract DE-AC06-76RLO 1830

Pacific Northwest National Laboratory Operated for the U.S. Department of Energy by Battelle

\%ำ Battelle

\section{RECEIVED}

MAR 26 1996 
. 


\section{DISCLAIMER}

This report was prepared as an account of work sponsored by an agency of the United States Government. Neither the United States Government nor any agency thereof, nor Battelle Memorial Institute, nor any of their employees, makes any warranty, express or implied, or assumes any legal liability or responsibility for the accuracy, completeness, or usefulness of any information, apparatus, product, or process disclosed, or represents that its use would not infringe privately owned rights. Reference herein to any specific commercial product, process, or service by trade name, trademark, manufacturer, or otherwise does not necessarily constitute or imply its endorsement, recommendation, or favoring by the United States Government or any agency thereof, or Battelle Memorial Institute. The views and opinions of authors expressed herein do not necessarily state or reflect those of the - United States Government or any agency thereof.

\section{PACIFIC NORTHWEST NATIONAL LABORATORY operated by \\ BATTELLE MEMORIAL INSTITUTE \\ for the \\ UNITED STATES DEPARTMENT OF ENERGY under Contract DE-AC06-76RLO 1830}

Printed in the United States of America

Available to DOE and DOE contractors from the

Office of Scientific and Technical Information, P.O. Box 62, Oak Ridge, TN 37831; prices available from (615) 576-8401.

Available to the public from the National Technical Information Service, U.S. Department of Commerce, 5285 Port Royal Rd., Springfield, VA 22161 
This report was prepared as an account of work sponsored by an agency of the United States Government. Neither the United States Government nor any agency thereof, nor any of their employees, makes any warranty, express or implied, or assumes any legal liability or responsibility for the accuracy, completeness, or usefulness of any information, apparatus, product, or process disclosed, or represents that its use would not infringe privately owned rights. Reference herein to any specific commercial product, process, or service by trade name, trademark, manufacturer, or otherwise does not necessarily constitute or imply its endorsement, recommendation, or favoring by the United States Government or any agency thereof. The views and opinions of authors expressed herein do not necessarily state or reflect those of the United States Government or any agency thereof.

\title{
A Comparative Assessment of Alternative Combustion Turbine Inlet Air Cooling Systems
}

\author{
D. R. Brown \\ S. Katipamula \\ J. H. Konynenbelt
}

February 1996

Prepared for

the U.S. Department of Energy

under Contract DE-AC06-76RLO 1830

Pacific Northwest National Laboratory

Richland, Washington 99352 


\section{Summary}

Interest in combustion turbine inlet air cooling (CTAC) has increased during the last few years as electric utilities face increasing demand for peak power. Inlet air cooling increases the generating capacity and decreases the heat rate of a combustion turbine during hot weather when the demand for electricity is generally the greatest. Several CTAC systems have been installed (e.g., see Ebeling et al. 1992), but the general applicability of the concept and the preference for specific concepts is still being debated.

Concurrently, Rocky Research of Boulder City, Nevada has been funded by the U.S. Department of Energy to conduct research on complex compound (ammoniated salt) chiller systems for lowtemperature refrigeration applications. While the focus of this work has been on food processing applications, complex compound refrigeration could also be applied to CTAC.

The principal objectives of this study were to:

1. identify the.preferred CTAC technology as a function of application conditions from currently available cooling technologies,

2. identify application conditions where currently available cooling technologies are not cost-effective,

3. determine the potential attractiveness of the complex compound cooling system proposed by Rocky Research for CTAC applications, and

4. determine the potential attractiveness of cooling inlet air to $0^{\circ} \mathrm{F}$, in addition to a more standard CTAC temperature of about 40 to $45^{\circ} \mathrm{F}$.

This study was designed to evaluate the principal cooling system technology options over a broad range of application conditions. Application variables included power plant type, power plant operating schedule, cooling system operating schedule, design inlet air temperature, and climate. Cooling system technology options included evaporative or refrigerative cooling, refrigerative chiller type, the inclusion of cool storage or not, and the type of storage (storage media type, daily or weekly cycle, and load-leveling or load-shifting design). Altogether, approximately 3500 different cases were evaluated.

The results of the study yielded the following conclusions corresponding to the objectives outlined above.

1. Ammonia vapor compression chillers with weekly ice storage were generally found to be preferred for most application conditions. 
2. CTAC was found to be more cost-effective than simply building additional uncooled power plant capacity for all application conditions investigated. This included relatively moderate climates such as San Francisco and applications where storage could not be effectively used (e.g., when cooling 24 hours per day).

3. The complex compound systems were found to be competitive, but generally not quite as attractive as ammonia vapor compression systems. Complex compound systems were most competitive (within a few \% of the vapor compression systems' $\$ / \mathrm{kW}$ and net present value (NPV) figures) for applications with combined-cycle plants running 24 hours per day, which allowed storage for heatactivated chillers to be charged up to 24 hours per day.

4. Cooling the inlet air to $0^{\circ} \mathrm{F}$ was found to be more cost-effective (higher NPV, although the $\$ / \mathrm{kW}$ was also higher) than limiting cooling to above-freezing temperatures.

The principal recommendations from this study are to:

1. consider inlet air cooling as a standard practice for most combustion turbine applications,

2. further investigate the cooling of inlet air to near $0^{\circ} \mathrm{F}$ to determine if compressor inlet icing can be effectively avoided or at least adequately minimized, and

3. identify better complex compound systems (lower cost and/or higher efficiencies) before proceeding with the development and demonstration of this concept for CTAC.

Additional conclusions and recommendations are presented in Section 10. 


\section{Contents}

Summary $\quad \ldots \ldots \ldots \ldots \ldots \ldots \ldots \ldots \ldots \ldots \ldots \ldots \ldots \ldots \ldots \ldots \ldots \ldots$ iii

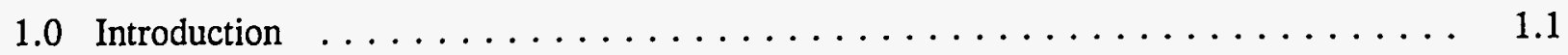

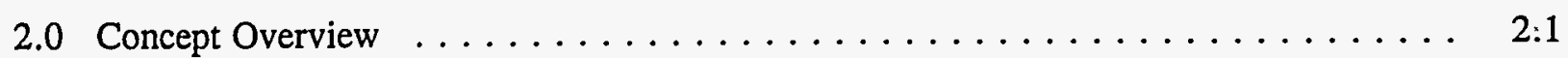

3.0 Cooling System Selection $\ldots \ldots \ldots \ldots \ldots \ldots \ldots \ldots \ldots \ldots \ldots \ldots \ldots \ldots \ldots \ldots$

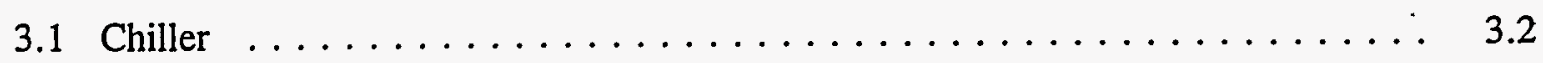

3.2 Air Cooling Heat Exchanger $\quad \ldots \ldots \ldots \ldots \ldots \ldots \ldots \ldots \ldots \ldots \ldots \ldots \ldots$

3.3 Heat Rejection $\ldots \ldots \ldots \ldots \ldots \ldots \ldots \ldots \ldots \ldots \ldots \ldots \ldots \ldots \ldots$

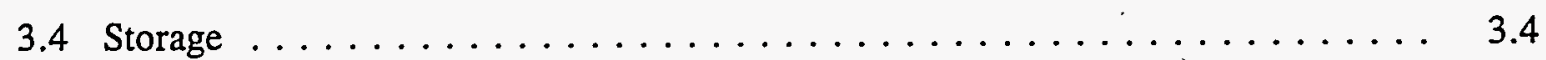

4.0 Application Condition Selection $\ldots \ldots \ldots \ldots \ldots \ldots \ldots \ldots \ldots \ldots \ldots \ldots \ldots$

4.1 Plant Type and Schedules $\ldots \ldots \ldots \ldots \ldots \ldots \ldots \ldots \ldots \ldots \ldots \ldots \ldots \ldots$

4.2 Inlet Air Temperature $\ldots \ldots \ldots \ldots \ldots \ldots \ldots \ldots \ldots \ldots \ldots \ldots \ldots \ldots \ldots \ldots$

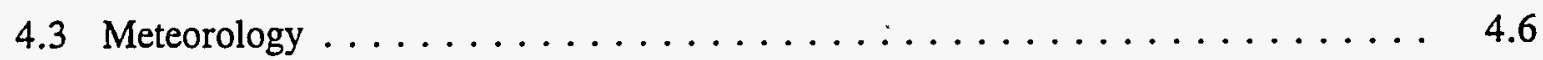

5.0 Analytical Approach $\ldots \ldots \ldots \ldots \ldots \ldots \ldots \ldots \ldots \ldots \ldots \ldots \ldots \ldots$

6.0 Performance Analysis $\ldots \ldots \ldots \ldots \ldots \ldots \ldots \ldots \ldots \ldots \ldots \ldots \ldots$

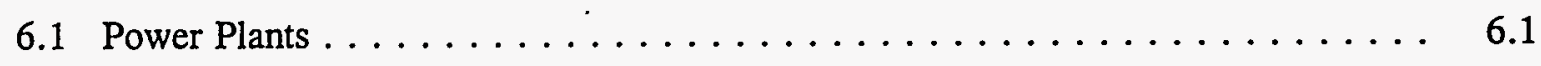

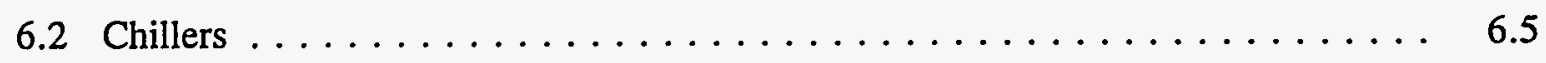

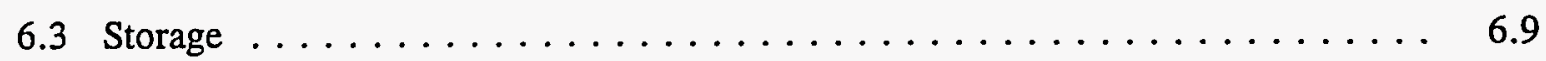

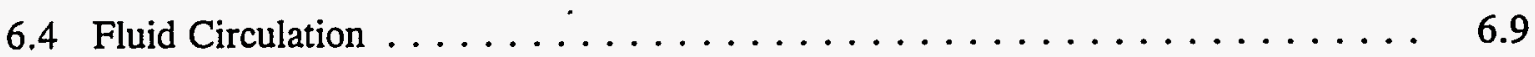

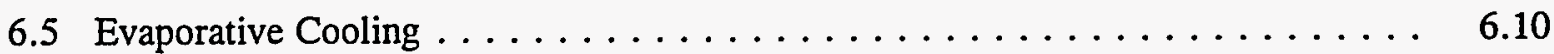

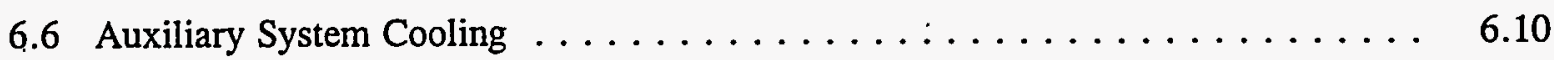

6.7 Turbine Inlet and Exit Excess Pressure Drop $\ldots \ldots \ldots \ldots \ldots \ldots \ldots$

6.8 Combined-Cycle Steam Extraction Power Output Reduction $\ldots \ldots \ldots \ldots . \ldots .6$ 
7.0 Cost Analysis $\ldots \ldots \ldots \ldots \ldots \ldots \ldots \ldots \ldots \ldots \ldots \ldots \ldots \ldots \ldots \ldots \ldots \ldots \ldots \ldots \ldots \ldots .1$

7.1 Chiller Capital Costs $\ldots \ldots \ldots \ldots \ldots \ldots \ldots \ldots \ldots \ldots \ldots \ldots \ldots \ldots \ldots \ldots \ldots$

7.2 Storage Capital Costs $\ldots \ldots \ldots \ldots \ldots \ldots \ldots \ldots \ldots \ldots \ldots \ldots \ldots \ldots \ldots \ldots \ldots$

7.3 Inlet Air Coil Capital Costs $\ldots \ldots \ldots \ldots \ldots \ldots \ldots \ldots \ldots \ldots .2$

7.4 Fluid Circulation Capital Costs $\ldots \ldots \ldots \ldots \ldots \ldots \ldots \ldots \ldots \ldots . . \ldots \ldots$

7.5 Miscellaneous Equipment Capital Costs $\ldots \ldots \ldots \ldots \ldots \ldots \ldots \ldots .7 .3$

7.6 Annual Maintenance Costs $\ldots . \ldots \ldots \ldots \ldots \ldots \ldots \ldots \ldots \ldots .4 .4$

8.0 Economic Analysis $\ldots \ldots \ldots \ldots \ldots \ldots \ldots \ldots \ldots \ldots \ldots \ldots \ldots \ldots \ldots \ldots \ldots .1$

8.1 Incremental Power and Energy Calculation $\ldots \ldots \ldots \ldots \ldots \ldots \ldots .1$

8.2 Incremental Power and Energy Value $\therefore \ldots \ldots \ldots \ldots \ldots \ldots \ldots .2$

9.0 Results $\ldots \ldots \ldots \ldots \ldots \ldots \ldots \ldots \ldots \ldots \ldots \ldots \ldots .1$

9.1 Nomenclature $\ldots \ldots \ldots \ldots \ldots \ldots \ldots \ldots \ldots \ldots \ldots \ldots .1$

9.2 Industrial Turbine $\ldots \ldots \ldots \ldots \ldots \ldots \ldots \ldots \ldots \ldots \ldots \ldots \ldots \ldots \ldots \ldots$

9.3 Aeroderivative Turbine $\ldots \ldots \ldots \ldots \ldots \ldots \ldots \ldots \ldots \ldots .4$

9.4. Combined-Cycle $\ldots \ldots \ldots \ldots \ldots \ldots \ldots \ldots \ldots \ldots \ldots .4$

9.4.1 Intermediate Duty Plant; Cooling Hours Less Than Plant Hours $\ldots \ldots .9 .6$

9.4.2 Intermediate Duty Plant; Cooling Hours Equal to Plant Hours $\ldots \ldots .9 .7$

9.4.3 Baseload Duty Plant; Cooling Hours Less Than Plant Hours $\ldots \ldots \ldots .9 .7$

9.4.4 Baseload Duty Plant; Cooling Hours Equal to Plant Hours . . . . . 9.10

9.5 Climate Impacts $\ldots \ldots \ldots \ldots \ldots \ldots \ldots \ldots \ldots \ldots \ldots \ldots \ldots \ldots \ldots \ldots$

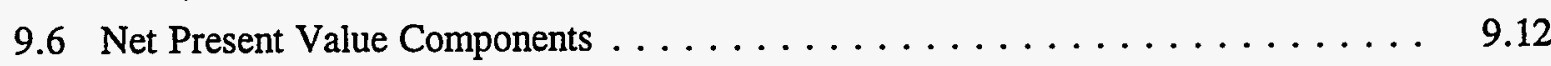

10.0 Conclusions and Recommendations $\ldots \ldots \ldots \ldots \ldots \ldots \ldots \ldots \ldots \ldots \ldots \ldots \ldots \ldots$

11.0 References $\quad \ldots \ldots \ldots \ldots \ldots \ldots \ldots \ldots \ldots \ldots \ldots \ldots \ldots \ldots \ldots \ldots \ldots \ldots \ldots \ldots$

12.0 Bibliography $\ldots \ldots \ldots \ldots \ldots \ldots \ldots \ldots \ldots \ldots \ldots \ldots \ldots \ldots \ldots \ldots \ldots \ldots \ldots \ldots \ldots \ldots$ 
Appendix A - Inlet Air Cooling Evaluation Model . . . . . . . . . . . . . A.1

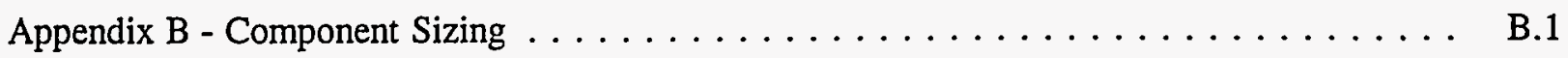

Appendix C - Complete Results $\ldots \ldots \ldots \ldots \ldots \ldots \ldots \ldots \ldots \ldots \ldots \ldots \ldots \ldots$ 


\section{Figures}

2.1 Effect of Inlet Air Temperature on Combustion Turbine Performance . . . . . . . . 2.2

2.2 Generic Inlet Air Cooling System $\ldots \ldots \ldots \ldots \ldots \ldots \ldots \ldots \ldots \ldots \ldots \ldots$

\section{Tables}

3.1 Cooling System Technology Options $\ldots \ldots \ldots \ldots \ldots \ldots \ldots \ldots \ldots \ldots \ldots$

4.1 Power Plant and Cooling System Schedules $\ldots \ldots \ldots \ldots \ldots \ldots \ldots \ldots$

8.1 Power Plant Cost and Performance Assumptions $\ldots \ldots \ldots \ldots \ldots \ldots$

8.2 Power Plant Economic Assumptions $\ldots \ldots \ldots \ldots \ldots \ldots \ldots$

8.3 Incremental Power and Energy Values $\ldots \ldots \ldots \ldots \ldots \ldots \ldots \ldots$

9.1 Industrial Turbine Results-Nashville $\ldots \ldots \ldots \ldots \ldots \ldots \ldots \ldots \ldots \ldots$

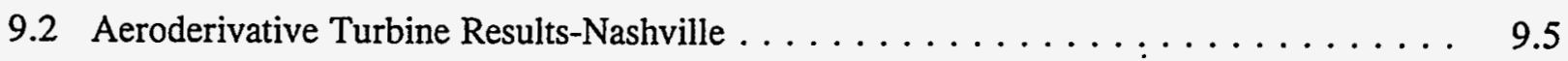

9.3 Combined-Cycle Results I-Nashville $\ldots \ldots \ldots \ldots \ldots \ldots \ldots \ldots \ldots$

9.4 Combined-Cycle Results II-Nashville $\ldots \ldots \ldots \ldots \ldots \ldots \ldots \ldots \ldots$

9.5 Combined-Cycle Results III-Nashville $\ldots \ldots \ldots \ldots \ldots \ldots \ldots \ldots \ldots$

9.6 Combined-Cycle Resuits IV-Nashville $\ldots \ldots \ldots \ldots \ldots \ldots \ldots \ldots \ldots$

9.7 Design Temperature Conditions $\ldots \ldots \ldots \ldots \ldots \ldots \ldots \ldots \ldots \ldots \ldots \ldots$

9.8 Climate Impacts on Economics $\ldots \ldots \ldots \ldots \ldots \ldots \ldots \ldots \ldots \ldots \ldots \ldots$

9.9 Net Present Value Components $\ldots \ldots \ldots \ldots \ldots \ldots \ldots \ldots \ldots \ldots \ldots \ldots \ldots$ 


\subsection{Introduction}

Interest in combustion turbine inlet air cooling (CTAC) has increased during the last few years as electric utilities continue to seek attractive sources of peaking power. Inlet air cooling increases the power production capacity and decreases the heat rate of a combustion turbine during hot weather when the demand for electricity is generally the greatest. Off-peak ice generation and storage using electrically-driven chillers has proven to be cost-effective under peak shaving conditions with a large difference between the value of peak and off-peak power (e.g., see Ebeling et al. 1992). The general applicability of the concept and the preference of specific concepts is still being debated in the literature, however.

For the past few years Rocky Research of Boulder City, Nevada has been funded by the U.S. Department of Energy to conduct research on complex compound (ammoniated salt) chill storage systems for low-temperature refrigeration applications. While the focus of this work has been on food processing applications, complex compound refrigeration could also be applied to CTAC. Advanced technologies such as this could improve CTAC economics and/or extend the range of cost-effective applications.

The Pacific Northwest National Laboratory ${ }^{(a)}$ conducted this assessment of CTAC options for the U.S. Department of Energy's Office of Energy Management as part of the Thermal Energy Storage Program. The principal objectives of this study were as follows:

1. identify the preferred CTAC technology as a function of application conditions from currently available cooling technologies,

2. identify application conditions where currently available cooling technologies are not cost-effective, i.e., construction of additional power plant capacity without CTAC would be preferred,

3. determine the potential attractiveness of the ammoniated salt solid/vapor absorption cooling system proposed by Rocky Research for CTAC applications, and

4. determine the potential attractiveness of cooling combustion turbine inlet air to $0^{\circ} \mathrm{F}$ (in addition to cooling inlet air to a temperature of around 40 to $45^{\circ} \mathrm{F}$, which is considered standard practice for CTAC).

Meeting the first two objectives identifies the fraction of combustion turbine applications that could be economically served by CTAC with currently available cooling technologies. It also establishes a baseline against which future development of CTAC technologies can be compared. Meeting the last

. (a) Operated for the U.S. Department of Energy by Battelle under Contract DE-AC06-76RLO 1830. 
two objectives directly measures the value of developing and demonstrating complex compound technology and/or cooling inlet air substantially below the freezing point.

To address the objectives established above, a screening study was designed to evaluate the principal cooling system technology options over a broad range of application conditions. Application variables included power plant type, power plant operating schedule, cooling system operating schedule, design inlet air temperature, and climate. Cooling system technology options included evaporative or refrigerative cooling, refrigerative chiller type, the inclusion of cool storage or not, and the type of storage (storage media type, daily or weekly cycle, and load-leveling or load-shifting design). A more explicit description of the application conditions and cooling system technologies evaluated is presented in the Sections that follow.

Altogether, approximately 3500 different cases were evaluated. Still, it's impossible to conduct a truly comprehensive analysis, with essentially endless variations of technology options and application conditions. Therefore, the results of this study are useful for establishing general rules-of-thumb regarding CTAC technology effectiveness, but better cooling system designs could always be proposed and alternative application conditions may yield different results.

The balance of the report documents the cooling systems and application conditions evaluated, key assumptions, and analysis leading up to the results, conclusions, and recommendations. An overview of the CTAC concept is presented in Section 2.0.

Note that English rather than metric units are used in this report. Although metric units are the standard for reports prepared for the U.S. Department of Energy, English units are used in this report to facilitate communication with cooling system vendors and users in the United States. 


\subsection{Concept Overview}

Combustion turbines are constant volume machines, i.e., air intake is limited to a fixed volume of air regardless of ambient air conditions. As air temperature rises, its density falls. Thus, although the volumetric flow rate remains constant, the mass flow rate is reduced as air temperature rises. Power output is also reduced as air temperature rises because power output is proportional to mass flow rate. The conversion efficiency of the gas turbine also falls as air temperature rises because more power is required to compress the warmer air.

The impact of compressor inlet air temperature on mass flow rate, power output, and conversion efficiency is shown in Figure 2.1 for a typical "industrial" type turbine. Per custom, conversion efficiency is reported as a heat rate, which is the amount of fuel energy consumed per kWh of electricity produced. Thus, a rise in the heat rate is consistent with a drop in conversion efficiency. In general, the relationships are linear with temperature, or nearly so.

The performance curves show the dramatic effect of temperature on turbine performance, and the opportunity to improve performance via inlet air cooling. Cooling the inlet air improves both the power output and the heat rate, but the impact on power output is greater. Furthermore, the positive impacts from inlet air cooling increase with higher ambient temperatures, when utilities typically experience the highest demand for power. Therefore, incremental power production is greatest at the time it is most valued. Usually, the primary objective of gas turbine inlet air cooling is to increase peak power output. The heat rate improvement is a significant, but secondary benefit.

The relative importance of the two impacts depends mostly on the value of incremental $\mathrm{kW}$ and $\mathrm{kWh}$ production, the number of operating hours per year, and ambient air temperatures during the operating period. A greater number of annual operating hours will increase the importance of the heat rate impact, while fewer hours will emphasize the increase in power output. Applications with a higher ratio of average to peak ambient operating temperature will also increase the importance of the heat rate impact, all else equal.

In theory, power output could be further increased by cooling below the temperature range indicated in Figure 2.1. In practice, all turbines are designed around a maximum thrust level that sets a useful limit on the inlet air temperature. In particular, the maximum power output of "aeroderivative" type turbines often occurs around the freezing point and may actually decline below this temperature. Cooling near or below the freezing point also presents concerns associated with icing, which will be discussed in Section 4.0.

A block diagram of a generic combustion turbine inlet air cooling system, with and without storage, is shown in Figure 2.2. The basic building blocks are the chiller, its cooling tower, the air coil, and interconnecting piping. Cold fluid from the chiller is pumped through the air coil, where the coolant is heated and returned to the chiller, while the inlet air is cooled prior to entering the compressor. The cooling tower provides cooling water to the chiller condenser. Alternatively, an evaporative 


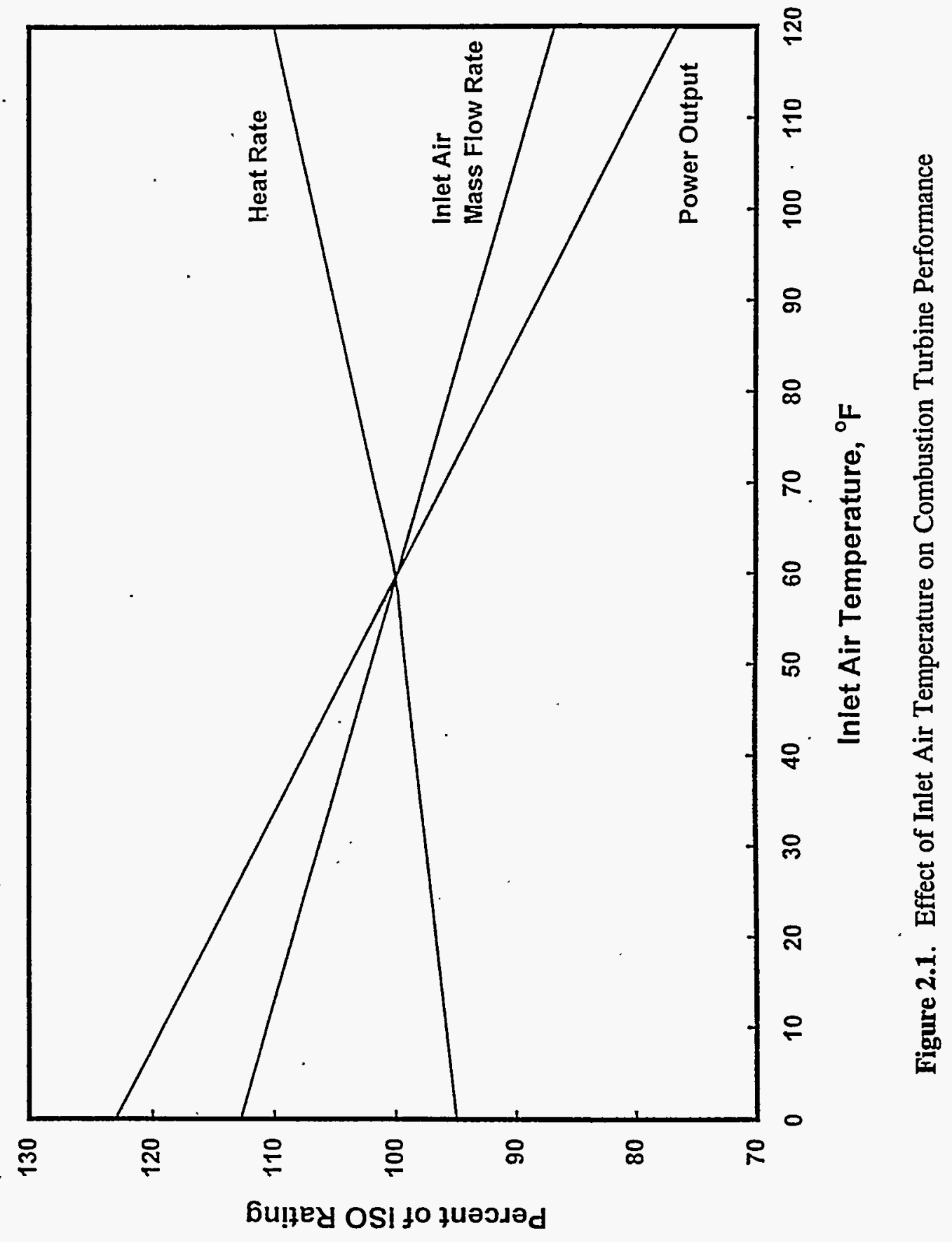




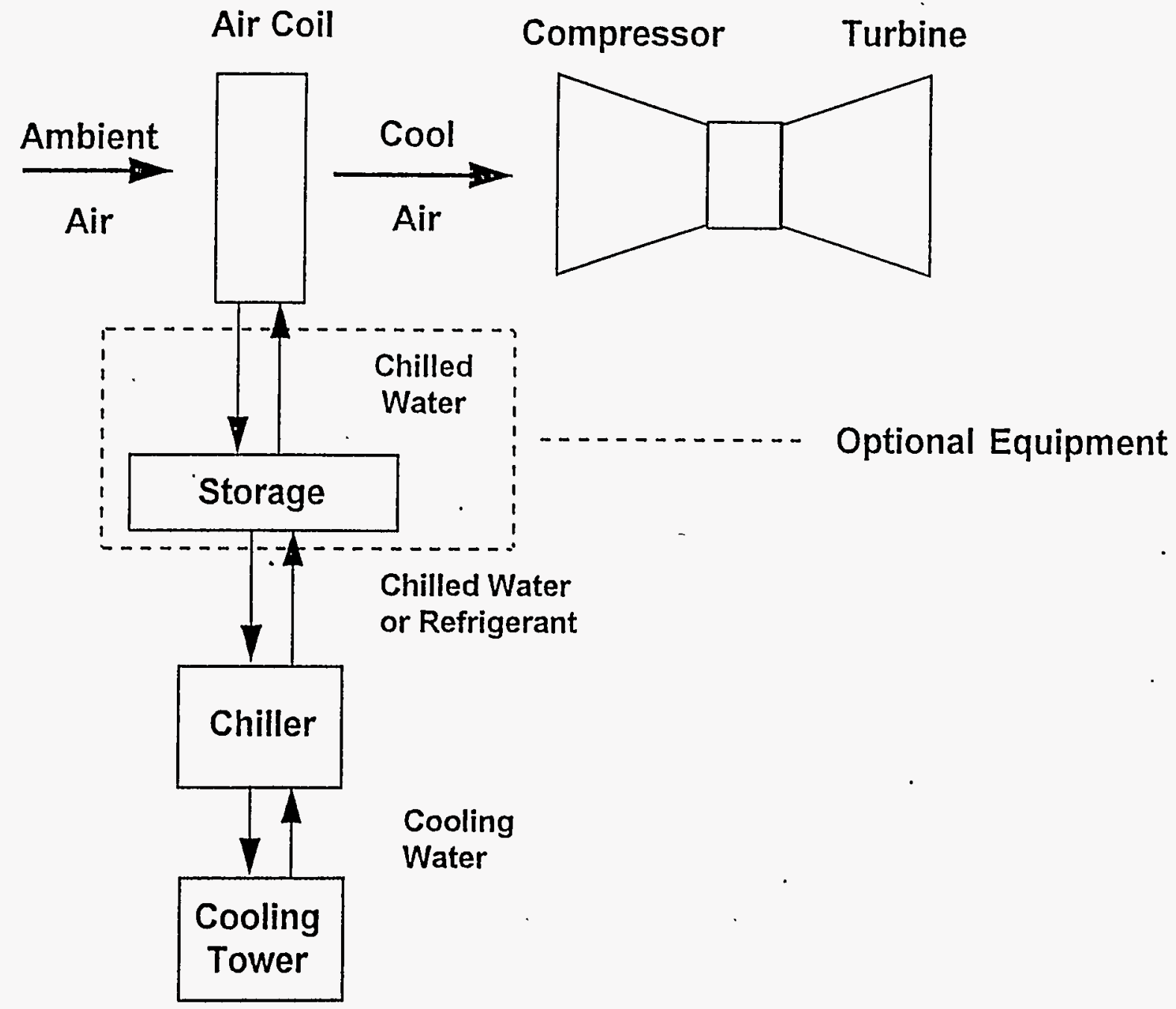

Figure 2.2. Generic Inlet Air Cooling System 
condenser might be used with some types of chillers. Including storage and its associated piping loop increases the number of system components, but allows the chiller and cooling tower components to be downsized, assuming that cooling is not conducted 24 hours per day. Storage also significantly reduces on-peak parasitic power consumption for electrically-driven chiller systems.

The fundamental benefits of inlet air cooling were'described above. The most obvious cost is the up-front investment and periodic maintenance of the inlet air cooling system hardware. The energy used to drive the chiller may also result in a significant expense, although the cost will vary significantly depending on whether the chiller is thermally or electrically driven and the source of thermal or electric energy. Inclusion of an air cooling coil within the inlet duct to the compressor will incur an additional pressure loșs, with negative consequences to power output and heat rate, but the impacts will generally be less than $0.5 \%$. These and other potential effects of inlet air cooling are discussed in more detail in the sections that follow.

The previous two paragraphs described the use of refrigerative systems for cooling turbine inlet air. A commonly used alternative, besides not cooling the inlet air at all, is to use evaporative cooling.

- Direct contact evaporative cooling, accomplished by passing the inlet air through a wetted media, can be particularly effective in drier climates. Any consideration of refrigerative inlet air cooling should also consider evaporative cooling as an option. Note that evaporative and refrigerative approaches should be considered independently. Direct evaporative cooling followed by refrigerative cooling would not reduce the refrigerative cooling load. It would only substitute latent load for sensible load. 


\subsection{Cooling System Selection}

For a concept that may seem relatively straight-forward, a plethora of options complicates the inlet air cooling system component selection and system design process. A literature review was conducted to identify prospective cooling system technologies to be included in the study. A bibliography of CTAC-related literature is included at the end of this report. The initial list of alternatives developed from this process is presented in Table 3.1. Options that were quantitatively evaluated in this study are listed in bold print. The rationale for making these selections is discussed below.

Table 3.1. Cooling System Technology Options

\begin{tabular}{|c|}
\hline $\begin{array}{l}\text { Chiller } \\
\text { mechanical } \\
\text { electric, gas-fired, or steam turbine drivers } \\
\text { ammonia, CFC, or air working fluid } \\
\text { screw, reciprocating, or centrifugal compressor } \\
\text { absorption } \\
\text { lithium bromide, single or double stage } \\
\text { aqua-ammonia } \\
\text { complex compounds, single or double stage } \\
\text { steam jet }\end{array}$ \\
\hline $\begin{array}{l}\text { Thermal Source for Heat-Activated Chillers } \\
\text { add heat recovery steam generator to combustion turbines } \\
\text { extract steam from combined-cycle or cogeneration plants }\end{array}$ \\
\hline $\begin{array}{l}\text { Air Cooling Heat Exchanger } \\
\text { evaporative cooling } \\
\text { direct/wetted media } \\
\text { indirect } \\
\text { evaporative/desiccant } \\
\text { refrigerative cooling } \\
\text { finned metal tubes } \\
\text { water or refrigerant in tubes } \\
\text { single or multiple evaporation temperatures } \\
\text { direct water spray }\end{array}$ \\
\hline $\begin{array}{l}\text { Heat Rejection } \\
\text { evaporative condenser } \\
\text { condenser and mechanical draft evaporative cooling tower } \\
\text { closed loop (finned tube/fan) cooler }\end{array}$ \\
\hline $\begin{array}{l}\text { Storage } \\
\text { storage type } \\
\text { ice/water } \\
\text { ice harvester or ice on tube } \\
\text { water } \\
\text { eutectic salts } \\
\text { brines } \\
\text { ice ponds } \\
\text { slush ponds } \\
\text { aquifer thermal energy storage (ATES) } \\
\text { storage cycle } \\
\text { daily or weekly } \\
\text { load-leveling or load shifting }\end{array}$ \\
\hline
\end{tabular}




\subsection{Chiller}

The chiller is the central piece of hardware in an inlet air cooling system. Its selection will determine or limit other equipment and design options. The two basic options are thermally-driven absorption chillers or mechanically-driven vapor compression chillers. Steam jet and mechanical air compression devices have also been suggested for use, but are significantly more expensive to own and/or operate.

Lithium bromide absorption chillers are commonly used to provide chilled water where steam or hot water is available. In these systems, lithium bromide is the absorbent and water is the refrigerant. A lithium bromide chiller operates at subatmospheric pressure in a hermetic vessel. Therefore, its evaporator cannot be directly placed in the path of the turbine inlet air. Thus, chilled water (limited to a minimum temperature of about $43^{\circ} \mathrm{F}$ ) is produced and would be piped through a coil to cool the inlet air. Single-stage and double-stage units are available, which offers a trade-off between initial capital cost and improved coefficient of performance (COP).

Aqua-ammonia is another absorption chilling option. In these systems, water is the absorbent and ammonia is the refrigerant. The COP of an aqua-ammonia system is no better than a single-stage lithium bromide system, while its initial cost is several times higher. Aqua-ammonia systems do have the capability, however, of serving refrigeration applications at temperatures well below $32^{\circ} \mathrm{F}$, where they would compete with complex compound or vapor compression chillers.

Complex compound technology is currently being developed by Rocky Research of Boulder City, Nevada for various refrigeration applications (Rockenfeller, Sarkisian, and Kirol 1992). The Rocky Research concept is a variation of absorption chillers that uses ammonia as the refrigerant and various proprietary solid salts as the "absorbent." The ammonia forms a complex compound with the salt, so this is not actually an absorption phenomena, but the complex compound cycle is similar to an absorption cycle. Like the aqua-ammonia systems, complex compounds can provide refrigeration at temperatures well below $32^{\circ} \mathrm{F}$, but the systems being developed by Rocky Research are expected to cost much less.

The standard cooling technology for industrial refrigeration applications is mechanical vapor compression with ammonia refrigerant and a screw compressor. 'The preference for ammonia stems from its superior heat transfer properties and resulting high COP. Centrifugal compressors using CFC-22 have been widely used as water chillers for space cooling applications. Because of ozone depletion concerns, HCFC-134a may become more common for this application in the future. Safety concerns have precluded the use of ammonia for space cooling applications, however. The superior performance of ammonia makes it the preferred refrigerant for combustion turbine inlet air cooling (Kohlenberger 1994). Centrifugal compressors using CFC or HCFC refrigerants may offer lower first cost, but at lower efficiency and generally with less durability than the screw compressors designed for industrial refrigeration applications. 
The mechanical vapor compression chiller can be powered by either electric motors, steam turbines, or gas-fired engines. Electric motors are the most common choice, with their advantages being lower first cost and simpler installation. For inlet air cooling, electric motors offer the flexibility of . using off-peak electricity to run the chiller and charge a storage system, even when the combustion turbine is not running. On the other hand, the availability of low-cost or essentially free steam while the combustion turbine is running may make the steam turbine option attractive. Gas-fired engines would also offer the system charging flexibility that electric motors provide.

\subsection{Air Cooling Heat Exchanger}

Refrigerative cooling systems must be compared to evaporative cooling, which is commonly applied to combustion turbines. The most common method of evaporative cooling uses a direct contact, wetted media design, which is the basis for evaluating evaporative inlet air cooling in this study. Indirect evaporative cooling, when coupled with direct evaporative cooling, can achieve lower air temperatures than direct evaporative cooling alone. However, the method consumes more water and causes a higher pressure drop, which makes it less desirable (Ondryas et al. 1991). Desiccant systems have also been proposed in conjunction with evaporative cooling, but the pressure drop for these systems is too great for combustion turbine applications.

In refrigerative cooling systems, the inlet air is generally cooled by passing it across a set of finned metal tubes containing either refrigerant or a secondary coolant such as water. The type of inlet air cooling coil used will depend on the type of chiller selected and whether or not storage is used. As described above, lithium bromide absorption chillers will always be coupled with an air/water coil. Vapor compression, aqua-ammonia, and complex compound chillers offer the option of evaporating the refrigerant directly in the coils, which reduces the air temperature for a given air coil approach temperature and also reduces equipment costs and pumping power compared to chilled water circulation systems.

If storage is included, the storage media is cooled and/or frozen by evaporating refrigerant in the storage vessel: In this case, a secondary coolant would be pumped from storage to the air cooling heat exchanger. If the secondary coolant is water it could be directly applied to the inlet air stream using evaporative cooling hardware. Routing the coolant through coils is generally preferred, however, because finned tubes suffer less pressure drop and water maintenance problems are minimized (Kohlenberger 1993).

Multiple coils, operating at sequentially declining evaporating temperatures can be used to lower the average "lift" and improve performance, but with increased capital costs. This design approach was used in this study for $0^{\circ} \mathrm{F}$ inlet air applications, but not for above-freezing applications.

\subsection{Heat Rejection}

As noted in Table 3.1, three different heat rejection approaches have been suggested in the literature. Either evaporative approach offers superior performance at a modest increase in cost compared 
to "dry cooling" with a closed-loop cooler. Industrial vapor compression refrigeration systems commonly use evaporative condensers while absorption systems are usually designed with standard condensers coupled with an evaporative cooling tower and connecting piping. The latter was applied to all cooling systems in this study to standardize the analysis. The impact on vapor compression system cost-effectiveness was assumed to be negligible.

\subsection{Storage}

Incorporating storage into the inlet air cooling system may be desirable to downsize the chiller and heat rejection components and significantly reduce on-peak parasitic power consumption for electrically-driven systems. The chiller is usually the most expensive system component, so reducing its size and cost at the expense of adding storage and related piping can be cost-effective. Reducing on-peak parasitic power consumption is also important because increasing peak power output is usually the primary objective of combustion turbine inlet air cooling.

Chilled water or ice (really a mixture of water and ice) are the most obvious and effective storage media for inlet air cooling systems. Both are applicable to diurnal storage, and ice storage is applicable to weekly storage cycles as well. Seasonal storage of ice via engineered ice or snow ponds or chilled water in naturally occurring aquifers would also be possible, but these concepts suffer from sitespecific limitations and have had only limited successful applications to date. Eutectic salts are another possibility, but the salts are more expensive than water, suffer availability losses on charge and discharge, and also suffer from limited application experience.

Steel or concrete cylindrical tanks can be used for water or ice storage. External insulation should be adequately thick to avoid condensation. Chilled water is added and removed from the bottom of water storage tanks, while warm water is added or removed from the top. This procedure forms a thermally stratified tank with a thermocline that rises on charge and falls on discharge. The preferred. ice-making method uses a harvesting approach that periodically passes hot refrigerant from the compressor through the evaporator to release ice from the evaporator surface. The ice falls from the evaporator and makes a pile within the tank. Several evaporators are used to aid in distributing the ice. The alternative approach is to build up logs of ice around evaporator coils that run back and forth throughout the tank. Although the defrost cycle increases the effective cooling load by about $15 \%$, the ice harvester is less costly to build because it requires much less evaporator surface and refrigerant inventory (Ebeling et al. 1992).

Selection of the storage media depends partly on the chiller type. Lithium bromide absorption chillers can only use water storage. Either water or ice storage is possible for vapor compression chillers. The principal advantage of ice is its greater chill storage density. The principal advantage of water is the mechanical simplicity of its storage system. Ice storage will generally allow the inlet air to be cooled to a lower temperature than with water storage, but ice generation requires a lower chiller evaporator temperature, which results in poorer chiller efficiency and higher chiller cost. 


\subsection{Application Condition Selection}

The cost-effectiveness of CTAC is affected by the application conditions as much as by the choice of cooling system technology. Alternative conditions evaluated in this study include power plant type, power plant operating schedule, power plant cooling schedule, inlet air temperature, and climate.

\subsection{Plant Type and Schedules}

Combustion turbines are used in simple-cycle and combined-cycle electric power and cogeneration plants. Key differences in these applications for inlet air cooling systems are the presumed value of low-temperature thermal energy and the number of operating hours per day. For simple-cycle electric power plants, the energy in the exhaust gases is free (except for the cost of collection and assuming other uses of this energy are not perceived), while steam extracted from a combined-cycle or cogeneration power plant results in foregone electricity or steam sales, which has value. Simple-cycle electric plants tend to operate only a few hours per day, while combined-cycle and cogeneration plants tend to operate at least 12 hours per day. The inlet air cooling system may operate for fewer hours than the plant operates, of course, which adds to the number of system possibilities.

The availability of free thermal energy in the form of gas turbine exhaust suggests that a thermallydriven chiller may be preferred over an electrically-driven chiller in that situation. The use of storage, however, can significantly reduce the size and cost of the electrically-driven chiller and allow it to be driven by low-valued off-peak electricity. While storage could be used to reduce the size and cost of the thermally-driven chiller, there would be no free energy to drive the chiller during off-peak hours. For combined-cycle and cogeneration plants operating 24 hours per day, the availability of low-valued thermal energy during off-peak hours makes storage a more reasonable option for thermally-driven systems. Assignment of value to the thermal' energy may also justify the expense of a more efficient thermally-driven chiller, whereas efficiency is of little concern when the energy is free.

The power plant types, plant operating schedules, and cooling system operating schedules evaluated in this study are summarized in Table 4.1. Simple-cycle applications were presumed to operate on schedules representative of peaking to intermediate duty while combined-cycle applications operate on intermediate to baseload schedules. Cooling system operation was presumed to always be coincident with power plant operation for simple-cycle applications, whereas the cooling period was allowed to be less than the plant operating period for combined-cycle applications. Thus, CTAC can be applied to a combined-cycle plant to produce incremental power on a peaking, intermediate, or baseload schedule, depending on the need. Both aeroderivative and industrial type turbines were evaluated for simplecycle applications because both are commonly considered for this application and the two turbine types have significantly different cost and performance characteristics. Combined-cycle applications were based solely on an industrial type turbine. All applications produce electric power only, except for steam that is produced for powering thermally-activated chillers. CTAC is applicable to simple-cycle 
Table 4.1. Power Plant and Cooling System Schedules

\begin{tabular}{|c|c|c|c|c|}
\hline \multirow[b]{2}{*}{ Plant Type } & \multicolumn{4}{|c|}{ Plant Operating Schedule } \\
\hline & Hours/Day & Time of Day & Days/Week & Months/Year \\
\hline Simple Cycle $e^{(a)}$ & 4 & 2 to $6 \mathrm{PM}$ & Mon. through Fri. & Apr. through Sept. \\
\hline Simple Cycle ${ }^{(a)}$ & 8 & Noon to $8 \mathrm{PM}$ & Mon. through Fri. & Apr. through Sept. \\
\hline Combined Cycle ${ }^{(b)}$ & 12 & $8 \mathrm{AM}$ to $8 \mathrm{PM}$ & Mon. through Fri. & Jan. through Dec. \\
\hline Combined Cycle ${ }^{(b)}$ & 24 & all day & Sun. through Sat. & Jan. through Dec. \\
\hline \multicolumn{5}{|c|}{$\begin{array}{l}\text { (a) Cooling system and power plant schedules are the same. } \\
\text { (b) Planned shutdowns occur the first two weeks of April and October. Cooling schedules } \\
\text { evaluated include the two simple-cycle schedules plus the first combined-cycle schedule for the } \\
12 \mathrm{hr} / \text { day combined-cycle plant and both combined-cycle schedules for the } 24 \mathrm{hr} / \text { day } \\
\text { combined-cycle plant. }\end{array}$} \\
\hline
\end{tabular}

or combined-cycle cogeneration plants too, but the operating hours and value of thermal energy are similar to the combined-cycle electric power plant, so cogeneration applications were not explicitly evaluated.

\subsection{Inlet Air. Temperature}

The inlet air cooling system must be designed to avoid icing at the compressor inlet or anywhere in the air intake structure. Ice fragments sucked into the compressor can cause serious structural damage. Icing is a potential problem anytime the ambient air temperature drops near the freezing mark. Compressor bleed air can be used to internally heat compressor inlet surfaces or directly injected into the inlet air stream (Dickson 1975). Exhaust from the turbine has also been routed back through the inlet air structure within closed heat exchanger surfaces, and electric heat tracing has been used as well (Wagar 1980).

The potential icing problem is exacerbated for inlet air cooling systems because warm ambient air will almost always be saturated after passing through the inlet air cooling coils. When the air is drawn into the mouth of the compressor, its velocity increases and its temperature drops further as air enthalpy is transformed into kinetic energy in an adiabatic process. Condensate icing can occur if the temperature drops below freezing. Equation (1) describes the relationship between air velocity and temperature. A temperature drop of about $10^{\circ} \mathrm{F}$ is common. Therefore, the design inlet air temperature should be at least $42^{\circ} \mathrm{F}$ to avoid potential icing problems. 


$$
V^{2} / 2 g=C_{p} * d T
$$

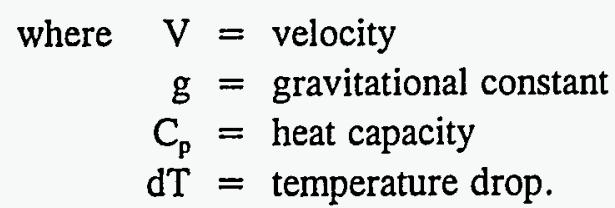

The design inlet temperature may also be affected by the capabilities of the chiller. The minimum chilled water temperature available from lithium bromide absorption chillers is about $43^{\circ} \mathrm{F}$. Therefore, practical approach temperatures at the air coil will limit the design inlet air temperature to about $50^{\circ} \mathrm{F}$ for this type of chiller. In this study, the design inlet air temperature was set at $52^{\circ} \mathrm{F}$ for lithium bromide absorption chillers and $42^{\circ} \mathrm{F}$ for other chiller types for above freezing applications.

The focus of inlet air cooling applications to date has been on above-freezing design conditions, and for good reason. As noted above, cooling the inlet air below freezing could lead to ice-caused damage of the compressor. At a minimum, periodic defrosting of the inlet air cooling coils would be required. In addition, while the performance benefit is linearly related to further reductions of the inlet air temperature (limited by the turbine's design maximum thrust limit), refrigeration costs per unit of . cooling increase as the refrigeration temperature declines. Still, the potential benefit of cooling the inlet air below freezing is significant, and although the incremental cost per $\mathrm{kW}$ may be greater than for cooling to more moderate temperatures, it.may still be less than installing a new power plant.

In addition to the above-freezing design conditions noted above, this study evaluated systems that cooled the inlet air to $0^{\circ} \mathrm{F}$. Systems cooling to $0^{\circ} \mathrm{F}$ were split into two sections. The first section cools the inlet air to $42^{\circ} \mathrm{F}$ with a refrigerant evaporating at $32^{\circ} \mathrm{F}$. The second section further cools the inlet air to $0^{\circ} \mathrm{F}$ with a refrigerant evaporating at $-20^{\circ} \mathrm{F}$. The design conditions for the first section avoid frost build-up while condensing a substantial portion of the moisture in the air before it can contribute to the icing problem. The approach temperature in the second section was doubled to allow for poorer heat transfer caused by icing of cooling coils.

Cooling the inlet air to $0^{\circ} \mathrm{F}$ will require periodic defrosting of the subfreezing cooling coils. In general, three half-size coil banks operating in parallel are proposed. Each half-size coil would be isolated from the others with metal ducting and louvered openings to allow defrosting to occur in one of the three half-size coils, while the inlet air would be cooled by the other two coils. Defrosting would occur on a rotating basis. The following design approaches were considered.

1. Hot Refrigerant Bypass. This approach is used for defrosting evaporative coils in most refrigeration applications. Hot refrigerant from the chiller is routed directly through the cooling coils, bypassing the condenser, to melt the ice from the coils. The same technique is also used in icemaking equipment. Hot refrigerant bypass has the advantage of a) being an established practice, b) allowing ice removal without having to melt all of the ice (like an ice-maker), and c) reduces 
condenser load. Its disadvantages include a) only being available when the chiller is running, which makes it impossible to incorporate with load-shifting storage, and b) requiring additional piping.

2. Turbine Exhaust. Part of the turbine exhaust could be routed past the frosted coils to melt away the ice. The principal advantage of this concept is the use of "free" waste heat. Disadvantages include a) requiring additional ducting, b) reducing turbine performance by increasing the exhaust pressure drop, and c) not being available in combined-cycle plants.

3. Electric Heat Tracing. Electric heat tracing might be externally applied to the cooling coils. The advantages of this concept are that it would a) always be available and b) allow ice removal without having to melt all of the ice. Its disadvantages include a) additional parasitic energy consumption, b) additional pressure drop across the coil, and c) questionable survival of the heat tracing in the operating environment.

4. Extraction Steam. Extraction steam might be used to defrost the coils, if a suitable means of application could be developed. Low-grade thermal energy in the form of steam could be extracted from combined-cycle plants, but its disadvantages include a) not being available in simple-cycle plants, b) reduced power output from the steam turbine, c) piping costs, and d) the difficulty of applying the steam to the frost.

5. Ambient Air. Ambient air could be used to defrost the coils using an approach similar to that envisioned for using turbine exhaust. Compared to turbine exhaust, ambient air has the advantage of a) requiring minimal ducting and b) minimal incremental parasitic power consumption. Its principal disadvantage stems from the fact that it won't be nearly as warm as turbine exhaust, and won't necessarily be above freezing. On the other hand, if ice build-up is not great, say over a 4-hr cooling cycle, it might be possible to let the ice melt naturally during the rest of the day.

6. Turbine Operation. The coils could be defrosted by simply running the turbine without circulating coolant through the air coils until the coils are defrosted. This approach would not require a spare half-sized coil and therefore would have the advantages of incurring a) no incremental capital cost and b) no incremental operating costs to accomplish defrosting. This approach would have the disadvantages of a) reduced power output during the defrosting period and b) potential problems associated with cycling the inlet air temperature so frequently.

Hot refrigerant bypass (HRB) was chosen as the basis for defrosting the coil for systems cooling the inlet air to $0^{\circ} \mathrm{F}$. This option is relatively simple to apply, is standard industry practice, and incurs minimal parasitic power consumption. Simply using ambient air may be practical for cooling applied in the summer only, but needs to be proven. Using turbine exhaust or electric heat tracing would be possible, but both would incur significant capital and operating costs. Note that HRB is only available while the chiller is running, so a load-leveling approach must be used if storage is incorporated. 
As described above, after the inlet air has been cooled to $0^{\circ} \mathrm{F}$ by the cooling coils, it will accelerate and further cool according to the relationship described by Equation (1). Therefore, condensate icing will almost surely occur if no thermally protective measures are taken. The magnitude of the problem will have been substantially reduced, however, by the moisture removed in the cooling coils. Saturated air at $42^{\circ} \mathrm{F}$ contains $0.0056 \mathrm{lb}$ of water per $\mathrm{lb}$ of dry air while this figure is reduced to $0.0008 \mathrm{lb}$ at $0^{\circ} \mathrm{F}$. At this latter condition, condensate icing may not be a problem, especially for applications that operate for only a portion of the day during the summer season.

In general, there are two basic options for minimizing or eliminating condensate icing: 1) reheating the air or 2) heating the surfaces of the intake structure. The following options were considered.

1. Compressor Bleed Air. Air from one of the early compressor stages is "bled" off of the main stream and routed past upstream inlet air structure surfaces to keep them relatively warm. Note that the surfaces don't have to be kept above freezing, just above the dew point, which would be $0^{\circ} \mathrm{F}$ after the cooling coils.

2. Compressor Cooling Air. Some air bled from the early compressor stages is used to cool hotter portions of the compressor. This air could be used as described above to keep upstream surfaces from icing.

3. Compressor Bleed Air Injection. Compressor bleed/cooling air could be injected immediately downstream of the cooling coils to reheat the inlet air.

4. Turbine Exhaust. Turbine exhaust could be routed back through the inlet air structure immediately after the cooling coils in a closed heat exchanger to reheat the inlet air.

5. Extraction Steam. Extraction steam could be routed back through the inlet air structure immediately after the cooling coils in a closed heat exchanger (or perhaps directly injected) to reheat the inlet air.

6. Electric Resistance Heating. Electric resistance heating could be used to warm the inlet air structure or to reheat the inlet air stream.

Reheating the air would avoid the formation of condensate icing, but would run counter to the purpose of cooling the inlet air. From a thermodynamic perspective, internally heating inlet air structure surfaces would be preferred because the air stream would not be reheated nearly as much. In addition, this approach is already used with compressor bleed air, although not necessarily at continuous icing conditions (Dickson 1975). In this study, if condensate icing is still a problem after moisture removal in the two cooling coils, then compressor cooling air is presumed to internally heat inlet air structure to further minimize ice build-up. If adequate compressor cooling air is available and inlet air structure heating channels are already incorporated into the design, then the marginal cost of 
avoiding condensate icing should be negligible. These assumptions have not been proven, however, and additional analysis and field testing will need to be conducted to confirm safe operating practices for subfreezing operating conditions.

\subsection{Meteorology}

The cost-effectiveness of CTAC will obviously depend on the reference operating conditions for an uncooled power plant. Warmer climates will show greater incremental power production, but will incur greater cooling loads and cooling system costs to meet those loads. Drier climates result in lower refrigerative cooling loads, but evaporative cooling also looks better in that situation.

Five climates, representing the range of climates found in the continental U.S., were evaluated. Cold, hot/cold, hot/humid, hot/arid, and temperate climate regions were defined in the Small Office Building Handbook (Holton et al. 1985). The cities selected to represent these five regions were Minneapolis, Nashville, Houston, Phoenix, and San Francisco, respectively. Minneapolis, Nashville, and Houston have similar peak design conditions, but their annual average conditions vary considerably. Phoenix is, of course, much warmer and drier, while San Francisco's weather is more moderate. 


\subsection{Analytical Approach}

The evaluation compared the benefit of incremental power and energy production with the cost of owning and operating the inlet air cooling system. Costs and benefits were denominated in dollars and the resulting net present value (NPV) was calculated for each combination of cooling system technology and application condition evaluated. In addition, the capital cost per incremental power output was calculated for each combination evaluated. Refrigerative and evaporative cooling system economics were calculated based on reference plants that were uncooled. Refrigerative cooling system economics were also calculated based on reference plants that were evaporatively cooled.

The evaluation of each case proceeded as follows. The starting point is a set of data characterizing a specific combination of cooling system technology and application conditions being evaluated. From this initial input, power plant power and energy production, and cooling system loads are calculated. Next, the cooling system components are sized. This allows the calculation of component costs (initial capital and annual operating and maintenance costs) and parasitic power consumption. Finally, the cooling system investment per $\mathrm{kW}$ of incremental power production and its NPV are calculated. All calculations are conducted within a computer model that allows the cooling loads and component performance to be simulated on an hourly basis.

Detailed assumptions regarding the cost, performance and economic analyses are presented in Sections 6.0, 7.0, and 8.0. Computer modeling and component sizing details are presented in Appendices A and B. 



\subsection{Performance Analysis}

The performance analysis included calculation of the power output and fuel consumption of the combustion turbine, with and without inlet air cooling, plus the parasitic power consumption of inlet air cooling system components. The latter includes compressor power for vapor compression chillers, steam and pump power for absorption chillers, pump power for the various fluid circulation systems, and fan power for the cooling tower.

Annual performance data were calculated by a computer model (see Appendix A) with the ability to aggregate performance calculated for each operating hour of the year, based on hourly weather data. Performance assumptions were developed based on a combination of information collected from equipment vendors and published literature. Specific assumptions are presented below for the power plants and cooling system components.

\subsection{Power Plants}

Three power plant types were evaluated in this study: 1) simple-cycle industrial turbine, 2) simplecycle aeroderivative turbine, and 3) combined-cycle (based on an industrial-type turbine). Analysis of inlet air cooling systems requires knowledge of the power plant's (combustion turbine and steam turbine, for combined-cycle plants) performance (power output, heat rate, and mass flow rate) as a function of various operating conditions (altitude, dry-bulb temperature, humidity, turbine inlet pressure drop, and turbine exit pressure drop). The impact of operating conditions on power output and heat rate directly affect inlet air cooling economics, of course, while understanding the impact on mass flow rate is crucial to sizing cooling system components.

Power output, heat rate, and inlet air mass flow rate at ISO conditions $\left(59^{\circ} \mathrm{F}\right.$ dry-bulb temperature, $60 \%$ relative humidity, and sea level elevation), and the correction factors for calculating these performance characteristics at non-ISO conditions are presented below for each power plant type. Up to five adjustment factors (F1 for altitude, F2 for dry-bulb temperature, F3 for humidity, F4 for excess inlet pressure drop, and F5 for excess exhaust pressure drop) are multiplied by the ISO performance to calculate performance at non-ISO conditions.

\section{Simple-Cycle Industrial Frame Combustion Turbine}

ISO power output $=100 \mathrm{MW}$

ISO heat rate $=11,700 \mathrm{Btu} / \mathrm{kWh}$ based on HHV

ISO inlet air mass flow rate $=2,342,346 \mathrm{lb} / \mathrm{hr}$. 
Power Adjustment Factors:

$\mathrm{F} 1=1.0-3.1875 \mathrm{E}-5 * \mathrm{~h} ; \mathrm{h}=$ altitude, feet

- $\mathrm{F} 2=1.23-3.875 \mathrm{E}-3 * \mathrm{~T} ; \mathrm{T}=$ inlet air dry-bulb temperature, ${ }^{\circ} \mathrm{F}$

$\mathrm{F} 3=1.0$

$\mathrm{F} 4=1.0-4.333 \mathrm{E}-3 * \mathrm{P}_{\mathrm{i}} ; \mathrm{P}_{\mathrm{i}}=$ excess inlet air pressure loss, inches $\mathrm{H}_{2} \mathrm{O}$

F5 $=1.0-1.634 \mathrm{E}-3 * \mathrm{P}_{\mathrm{e}} ; \mathrm{P}_{\mathrm{e}}=$ excess exhaust air pressure loss, inches $\mathrm{H}_{2} \mathrm{O}$.

Heat Rate Adjustment Factors:

$\mathrm{F} 1=1.0$

$\mathrm{F} 2=0.95+8.333 \mathrm{E}-4 * \mathrm{~T}$ for $\mathrm{T}<=60^{\circ} \mathrm{F} ; \mathrm{F} 2=1.0+1.666 \mathrm{E}-3 *(\mathrm{~T}-60)$ for $\mathrm{T}>60^{\circ} \mathrm{F}$

$\mathrm{F} 3=1.0$

$\mathrm{F} 4=1.0+1.666 \mathrm{E}-3 * \mathrm{P}_{\mathrm{i}}$

$\mathrm{F} 5=1.0+1.666 \mathrm{E}-3 * \mathrm{P}_{\mathrm{e}}$.

. Inlet Air Mass Flow Rate Adjustment Factors:

$\mathrm{F} 1=1.0-3.1875 \mathrm{E}-5 * \mathrm{~h}$

$\mathrm{F} 2=1.128-2.17 . \mathrm{E}-3 * \mathrm{~T}$

$\mathrm{F} 3=1.0$

$\mathrm{F} 4=1.0-2.333 \mathrm{E}-3 * \mathrm{P}_{\mathrm{i}}$

$\mathrm{F} 5=1.0$.

\section{Simple-Cycle Aeroderivative Combustion Turbine}

ISO power output $=45 \mathrm{MW}$

ISO heat rate $=10,000 \mathrm{Btu} / \mathrm{kWh}$ based on HHV

ISO inlet air mass flow rate $=1,093,482 \mathrm{lb} / \mathrm{hr}$.

Power Adjustment Factors:

$\mathrm{F} 1=1.0-3.3125 \mathrm{E}-5 * \mathrm{~h}$

$\mathrm{F} 2=1.125$ for $\mathrm{T}<=32^{\circ} \mathrm{F} ; \mathrm{F} 2=1.125-5.06 \mathrm{E}-3 *(\mathrm{~T}-32)$ for $\mathrm{T}>32^{\circ} \mathrm{F}$

$\mathrm{F} 3=1.0$

$\mathrm{F} 4=1.0-3.6 \mathrm{E}-3 * \mathrm{P}_{\mathrm{i}}$

$\mathrm{F} 5=1.0-1.4 \mathrm{E}-3 * \mathrm{P}_{\mathrm{e}}$. 
Heat Rate Adjustment Factors:

$\mathrm{F} 1=1.0$

$\mathrm{F} 2=0.94+1.00 \mathrm{E}-3 * \mathrm{~T}$ for $\mathrm{T}<=60^{\circ} \mathrm{F} ; \mathrm{F} 2=1.0+1.666 \mathrm{E}-3 *(\mathrm{~T}-60)$ for $\mathrm{T}>60^{\circ} \mathrm{F}$

$\mathrm{F} 3=1.0$

$\mathrm{F} 4=1.0+1.2 \mathrm{E}-3 * \mathrm{P}_{\mathrm{i}}$

$\mathrm{F} 5=1.0+1.1875 \mathrm{E}-3 * \mathrm{P}_{\mathrm{c}}$.

Inlet Air Mass Flow Rate Adjustment Factors:

$\mathrm{F} 1=1.0-3.3125 \mathrm{E}-5 * \mathrm{~h}$

$\mathrm{F} 2=1.15-1.875 \mathrm{E}-3 * \mathrm{~T}$ for $\mathrm{T}<=32^{\circ} \mathrm{F} ; \mathrm{F} 2=1.09-3.21 \mathrm{E}-3 *(\mathrm{~T}-32) \cdot$ for $32^{\circ} \mathrm{F}<\mathrm{T}<60^{\circ} \mathrm{F}$; $\mathrm{F} 2=1.0-4.67 \mathrm{E}-3 *(\mathrm{~T}-60)$ for $\mathrm{T}>=60^{\circ} \mathrm{F}$

$\mathrm{F} 3=1.0$

$\mathrm{F} 4=1.0-2.55 \mathrm{E}-3 * \mathrm{P}_{\mathrm{i}}$

$\mathrm{F} 5=1.0-3.125 \mathrm{E}-3 * \mathrm{P}_{\mathrm{e}}$.

\section{Combined-Cycle}

ISO power output $=225 \mathrm{MW}$

Combustion turbine portion $=155 \mathrm{MW}$

Steam turbine portion $=70 \mathrm{MW}$

ISO heat rate $=7300 \mathrm{Btu} / \mathrm{kWh}$ based on HHV

ISO inlet air mass flow rate $=3,365,475 \mathrm{lb} / \mathrm{hr}$.

Power Adjustment Factors for Combustion Turbine Portion:

$\mathrm{F} 1=1.0-3.33 \mathrm{E}-5 * \mathrm{~h}$

$\mathrm{F} 2=1.22-3.7 \mathrm{E}-3 * \mathrm{~T}$

$\mathrm{F} 3=1.0$

$\mathrm{F} 4=1.0-3.2 \mathrm{E}-3 * \mathrm{P}_{\mathrm{i}}$

$\mathrm{F} 5=1.0-1.2 \mathrm{E}-3 * \mathrm{P}_{\mathrm{e}}$.

Power Adjustment Factors for Steam Turbine Portion:

The power adjustment factors for the steam turbine require a more complicated format. In general, steam turbine power is presumed to be proportional to steam production from the heat recovery steam generator (HRSG), with an adjustment for the impact of ambient temperature on condenser temperature. The general form for steam turbine power adjustment is as follows:

$\mathrm{P} / \mathrm{P}_{\mathrm{ISO}}=$ exhaust flow factor $*$ exhaust temperature factor $*$ condenser temperature factor. 
Each of these three factors is defined below.

Exhaust Flow Factor $=\mathrm{F} 1 * \mathrm{~F} 2 * \mathrm{~F} 3 * \mathrm{~F} 4 * \mathrm{~F} 5$, where

$$
\begin{aligned}
& \mathrm{F} 1=1.0-3.33 \mathrm{E}-5 * \mathrm{~h} \\
& \mathrm{~F} 2=1.12-2.15 \mathrm{E}-3 * \mathrm{~T} \\
& \mathrm{~F} 3=1.0 \\
& \mathrm{~F} 4=1.0-2.5 \mathrm{E}-3 * \mathrm{P}_{\mathrm{i}} \\
& \mathrm{F} 5=1.0 .
\end{aligned}
$$

Exhaust Temperature Factor $=\left(\mathrm{T}_{\text {exhaust }}-550\right) / 542$, where

$$
\begin{aligned}
& \mathrm{T}_{\text {exhaust }}=1054+0.517 * \mathrm{~T}+\mathrm{P}_{\mathrm{i}}+0.8 * \mathrm{P}_{\mathrm{e}} \text { for } \mathrm{T}<=60^{\circ} \mathrm{F} \text { or } \\
& \mathrm{T}_{\text {exhaust }}=1085+0.850 *(\mathrm{~T}-60)+\mathrm{P}_{\mathrm{i}}+0.8 * \mathrm{P}_{\mathrm{e}} \text { for } \mathrm{T}>60^{\circ} \mathrm{F} .
\end{aligned}
$$

Condenser Temperature Factor $=$

$1-1.9 \mathrm{E}-4 *\left(\mathrm{~T}_{\mathrm{wb}}-54\right)$ for $\mathrm{T}_{\mathrm{wb}}<=54^{\circ} \mathrm{F}$ or

$1-9.0 \mathrm{E}-4 *\left(\mathrm{~T}_{\mathrm{wb}}-54\right)$ for $\mathrm{T}_{\mathrm{wb}}>54^{\circ} \mathrm{F}$, and

$\mathrm{T}_{\mathrm{wb}}=$ ambient wet-bulb temperature, ${ }^{\circ} \mathrm{F}$.

Heat Rate (HR) Adjustment Factors for Combustion Turbine (CT) Portion:

$$
\begin{aligned}
& \mathrm{F} 1=1.0 \\
& \mathrm{~F} 2=0.94+1.00 \mathrm{E}-3 * \mathrm{~T} \text { for } \mathrm{T}<=60^{\circ} \mathrm{F} ; \mathrm{F} 2=1.0+1.5 \mathrm{E}-3 *(\mathrm{~T}-60) \text { for } \mathrm{T}>60^{\circ} \mathrm{F} \\
& \mathrm{F} 3=1.0 \\
& \mathrm{~F} 4=1.0+1.7 \mathrm{E}-3 * \mathrm{P}_{\mathrm{i}} \\
& \mathrm{F} 5=1.0+1.45 \mathrm{E}-3 * \mathrm{P}_{\mathrm{e}} .
\end{aligned}
$$

Heat Rate Adjustment Factors for Combined-Cycle (CC):

Overall heat rate $=\mathrm{CT}$ heat rate $* \mathrm{CT}$ power $/ \mathrm{CC}$ power

$7300=\mathrm{CT}$ heat rate $* 155 / 225$; Reference CT heat rate $=10,597 \mathrm{Btu} / \mathrm{kWh}$

Adjusted CT heat rate $=10,597 * \mathrm{~F} 1 * \mathrm{~F} 2 * \mathrm{~F} 3 * \mathrm{~F} 4 * \mathrm{~F} 5$

Adjusted CC power $=$ Adj. CT power + Adj. ST power

Adjusted $\mathrm{CC}$ heat rate $=$ Adj. CT heat rate $*$ Adj. CT power $/ \mathrm{Adj} . \mathrm{CC}$ power. 
Inlet Air Mass Flow Rate Adjustment Factors:

$$
\begin{aligned}
& \mathrm{F} 1=1.0-3.33 \mathrm{E}-5 * \mathrm{~h} \\
& \mathrm{~F} 2=1.12-2.15 \mathrm{E}-3 * \mathrm{~T} \\
& \mathrm{~F} 3=1.0 \\
& \mathrm{~F} 4=1.0-2.5 \mathrm{E}-3 * \mathrm{P}_{\mathrm{i}} \\
& \mathrm{F} 5=1.0 .
\end{aligned}
$$

\subsection{Chillers}

The cost and performance of the chiller are key to the cost-effectiveness of inlet air cooling systems. Chiller performance is characterized by its coefficient of performance (COP), "relative capacity," heat rejection rate, and, for absorption-type chillers, the steam conditions and additional electric power consumption, if any. Performance assumptions for complex compound, vapor compression, aqua-ammonia, and lithium bromide chillers are presented below.

The COP, of course, is the amount of cooling obtained per unit of input energy, with the input and output measured in the same units. The COP varies considerably between chiller types and for the same chiller type, depending on the evaporating and condensing temperature, with the difference between these two temperatures defined as the "lift." In general, COP increases as the lift is reduced. Absorption-type chillers also come in single- and double-stage versions. Double-stage chillers use waste heat from the higher temperature stage to drive the lower temperature stage. A higher COP results, but the double-stage unit is more expensive. COP equations are presented here as a function of wet-bulb temperature for explicit chiller types, number of stages, and evaporator temperatures. The $\mathrm{COP}$ equations assume the condenser temperature is $15^{\circ} \mathrm{F}$ higher than the wet-bulb temperature. In general, the wet-bulb temperature is limited to a minimum of $25^{\circ} \mathrm{F}$ for COP modeling purposes, with more restrictive assumptions listed below for. lithium bromide chillers.

Like the COP, the cooling capacity of a chiller is a function of the condenser temperature, and is expressed here as a function of the wet-bulb temperature. The chiller cost equations presented in Section 8 are based on chiller capacity at "rated" temperature conditions. Capacity is typically less at temperature conditions corresponding to the peak cooling load. Thus, the "relative" capacity equation must be applied to adjust the peak chiller capacity to the rated chiller capacity.

All energy absorbed by a chiller at the evaporator and input to the chiller in the form of steam or electricity must ultimately be rejected at a cooling tower. Thus, heat rejection requirements are directiy related to chiller COP and vary considerably, especially when absorption systems are compared to vapor compression systems. 


\section{Complex Compound (CC) Chillers:}

CC chiller 1 (CC-1); single-stage, $20^{\circ} \mathrm{F}$ evaporator:

COP $=0.496-7.0 \mathrm{E}-4 *$ Twb

Relative capacity $=1.652-0.0079 * \mathrm{Twb}$

Steam temperature $=228^{\circ} \mathrm{F}$; pressure $=19 \mathrm{psia} ; \mathrm{h}_{\mathrm{fg}}=960 \mathrm{Btu} / \mathrm{lb}$

Heat rejection rate $=39,335 \mathrm{Btu} / \mathrm{hr}$ per ton

Parasitic power $=0$

CC chiller 2 (CC-2); single-stage, $32^{\circ} \mathrm{F}$ evaporator:

COP $=0.496-7.0 \mathrm{E}-4 * \mathrm{Twb}$

Relative capacity $=1.415-0.0051 * \mathrm{Twb}$

Steam temperature $=228^{\circ} \mathrm{F}$; pressure $=19 \mathrm{psia} ; \mathrm{h}_{\mathrm{fg}}=960 \mathrm{Btu} / \mathrm{lb}$

Heat rejection rate $=39,211 \mathrm{Btu} / \mathrm{hr}$ per ton

Parasitic power $=0$

$\mathrm{CC}$ chiller 3 (CC-3); double-stage, $20^{\circ} \mathrm{F}$ evaporator:

COP $=0.867-2.5 \mathrm{E}-3 *$ Twb

Relative capacity $=1.566-0.0069 *$ Twb

Steam temperature $=351^{\circ} \mathrm{F} ;$ pressure $=137 \mathrm{psia} ; \mathrm{h}_{\mathrm{fg}}=870 \mathrm{Btu} / \mathrm{lb}$

Heat rejection rate $=29,991 \mathrm{Btu} / \mathrm{hr}$ per ton

Parasitic power $=0$

CC chiller $4(\mathrm{CC}-4)$; double-stage, $32^{\circ} \mathrm{F}$ evaporator:

$\mathrm{COP}=0.850-1.85 \mathrm{E}-3 * \mathrm{Twb}$

Relative capacity $=1.334-0.0041 *$ Twb

Steam temperature $=351^{\circ} \mathrm{F} ;$ pressure $=137$ psiá; $h_{\mathrm{fg}}=870 \mathrm{Btu} / \mathrm{lb}$

Heat rejection rate $=29,094 \mathrm{Btu} / \mathrm{hr}$ per ton

Parasitic power $=0$

CC chiller 5 (CC-5); single-stage, $-20^{\circ} \mathrm{F}$ evaporator:

$\mathrm{COP}=0.42-6.75 \mathrm{E}-4 * \mathrm{Twb}$

Relative capacity $=1.231-0.003 *$ Twb

Steam temperature $=293^{\circ} \mathrm{F} ;$ pressure $=60 \mathrm{psia} ; \mathrm{h}_{\mathrm{fg}}=915 \mathrm{Btu} / \mathrm{lb}$

Heat rejection rate $=44,787 \mathrm{Btu} / \mathrm{hr}$ per ton

Parasitic power $=0$ 
CC chiller 6 (CC-6); single-stage, storage type, $-20^{\circ} \mathrm{F}$ evaporator:

$\mathrm{COP}=0.52$

Relative capacity $=1$

Steam temperature $=213^{\circ} \mathrm{F}$; pressure $=15 \mathrm{psia} ; \mathrm{h}_{\mathrm{fg}}=969 \mathrm{Btu} / \mathrm{lb}$

Heat rejection rate $=21,624 \mathrm{Btu} / \mathrm{hr}$ per ton for sizing heat rejection equipment

Heat rejection rate $=35,076 \mathrm{Btu} / \mathrm{hr}$ per ton for calculating annual heat rejection load

Parasitic power $=0$

The storage version of the complex compound chiller is actually an integrated chiller/storage device that is sized based on ton-hours rather than tons.

\section{Ammonia Vapor Compression (VC) Chillers:}

VC chiller 1 (VC-1); $20^{\circ} \mathrm{F}$ evaporator:

$\mathrm{COP}=14.1277 \exp (-0.0144 * \mathrm{Twb})$

Relative capacity $=1.08-0.001 *$ Twb

Heat rejection rate $=14,734 \mathrm{Btu} / \mathrm{hr}$ per ton

Parasitic power $=0$

VC chiller 2 (VC-2); $32^{\circ} \mathrm{F}$ evaporator:

$\mathrm{COP}=20.1417 \exp (-0.0171 * \mathrm{Twb})$

Relative capacity $=1.265-0.0033 *$ Twb

Heat rejection rate $=14,334 \mathrm{Btu} / \mathrm{hr}$ per ton

Parasitic power $=0$

VC chiller 3 (VC-3); $-20^{\circ} \mathrm{F}$ evaporator:

$\mathrm{COP}=5.863 \exp \left(-0.0123^{*} * \mathrm{Twb}\right)$

Relative capacity $=1.008-0.001 *$ Twb

Heat rejection rate $=17,444 \mathrm{Btu} / \mathrm{hr}$ per ton

Parasitic power $=0$ 


\section{Aqua-Ammonia (AA) Chillers}

AA chiller 1 (AA-1); $20^{\circ} \mathrm{F}$ evaporator:

$\mathrm{COP}=0.820-0.00374 * \mathrm{Twb}$

Relative capacity $=1.5625-0.0075 *$ Twb

Steam temperature $=252^{\circ} \mathrm{F} ;$ pressure $=31 \mathrm{psia} ; \mathrm{h}_{\mathrm{fg}}=944 \mathrm{Btu} / \mathrm{lb}$

Heat rejection rate $=34,263 \mathrm{Btu} / \mathrm{hr}$ per ton

Parasitic power $=0$

AA chiller $2(\mathrm{AA}-2) ; 32^{\circ} \mathrm{F}$ evaporator:

$\mathrm{COP}=0.857-0.00372 * \mathrm{Twb}$

Relative capacity $=1.5625-0.0075 *$ Twb

Steam temperature $=240^{\circ} \mathrm{F} ;$ pressure $=25 \mathrm{psia} ; \mathrm{h}_{\mathrm{fg}}=952 \mathrm{Btu} / \mathrm{lb}$

Heat rejection rate $=32,754 \mathrm{Btu} / \mathrm{hr}$ per ton

Parasitic power $=0$

AA chiller 3 (AA-3); $-20^{\circ} \mathrm{F}$ evaporator:

$\mathrm{COP}=0.8672-0.00635 * \mathrm{Twb}$

Relative capacity $=1.5625-0.0075 *$ Twb

Steam temperature $=315^{\circ} \mathrm{F}$; pressure $=83 \mathrm{psia} ; \mathrm{h}_{\mathrm{fg}}=899 \mathrm{Btu} / \mathrm{lb}$

Heat rejection rate $=42,691 \mathrm{Btu} / \mathrm{hr}$ per ton

Parasitic power $=0$

\section{Lithium Bromide (LiBr) Chillers}

LiBr chiller 1 (LiBr-1); single-stage:

$\mathrm{COP}=0.671-9.7 \mathrm{E}-4 *(\mathrm{Twb}-65)^{1.5}$

Relative capacity $=1.22-0.024 *(\mathrm{Twb}-65)$

Steam temperature $=244^{\circ} \mathrm{F} ;$ pressure $=27 \mathrm{psia} ; \mathrm{h}_{\mathrm{fg}}=950 \mathrm{Btu} / \mathrm{lb}$

Heat rejection rate $=29,200 \mathrm{Btu} / \mathrm{hr}$ per ton

Parasitic power $=0.0136 \mathrm{~kW} /$ ton

The minimum cooling water temperature allowable for single-stage $\mathrm{LiBr}$ chillers is $75^{\circ} \mathrm{F}$. Therefore, $\mathrm{Twb}$ is limited to a minimum of $65^{\circ} \mathrm{F}$. 
$\mathrm{LiBr}$ chiller $2(\mathrm{LiBr}-2)$; double-stage, $32^{\circ} \mathrm{F}$ evaporator:

$\mathrm{COP}=1.237-4.258 \mathrm{E}-3 *(\mathrm{Twb}-68)^{1.2}$

Relative capacity $=1.074-0.0255 *(\mathrm{Twb}-68)$

Steam temperature $=347^{\circ} \mathrm{F} ;$ pressure $=130 \mathrm{psia} ; \mathrm{h}_{\mathrm{fg}}=873 \mathrm{Btu} / \mathrm{lb}$

Heat rejection rate $=21,800 \mathrm{Btu} / \mathrm{hr}$ per ton

Parasitic power $=0.028 \mathrm{~kW} /$ ton

The minimum cooling water temperature allowable for double-stage $\mathrm{LiBr}$ chillers is $78^{\circ} \mathrm{F}$. Therefore, Twb is limited to a minimum of $68^{\circ} \mathrm{F}$.

\subsection{Storage}

Storage is a significant component of a CTAC system, but can be effectively modeled with a few simple inputs. Thermal losses through the walls of the storage tank are typically no more than $1 \%$, but other loss mechanisms have a much greater impact. Water storage relies on the creation of a thermocline to separate the hot and cold portions of the water. The difference between hot and cold temperatures, hence hot and cold buoyancies, is not much in this application of water/thermal storage. Therefore, losses across the thermocline are relatively high. The combined water storage efficiency was assumed to be $85 \%$ (ASHRAE 1987; EPRI 1988; Zwillenberg et al. 1991). Ice storage is really a mixture of water and ice. During discharge, warm return water is sprayed on top of the ice to facilitate melting. Here, mixing is not only beneficial, but required. During the charging cycle, however, periodic defrosting of the ice generator is required to release the ice from the evaporator surfaces. The defrost energy increases the refrigeration load and chiller capacity, but, unlike the water storage losses or the $1 \%$ loss through the tank walls, it does not affect the capacity of the storage tank. The defrost efficiency factor was presumed to be $85 \%$ (i.e., the chiller load and refrigeration capacity are increased by a factor of $1 / 0.85$ to account for the defrost energy that must be removed), which is separate from the ice storage efficiency, which was presumed to be $99 \%$ (Babcock and Wilcox 1994). ${ }^{(2)}$

\subsection{Fluid Circulation}

CTAC systems include several fluid circulation loops, with the specific number and type depending on the type of chiller and storage. Included here are the ammonia loop connecting the chiller evaporator and other chiller components (except for $\mathrm{LiBr}$ chillers), the chilled water loop connecting $\mathrm{LiBr}$ chillers and storage with the inlet air cooling coils, the cooling water loop connecting the chiller with the cooling tower, the steam loop connecting the steam source with absorption-type chillers, and storage water loops connecting relatively warm storage water with evaporators in the ice generator or water chiller. The following pumping power rules-of-thumb were established from a collection of published data describing CTAC systems.

(a) Personal communication with representatives of Lincoln Electric System and Henry Vogt Company. 
Ammonia loop power: $0.005 \mathrm{~kW} /$ ton or $2.0 \mathrm{E}-5 \mathrm{~kW} / \mathrm{lb}$ per $\mathrm{hr}$ ammonia

Chilled water loop power: $0.03 \mathrm{~kW} / \mathrm{gpm}$ water

Cooling water loop power: $0.02 \mathrm{~kW} / \mathrm{gpm}$ water

Steam loop power: $0.03 \mathrm{~kW} / \mathrm{gpm}$ or $6.0 \mathrm{E}-5 \mathrm{~kW} / \mathrm{lb}$ per hr steam

Storage charging water loop power

Ice generation: $0.03 \mathrm{~kW} /$ ton

Chilled water generation: $0.02 \mathrm{~kW} /$ ton.

\subsection{Evaporative Cooling}

Evaporative cooling towers are used by every chiller to reject heat. In addition, evaporative inlet air cooling is an alternative to refrigerative inlet air cooling. Water consumption for both types of evaporators is calculated based on the thermodynamic requirement plus a $10 \%$ allowance for blowdown and carryover. The inlet air evaporator consumes $0.01 \mathrm{~kW} / \mathrm{gpm}$ of water circulating through the cooler or $0.3 \mathrm{~kW} / \mathrm{gpm}$ evaporating. The cooling tower fan consumes $1.25 \mathrm{~kW} / \mathrm{MMBtu}$ per hour of heat rejected.

\subsection{Auxiliary System Cooling}

Cooling the inlet air of the turbine will increase its shaft power output, but care must be taken not to exceed the operating capabilities of other power plant components, specifically the generator, transformer, and lube oil system. Depending on the capabilities of these components, supplemental cooling may be required. This study assumed that supplemental cooling equal to $5 \%$ of the inlet air cooling load would be required (Babcock and Wilcox 1994). ${ }^{\text {(a) }}$ Chillers and storage components were oversized by this factor and a separate cooling loop and heat exchanger was provided to cool the auxiliary equipment.

\subsection{Turbine Inlet and Exit Excess Pressure Drop}

Adding an inlet air cooling device increases the compressor pressure drop, resulting in decreased power output and increased heat rate. Although these losses are relatively small compared to the improvement in these same factors achieved from cooling the air, they are significant enough to warrant inclusion in the analysis. A similar effect occurs if a heat recovery steam generator is added to a simple-cycle turbine to provide steam for an absorption-type chiller. The increase in exhaust pressure

(a) Personal communication with representatives of Lincoln Electric System. 
drop also reduces power output and increases heat rate, but by a relatively small amount. The specific assumptions used for excess inlet and exhaust pressure drop are shown below.

Inlet Air Cooling Coil Air-Side Pressure Drop:

Evaporative cooling: 1.0 in. of water

Refrigerative cooling to $42^{\circ} \mathrm{F}: 0.5$ in. of water

Refrigerative cooling to $0^{\circ} \mathrm{F}: 1.3$ in. of water

HRSG Air-Side Pressure Drop:

Maximum pressure drop for full heat recovery $=10$ in. of water

Actual pressure drop $=10$ in. $*\left(1000-\mathrm{T}_{\mathrm{r}}\right) /(1000-300)$

$\mathrm{T}_{\mathrm{r}}=$ calculated stack reject temperature, ${ }^{\circ} \mathrm{F}$.

\subsection{Combined-Cycle Steam Extraction Power Output Reduction}

Absorption-type chillers require a source of low pressure steam. For simple-cycle power plants, an HRSG and related steam/condensate piping are added to provide the steam. In combined-cycle plants, steam is presumed to be extracted from the lower pressure stages of the steam turbine. While no additional fuel is required in either case (except for the effect of increasing the exhaust pressure when adding an HRSG), extracting steam from a combined-cycle plant's steam turbine does incur a loss of power production. The loss increases as the extraction pressure increases and is described by the following relationship:

$\mathrm{kW} / \mathrm{lb}$ per hr steam $=-0.0079+0.0172 \ln (\mathrm{P})$.

where $\mathrm{P}=$ steam pressure, psia. 


\subsection{Cost Analysis}

Initial capital cost and annual operating and maintenance cost estimating equations were developed for each cooling system component. Cost data acquired from equipment vendors, published literature describing inlet air cooling systems, and cost estimating reference books were the basis for developing the equations. The equations were applied to equipment sizing results to produce system cost estimates peculiar to each case evaluated.

All costs were estimated in mid-1994 dollars and are intended to include all costs associated with equipment and material purchase and installation. All components except for the complex compound chiller are mature, commercially available products. Complex compound chiller costs were estimated based on a mature production scenario, i.e., the first unit would probably be more expensive.

Note that no equations for estimating annual operating labor costs are presented. No incremental operating labor is presumed to be required based on advice received from personnel at Lincoln Electric System, which has operated an inlet air cooling system on one of their turbines since 1992.

\subsection{Chiller Capital Costs}

The most striking observation for chillers is the extremely high cost of the aqua-ammonia systems compared to the other options. Otherwise, all chillers increase in cost as the evaporator temperature is lowered, and double-stage units cost more than single-stage units. Absorption chiller costs are less sensitive to evaporator temperature than vapor compression chillers, resulting in a significant cost advantage for complex compound chillers at the lower evaporating temperature required for cooling inlet air to $0^{\circ} \mathrm{F}$.

LiBr Absorption Chillers:

$44^{\circ} \mathrm{F}$ water, single stage $=\$ 480 /$ ton

$44^{\circ} \mathrm{F}$ water, double stage $=\$ 650 /$ ton

Complex Compound Absorption Chillers:

$-20^{\circ} \mathrm{F}$ evaporator temperature, single stage $=\$ 490 /$ ton

$20^{\circ} \mathrm{F}$ evaporator temperature, single stage $=\$ 390 /$ ton

$20^{\circ} \mathrm{F}$ evaporator temperature, double stage $=\$ 550 /$ ton

$32^{\circ} \mathrm{F}$ evaporator temperature, single stage $=\$ 380 /$ ton

$32^{\circ} \mathrm{F}$ evaporator temperature, double stage $=\$ 530 /$ ton

$-20^{\circ} \mathrm{F}$ evaporator temperature, single stage storage $=\$ 310 /$ ton-hr

Note: The storage version of the complex compound absorption chiller integrates the chiller and storage into a single component. The cost for both is based on the required storage size. 
Aqua-Ammonia Absorption Chillers:

$-20^{\circ} \mathrm{F}$ evaporator temperature $=\$ 3000 /$ ton

$20^{\circ} \mathrm{F}$ evaporator temperature $=\$ 2800 /$ ton

$32^{\circ} \mathrm{F}$ evaporator temperature $=\$ 2700 /$ ton

Ammonia Vapor Compression Chillers:

$-20^{\circ} \mathrm{F}$ evaporator temperature $=\$ 780 /$ ton

$20^{\circ} \mathrm{F}$ evaporator temperature $=\$ 520 /$ ton

$32^{\circ} \mathrm{F}$ evaporator temperature $=\$ 480 /$ ton .

\subsection{Storage Capital Costs}

Except for the $\mathrm{LiBr}$ units, the chiller costs presented above do not include the cost of the evaporator. Without storage, refrigerant (ammonia) evaporation for the other units occurs directly in the inlet air cooling coils. Otherwise, refrigerant is evaporated in an ice or chilled water generator, depending on the storage type selected. Note that chilled water can be generated in a relatively simple and inexpensive, shell-and-tube type heat exchanger, while ice generation requires more complex and costly ice harvesting equipment. Water and ice storage tanks are essentially the same, but ice storage (actually an ice/water mixture) is less costly per ton-hr because of its higher chill energy density.

Ice Generator $=\$ 590 /$ ton

Chilled Water Generator $=\$ 50 /$ ton

Ice Storage $=\$ 163.6 *(\text { ton-hrs })^{0.75}$

Water Storage $=\$ 572.4 *(\text { ton-hrs })^{0.75}$.

\subsection{Inlet Air Coil Capital Costs}

The cooling coils include the coil, its enclosure, and foundation. For refrigerative cooling, the same cost is assumed for either water or ammonia fluid circulating through the coils. The higher cost for the $0^{\circ} \mathrm{F}$ air cooling coils is based on having three 50\% capacity banks (with two cooling and one defrosting at any point in time) and the extra cost of dampers required to isolate each of the banks for defrosting.

Evaporative Cooling Coils $=\$ 3 / \mathrm{kW}$ of ISO turbine capacity

Refrigerative Cooling Coils:

For 42 or $52^{\circ} \mathrm{F}$ air $=\$ 0.20 / \mathrm{UA}$

For $0^{\circ} \mathrm{F}$ air $=\$ 0.33 / \mathrm{UA}$

where $\mathrm{UA}=$ heat transfer surface conductance, $\mathrm{Btu} / \mathrm{hr}-{ }^{\circ} \mathrm{F}$. 


\subsection{Fluid Circulation Capital Costs}

Individual estimates for pumps and piping were aggregated to develop the water circulation cost equations shown below. Unit cost differences are directly related to the length of the piping run and pumping head. An insulation premium was also added for the steam/condensate pipe. Ammonia circulation costs are much lower than water circulation because ammonia passes through a phase change, so its mass flow rate is much lower for the same thermal duty. Note that ammonia circulation costs are doubled for $0^{\circ} \mathrm{F}$ inlet air temperature applications to allow for hot refrigerant bypass for defrosting.

Water Circulation:

Steam/condensate $=\$ 320,000 *(\mathrm{gpm} / 10,000)^{0.6}$

Chilled water $=\$ 290,000 *(\mathrm{gpm} / 10,000)^{0.6}$

Cooling water $=\$ 260,000 *(\mathrm{gpm} / 10,000)^{0.6}$

Storage charging water $=\$ 100,000 *(\mathrm{gpm} / 10,000)^{0.6}$.

Ammonia Circulation:

For 42 or $52^{\circ} \mathrm{F}$ air $=\$ 54,000 *(\mathrm{lb} / \mathrm{hr} / 15,000)^{0.6}$

For $0^{\circ} \mathrm{F}$ air $=\$ 108,000 *(\mathrm{lb} / \mathrm{hr} / 15,000)^{0.6}$.

\subsection{Miscellaneous Equipment Capital Costs}

Capital cost estimating equations for other cooling system components are listed below. Heat recovery steam generators are only used for simple-cycle power plants with absorption-type chillers.

Cooling Tower $=\$ 662,000 *(\mathrm{MMBtu} / \mathrm{hr} / 192)^{0.876}$

System Controls $=\$ 250,000$ (fixed for all systems)

Plant Electrical $=\$ 100,000$ (fixed for all systems)

Transformer $=\$ 5,553 *(\text { peak auxiliary } \mathrm{kW})^{0.4359}$.

Heat Recovery Steam Generator:

$$
\begin{aligned}
& \$ 10,980 *(\mathrm{UA})^{0.8}+ \\
& \$ 9,658 *(\mathrm{SF})+ \\
& \$ 918 *(\mathrm{EF})^{1.2} *(1000-\mathrm{TR}) / 300
\end{aligned}
$$

where $\mathrm{UA}=$ heat transfer surface conductance, Btu/s $-{ }^{\circ} \mathrm{F}$

$\mathrm{SF}=$ steam flow, $\mathrm{lb} / \mathrm{s}$

$\mathrm{EF}=$ turbine exhaust flow, $\mathrm{lb} / \mathrm{s}$

$\mathrm{TR}=$ exhaust gas reject temperature after HRSG, ${ }^{\circ} \mathrm{F}$. 
Generator Cooling Loop Heat Exchanger $=\$ 865 *(\mathrm{HTA})^{0.511}$

where HTA = heat exchanger heat transfer area, square feet.

\subsection{Annual Maintenance Costs}

Annual maintenance costs were estimated as a percentage of initial capital cost for each inlet air cooling component. In addition, make-up water, for water consumed at either an evaporative inlet air cooler or a cooling tower, was estimated to cost $\$ 1 / 1000$ gallons. Maintenance cost estimating percentages are listed below.

\begin{tabular}{|c|c|}
\hline Component & Percentage \\
\hline LiBr chiller & 5.0 \\
\hline $\mathrm{NH}_{3} / \mathrm{H}_{2} \mathrm{O}$ chiller & 4.0 \\
\hline Vapor compression chiller & 4.0 \\
\hline Complex compound chiller & 3.0 \\
\hline Ice generator & 2.0 \\
\hline Chilled water generator & 1.0 \\
\hline Ice storage & 1.5 \\
\hline Water storage & 1.5 \\
\hline $\begin{array}{l}\text { Direct contact evaporative } \\
\text { air cooler }\end{array}$ & 2.0 \\
\hline \multicolumn{2}{|l|}{ Inlet air coil } \\
\hline $42^{\circ} \mathrm{F}$ and $52^{\circ} \mathrm{F}$ air & 2.0 \\
\hline $0^{\circ} \mathrm{F}$ air & 3.0 \\
\hline Circulation (pumps and pipes) & 3.0 \\
\hline Cooling tower & 2.0 \\
\hline Controls & 6.0 \\
\hline Plant electrical & 2.0 \\
\hline Transformer & 2.0 \\
\hline HRSG & 3.0 \\
\hline Generator cooling heat exchanger & 1.0 \\
\hline
\end{tabular}

7.4 . 


\subsection{Economic Analysis}

The economic analysis compared the benefit of incremental power and energy production with the cost of owning and operating the inlet air cooling system. With costs and benefits denominated in dollars, economic feasibility was determined by calculating the net present value (NPV) of the investment. The preferred cooling systems were, of course, those with the highest NPVs for a given set of application conditions. Refrigerative and evaporative cooling systems were compared against reference plants that were uncooled, and refrigerative cooling systems were also compared against reference plants that were already evaporatively cooled.

The value of incremental power and energy production varies depending on ownership perspective. From a utility perspective, value is defined by the alternative to inlet air cooling for providing additional capacity. The most likely alternative would be to build a new turbine without refrigerative inlet air cooling. The value of incremental power would be equal to the expected fixed costs (capital and fixed operation and maintenance [O\&M]), while the value of incremental energy would be equal to the expected variable costs (fuel and variable $O \& M$ ). From an industrial perspective, the value of incremental power and energy is set more specifically by the prevailing contract with the utility for power purchases or sales. This contract will also probably contain requirements that will dictate the period the inlet air cooling system will need to operate to achieve the maximum credit for increased generating capacity. This study takes the utility perspective.

Obviously, the value of incremental power and energy not only varies with the general differences between a utility and an industrial perspective, but also because of all the differences that exist between individual utilities and industrial companies. While this will have a significant effect on the magnitudes of the NPVs calculated for each case, it shouldn't significantly affect the rankings of the NPVs for each case. Given the uncertainty in the values for incremental power and energy, the capital cost per incremental power output has also been calculated for each case. While this is an inferior investment

decision criteria, it is independent of any assumed values for incremental power and energy and can be quickly compared to the cost of adding capacity via another means.

\subsection{Incremental Power and Energy Calculation}

Incremental power and energy production is simply the difference between the cooled and uncooled output of the power plant. The difference increases as the ambient temperature climbs. For incremental energy, hourly differences are aggregated over all cooling hours to calculate the annual incremental energy production. For incremental power, the figure of interest to utilities is the increase in capacity (or incremental power) occurring when the utility experiences its peak power demand. For most utilities, peak demand occurs during the summer, and is driven by air conditioning loads. While peak incremental power production will always occur at the peak dry-bulb temperature, peak air conditioning loads and peak power demand correspond more closely to peak air enthalpy conditions. Thus, the peak hourly air enthalpy was selected as the design point for calculating incremental power. Peak enthalpy tends to occur at higher wet-bulb, but lower dry-bulb temperatures. As a result, the 
incremental power calculated is less than if the basis were the peak dry-bulb temperature. A utilityspecific analysis would allow the timing of peak demand to be more accurately defined, but was beyond the scope of this study.

\subsection{Incremental Power and Energy Value}

Taking the utility perspective described above, the value of incremental power and energy depends mostly on the cost and performance characteristics of the power plant being displaced by inlet air cooling and the peak power demand temperature and humidity conditions. Power plant cost and performance characteristics and utility economic assumptions presented in Tables 8.1 and 8.2 were coupled with the levelized cost methodology described in Brown et al. (1987) to calculate the incremental power and energy figures shown in Table 8.3. The same economic assumptions and levelized cost methodology were also used to calculate the NPV for each case once the incremental costs and revenues (from incremental power and energy production) were calculated. The key inputs affecting the differences in the value of power and energy are the plant capital cost and heat rate. Climate also has an interesting impact. The severe peak demand conditions in Phoenix reduce power plant output, causing the cost per $\mathrm{kW}$ to rise. The opposite is found for a mild climate like that found in San Francisco.

In general, the power and energy values shown in Table 8.3 were applied to the incremental power and energy generated by each plant type while the cooling system was operating. However, when the combined-cycle plant was cooled on a simple-cycle schedule, its incremental power and energy production were valued at the industrial turbine rates. Off-peak energy to drive vapor compression chillers for power plants running less than 24 hours/day was presumed to come from a coal-fired power plant. The value of this energy was set at $\$ 0.0195 / \mathrm{kWh}$ based on a heat rate of $10,500 \mathrm{Btu} / \mathrm{kWh}$, variable O\&M equal to $\$ 0.004 / \mathrm{kWh}$, and coal at $\$ 1.36 / \mathrm{MMBtu}$ in 1994 dollars, escalating at $0.5 \%$ per year in excess of general inflation.

Table 8.1. Power Plant Cost and Performance Assumptions

\begin{tabular}{|l|c|c|c|}
\hline & $\begin{array}{c}\text { Industrial } \\
\text { Simple-Cycle }\end{array}$ & $\begin{array}{c}\text { Aeroderivative } \\
\text { Simple-Cycle }\end{array}$ & $\begin{array}{c}\text { Industrial } \\
\text { Combined-Cycle }\end{array}$ \\
\hline \hline Capital cost, \$/kW & 449 & 749 & 602 \\
\hline Fixed annual O\&M, \$/kW/yr & 10.9 & 15.6 & 27.6 \\
\hline Variable O\&M, \$/kWh & 0.0002 & 0.0002 & 0.0008 \\
\hline Heat rate, Btu/kWh & 11,700 & 10,000 & 7,300 \\
\hline Source: Technical Assessment Guide (EPRI 1993) \\
\hline
\end{tabular}


Table 8.2. Power Plant Economic Assumptions

\begin{tabular}{||l|l||}
\hline Economic life & 30 years \\
\hline Depreciable life & 20 years \\
\hline Income tax rate & $38 \%$ \\
\hline Nominal discount rate & $9.25 \%$ \\
\hline General inflation rate & $4.1 \%$ \\
\hline Property tax and insurance & $2 \%$ \\
\hline Price year & 1994 \\
\hline 1st operating year & 1997 \\
\hline Construction period & $1-2$ years \\
\hline Natural gas price & $\$ 2.25 / \mathrm{MMBtu}$ \\
\hline Natural gas inflation rate & $6.4 \%$ \\
\hline Sources: Technical Assessment Guide (EPRI 1993) \\
$\begin{array}{l}\text { Annual Energy Outlook 1995 (EIA 1995a) } \\
\text { Monthly Energy Review (for March 1995) (EIA } \\
\text { 1995b) }\end{array}$ \\
\hline
\end{tabular}

Table 8.3. Incremental Power and Energy Values

\begin{tabular}{||l|c|c|c|c|c|c||}
\hline \multirow{2}{*}{\multicolumn{1}{|c|}{ City }} & \multicolumn{2}{|c|}{ Indust. Turbine } & \multicolumn{2}{c|}{ Aero. Turbine } & \multicolumn{2}{c|}{ Combined-Cycle } \\
\cline { 2 - 8 } & $\$ / \mathrm{kW}$ & $\$ / \mathrm{kWh}$ & $\$ / \mathrm{kW}$ & $\$ / \mathrm{kWh}$ & $\$ / \mathrm{kW}$ & $\$ / \mathrm{kWh}$ \\
\hline \hline Houston & 63 & 0.038 & 110 & 0.032 & 98 & 0.024 \\
\hline$\cdot$ Minneapolis & 64 & 0.037 & 109 & 0.032 & 98 & 0.024 \\
\hline Nashville & 64 & 0.038 & 110 & 0.032 & 98 & 0.024 \\
\hline Phoenix & 69 & 0.039 & 123 & 0.033 & 105 & 0.024 \\
\hline San Francisco & 62 & 0.037 & 106 & 0.031 & 95 & 0.024 \\
\hline
\end{tabular}





\subsection{Results}

The net present value (NPV) and capital cost per incremental $\mathrm{kW}(\$ / \mathrm{kW})$ were calculated for about 3500 cases. This includes 44 industrial turbine simple-cycle cases, 24 aeroderivative turbine simplecycle cases and 288 combined-cycle cases, with each evaluated for five different cities and with the reference case being either an uncooled or evaporatively cooled plant. A complete listing of these results is presented in Appendix C. This section presents and discusses selected results.

\subsection{Nomenclature}

Each case is distinguished by its case number, chiller type, plant operating hours per day, cooling hours per day, and storage type. The case number uniquely defines one of 356 cases. Industrial turbine cases begin with an "i," aeroderivative turbine cases with an "a," and combined-cycle cases with a "c,", "d," "e," or "f." The four combined-cycle groups represent different combinations of plant operating hours and cooling system operating hours. The second letter of the case number, an " $e$ " or an "r," designates a case as being evaporatively or refrigeratively cooled. The chiller type can be either aqua-ammonia (AA), complex compound (CC), lithium bromide ( $\mathrm{LiBr}$ ), or vapor compression (VC). The chiller numbers refer to the specific versions of each chiller type defined in Section 6.0. Plant operating hours and cooling system operating hours are designated by two numbers separated by a backslash. For example, "12/4" would mean the plant runs 12 hours per day while the cooling system runs 4 hours per day. The specific power plant and cooling system schedule assumptions were defined in Section 4.0. The storage type is defined by a four letter code. The first letter refers to ice (I) or water (W) storage, the second letter to a daily (D) or weekly (W) cycle, and the final two letters to a load-shifting (LS) or load-leveling (LL) design basis.

\subsection{Industrial Turbine}

NPV and $\$ / \mathrm{kW}$ results for cooling an industrial turbine in a simple-cycle application are presented in Table 9.1 for the Nashville climate. The magnitude of the NPV and $\$ / \mathrm{kW}$ figures are affected by the climate, but technology rankings generally are not. A comparison of results across climates is presented later.

A quick review of the figures presented in Table 9.1 identifies the aqua-ammonia systems as the only ones with negative NPVs for the uncooled base and installed costs that are far too high for this technology to be cost-effective. The poor results for the aqua-ammonia system stem directly from the high capital cost for its chiller. Evaporative cooling yields the lowest $\$ / \mathrm{kW}$ for the uncooled base by more than a factor of two, but its NPV is relatively low. Thus, some form of refrigerative cooling is preferred. 
Table 9.1. Industrial Turbine Results-Nashville

\begin{tabular}{|c|c|c|c|c|c|c|c|}
\hline \multirow[b]{2}{*}{ Case } & \multirow[b]{2}{*}{ Chiller } & \multirow[b]{2}{*}{ OpHrs } & \multirow[b]{2}{*}{ Storage } & \multicolumn{2}{|c|}{ Uncooled Base } & \multicolumn{2}{|c|}{ Evap. Cooled Base } \\
\hline & & & & $\$ / k W$ & NPV, \$M & $\$ / \mathrm{kW}$ & NPV, \$M \\
\hline iel & None & $4 / 4$ & None & 68 & 2.86 & -- & -- \\
\hline ie2 & None & $8 / 8$ & None & 68 & 3.10 & -- & - \\
\hline irl & $\mathrm{AA}-2$ & $4 / 4$ & None & 1075 & -14.00 & 1400 & -17.00 \\
\hline ir2 & $A A-2$ & $8 / 8$ & None & 1075 & -13.40 & 1400 & -16.60 \\
\hline ir3 & $\mathrm{CC}-2$ & $4 / 4$ & None & 353 & 3.75 & 462 & 0.76 \\
\hline ir 4 & $\mathrm{CC}-2$ & $8 / 8$ & None & 353 & 4.36 & 462 & 1.13 \\
\hline ir5 & $\mathrm{LiBr}-1$ & $4 / 4$ & None & 397 & 2.05 & 564 & -0.95 \\
\hline ir6 & $\mathrm{LiBr}-1$ & $8 / 8$ & None & 397 & 2.53 & 564 & -0.71 \\
\hline ir7 & VC-2 & $4 / 4$ & None & 307 & 4.07 & 424 & 1.08 \\
\hline ir8 & VC-2 & $8 / 8$ & None & 307 & 4.51 & 424 & 1.27 \\
\hline ir9 & VC-1 & $4 / 4$ & IWLS & 158 & 9.09 & 203 & 6.10 \\
\hline ir 10 & VC-1 & $4 / 4$ & IWLL & 155 & 8.92 & 200 & 5.92 \\
\hline irll & VC-1 & $4 / 4$ & IDLS & 182 & 8.48 & 234 & 5.48 \\
\hline ir 12 & $V C-1$ & $4 / 4$ & IDLL & 175 & 8.28 & 227 & 5.29 \\
\hline ir 13 & VC-I & $8 / 8$ & IWLS & 249 & 7.49 & 319 & 4.25 \\
\hline ir 14 & VC-1 & $8 / 8$ & IWLL & 225 & 7.59 & 293 & 4.35 \\
\hline ir 15 & VC-1 & $8 / 8$ & IDLS & 323 & 5.64 & 413 & 2.40 \\
\hline ir 16 & VC-1 & $8 / 8$ & IDLL & 271 & 6.26 & 357 & 3.02 \\
\hline ir 17 & VC-2 & $4 / 4$ & WWLS & 221 & 6.25 & 305 & 3.26 \\
\hline ir18 & VC-2 & $4 / 4$ & WWLL & 214 & 6.24 & 298 & 3.24 \\
\hline ir 19 & VC-2 & $4 / 4$ & WDLS & 200 & 6.56 & 276 & 3.56 \\
\hline ir20 & VC-2 & $4 / 4$ & WDLL & 192 & 6.46 & 269 & 3.47 \\
\hline ir 21 & VC-2 & $8 / 8$ & WWLS & 339 & 4.60 & 468 & 1.36 \\
\hline ir22 & VC-2 & $8 / 8$ & WWLL & 305 & 4.99 & 428 & 1.75 \\
\hline ir23 & VC-2 & $8 / 8$ & WDLS & 311 & 4.91 & 430 & 1.68 \\
\hline ir 24 & VC-2 & $8 / 8$ & WDLL & 268 & 5.32 & 382 & 2.09 \\
\hline ir 25 & $\mathrm{CC}-2 / \mathrm{CC}-5$ & $4 / 4$ & None & 413 & 4.48 & 474 & 1.48 \\
\hline ir 26 & $\mathrm{CC}-2 / \mathrm{CC}-5$ & $8 / 8$ & None & 413 & 5.78 & 474 & 2.54 \\
\hline ir 27 & $A A-2 / A A-3$ & $4 / 4$ & None & 1126 & -28.00 & 1289 & -30.70 \\
\hline ir 28 & AA-2/AA-3 & $8 / 8$ & None & 1126 & -26.00 & 1289 & -29.59 \\
\hline ir 29 & $\mathrm{VC}-2 / \mathrm{VC}-3$ & $4 / 4$ & None & 367 & 4.20 & 441 & 1.20 \\
\hline ir30 & $\mathrm{VC}-2 / \mathrm{VC}-3$ & $8 / 8$ & None & 367 & 4.50 & 441 & 1.26 \\
\hline ir31 & $V C-1 / V C-3$ & $4 / 4$ & IWLS & 254 & 9.60 & 297 & 6.60 \\
\hline ir32 & $V C-1 / V C-3$ & $8 / 8$ & IWLS & 316 & 7.76 & 369 & 4.52 \\
\hline ir33 & $V C-1 / V C-3$ & $4 / 4$ & IWLL & 253 & 9.91 & 297 & 6.92 \\
\hline ir34 & VC-1/VC-3 & $8 / 8$ & IWLL & 303 & 8.76 & 357 & 5.52 \\
\hline
\end{tabular}


Table 9.1. (contd)

\begin{tabular}{||c|c|c|c|c|c|c|c||}
\hline \multirow{2}{*}{ Case } & \multirow{2}{*}{ Chiller } & \multirow{2}{*}{ OpHrs } & Storage & \multicolumn{2}{|c|}{ Uncooled Base } & \multicolumn{2}{|c|}{ Evap. Cooled Base } \\
\cline { 5 - 8 } & & S/kW & NPV, \$M & $\$ / k W$ & NPV, \$M \\
\hline \hline ir35 & VC-1/VC-3 & $4 / 4$ & IDLS & 270 & 8.95 & 316 & 5.96 \\
\hline ir36 & VC-1/VC-3 & $8 / 8$ & IDLS & 368 & 5.79 & 430 & 2.55 \\
\hline ir37 & VC-1/VC-3 & $4 / 4$ & IDLL & 268 & 9.22 & 315 & 6.23 \\
\hline ir38 & VC-1/VC-3 & $8 / 8$ & IDLL & 337 & 7.29 & 399 & 4.05 \\
\hline ir39 & VC-2/CC-5 & $4 / 4$ & None & 410 & 4.41 & 478 & 1.08 \\
\hline ir40 & VC-2/CC-5 & $8 / 8$ & None & 410 & 5.10 & 478 & 1.87 \\
\hline ir41 & VC-1/CC-5 & $4 / 4$ & IWLL & 309 & 9.27 & 353 & 6.27 \\
\hline ir42 & VC-1/CC-5 & $8 / 8$ & IWLL & 352 & 8.42 & 404 & 5.18 \\
\hline
\end{tabular}

For the single chiller cases without storage, ammonia vapor compression cooling produces the lowest $\$ / \mathrm{kWs}$ and highest NPVs, although the complex compound systems are competitive on an NPV basis. Note that the $\$ / \mathrm{kW}$ for a given chiller type is the same for either 4 or 8 cooling hours per day. This result occurs because the peak design condition is the same for the two periods. The NPV increases for the 8-hour cases because the marginal cost of running the system is less than the marginal benefit of improving the heat rate over an extended operating period.

The importance of storage for reducing $\$ / \mathrm{kW}$ and increasing NPV are clearly shown by comparing the results of cases ir9 through ir24 with irl through ir8. Comparing the best cases with and without storage shows that storage can reduce the $\$ / \mathrm{kW}$ and increase the NPV by a factor of two or more. Storage reduces the size and cost of the most expensive cooling system component (the chiller), while also reducing the consumption of on-peak parasitic power for vapor compression chillers. Note that storage was only considered for vapor compression systems. With cooling required for the duration of the plant operating period, there is no "off-peak" waste heat source available to drive absorption-type chillers. Natural gas firing was presumed to be too expensive, but this assumption should probably be verified by additional analysis.

Closer examination of cases ir9 through ir24 shows that ice storage is preferred to water storage and that weekly storage is preferred for ice while daily storage is preferred for water. Weekly storage allows the greatest reduction in chiller size and cost at the expense of increased storage size and cost. The high cost of the ice generator compared to the chilled water generator drives this difference in cycle preference. A load-leveling storage design results in the lowest $\$ / \mathrm{kW}$ because chiller size is reduced the most, but load-shifting reduces on-peak parasitic power consumption the most, and sometimes has the higher NPV. Storage is most cost-effective for plants being cooled only a few hours a day, where the benefits of downsizing the chiller are maximized.

Cases ir 25 through ir42 examine the benefits of cooling the inlet air to $0^{\circ} \mathrm{F}$. Various ice storage configurations are incorporated on the first cooling stage for some cases. Cooling to $0^{\circ} \mathrm{F}$ increases the $\$ / \mathrm{kW}$, but also increases the NPV. The increased $\$ / \mathrm{kW}$ can be attributed to a linear increase in the 
generating capacity and heat rate benefits, but increasing unit costs and decreasing COPs at lower evaporator temperatures for chillers. Increasing chiller unit costs are exacerbated by the lack of storage for the subfreezing second stage. Various brines or other media could potentially be used for storage at. this lower temperature, but were presumed to be too costly. Additional analysis of prospective lowtemperature storage media may be warranted to test this assumption.

Refrigerative cooling is less attractive, but still cost-effective if an evaporative cooling system is already installed. In this case, the incremental power and energy production is reduced, while the refrigerative cooling system cost remains the same. Note that evaporative cooling followed by refrigerative cooling would not reduce the refrigerative cooling load, hence the size and cost of the refrigerative cooling system. Evaporative cooling just exchanges sensible cooling load for latent cooling load. Refrigerative cooling followed by evaporative cooling makes no sense either, because the air is almost always saturated after refrigerative cooling. ${ }^{(a)}$

\subsection{Aeroderivative Turbine}

Inlet air cooling results for the aeroderivative turbine are presented in Table 9.2, again for the Nashville climate. In general, the results are similar to that for the industrial turbine. For example, the preferred cooling system uses ammonia vapor compression chillers and weekly ice storage. There are several interesting differences, however. Note that $0^{\circ} \mathrm{F}$ inlet air (two-chiller) cases were not evaluated because power output is constant for below freezing temperatures for this type of turbine. The $\$ / \mathrm{kW}$ figures have dropped by about $10-20 \%$ for the non-storage cases, which can be attributed directly to the greater sensitivity of aeroderivative turbine power output to inlet air temperature. This effect is masked for the storage cases for two reasons: 1) the benefits of downsizing the chiller while adding storage are larger for the industrial turbine because it was assumed to be a larger machine, and 2) adding storage increases peak power output per ISO $\mathrm{kW}$ output the same for both turbine types, which benefits the industrial turbine the most on a percentage basis. Finally, the increase in NPVs for the aeroderivative cases is driven by its higher value per incremental $\mathrm{kW}$.

\subsection{Combined-Cycle}

The combined-cycle analysis was more complicated than the industrial or aeroderivative simplecycle analyses because two plant operating schedules were evaluated and the cooling system operating cycle was allowed to be different than the plant operating cycle. When the cooling period is shorter than the plant operating period, storage is possible for the heat-activated absorption-type chillers. Thus, the number of cases evaluated increased significantly. Not all cases evaluated are presented here to focus on the more relevant results. In particular, the aqua-ammonia results have been excluded because of their extremely poor economics. A complete list of the results for all cases is presented in Appendix C.

(a) These comments apply to direct evaporative cooling and not to indirect methods of evaporative cooling. 
Table 9.2. Aeroderivative Turbine Results-Nashville

\begin{tabular}{|c|c|c|c|c|c|c|c|}
\hline \multirow[b]{2}{*}{ Case } & \multirow[b]{2}{*}{ Chiller } & \multirow[b]{2}{*}{ OpHrs } & \multirow[b]{2}{*}{ Storage } & \multicolumn{2}{|c|}{ Uncooled Base } & \multicolumn{2}{|c|}{ Evap. Cooled Base } \\
\hline & & & & $\$ / \mathrm{kW}$ & NPV, \$M & $\$ / \mathrm{kW}$ & NPV, SM \\
\hline ael & None & $4 / 4$ & None & 52 & 2.91 & - & -- \\
\hline ae2 & None & $8 / 8$ & None & 52 & 3.00 & -- & -- \\
\hline arl & AA-2 & $4 / 4$ & None & 881 & $: 6.92$ & 1153 & -3.63 \\
\hline $\operatorname{ar} 2$ & $\mathrm{AA}-2$ & $8 / 8$ & None & 881 & -4.31 & 1153 & -3.46 \\
\hline ar3 & $\mathrm{CC}-2$ & $4 / 4$ & None & 313 & 7.66 & 411 & 4.73 \\
\hline ar4 & $\mathrm{CC}-2$ & $8 / 8$ & None & 313 & 7.91 & 411 & 4.88 \\
\hline $\operatorname{ar} 5$ & LiBr-1 & $4 / 4$ & None & 350 & 5.60 & 500 & 2.67 \\
\hline ar6 & $\mathrm{LiBr}-1$ & $8 / 8$ & None & 350 & 5.79 & 500 & 2.76 \\
\hline $\operatorname{ar} 7$ & VC-2 & $4 / 4$ & None & 273 & 7.19 & 374 & 4.26 \\
\hline $\operatorname{ar} 8$ & VC-2 & $8 / 8$ & None & 273 & 7.36 & 374 & 4.35 \\
\hline $\operatorname{ar} 9$ & VC-1 & $4 / 4$ & IWLS & 159 & 10.41 & 206 & 7.47 \\
\hline $\operatorname{ar} 10$ & VC-1 & $4 / 4$ & IWLL & 156 & 10.21 & 203 & 7.27 \\
\hline arll & $V C-1$ & $4 / 4$ & IDLS & 179 & 10.12 & 231 & 7.18 \\
\hline $\operatorname{ar} 12$ & VC-1 & $4 / 4$ & IDLL & 172 & 9.84 & 224 & 6.90 \\
\hline $\operatorname{arl3}$ & VC-1 & $8 / 8$ & IWLS & 238 & 9.49 & 308 & 6.46 \\
\hline $\operatorname{ar} 14$ & VC-1 & $8 / 8$ & IWLL & 217 & 9.34 & 284 & 6.31 \\
\hline $\operatorname{ar} 15$ & VC-1. & $8 / 8$ & IDLS & 298 & 8.61 & 385 & 5.58 \\
\hline $\operatorname{ar} 16$ & VC-1 & $8 / 8$ & IDLL & 251 & 8.57 & 333 & 5.54 \\
\hline $\operatorname{ar} 17$ & VC-2 & $4 / 4$ & WWLS & 225 & 7.66 & 314 & 4.72 \\
\hline $\operatorname{ar} 18$ & VC-2 & $4 / 4$ & WWLL & 219 & 7.59 & 307 & 4.65 \\
\hline $\operatorname{ar} 19$ & VC-2 & $4 / 4$ & WDLS & 203 & 7.85 & 284 & 4.91 \\
\hline $\operatorname{ar} 20$ & VC-2 & $4 / 4$ & WDLL & 196 & 7.70 & 277 & 4.76 \\
\hline $\operatorname{ar} 21$ & VC-2 & $8 / 8$ & WWLS & 335 & 6.65 & 468 & 3.62 \\
\hline $\operatorname{ar} 22$ & VC-2 & $8 / 8$ & WWLL & 302 & 6.75 & 427 & 3.72 \\
\hline $\operatorname{ar} 23$ & VC-2 & $8 / 8$ & WDLS & 304 & 6.89 & 424 & 3.86 \\
\hline $\operatorname{ar} 24$ & VC-2 & $8 / 8$ & WDLL & 263. & 6.91 & 376 & 3.88 \\
\hline
\end{tabular}




\subsubsection{Intermediate Duty Plant; Cooling Hours Less Than Plant Hours}

The intermediate duty combined-cycle plant operates 12 hours per day, 5 days per week. The results for the best cases (lowest \$/kW and/or highest NPV) for each combination of chiller type and daily cooling period are presented in Table 9.3 for a combined-cycle plant operating 12 hours per day while the cooling system operates only 4 or 8 hours per day. Note that 4 and 8 hour cooling follows the same schedule as the simple-cycle plants and the incremental power and energy is valued the same as the simple-cycle industrial turbine application.

Inlet air cooling affects the performance of the steam turbine as well as the combustion turbine in a combined-cycle plant. Inlet air cooling reduces the exhaust temperature, but increases the exhaust flow rate, with the net result being an increase in steam turbine power output in addition to the increase in combustion turbine power output. As a result, $\$ / \mathrm{kW}$ results are generally lower than for corresponding industrial turbine simple-cycle cases. NPV results are generally higher for the combined-cycle cases, but this is primarily because of the larger size of the combined-cycle plant.

Table 9.3. Combined-Cycle Results I-Nashville

\begin{tabular}{|c|c|c|c|c|c|c|c|}
\hline \multirow[b]{2}{*}{ Case } & \multirow[b]{2}{*}{ Chiller } & \multirow[b]{2}{*}{ OpHrs } & \multirow[b]{2}{*}{ Storage } & \multicolumn{2}{|c|}{ Uncooled Base } & \multicolumn{2}{|c|}{ Evap. Cooled Base } \\
\hline & & & & $\$ / k W$ & NPV, \$M & $\$ / \mathrm{kW}$ & NPV, \$M \\
\hline cel & None & $12 / 4$ & None & 65 & 4.40 & -- & -- \\
\hline ce2 & None & $12 / 8$ & None & 65 & 4.90 & -- & -- \\
\hline $\operatorname{cr} 14$ & $\mathrm{LiBr}-2$ & $12 / 4$ & WDLL & 215 & 8.87 & 311 & 4.19 \\
\hline $\operatorname{crl} 16$ & $\mathrm{LiBr}-2$ & $12 / 8$ & WDLL & 358 & 4.50 & 555 & -0.19 \\
\hline $\operatorname{cr} 19$ & VC-1 & $12 / 4$ & IWLS & 127 & 16.61 & 163 & 11.42 \\
\hline $\mathrm{cr} 20$ & VC-1 & $12 / 4$ & - IWLL & 123 & 16.36 & 159 & 11.17 \\
\hline cr24 & VC-1 & $12 / 8$ & IWLL & 180 & 15.28 & 235 & 10.09 \\
\hline cr70 & $\mathrm{CC}-2$ & $12 / 4^{\circ}$ & WDLL & 195 & 9.72 & 281 & 5.04 \\
\hline $\operatorname{cr} 74$ & CC-1 & $12 / 4$ & IDLL & 214 & 11.48 & 284 & 6.80 \\
\hline $\operatorname{cr} 68$ & $\mathrm{CC}-2$ & $12 / 8$ & None ${ }^{\circ}$ & 266 & 8.74 & 374 & 4.06 \\
\hline $\operatorname{cr} 57$ & VC-1/VC-3 & $12 / 4$ & IWLL & 201 & 21.41 & 234 & 16.20 \\
\hline $\operatorname{cr} 58$ & VC-1/VC-3 & $12 / 8$ & IWLL & 240 & 21.72 & 281 & 16.50 \\
\hline cr81 & CC-1/CC-6 & $12 / 4$ & IDLL & 227 & 21.04 & 261 & 16.33 \\
\hline cr78 & CC-2/CC-5 & $12 / 8$ & None & 314 & 9.80 & 385 & 5.10 \\
\hline cr82 & CC-1/CC- 6 & $12 / 8$ & IDLL & 339 & 14.80 & 397 & 10.09 \\
\hline cr85 & VC-1/CC-6 & $12 / 4$ & IWLL & 213 & 23.09 & 244 & 18.39 \\
\hline cr84 & VC-2/CC-5 & $12 / 8$ & None & 299 & 11.95 & 363 & 7.24 \\
\hline cr86 & VC-2/CC-6 & $12 / 8$ & IWLL & 380 & 13.37 & 438 & 8.66 \\
\hline
\end{tabular}


The preferred cooling system is still an ammonia vapor compression cooling system with weekly ice storage, which has the lowest $\$ / \mathrm{kW}$ and highest NPV for the above-freezing (single chiller) applications (cr20 and $\mathrm{cr} 24$ ). For $0^{\circ} \mathrm{F}$ inlet air applications, ammonia vapor compression also has the lowest $\$ \mathrm{~kW}$, . but a combination vapor compression and complex compound system (cr85) has the highest NPV when cooling for only 4 hours per day.

Storage improves the economics of the heat-activated chillers, but not as much as it improves the economics of the vapor compression chiller because heat is still only available for 12 hours per day. Thus, a load-leveling storage design is generally preferred to a load-shifting design for heat-activated chillers for this application. In addition, storage looks much more attractive when cooling only 4 hours per day, as would be expected.

Single-stage (CC-1 and CC-2) and double-stage (CC-3 and CC-4) complex compound chillers were investigated. Double-stage chillers are more efficient, but cost more to build and consume higher pressure steam, which increases the extraction loss effect in the steam turbine. The results of this analysis show the single-stage complex compound chillers to be preferred, which suggests that single-stage lithium bromide chillers may also be better than the double-stage lithium bromide chillers (crl1 through cr16) that were evaluated.

\subsubsection{Intermediate Duty Plant; Cooling Hours Equal to Plant Hours}

Table 9.4 presents the results for cooling and operating a combined-cycle power plant 12 hours per day. Again, the ammonia vapor compression system with weekly ice storage is the preferred system for both above-freezing and $0^{\circ} \mathrm{F}$ inlet air temperature applications. Storage results in only a moderate advantage for the vapor compression system because the chiller size can at most be cut in half. Storage is not possible for the heat-activated systems.

Note that the $\$ / \mathrm{kW}$ for the evaporative cooler has increased from $\$ 68$ for cooling 4 or 8 hours per day to $\$ 77$ for 12 hours per day. This occurs because the design condition (maximum ambient air enthalpy) for the longer cooling cycle is slightly more humid.

\subsubsection{Baseload Duty Plant; Cooling Hours Less Than Plant Hours}

The baseload duty combined-cycle plant operates 24 hours per day, 7 days per week. The results for the best cases (lowest $\$ / \mathrm{kW}$ and/or highest NPV) for each combination of chiller type and daily cooling period are presented in Table 9.5. Again, note that 4- and 8-hour cooling follows the same schedule as the simple-cycle plants, and the incremental power and energy is valued the same as the simple-cycle industrial turbine application. 
Table 9.4. Combined-Cycle Results II-Nashville

\begin{tabular}{|c|c|c|c|c|c|c|c|}
\hline \multirow[b]{2}{*}{ Case } & \multirow[b]{2}{*}{ Chiller } & \multirow[b]{2}{*}{ OpHrs } & \multirow[b]{2}{*}{ Storage } & \multicolumn{2}{|c|}{ Uncooled Base } & \multicolumn{2}{|c|}{ Evap. Cooled Base } \\
\hline & & & & $\$ / k W$ & NPV, \$M & $\$ / \mathrm{kW}$ & NPV, \$M \\
\hline ce3 & None & $12 / 12$ & None & 77 & 5.95 & -- & - \\
\hline $\mathrm{dr} 1$ & $\mathrm{CC}-4$ & $12 / 12$ & None & 435 & 4.45 & 656 & -1.66 \\
\hline $\mathrm{dr} 2$ & $\mathrm{LiBr}-2$ & $12 / 12$ & None & 520 & 3.62 & 810 & -2.49 \\
\hline $\mathrm{d} r 4$ & $v C-2$ & $12 / 12$ & None & 265 & 15.81 & 345 & 9.70 \\
\hline $\mathrm{dr} 5$ & VC-1 & $12 / 12$ & IWLS & 309 & 18.31 & 381 & 12.20 \\
\hline dr6 & VC-1 & $12 / 12$ & IWLL & 246 & 18.98 & 310 & 12.88 \\
\hline $\mathrm{dr} 7$ & VC-1 & $12 / 12$ & IDLS & 465 & 12.10 & 573 & 5.99 \\
\hline dr8 & VC-1 & $12 / 12$ & IDLL & 310 & 15.69 & 395 & 9.59 \\
\hline dr9 & VC-2 & $.12 / 12$ & WWLS & 396 & 12.44 & 521 & 6.33 \\
\hline dr 10 & VC-2 & $12 / 12$ & WWLL & 320 & 13.68 & 430 & 7.58 \\
\hline drl1 & $V C-2$ & $12 / 12$ & WDLS & 386 & 12.23 & 507 & 6.13 \\
\hline dr 12 & VC-2 & $12 / 12$ & WDLL & 274 & 13.95 & 374 & 7.85 \\
\hline dr 13 & CC- $4 / C C-5$ & $12 / 12$ & None & 430 & 4.79 & 533 & -1.66 \\
\hline dr 15 & $\mathrm{VC}-2 / \mathrm{VC}-3$ & $12 / 12$ & None & 301 & 23.73 & 349 & 17.59 \\
\hline dr16 & VC-1/VC-3 & $12 / 12$ & IWLL & 285 & 27.89 & 327 & 21.74 \\
\hline $\mathrm{dr} 17$ & $\mathrm{CC}-2$ & $12 / 12$ & None & 287 & 12.90 & 384 & 6.79 \\
\hline $\mathrm{dr} 18$ & $\mathrm{CC}-2 / \mathrm{CC}-5$ & $12 / 12$ & None & 330 & 13.66 & 392 & 7.52 \\
\hline dr19 & $\mathrm{VC}-2 / \mathrm{CC}-5$ & $12 / 12$ & None & 314 & 16.71 & 370 & 10.57 \\
\hline $\mathrm{dr} 20$ & $V C-2 / C C-5$ & $12 / 12$ & IWLL & 297 & 19.83 & 344 & 13.69 \\
\hline
\end{tabular}

Operation of the plant 24 hours per day significantly improves the economics of heat-activated chiller systems because storage systems can be charged around the clock. Thus, the $\$ / \mathrm{kW}$ is lower and the NPV is higher for most heat-activated chiller systems when the results for the best cases from the 24 hour per day combined-cycle plant are compared to the best cases from the 12 hour per day combined-cycle plant. On the other hand, the results for the vapor compression systems are about the same. Still, the ammonia vapor compression systems still produce the lowest $\$ / \mathrm{kWs}$ and highest NPVs for above-freezing and $0^{\circ} \mathrm{F}$ temperatures at all daily cooling hours. The complex compound systems produce similar, but never better results. The lithium bromide systems are less attractive, but the singlestage lithium bromide chiller should also be run for this application to see if it provides better results. 
Table 9.5. Combined-Cycle Results III-Nashville

\begin{tabular}{|c|c|c|c|c|c|c|c|}
\hline \multirow[b]{2}{*}{ Case } & \multirow[b]{2}{*}{ Chiller } & \multirow[b]{2}{*}{ OpHrs } & \multirow[b]{2}{*}{ Storage } & \multicolumn{2}{|c|}{ Uncooled Base } & \multicolumn{2}{|c|}{ Evap. Cooled Base } \\
\hline & & & & $\$ / k W$ & $\mathrm{NPV}, \mathrm{SM}$ & $\$ / \mathrm{kW}$ & NPV, \$M \\
\hline $\operatorname{ce} 4$ & None & $24 / 4$ & None & 65 & 3.71 & -- & -- \\
\hline $\operatorname{ces} 5$ & None & $24 / 8$ & None & 65 & 4.21 & -- & -- \\
\hline $\operatorname{ce} 6$ & None & $24 / 12$ & None & 77 & 5.89 & -- & -- \\
\hline er19 & $\mathrm{LjBr}-2$ & $24 / 4$ & WDLS & 168 & 11.71 & 233 & 7.71 \\
\hline er20 & $\mathrm{LiBr}-2$ & $24 / 4$ & WDLL & 162 & 11.39 & 229 & 7.39 \\
\hline $\operatorname{er} 22$ & $\mathrm{LiBr}-2$ & $24 / 8$ & WDLL & 240 & 9.80 & 349 & 5.30 \\
\hline er24 & LiBr-2 & $24 / 12$ & WDLL & 324 & 10.25 & 453 & 4.20 \\
\hline er28 & VC-1 & $24 / 4$ & IWLS & 128 & 17.14 & 165 & 13.14 \\
\hline er29 & VC-1 & $24 / 4$ & IWLL & 123 & 16.95 & 159 & 12.95 \\
\hline er33 & VC-1 & $24 / 8$ & IWLL & 180 & 16.68 & 235 & 12.18 \\
\hline er 27 & VC-2 & $24 / 12$ & None & 265 & 15.78 & 345 & 9.72 \\
\hline er142 & $\mathrm{CC}-1$ & $24 / 4$ & IWLS & 129 & 16.83 & 166 & 12.83 \\
\hline er143 & $\mathrm{CC}-1$ & $24 / 4$ & IWLL & 125 & 16.51 & 162 & 12.51 \\
\hline er145 & CC-1 & $24 / 8$ & IWLL & 183 & 15.86 & 239 & 11.86 \\
\hline er 126 & $\mathrm{CC}-2$ & $24 / 12$ & None & 287 & 12.52 & 384 & 6.46 \\
\hline er138 & $\mathrm{CC}-1$ & $24 / 12$ & IDLL & 315 & 13.08 & 406 & 7.02 \\
\hline er115 & VC-1/VC-3 & $24 / 4$ & IWLL & 201 & 23.26 & 234 & 19.24 \\
\hline er116 & VC-1/VC-3 & $24 / 8$ & IWLL & 240 & 26.15 & 281 & 21.62 \\
\hline er75 & VC-2/VC-3 & $24 / 12$ & None & 301 & 23.10 & 349 & 17.01 \\
\hline er154 & CC-1/CC-6 & $24 / 4$ & IDLS & 215 & 25.63 & 244 & 21.60 \\
\hline er140 & $\mathrm{CC}-2 / \mathrm{CC}-5$ & $24 / 8$ & None & 314 & 14.88 & 385 & 10.85 \\
\hline er155 & CC-1/CC- 6 & $24 / 8$ & IDLS & 396 & 17.53 & 451 & 13.51 \\
\hline er141 & $\mathrm{CC}-2 / \mathrm{CC}-5$ & $24 / 12$ & None & 330 & 11.05 & 392 & 4.96 \\
\hline erl63 & VC-1/CC-6 & $24 / 4$ & IWLL & 207 & 26.00 & 236 & 21.98 \\
\hline er161 & VC-2/CC-5 & $24 / 8$ & None & 299 & 17.02 & 363 & 13.00 \\
\hline erl62 & VC-2/CC-5 & $24 / 12$ & None & 314 & 14.48 & 370 & 8.38 \\
\hline
\end{tabular}




\subsubsection{Baseload Duty Plant; Cooling Hours Equal to Plant Hours}

Storage was not considered when both the plant and cooling system operate 24 hours per day, so the - number of cases considered for this application was limited. It would be possible to incorporate loadleveling storage, but the results in Table 9.5 show that storage is not usually desirable even when the inlet air is being cooled only 12 hours per day.

The results for cooling 24 hours per day are shown in Table 9.6. While inlet air cooling is costeffective, the results are not as attractive as when storage can be effectively incorporated. Otherwise, the technology rankings are the same as seen for the other combined-cycle applications.

\subsection{Climate Impacts}

The peak hourly design conditions have a significant impact on the economics of inlet air cooling. Design conditions are affected by the climate and the cooling period selected, as shown in Table 9.7, which presents the design dry-bulb and wet-bulb temperatures for each of the combinations of plant operating hours, cooling operating hours, and city evaluated. As described in Section 8.0, the peak hourly enthalpy was selected as the design condition, which is essentially the same as the hour with the peak wet-bulb temperature.

The impact of climate and the design conditions on $\$ / \mathrm{kW}$ and NPV is illustrated in Table 9.8 for selected cases. In general, climate affects the magnitude of the $\$ / \mathrm{kW}$ and NPV results, but does not affect the ranking of the alternative cooling systems. Both evaporative and refrigerative cooling are most attractive in warm, dry climates. Note that turbine generating capacity and heat rate are driven by the dry-bulb temperature, but the cooling load is driven by the wet-bulb temperature. $\$ / \mathrm{kW}$ results track directly with the design conditions, while NPV results are also affected by average operating conditions. Thus, Houston looks the poorest, while Phoenix or San Francisco look the best in terms of $\$ / \mathrm{kW}$. On the other hand, San Francisco isn't nearly as attractive compared to Phoenix on a NPV basis. Yet,

Table 9.6. Combined-Cycle Results IV-Nashville

\begin{tabular}{|c|c|c|c|c|c|c|c|}
\hline \multirow[b]{2}{*}{ Case } & \multirow[b]{2}{*}{ Chiller } & \multirow[b]{2}{*}{ OpHrs } & \multirow[b]{2}{*}{ Storage } & \multicolumn{2}{|c|}{ Uncooled Base } & \multicolumn{2}{|c|}{ Evap. Cooled Base } \\
\hline & & & & $\$ / \mathrm{kW}$ & $\mathrm{NPV}, \$ \mathrm{M}$ & $\$ / \mathrm{kW}$ & NPV, \$M \\
\hline ce7 & None & $24 / 24$ & None & 77 & 6.17 & -- & -- \\
\hline fr2 & $\mathrm{LiBr}-2$ & $24 / 24$ & None & 520 & 2.71 & 857 & -6.09 \\
\hline fr8 & $\mathrm{CC}-2$ & $24 / 24$ & None & 287 & 11.49 & 389 & 3.61 \\
\hline fr4 & VC-2 & $24 / 24$ & None & 265 & 15.78 & 352 & 8.99 \\
\hline fr7 & VC-2/VC-3 & $24 / 24$ & None & 301 & 22.00 & 354 & 13.43 \\
\hline fr9 & $\mathrm{CC}-2 / \mathrm{CC}-5$ & $24 / 24$ & None & 330 & 3.29 & 397 & -6.55 \\
\hline fr10 & $\mathrm{VC}-2 / \mathrm{CC}-5$ & $24 / 24$ & None & 314 & 7.83 & 375 & -0.81 \\
\hline
\end{tabular}


Table 9.7. Design Temperature Conditions

\begin{tabular}{||l|c|c|c|c|c||}
\hline \multirow{2}{*}{$\begin{array}{c}\text { Plant Hour/Cooling } \\
\text { Hour Pairs }\end{array}$} & \multicolumn{5}{|c|}{ Dry-Bulb/Wet-Bulb Temperature Pairs (F) } \\
\cline { 2 - 6 } & Nashville & Houston & Minneapolis & Phoenix & San Francisco \\
\hline \hline $4 / 4$ & $92 / 79$ & $91 / 80$ & $92 / 78$ & $100 / 75$ & $71 / 63$ \\
\hline $8 / 8$ & $92 / 79$ & $87 / 80$ & $90 / 79$ & $92 / 75$ & $84 / 65$ \\
\hline $12 / 4$ & $92 / 79$ & $91 / 80$ & $92 / 78$ & $100 / 75$ & $71 / 63$ \\
\hline $12 / 8$ & $92 / 79$ & $87 / 80$ & $90 / 79$ & $92 / 75$ & $84 / 65$ \\
\hline $12 / 12$ & $91 / 80$ & $85 / 80$ & $90 / 79$ & $92 / 75$ & $80 / 66$ \\
\hline $24 / 4$ & $92 / 79$ & $91 / 80$ & $92 / 78$ & $100 / 75$ & $71 / 63$ \\
\hline $24 / 8$ & $92 / 79$ & $87 / 80$ & $90 / 79$ & $92 / 75$ & $84 / 65$ \\
\hline $24 / 12$ & $91 / 80$ & $82 / 81$ & $90 / 79$ & $92 / 75$ & $85 / 67$ \\
\hline $24 / 24$ & $91 / 80$ & $82 / 81$ & $90 / 79$ & $92 / 75$ & $85 / 67$ \\
\hline
\end{tabular}

Table 9.8. Climate Impacts on Economics

\begin{tabular}{|c|c|c|c|c|c|c|c|c|}
\hline \multirow[b]{2}{*}{ Case } & \multirow[b]{2}{*}{ Chiller } & \multirow[b]{2}{*}{ OpHrs } & \multirow[b]{2}{*}{ Storage } & Nashville & Houston & Minneapolis & Phoenix & San Francisco \\
\hline & & & & \multicolumn{5}{|c|}{$\$ / \mathrm{kW}$} \\
\hline cel & None & $12 / 4$ & None & 65 & 82 & 61 & 34 & 119 \\
\hline ce2 & None & $12 / 8$ & None & 65 & 145 & 78 & 54 & 44 \\
\hline $\operatorname{ce} 3$ & None & $12 / 12$ & None & 77 & 236 & 78 & 54 & 60 \\
\hline ce4 & None & $24 / 4$ & None & 65 & 82 & 61 & 34 & 119 \\
\hline $\operatorname{ces}$ & None & $24 / 8$ & None & 65 & 145 & 78 & 54 & 44 \\
\hline ce6 & None & $24 / 12$ & None & 77 & (a) & 78 & 54 & 46 \\
\hline $\operatorname{ce} 7$ & None & $24 / 24$ & None & 77 & (a) & 78 & 54 & 46 \\
\hline $\operatorname{crl7}$ & VC-2 & $12 / 4$ & None & 245 & 264 & 234 & 169 & 204 \\
\hline crl8 & VC-2 & $12 / 8$ & None & 245 & 296 & 259 & 203 & 148 \\
\hline cr20 & VC-1 & $12 / 4$ & IWLL & 123 & 136 & 114 & 96 & 127 \\
\hline \multirow[t]{2}{*}{$\mathrm{cr} 24$} & VC-1 & $12 / 8$ & IWLL & 180 & 223 & 172 & 167 & 115 \\
\hline & & & & \multicolumn{5}{|c|}{ NPV (\$M) } \\
\hline cel & None & $12 / 4$ & None & 4.40 & 3.36 & 4.71 & 10.28 & 1.98 \\
\hline ce2 & None & $12 / 8$ & None & 4.90 & 2.21 & 4.12 & 8.21 & 6.62 \\
\hline ce3 & None & $12 / 12$ & None & 5.95 & 1.89 & 5.77 & 10.09 & 7.38 \\
\hline$\overline{c e 4}$ & None & $24 / 4$ & None & 3.71 & 2.69 & 4.03 & 9.61 & 1.31 \\
\hline $\operatorname{ce} 5$ & None & $24 / 8$ & None & 4.21 & 1.54 & 3.44 & 7.54 & 5.94 \\
\hline ce6 & None & $24 / 12$ & None & 5.89 & -0.53 & 5.62 & 10.39 & 9.47 \\
\hline ce7 & None & $24 / 24$ & None & 6.17 & $=0.24$ & 5.84 & 11.55 & 9.69 \\
\hline crl7 & VC-2 & $12 / 4$ & Ivone & 9.46 & 8.45 & 9.57 & 17.07 & 6.60 \\
\hline $\operatorname{cr} 18$ & VC-2 & $12 / 8$ & None & 10.82 & 8.17 & 9.34 & 15.88 & 12.14 \\
\hline cr20 & $V C-1$ & $12 / 4$ & IWLL & 16.36 & 15.53 & 16.30 & 22.54 & 9.30 \\
\hline cr24 & $V C-1$ & $12 / 8$ & IWLL & 15.28 & 12.48 & 14.41 & 19.10 & 14.30 \\
\hline
\end{tabular}

(a) At the design conditions for this case $\left(82^{\circ} \mathrm{F}\right.$, dry-bulb and $81^{\circ} \mathrm{F}$, wet-bulb) evaporative cooling provides essentially no benefit, so its $\$ / \mathrm{kW}$ approaches infinity. 
its important to note that the results show inlet air cooling to be economically attractive for all of the climates investigated, which represent the majority of the climate range found in the U.S. outside of Alaska.

\subsection{Net Present Value Components}

The NPVs for selected combined-cycle cases are broken into revenue (positive cash flows) and cost (negative cash flows) components in Table 9.9. As expected, incremental power output is always the principal benefit, but incremental energy output is also quite important. Incremental energy output increases in importance as the number of cooling hours per day increases, although this effect is partly masked by a change in the value of incremental power and energy when comparing 4 or 8 hour per day cases to the 12 hour per day cases. Incremental energy output is also generally more important for cases that cool the inlet air to $0^{\circ} \mathrm{F}$ (those with two chillers). Costs are dominated by fuel and capital. Even though the heat rate deçreases with inlet air cooling, the power output increases more, so fuel consumption is greater. As expected, fuel consumption costs are greatest for longer daily cooling hours. 
Table 9.9. Net Present Value Components

\begin{tabular}{|c|c|c|c|c|c|c|c|c|c|}
\hline \multirow[b]{2}{*}{ Case } & \multirow[b]{2}{*}{ Chiller } & \multirow[b]{2}{*}{ OpHrs } & \multirow[b]{2}{*}{ Storage } & \multicolumn{2}{|c|}{ Revenue Fractions } & \multicolumn{4}{|c|}{ Cost Fractions ${ }^{\circ}$} \\
\hline & & & & On-peak kW & On-peak kWh & Off-Peak kwII & O\&M & Fuel & Capital \\
\hline cel & None & $12 / 4$ & None & 0.88 & 0.12 & 0.00 & 0.10 & 0.43 & 0.47 \\
\hline $\operatorname{ce} 2$ & None & $12 / 8$ & None & 0.74 & 0.26 & 0.00 & 0.07 & 0.63 & 0.30 \\
\hline er20 & $\mathrm{LiBr}-2$ & $24 / 4$ & WDLL & 0.81 & 0.19 & 0.06 & 0.16 & 0.27 & 0.50 \\
\hline er22 & $\mathrm{LiBr}-2$ & $24 / 8$ & WDLL & 0.66 & 0.34 & 0.07 & 0.15 & 0.34 & 0.43 \\
\hline er24 & $\mathrm{LiBr}-2$ & $24 / 12$ & WDLL & 0.71 & 0.29 & 0.10 & 0.13 & 0.41 & 0.36 \\
\hline er29 & VC-1 & $24 / 4$ & IWLL & 0.77 & 0.23 & 0.06 & 0.12 & 0.38 & 0.43 \\
\hline er33 & VC-1 & $24 / 8$ & IWLL & 0.62 & 0.38 & 0.06 & 0.11 & 0.46 & 0.37 \\
\hline er27 & VC-2 & $24 / 12$ & None & 0.67 & 0.33 & 0.00 & 0.12 & 0.57 & 0.31 \\
\hline er143 & $\mathrm{CC}-1$ & $24 / 4$ & IWLL & 0.77 & 0.23 & 0.08 & 0.13 & 0.37 & 0.42 \\
\hline er145 & CC-1 & $24 / 8$ & IWLL & 0.62 & 0.38 & 0.08 & 0.12 & 0.44 & 0.36 \\
\hline er138 & CC-1 & $24 / 12$ & IDLL & 0.66 & 0.34 & 0.10 & 0.12 & 0.46 & 0.31 \\
\hline er115 & VC-1/VC-3 & $24 / 4$ & IWLL & 0.70 & 0.30 & 0.07 & 0.15 & 0.34 & 0.45 \\
\hline erl16 & VC-1/VC-3 & $24 / 8$ & IWLL & 0.53 & 0.47 & 0.07 & 0.12 & 0.46 & 0.35 \\
\hline er75 & VC-2/VC-3 & $24 / 12$ & None & 0.58 & 0.42 & 0.00 & 0.11 & 0.64 & 0.25 \\
\hline er 154 & $\mathrm{CC}-1 / \mathrm{CC}-6$ & $24 / 4$ & IDLS & 0.74 & 0.26 & 0.04 & 0.18 & 0.29 & 0.49 \\
\hline er155 & CC-1/CC- 6 & $24 / 8$ & IDLS & 0.57 & 0.43 & 0.04 & 0.18 & 0.31 & 0.47 \\
\hline er141 & CC-2/CC-5 & $24 / 12$ & None & 0.59 & 0.41 & 0.00 & 0.13 & 0.64 & 0.24 \\
\hline er163 & VC-1/CC-5 & $24 / 4$ & IWLL & 0.73 & 0.27 & 0.04 & 0.17 & 0.31 & 0.48 \\
\hline er161 & $\mathrm{VC}-2 / \mathrm{CC}-5$ & $24 / 8$ & None & 0.53 & 0.47 & 0.00 & 0.15 & 0.48 & 0.37 \\
\hline er162 & VC-2/CC-5 & $24 / 12$ & None & 0.59 & 0.41 & 0.00 & 0.12 & 0.64 & 0.24 \\
\hline
\end{tabular}





\subsection{Conclusions and Recommendations}

The principal objectives of this study were presented in the Introduction. These are repeated below along with the corresponding conclusions.

1. Identify the preferred CTAC technology as a function of application conditions from currently available cooling technologies.

Ammonia vapor compression chillers with weekly ice storage were generally found to be preferred for most application conditions.

2. Identify application conditions where currently available cooling technology is not cost-effective.

CTAC was found to be more cost-effective than simply building additional uncooled power plant capacity for all application conditions investigated. This included relatively moderate climates such as San Francisco and applications where storage was limited (e.g, cooling 24 hours per day).

3. Determine the potential attractiveness of the complex compound (ammoniated salt solid/vapor "absorption") cooling system.

The complex compound systems were found to be competitive, but generally not quite as attractive as ammonia vapor compression systems. Complex compound systems. were most competitive (within a few \% of the vapor compression systems' $\$ / \mathrm{kW}$ and NPV figures) for applications with combined-cycle plants running 24 hours per day, which allowed storage for heat-activated chillers to be charged up to 24 hours per day.

4. Determine the potential attractiveness of cooling combustion turbine inlet air to $0^{\circ} \mathrm{F}$.

Cooling the inlet air to $0^{\circ} \mathrm{F}$ was found to be more cost-effective (higher NPV, although the $\$ / \mathrm{kW}$ was also higher) than limiting cooling to above-freezing temperatures.

Additional conclusions resulting from the study are as follows:

5. Lithium bromide absorption chillers were generally less attractive than either complex compound or ammonia vapor compression systems.

6. Ammonia vapor compression, complex compound, and lithium bromide cooling systems all yielded cost-effective (positive NPV) results.

7. Aqua-ammonia absorption chillers have significantly higher capital costs, were rarely costeffective, and were never the preferred system. 
8. Single-stage complex compound systems were more cost-effective than double-stage complex compound systems. The double-stage systems cost less and use less steam, but require higher pressure steam, which results in a greater loss of power when extracted from the steam turbine in . the combined-cycle plant.

9. Storage significantly improves the cost-effectiveness of inlet air cooling, especially for applications requiring cooling for about one-third of the day or less.

10. Limitations on the application of storage significantly hamper the cost-effective application of CTAC. This included a) no storage for heat-activated chillers in simple-cycle applications (no waste heat source when the power plant isn't running), b) limited storage for heat-activated chillers running less than 24 hours per day, and c) no cost-effective storage media for below freezing applications.

11. Refrigerative cooling was found to be cost effective even if evaporative cooling was already in place.

12. Incremental power output is most important, but incremental energy output was found to contribute from about 20 to $45 \%$ of the incremental revenues resulting from CTAC, depending on the application conditions and the cooling system used.

13. Evaporative cooling results in a lower $\$ / \mathrm{kW}$, but also a lower NPV than refrigerative cooling systems. The evaporative cooling capital cost per incremental peak power output was less than $\$ 100 / \mathrm{kW}$ for most application conditions. The best refrigerative cooling application yielded an incremental cost of about $\$ 100 / \mathrm{kW}$ for inlet air cooling provided 4 hours per day. The best application cost rose to about $\$ 200 / \mathrm{kW}$ for cooling provided 24 hours per day.

The results of the study provide the basis for making the following recommendations:

1. Inlet air cooling should be considered a standard practice to be incorporated with combustion turbine.installation.

2. The potential cost-effectiveness of cooling the inlet air to near $0^{\circ} \mathrm{F}$ warrants further investigation (modeling and testing) of options for defrosting cooling coils and minimizing or eliminating condensate icing.

3. Off-peak operation with natural gas should be evaluated to determine the cost-effectiveness of storage with heat-activated chillers for simple-cycle applications and for combined-cycle plants operating less than 24 hours per day.

4. Single-stage lithium bromide chillers should be evaluated for combined-cycle plants in addition to the double-stage lithium bromide chillers that were evaluated. 
5. Potential storage media for subfreezing applications should be identified and evaluated.

6. Better complex compound systems (lower cost and/or higher efficiencies) need to be identified . before development and demonstration of this concept for inlet air cooling is warranted.

7. CTAC NPVs should be evaluated from an industrial perspective with a broader range of values for power, on-peak energy, and off-peak energy.

8. The computer model developed for this study should be upgraded to allow the investigation of a) variable inlet air temperatures, b) multiple evaporation temperatures above and below the freezing point, and c) variable fractions of the peak cooling load. These three capabilities would allow further investigation of optimum CTAC systems. 
. 


\subsection{References}

Aho, V. A., B. W. Kernigan, and P. J. Weinberger. 1988. The AWK Programming Language, Addison-Wesley Publishing Company, New York.

American Society of Heating, Refrigeration, and Air Conditioning (ASHRAE). 1987. 1987 ASHRAE Handbook, HVAC Systems and Applications. Atlanta, Georgia.

Babcock and Wilcox. 1994. Ice Thermal Energy Storage for Gas Turbine Inlet Air Cooling. New York.

Brown, D. R., J. A. Dirks, M. K. Drost, G. E. Spanner, and T. A. Williams. 1987. An Assessment Methodology for Thermal Energy Storage Evaluation. PNL-6372. Pacific Northwest Laboratory. Richland, Washington.

Close D. B., A. D. Robbins, P. H. Rubin, and R. Stallman. 1993. The GAWK Manual, version 2.15, ed. 0.15, Free Software Foundation, Cambridge, Massachusetts.

Dickson, J. 1975. "Reducing the Hazards of Intake Icing." Gas Turbine International. Vol. 16, No. 4.

Ebeling, J. A., R. Halil, D. Bantam, B. Bakenhus, H. Schreiber, and R. Wendland. 1992. "Peaking Gas Turbine Capacity Enhancement Using Ice Storage for Compressor Inlet Air Cooling."

Proceedings, International Gas Turbine and Aeroengine Congress and Exposition, 1992. The American Society of Mechanical Engineers. New York.

Electric Power Research Institute. 1988. Commercial Cool Storage; Reduced Cooling Costs With OffPeak Electricity. Palo Alto, California.

Electric Power Research Institute. 1993. Technical Assessment Guide, Electricity Supply-1993. EPRI TR-102276-V1R7. Palo Alto, California.

Energy Information Administration. 1995a. Annual Energy Outlook 1995, With Projections to 2010. DOE/EIA-0383(95). Washington, D.C.

Energy Information Administration. 1995b. Monthly Energy Review, March 1995.

DOE/EIA-0035(95/3). Washington D.C.

Hall I. J., R. R. Prarie, H. E. Anderson and E. C. Boes. 1981. "Generation of typical meteorological years for 26 SOLMET stations," Appendix to TMY User's Manual, National Climatic Center, Asheville, North Carolina. 
Holton, J. K., T. D. Swanson, R. Gulati, and G. K. Hart. 1985. Smail Office Building Handbook. Van Nostrand Reinhold. New York.

Kohlenberger, C. 1993. "A Review of Inlet Air Cooling Systems for Increasing Gas Turbine Performance." Published by the American Society of Mechanical Engineers, Los Angeles Section Power Division.

Kohlenberger, C. 1994. "A Review of Inlet Air Cooling Systems for Increasing Gas Turbine Performance." Proceedings, 1994 Power-Gen Conference. Pennwell Conferences and Exhibitions. Houston, Texas.

Ondryas, I. S., D. A. Wilson, M. Kawamoto, and G. L. Haub. 1991. "Options in Gas Turbine Power Augmentation Using Inlet Air Chilling." Journal of Engineering for Gas Turbines and Power. Vol. 113, pp. 203-211.

Rockenfeller, U., P. Sarkisian, and L. D. Kirol. 1992. "Coordinative Complex Compounds for - Efficient Storage of Polar Refrigerants and Gases." Proceedings, 1992 International Energy Conversion Engineering Conference. SAE International. Warrendale, Pennsylvania.

Wagar, S. N. 1980. "Indirect Heating System for Turbine Anti-Icing." Diesel \& Gas Turbine Worldwide. Vol. 12, No. 2.

Zwillenberg, M. L., D. Smith, A. Cohn, I. Oliker, and W. Major. 1991. "Assessment of Refrigeration-Type Cooling of Inlet Air for Essex Unit No. 9." Proceedings, 1991 International Power Generation Conference. The American Society of Mechanical Engineers. New York. 


\subsection{Bibliography}

Andreport, J. S. 1994. "Performance and Economics of CT Inlet Air Cooling using Chilled Water Storage." ASHRAE Transactions 1994. Vol. 100, Pt. 1. American Society of Heating, Refrigeration, and Air-Conditioning. Atlanta, Georgia.

Babcock and Wilcox. 1994. Ice Thermal Energy Storage for Gas Turbine Inlet Air Cooling. New York.

Bacigalupo, E., L. Tasso, and R. G. Zinnari. 1993. "Power Augmentation Using An Inlet Air Chilling System in a Cogenerative Power Plant Equipped With a Heavy Duty Gas Turbine." Published in the proceedings of the 1993 ASME Cogen-Turbo Conference. American Society of Mechanical Engineers. New York.

Cross, J. K., W. A. Beckman, J. W. Mitchell, D. T. Reindl, and D. E. Knebel. 1995. "Modeling of "Hybrid Combustion Turbine Inlet Air Cooling Systems." ASHRAE Transactions 1995. Vol. 101, Pt.

2. American Society of Heating, Refrigeration, and Air-Conditioning. Atlanta, Georgia.

Davis, T. L., A. Hobbs, J. Shell, K. McAllister, L. Beaty, and R. Reid. 1995. Combustion Turbine Capacity Augmentation Utilizing Inlet Air Direct Contact Cooling and Compression. Carolina Power and Light. Raleigh, North Carolina.

DeLucia, M., R. Bronconi, and E. Carnevale. 1993. "Performance and Economic Enhancement of Cogeneration Gas Turbines Through Compressor Inlet Air Cooling." Proceedings, International Gas Turbine and Aeroengine Congress and Exposition, 1993. The American Society of Mechanical Engineers. New York.

Dickson, J. 1975. "Reducing the Hazards of Intake Icing." Gas Turbine International. Vol. 16, No. 4.

Ebeling, J. A. 1991. "Combustion Turbine Inlet Air Cooling With Thermal Energy Storage." Published in the proceedings of POWER-GEN ' 91 . Pennwell Conferences and Exhibitions Company. Houston, Texas.

Ebeling, J. A., R. Halil, D. Bantam, B. Bakenhus, H. Schreiber, and R. Wendland. 1992. "Peaking Gas Turbine Capacity Enhancement Using Ice Storage for Compressor Inlet Air Cooling."

Proceedings, International Gas Turbine and Aeroengine Congress and Exposition, 1992. The American Society of Mechanical Engineers. New York.

Ebeling, J. A., L. H. Beaty, and P. A. Garrett. 1994. "TIP ${ }^{2}$ Capacity Performance Test Results for the Butler Warner Generation Plant." Published in the proceedings of POWER-GEN '94. Pennwell Conferences and Exhibitions Company. Houston, Texas. 
Ebeling, J., R. Balsbaugh, S. Blanchard, and L. Beaty. 1994. "Thermal Energy Storage and Inlet Air Cooling for Combined Cycle." Published in the proceedings of the International Gas Turbine and Aeroengine Congress and Exposition. ASME-94-GT-310. American Society of Mechanical Engineers. New York.

Electric Power Research Institute. 1988. Commercial Cool Storage; Reduced Cooling Costs With OffPeak Electricity. Palo Alto, California.

Gillingham, G. R. 1976. A New System for Preventing Icing of Gas Turbine Inlets. ASME-76-GT-84. American Society of Mechanical Engineers. New York.

Giourof, A. 1995. "Gas-turbine inlet air cooling: You can almost pick your payback." Power. May, 1995. pp. 56-58. McGraw-Hill Publishing Company. New York.

Guinn, G. R. 1993. "Evaluation of Combustion Gas Turbine Inlet Air Precooling for Time Varying Annual Climatic Conditions." Published in the proceedings of the 1993 ASME Cogen-Turbo Conference. American Society of Mechanical Engineers. New York.

Hall, A. D., J. C. Stover, and R. L. Breisch. 1994. "Gas Turbine Inlet-Air Chilling at a Cogeneration Facility." ASHRAE Transactions 1994. Vol. 100, Pt. 1. American Society of Heating, Refrigeration, and Air-Conditioning. Atlanta, Georgia.

Herold, K. E. 1995. "Design challenges in absorption chillers." Mechanical Engineering. October, 1995. pp. 80-83. American Society of Mechanical Engineers. New York.

Hufford, P. E. 1991. "Absorption Chillers Maximize Cogeneration Value." ASHRAE Transactions: Symposia. NY-91-2-3. American Society of Heating, Refrigeration, and Air-Conditioning. Atlanta, Georgia.

Kohlenberger, C. 1993. A Review of Inlet Air Cooling Systems for Increasing Gas Turbine Performance. Published by the American Society of Mechanical Engineers, Los Angeles Section Power Division, Los Angeles, California.

Kohlenberger, C. 1994. "A Review of Inlet Air Cooling Systems for Increasing Gas Turbine Performance." Proceedings, 1994 Power-Gen Conference. Pennwell Conferences and Exhibitions. Houston, Texas.

Kolp, D. A., and D.J. Moeller. 1989. "World's First STIG LM5000 Installed at Simpson Paper Company." Journal of Engineering for Gas Turbines and Power. April, 1989. Vol. 111. pp. 200-210. 
Kolp, D. A., W. M. Flye, and $\dot{H}$. A. Guidotti. 1995. "Advantages of Air Conditioning and Supercharging an LM6000 Gas Turbine Inlet." Journal of Engineering for Gas Turbines and Power. July, 1995. Vol. 117 pp. 513-527.

MacCracken, C. D. 1994. "An Overview of the Progress and the Potential of Thermal Storage in Off-Peak Turbine Inlet Cooling." ASHRAE Transactions 1994. Vol. 100, Pt. 1. American Society of Heating, Refrigeration, and Air-Conditioning. Atlanta, Georgia.

Mackie, E. I. 1994. "Inlet Air Cooling for a Combustion Turbine Using Thermal Storage." ASHRAE Transactions 1994. Vol. 100, Pt. 1. American Society of Heating, Refrigeration, and AirConditioning. Atlanta, Georgia.

Moftah, M. 1971. Gas Turbine Performance Under Varying Ambient Temperature. ASME 71-GT-57. American Society of Mechanical Engineers. New York.

Nasser, A.E.M., and M. A. El-Kalay. 1991. "A Heat-Recovery Cooling System to Conserve Energy in Gas-Turbine Power Stations in the Arabian Gulf." Applied Energy. Vol. 38. pp. 133-142.

Ondryas, I. S. 1991. "Go beyond evaporative coolers to stretch gas-turbine output." Power. July, 1991. pp. 27-29.

Ondryas, I. S., D. A. Wilson, M. Kawamoto, and G. L. Haub. 1991. "Options in Gas Turbine Power Augmentation Using Inlet Air Chilling." Journal of Engineering for Gas Turbines and Power. Vol. 113, pp. 203-211.

Rockenfeller, U., P. Sarkisian, and L. D. Kirol. 1992. "Coordinative Complex Compounds for Efficient Storage of Polar Refrigerants and Gases." Proceedings, 1992 International Energy Conversion Engineering Conference. SAE International. Warrendale, Pennsylvania.

Rose, D. T., W. A. Ryan, and H. Perez-Blanco. 1995. "Adopting steam-driven absorption cooling." Mechanical Engineering. October, 1995. pp. 76-78. American Society of Mechanical Engineers. New York.

Sengupta, U., and G. Soroka. 1989. "An Inlet Air Washer/Chiller System for Combined Cycle Plant Repowering." Published in the proceedings of the American Power Conference. Illinois Institute of Technology. Chicago, Illinois.

Sundbom, T. A., and J. A. Ebeling. 1994. "Increasing Capacity Sales with Inlet Air Cooling." In the proceedings of the 1994 ASME Cogen-Turbo Conference. American Society of Mechanical Engineers. New York. 
Sullivan, J., and J. A. Ebeling. 1994. "Selling Cold Air DSM Incentives Lead to Combustion Turbine Inlet Air Cooling Opportunities for ESCOs." In the proceedings of the 1994 ASME CogenTurbo Conference. American Society of Mechanical Engineers. New York.

Tanabe, K., and R. Okugawa. 1976. Evaluation of Improved Cycles for Marine Application of an Aircraft Derivative Gas Turbine. ASME-76-GT-114. American Society of Mechanical Engineers. New York.

Wagar, S. N. 1980. "Indirect Heating System for Turbine Anti-Icing." Diesel \& Gas Turbine Worldwide. Vol. 12, No. 2.

Zwillenberg, M. L., D. Smith, A. Cohn, I. Oliker, and W. Major. 1991. "Assessment of Refrigeration-Type Cooling of Inlet Air for Essex Unit No. 9." Proceedings, 1991 International Power Generation Conference. The American Society of Mechanical Engineers. New York. 
Appendix A

Inlet Air Cooling Evaluation Model 



\section{Appendix A}

\section{Inlet Air Cooling Evaluation Model}

The combustion turbine inlet air cooling performance evaluation model is a collection of $a w k$ and $\mathrm{UNIX}^{\mathrm{TM}}$ shell scripts. The $a w k$ is a powerful file processing programming language originally developed in 1977 for the UNIX'M operating system. The name awk comes from the initials of its designers: Alfred V. Aho, Peter J. Weinberger, and Brian W. Kernigan. In 1985 a new version made the programming language more powerful, introducing user-defined functions, multiple input streams, and computed regular expressions (Aho et al. 1988). The $\mathrm{GNU}^{(\mathrm{a})}$ version of awk implementation, called gawk, was used for modeling the performance of inlet air cooling technologies (Close et al. 1993). The gawk is.a free program and is available for UNIX, MS-DOS and MAC operating systems.

The awk language was chosen because of its simplicity and convenience of programming a wide variety of computing and data-manipulation tasks. Because $a w k$ is an interpreted language (like BASIC), the development time is minimal. To write a program to do the same task in a language such as C, Pascal, or FORTRAN would not only be time-consuming but would need many more lines of code. In spite of its simplicity, the structure of the $a w k$ language is similar to $\mathrm{C}$; therefore, awk scripts can be converted to $\mathrm{C}$ with minimal effort.

\section{A.1 Computer Requirements}

The model was developed on a SUN SPARCStation ${ }^{\mathrm{TM}} 10 \mathrm{UNIX}^{\mathrm{TM}}$ workstation running SunOS ${ }^{\mathrm{TM}}$ 4.2 operating system. Although $a w k$ scripts are portable across operating systems (UNIX ${ }^{\mathrm{TM}}$, MAC ${ }^{\mathrm{TM}}$, or MS-DOSTM), the accompanying UNIX ${ }^{\mathrm{TM}}$ shell scripts are not. These scripts enable post-processing of the output for detailed analysis and run a series of simulations in an automated way. However, the model itself can be run on any platform. It takes less than 1 minute to run on the UNIX ${ }^{\mathrm{rM}}$ workstation, but it may take several minutes on a PC with an Intel $486^{\mathrm{TM}} \mathrm{CPU}$.

(a) GNU, which stands for Gnu's Not UNIX, is the name for the complete UNIX-compatible software system being developed by the Free Software Foundation (FSF). The FSF is a group started by Richard Stallman to embody his ideas of personal freedom and how software should be produced. The free software includes a UNIX shell, machine language, compilers, editors and many other things which have, in the past, been considered part of the operating system. These are very well known and respected programs and can be found at the "prep.ai.mit.edu" ftp site. 


\section{A.2 Model Structure}

The model consists of seven major modules and several small functions. The first module initializes all the variables, assigns values to constants and reads the command line inputs (input file name, parameter file name, etc.). The second module reads parameter inputs from the parameter file and calculates the outdoor condition independent corrections factors for gas turbine power, heat rate, air mass flow rate, etc. The third module reads the hourly $\mathrm{TMY}^{(\mathrm{a})}$ weather file (Hall et al. 1981) and performs the hourly simulation. The fourth module calculates minimum and maximum values of certain variables for the storage cases and also sizes the chiller and storage tanks. The fifth module calculates daily/weekly and annual chiller energy consumption. The sixth module sizes various components and also calculates the costs of those components. The seventh module calculates the incremental power generation cost and the net present value (NPV) of the investment. Figure A.1 shows schematically the combustion turbine inlet air cooling performance evaluation model structure.

\section{A.3 Model Capabilities .}

In general, the model is capable of assessing the economic feasibility of cooling the inlet air to combustion turbines for site-specific conditions by simulating the performance of the gas turbine with inlet air cooling, sizing necessary components, calculating the cost of the components, and calculating the monetary value of the incremental power and the NPV of the investment. Sample output from the model is presented in Table A.1.

The model is capable of evaluating the performance of cooling the inlet air to turbines in simplecycle (industrial frame and aeroderivative type) or combined-cycle plant configurations. The air to the turbine can either be cooled refrigeratively or evaporatively. Thermal energy storage is an option for refrigeratively cooled systems. The model allows either daily or weekly ice or water storage with loadshifting or load-leveling storage designs. At the present time, the model can only handle three different inlet air temperatures: 1) $52^{\circ} \mathrm{F}$, 2) $42^{\circ} \mathrm{F}$, and 3) $0^{\circ} \mathrm{F}$. For $0^{\circ} \mathrm{F}$ cooling, the model cools the air in two stages with two different chillers: 1) from the ambient condition to $42^{\circ} \mathrm{F}$, and 2) from $42^{\circ} \mathrm{F}$ to $0^{\circ} \mathrm{F}$. The chillers can either be electrically-driven or thermally-activated; for thermally-activated chillers, the turbine exhaust gas (simple-cycle) or steam from the combined-cycle plant is used.

(a) The Typical Meteorological Year (TMY) is a "typical" year of weather prepared from a large data base of the SOLMET (SOLar and METeorological) data and is available for 239 stations in the U.S. The data include 1 complete year of hourly values ( 8760 values) for each of the following parameters: direct (beam) solar radiation, total horizontal solar radiation, dry-bulb (temperature), wet-bulb (temperature), dew-point (humidity), wind speed and cloud cover. These data are provided in a single file in ASCII format. The SOLMET hourly data base was first prepared for 26 cities that had measured hourly solar radiation data. Then it was extended to 222 additional locations by using models to generate synthetic solar radiation measures for these locations. 


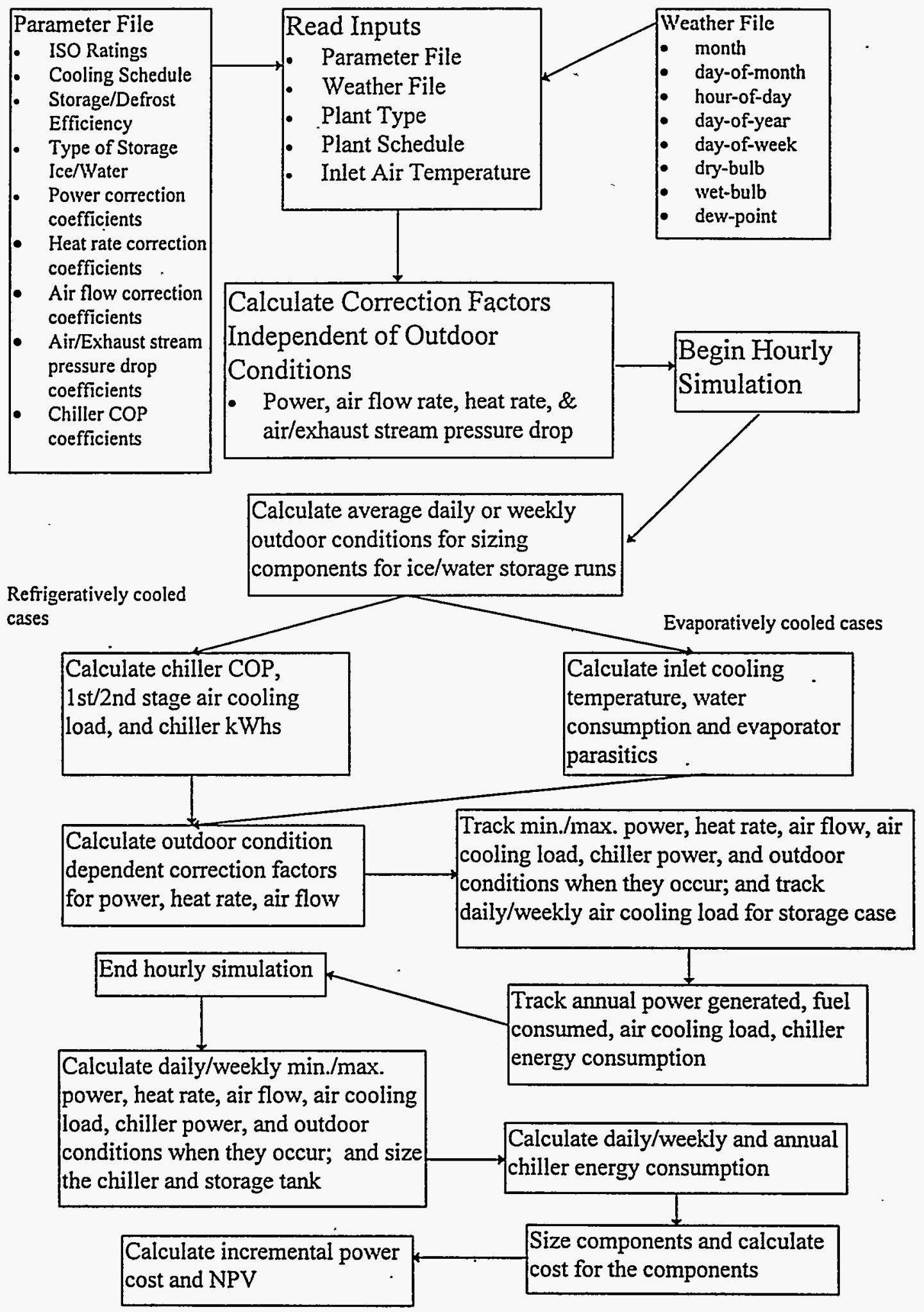

Figure A.1. Schematic of the Combustion Turbine Inlet Air Cooling Performance Evaluation Method 


\section{A.4 Model Limitations}

Although the model is a powerful analysis tool, it has the following limitations: 1) the model does not allow for entering the input values interactively because the user interface is inadequate; in addition, the shell scripts that automate the parametric runs are not portable to MS-DOS or MAC operating systems, 2) the range checks are not performed on all input values, i.e., the inputs are not checked if they are within the acceptable range, 3$)$ the inlet air temperature is fixed to three values $\left(52^{\circ} \mathrm{F}, 42^{\circ} \mathrm{F}\right.$, and $\left.0^{\circ} \mathrm{F}\right)$, 4) storage media is limited to ice and water, 5) cooling in multiple stages is not possible; currently, the model cools the air in a single stage when the air is cooled to $42^{\circ} \mathrm{F}$ or $52^{\circ} \mathrm{F}$ and in two stages when the air is cooled to $0^{\circ} \mathrm{F}$, and 6 ) the component sizing basis is limited to meeting $100 \%$ of the peak design conditions. 
Table A.1. Sample Model Output

\begin{tabular}{|c|c|}
\hline Parameter File & cr5l \\
\hline Weather File & nashville.tmy \\
\hline Plant Type & CC Plant \\
\hline \multicolumn{2}{|l|}{ Schedule Information } \\
\hline \multicolumn{2}{|l|}{ Weekends are not simulated } \\
\hline Beginning for the operation period (inclusive) & 9 \\
\hline End for the operation period (inclusive) & 20 \\
\hline Beginning month (inclusive) & 1 \\
\hline End month (inclusive) & 12 \\
\hline Inlet air is cooled to (F) & 0 \\
\hline Generator Cooling Factor & 1.050 \\
\hline ISO Power (MW) & 225 \\
\hline ISO GT Power (MW) & 155 \\
\hline ISO ST Power (MW) & 70 \\
\hline ISO Heat Rate (Btu/kWh) & 7300 \\
\hline ISO Air Flow Rate(lbs/h) & 3365475 \\
\hline Beginning of cooling period (inclusive) & 15 \\
\hline End of cooling period (inclusive) & 18 \\
\hline Beginning month for cooling (inclusive) & 4 \\
\hline End month for cooling (inclusive) & 9 \\
\hline \multicolumn{2}{|l|}{ Daily load shifting storage being used } \\
\hline 1st stage daily storage efficiency & 0.990 \\
\hline 1st stage ice generation (defrost) efficiency & 0.850 \\
\hline 2nd stage daily storage efficiency & 1.000 \\
\hline 2nd stage ice generation (defrost) efficiency & 1.000 \\
\hline \multicolumn{2}{|l|}{ Ice is the storage media } \\
\hline \multicolumn{2}{|l|}{ Power Coefficients Echo } \\
\hline Intercept for Altitude & $1.0000 e+00$ \\
\hline Intercept for Dry-Bulb Temperature/T_evap: First Range & $1.2200 \mathrm{e}+00$ \\
\hline Intercept for Dry-Bulb Temperature/T_evap: Second Range & $1.0000 \mathrm{e}+00$ \\
\hline Intercept for Absolute Humidity & $1.0000 \mathrm{e}+00$ \\
\hline Intercept for Incremental Inlet Air Pr. Drop in of water & $1.0000 \mathrm{e}+00$ \\
\hline Intercept for Incremental Inlet Exhaust Pr. Drop in of water & $1.0000 \mathrm{e}+00$ \\
\hline Slope for Altitude & $-3.3300 \mathrm{e}-05$ \\
\hline Slope for Dry-Bulb Temperature/T_evap: First Range & $-3.7000 \mathrm{e}-03$ \\
\hline Slope for Dry-Bulb Temperature/T_evap: Second Range & $0.0000 \mathrm{e}+00$ \\
\hline Slope for Absolute Humidity & $0.0000 e+00$ \\
\hline Slope for Incremental Inlet Air Pr. Drop in of water & $-3.2000 \mathrm{e}-03$ \\
\hline Slope for Incremental Inlet Exhaust Pr. Drop in of water & $-1.2000 \mathrm{e}-03$ \\
\hline
\end{tabular}


Table A.1. (contd)

\begin{tabular}{|c|c|}
\hline \multicolumn{2}{|l|}{ Heat Rate Coefficients Echo } \\
\hline Intercept for Altitude & $1.0000 \mathrm{e}+00$ \\
\hline Intercept for Dry-Bulb Temperature/T_evap: First Range & $9.4000 \mathrm{e}-01$ \\
\hline Intercept for Dry-Bulb Temperature/T_evap: Second Range & $1.0000 \mathrm{e}+00$ \\
\hline Intercept for Absolute Humidity & $1.0000 \mathrm{e}+00$ \\
\hline Intercept for Incremental Inlet Air Pr. Drop in of water & $1.0000 \mathrm{e}+00$ \\
\hline Intercept for Incremental Inlet Exhaust Pr. Drop in of water & $1.0000 \mathrm{e}+00$ \\
\hline Slope for Altitude & $0.0000 e+00$ \\
\hline Slope for Dry-Bulb Temperature/T_evap: First Range & $1.0000 \mathrm{e}-03$ \\
\hline Slope for Dry-Bulb Temperature/T_evap: Second Range & $1.5000 \mathrm{e}-03$ \\
\hline Slope for Absolute Humidity & $0.0000 \mathrm{e}+00$ \\
\hline Slope for Incremental Inlet Air Pr. Drop in of water & $1.7000 \mathrm{e}-03$ \\
\hline Slope for Incremental Inlet Exhaust Pr. Drop in of water & $1.4500 \mathrm{e}-03$ \\
\hline \multicolumn{2}{|l|}{ Air Flow Coefficients Echo } \\
\hline Intercept for Altitude & $1.0000 \mathrm{e}+00$ \\
\hline Intercept for Dry-Bulb Temperature/T_evap: First Range & $1.1200 \mathrm{e}+00$ \\
\hline Intercept for Dry-Bulb Temperature/T_evap: Second Range & $1.0000 \mathrm{e}+00$ \\
\hline Intercept for Dry-Bulb Temperature/T_evap: Third Range & $1.0000 \mathrm{e}+00$ \\
\hline Intercept for Absolute Humidity & $1.0000 e+00$ \\
\hline Intercept for Incremental Inlet Air Pr. Drop in of water & $1.0000 \mathrm{e}+00$ \\
\hline Intercept for Incremental Inlet Exhaust Pr. Drop in of water & $1.0000 \mathrm{e}+00$ \\
\hline Slope for Altitude & $-3.3300 \mathrm{e}-05$ \\
\hline Slope for Dry-Bulb Temperature/T_evap: First Range & $-2.1500 e-03$ \\
\hline Slope for Dry-Bulb Temperature/T_evap: Second Range & $0.0000 e+00$ \\
\hline Slope for Dry-Bulb Temperature/T_evap: Third Range & $0.0000 e+00$ \\
\hline Slope for Absolute Humidity & $0.0000 \mathrm{e}+00$ \\
\hline Slope for Incremental Inlet Air Pr. Drop in of water & $-2.5000 \mathrm{e}-03$ \\
\hline Slope for Incremental Inlet Exhaust Pr. Drop in of water & $0.0000 \mathrm{e}+00$ \\
\hline \multicolumn{2}{|l|}{ Exhaust Flow Factor Echo } \\
\hline Intercept for Altitude & $1.0000 \mathrm{e}+00$ \\
\hline Intercept for Dry-Bulb Temperature/T_evap: First Range & $1.1200 \mathrm{e}+00$ \\
\hline Intercept for Dry-Bulb Temperature/T_evap: Second Range & $1.0000 \mathrm{e}+00$ \\
\hline Intercept for Absolute Humidity & $1.0000 \mathrm{e}+00$ \\
\hline Intercept for Incremental Inlet Air Pr. Drop in of water & $1.0000 \mathrm{e}+00$ \\
\hline Slope for Altitude & $-3.3300 \mathrm{e}-05$ \\
\hline Slope for Dry-Bulb Temperature/T_evap: First Range & $-2.1500 \mathrm{e}-03$ \\
\hline Slope for Dry-Bulb Temperature $/ T_{-}$evap: Second Range & $0.0000 e+00$ \\
\hline Slope for Absolute Humidity & $-2.5000 \mathrm{e}-03$ \\
\hline Slope for Incremental Inlet Air Pr. Drop in of water & $0.0000 e+00$ \\
\hline
\end{tabular}


Table A.1. (contd)

\begin{tabular}{|c|c|}
\hline \multicolumn{2}{|l|}{ Condenser Temperature Factor Echo } \\
\hline "Intercept for $\mathrm{Twb}<54^{\circ} \mathrm{F}$ & $1.0000 e+00$ \\
\hline Intercept for $\mathrm{Twb}>54^{\circ} \mathrm{F}$ & $1.0000 \mathrm{e}+00$ \\
\hline Slope for $\mathrm{Twb}<54^{\circ} \mathrm{F}$ & $-1.9000 \mathrm{e}-04$ \\
\hline Slope for $\mathrm{Twb}>54^{\circ} \mathrm{F}$ & $-9.0000 \mathrm{e}-04$ \\
\hline \multicolumn{2}{|l|}{ Echo Adjustments } \\
\hline Altitude & 577 \\
\hline Air Stream Pressure Drop (in of $\mathrm{H}_{2} \mathrm{O}$ ) & 1.300 \\
\hline Exhaust Stream Pressure Drop (in of $\mathrm{H}_{2} \mathrm{O}$ ) & 0.000 \\
\hline \multicolumn{2}{|l|}{ Chiller Coefficients Echo } \\
\hline \multicolumn{2}{|l|}{ Chiller Data } \\
\hline Chiller Type is & Complex Compound Chiller \\
\hline Ist stage chiller intercept & $8.6700 \mathrm{e}-01$ \\
\hline Ist stage chiller slope & $-2.5000 \mathrm{e}-03$ \\
\hline 2nd stage chiller intercept & $5.2000 \mathrm{e}-01$ \\
\hline 2nd stage chiller slope & $-0.0000 e+00$ \\
\hline \multicolumn{2}{|l|}{ Echo Storage Script } \\
\hline Parameter file & cr51 \\
\hline Input file & cr5l.day \\
\hline Plant Type & CC Plant \\
\hline Inlet air is cooled to (F) & 42 \\
\hline \multicolumn{2}{|l|}{ Chiller Coefficients Echo } \\
\hline Chiller Type is & Complex Compound Chiller \\
\hline 1st stage chiller intercept & $8.6700 \mathrm{e}-01$ \\
\hline lst stage chiller slope & $-2.5000 \mathrm{e}-03$ \\
\hline 2nd stage chiller intercept & $5.2000 \mathrm{e}-01$ \\
\hline 2nd stage chiller slope & $-0.0000 e+00$ \\
\hline \multicolumn{2}{|l|}{ Echo Constants Post-Processor ... } \\
\hline \multicolumn{2}{|l|}{ Cooling Media NH3 } \\
\hline \multicolumn{2}{|l|}{ lst Stage } \\
\hline Chilled water/NH3 supplied temperature (F) & 34 \\
\hline Chilled water $\mathrm{NH} 3$ return temperature (F) & 46 \\
\hline \multicolumn{2}{|l|}{ Ist Stage Generator } \\
\hline Cooling hx Imtd (F) & 10 \\
\hline U-Value of heat exchanger (Btu/h-F-ft2) & 225 \\
\hline \multicolumn{2}{|l|}{ 2nd Stage Generator } \\
\hline Cooling hx Imtd (F) & 60 \\
\hline U-Value of heat exchanger (Btu/h-F-ft2) & 225 \\
\hline GT exhaust gas temperature (F) & 1000 \\
\hline GT exhaust gas cp (Btu/lb-F) & 0.253 \\
\hline
\end{tabular}


Table A.1. (contd)

\begin{tabular}{|c|c|}
\hline Cooling water delta $T$ range $(F)$ & 10 \\
\hline Chilled water circulation power (kW/gpm) & 0.0300 \\
\hline NH3 circulation power $(\mathrm{kW} / \mathrm{lb} / \mathrm{h})$ & $2.00000 \mathrm{e}-05$ \\
\hline Steam/Water piping power $(\mathrm{kW} / \mathrm{b} / \mathrm{h})$ & $6.00000 \mathrm{e}-05$ \\
\hline Cooling water piping power (kW/gpm) & 0.0200 \\
\hline Cooling tower fan power $(\mathrm{kW} / \mathrm{mmBtu} / \mathrm{h})$ & 1.2500 \\
\hline Ice generator power (kW/ton) & 0.0300 \\
\hline Ice generator loop sizing (gpm/ton) & 3.0000 \\
\hline Water chiller generator power (kW/ton) & 0.0200 \\
\hline Water chiller generator loop sizing (gpm/ton) & 2.0000 \\
\hline \multicolumn{2}{|l|}{ First stage } \\
\hline Feed water temperature to HRSG (F) & 351 \\
\hline Steam pressure (psia) & 137 \\
\hline Latent heat of steam at HRSG outlet condition (Btu/lb) & 870 \\
\hline Chiller parasitic power (kW/ton) & 0.0000 \\
\hline Chiller heat rejection rate (Btu/h/ton cooling) & 29991 \\
\hline \multicolumn{2}{|l|}{ Second stage } \\
\hline Feed water temperature to HRSG (F) & 213 \\
\hline Steam pressure (psia) & 15 \\
\hline Latent heat of steam at HRSG outlet condition (Btu/lb) & 969 \\
\hline Chiller parasitic power (kW/ton) & 0.0000 \\
\hline Chiller heat rejection rate (Btu/h/ton cooling) & 35076 \\
\hline Chiller heat rejection rate: Sizing (Btu/h/ton cooling) & 21624 \\
\hline \multicolumn{2}{|l|}{ ist Stage Relative cost equation } \\
\hline Intercept & 1.566 \\
\hline Slope & $-6.90000 e-03$ \\
\hline \multicolumn{2}{|l|}{ 2nd Stage Relative cost equation } \\
\hline Intercept & 1.000 \\
\hline Slope & $-0.00000 e+00$ \\
\hline \multicolumn{2}{|l|}{ Output Results with cr51 Parameter File } \\
\hline Number of plant operating hours & 2868 \\
\hline Number of inlet cooling hours & 480 \\
\hline A. GT Energy Output (MWh) & 448135.525 \\
\hline Average power output (MW) & 156.254 \\
\hline Net GT MW @max cooling load condition (uncooled) & 133.718 \\
\hline Average GT heat rate (Btu/kWh) & 10524.276 \\
\hline A. CC Energy Output (MWh) & 642002.833 \\
\hline Average power output (MW) & 223.850 \\
\hline Ref. power at max. enthalpy (uncooled) 8201523259279 & 197.853 \\
\hline 8201523259279 & 254.541 \\
\hline
\end{tabular}

\section{A.8}


Table A.1. (contd)

\begin{tabular}{|c|c|c|}
\hline \multicolumn{2}{|l|}{ A. CC Fuel Input (mmBtu) } & 4716301.796 \\
\hline \multicolumn{2}{|l|}{ Average $\mathrm{CC}$ heat rate (Btu/kWh) } & 7346.232 \\
\hline P. Hourly GT Power (MW) & 4161510655252 & 184.695 \\
\hline P. Hourly ST Power (MW) & 511512166045 & 71.576 \\
\hline P. Hourly CC Power (MW) & 511512166045 & 256.271 \\
\hline P. Hourly GT Heat Rate (Btu/kWh) & 6301418139475 & 11161.823 \\
\hline P. Hourly CC Heat Rate (Btu/kWh) & 7241220569180 & 7511.692 \\
\hline P. Hourly Flow Rate CC (lbs/h) & 4161510655252 & 3684892.728 \\
\hline Min. Hourly GT Power (MW) & 6301418139475 & 132.042 \\
\hline Min. Hourly ST Power (MW) & 7241220569180 & 64.128 \\
\hline Min. Hourly CC Power (MW) & 6301418139475 & 196.306 \\
\hline Min. Hourly G'T Heat Rate (Btu/kWh) & 4161510655252 & 9982.981 \\
\hline Min. Hourly CC Heat Rate (Btu/kWh) & 511512166045 & 7194.749 \\
\hline Min. Hourly CC Flow Rate (lbs/h) & 6301418139475 & 3019966.996 \\
\hline \multicolumn{3}{|l|}{ Air Cooling Load Output } \\
\hline P. Hourly 1st Stage CL (mmBtuh) & 8201523259279 & 96.948 \\
\hline A. Ist Stage CL (mmBtu) & & 29954.180 \\
\hline Average hourly 1st Stage CL (Btu/h) & & 62.405 \\
\hline P. Hourly 2nd Stage CL (mmBtuh) & 4161510655252 & 56.420 \\
\hline A. 2nd Stage CL (mmBtu) & & 26995.434 \\
\hline Average hourly 2nd Stage CL (Btu/h) & & 56.240 \\
\hline P. Daily 1st Stage CL (mmBtu) & 2028577 & 358.095 \\
\hline P. Daily 2nd Stage CL (mmBtu) & 10650.550 & 225.681 \\
\hline \multicolumn{3}{|c|}{ Chiller Peak Energy Non-Storage Case (adjusted by gencoolfac) } \\
\hline P. Hourly lst Stage ChE (mmBtuh) & 8201523259279 & 152.047 \\
\hline P. Hourly 2nd Stage ChE (mmBtuh) & 4161510655252 & 113.925 \\
\hline P. Hourly lst Stage $\mathrm{ChE}(\mathrm{kW})$ & 8201523259279 & 44549.500 \\
\hline P. Hourly 2nd Stage ChE (kW) & 4161510655252 & 33379.867 \\
\hline A. Ist Stage ChE (mmBtu & & 45517.187 \\
\hline A. 2nd Stage ChE (mmBtu) & & 54510.010 \\
\hline A. Ist Stage ChE (kWh) & & 13336415.726 \\
\hline A. 2nd Stage ChE (kWh) & & 15971289.321 \\
\hline \multicolumn{3}{|c|}{ Chiller Sizing Output (adjusted by gencoolfac) } \\
\hline Non-Storage Ist Stage ChC (mmBtu) & 8201523259279 & 101.796 \\
\hline Non-Storage 2nd Stage ChC (mmBtu) & 4161510655252 & 59.241 \\
\hline \multicolumn{3}{|c|}{ Adjusted for generating cooling and storage losses ... } \\
\hline D. LS lst Stage ChC (mmBtu) & 2028577 & 55.853 \\
\hline D. LS 2nd Stage ChC (mmBtu) & 10650.550 & 29.621 \\
\hline
\end{tabular}


Table A.1. (contd)

\begin{tabular}{|c|c|}
\hline \multicolumn{2}{|l|}{ Storage Sizing Output Adjusted (gencoolfac and storage eff.) } \\
\hline D. LS 1st Stage SC (mmBtu) & 379.798 \\
\hline D. LS 2nd Stage SC (mmBtu) & 236.965 \\
\hline \multicolumn{2}{|l|}{ Results: Post-Processing Storage Script .... } \\
\hline \multicolumn{2}{|c|}{ 1st Stage Peak Chiller Energy Consumption Storage Case (adjusted by gencoolfac and storage efficiency) } \\
\hline Hourly lst Stage ChE (mmBtu) $\quad 82.2577 .50$ & 82.960 \\
\hline Hourly lst Stage ChE (kWh) & 24306.966 \\
\hline Annual Ist Stage ChE (mmBtu) & 54009.325 \\
\hline Annual 1st Stage ChE (kWh) & 15824589.937 \\
\hline \multicolumn{2}{|l|}{ 2nd Stage Peak Chiller Energy Consumption (adjusted by gencoolfac) } \\
\hline Hourly 2nd Stage ChE (mmBtu) $\quad 82.2577 .50$ & 56.963 \\
\hline Hourly 2nd Stage ChE (kWh) & 16689.934 \\
\hline Annual 2nd Stage ChE (mmBtu) & 27255.005 \\
\hline Annual 2nd Stage ChE (kWh) & 7985644.661 \\
\hline Maximum air side exhaust pressure drop in HRSG (in of $\mathrm{H}_{2} \mathrm{O}$ ) & 10 \\
\hline \multicolumn{2}{|l|}{ Results From Post-Processing.... } \\
\hline \multicolumn{2}{|l|}{ lst Stage Ice Storage } \\
\hline Cooling coil UA [42] (Btu/F-h) & 4462682.955 \\
\hline Generator cooling heat exchanger area (sf) & 2154.407 \\
\hline Chilled water circulation loop size $[42 / 52 \mathrm{~F}](\mathrm{gpm})$ & 16145.134 \\
\hline Chilled water generator loop size [42/52 F] (gpm) & 807.257 \\
\hline Chilled water pump peak $\mathrm{kW}$ & 484.354 \\
\hline Chilled water pump annual energy consumption ( $k W h)$ & 149651.279 \\
\hline Generator cooling loop pump peak $\mathrm{kW}$ & 24.218 \\
\hline Generator cooling loop annual pumping energy (kWh) & 7482.564 \\
\hline \multicolumn{2}{|l|}{ Ammonia loop (chiller-to-storage) } \\
\hline Circulation loop size $(\mathrm{lb} / \mathrm{h})$ & 101735.155 \\
\hline Peak pumping power $(\mathrm{kW})$ & 2.035 \\
\hline Annual pumping energy $(\mathrm{kWh})$ & 1361.603 \\
\hline \multicolumn{2}{|l|}{ 2nd Stage Ammonia } \\
\hline Cooling coil UA $[0 \mathrm{~F}](\mathrm{Btu} / \mathrm{F}-\mathrm{h})$ & 1519855.557 \\
\hline Generator cooling heat exchanger area (sf) & 208.964 \\
\hline Ammonia circulation loop size $[0 \mathrm{~F}](\mathrm{lb} / \mathrm{h})$ & 96775.643 \\
\hline Generator circulation loop size [0 F] (lbh) & 4838.782 \\
\hline Peak pumping power $(k W)$ & 1.936 \\
\hline Annual pumping energy $(\mathrm{kWh})$ & 926.086 \\
\hline Peak pumping power [generator] $(\mathrm{kW})$ & 0.097 \\
\hline Annual pumping energy [generator] (kWh) & 46.304 \\
\hline \multicolumn{2}{|l|}{ 1st Stage ice generator sizing } \\
\hline Circulation loop size (gpm) . & 13963.150 \\
\hline
\end{tabular}


Table A.1. (contd)

\begin{tabular}{|c|c|}
\hline Peak pumping power $(\mathrm{kW})$ & 139.631 \\
\hline Annual pumping energy $(\mathrm{kWh})$ & 93440.018 \\
\hline \multicolumn{2}{|l|}{ Ist Stage Cooling Tower } \\
\hline Peak heat rejection (Btu/h) & 139589610.550 \\
\hline Water pipe sizing (gpm) & 27895.606 \\
\hline Peak water pumping power (kW) & 557.912 \\
\hline Annual water pumping energy (kWh) & 373349.264 \\
\hline Chiller parasitic power $(\mathrm{kW})$ & 0.000 \\
\hline Annual chiller parasitic energy ( $k W h)$ & 0.000 \\
\hline Peak fan power $(\mathrm{kW})$ & 174.487 \\
\hline Annual fan energy $(\mathrm{kWh})$ & 116764.982 \\
\hline Annual water consumption (gals) & 11623137.460 \\
\hline \multicolumn{2}{|l|}{ 2nd Stage Cooling Tower } \\
\hline Peak heat rejection $(\dot{B} t u / h)$ & 53376321.200 \\
\hline Water pipe sizing (gpm) & 10666.731 \\
\hline Peak water pumping power $(\mathrm{kW})$ & 213.335 \\
\hline Annual water pumping energy $(\mathrm{kWh})$ & 331146.810 \\
\hline Chiller parasitic power $(\mathrm{kW})$ & 0.000 \\
\hline Annual chiller parasitic energy (kWh) & 0.000 \\
\hline Peak fan power $(\mathrm{kW})$ & 66.720 \\
\hline Annual fan energy $(k W h)$ & 103566.165 \\
\hline Annual water consumption (gals) & 6355571.691 \\
\hline \multicolumn{2}{|l|}{ 1st Stage } \\
\hline Steam extraction $(\mathrm{lb} / \mathrm{h})$ & 95355.977 \\
\hline Power reduction (kW) & 7316.061 \\
\hline \multicolumn{2}{|l|}{ 2nd Stage } \\
\hline -Steam extraction $(\mathrm{lb} / \mathrm{h})$ & 58785.036 \\
\hline Power reduction $(\mathrm{kW})$ & 2273.715 \\
\hline lst stage annual energy loss $(\mathrm{kWh})$ & 4762979.097 \\
\hline 2nd stage annual energy loss (kWh) & 1087906.627 \\
\hline \multicolumn{2}{|c|}{484.3541 .9355124 .21770 .0967756213 .33566 .72040} \\
\hline \multicolumn{2}{|l|}{ Cost Information } \\
\hline \multicolumn{2}{|l|}{ Ist Stage Chiller } \\
\hline Type: & Complex Compound Chiller \\
\hline Cost (\$/ton): & 550.00 \\
\hline O\&M cost (as \% of initial cost): & 5.00 \\
\hline Cost (\$): & 2482337.78 \\
\hline O\&M Costs (\$): & 124116.89 \\
\hline \multicolumn{2}{|l|}{ 2nd Stage Chiller } \\
\hline Type: & Complex Compound Chiller \\
\hline
\end{tabular}

A. 11 
Table A.1. (contd)

\begin{tabular}{|c|c|}
\hline Cost (\$/ton): & 0.00 \\
\hline O\&M cost (as \% of initial cost): & 5.00 \\
\hline Cost (\$): & 0.00 \\
\hline O\&M Costs (\$): & 0.00 \\
\hline \multicolumn{2}{|l|}{ 2nd Stage Chiller/Storage Cost } \\
\hline Chiller/Storage cost (\$/ton-hr): & 310.00 \\
\hline Chiller/Storage O\&M cost as (\% of initial cost): & 4.00 \\
\hline Chiller/Storage cost (\$/ton-hr): & 6121595.83 \\
\hline Chiller/storage O\&M cost (as \% of initial cost): & 244863.83 \\
\hline \multicolumn{2}{|l|}{ Ist Stage Ice Generator/Storage } \\
\hline Generator cost (\$/ton): & 590.00 \\
\hline Generator $O \& M$ cost as ( $\%$ of initial cost): & 2.00 \\
\hline Ice storage cost (\$/ton-hrs)^ $0.75:$ & 163.60 \\
\hline Ice storage $O \& M$ cost (as $\%$ of initial cost): & 1.50 \\
\hline Generator cost $(\$)$ : & 2746086.17 \\
\hline Generator $O \& M$ costs $(\$)$ : & 54921.72 \\
\hline Ice storage cost $(\$)$ : & 388205.67 \\
\hline Ice storage $O \& M$ costs $(\$)$ : & 5823.08 \\
\hline \multicolumn{2}{|l|}{ 1st Stage Chilled Water Generator } \\
\hline Generator cost ( $\$ /$ ton): & 50.00 \\
\hline Generator O\&M cost as (\% of initial cost): & 1.00 \\
\hline Generator cost (\$): & 0.00 \\
\hline Generator O\&M costs (\$): & 0.00 \\
\hline Water storage cost $(\$ / \text { ton })^{\wedge} 0.75:$ & 572.40 \\
\hline Water storage O\&M cost (as \% of initial cost): & 1.50 \\
\hline Water storage cost $(\$)$ : & 0.00 \\
\hline Water storage O\&M costs $(\$)$ : & 0.00 \\
\hline \multicolumn{2}{|l|}{ 1st Stage air cooling coil } \\
\hline Cost $(\$ /[B t u / h-f]):$ & 0.20 \\
\hline O\&M cost (as \% of initial cost): & 2.00 \\
\hline Cost (\$): & 892536.59 \\
\hline O\&M costs $(\$):$ & 17850.73 \\
\hline \multicolumn{2}{|l|}{ 2nd Stage air cooling coil } \\
\hline $\operatorname{Cost}(\$ /[B$ tw/h-f]): & 0.33 \\
\hline O\&M cost (as \% of initial cost): & 3.00 \\
\hline Cost (\$): & 501552.33 \\
\hline O\&M costs $(\$):$ & 15046.57 \\
\hline \multicolumn{2}{|l|}{ lst Stage generator cooling coil } \\
\hline Cost $\left(\$ / t^{\wedge} 2\right)^{\wedge} 0.511:$ & 865.00 \\
\hline O\&M cost (as \% of initial cost): & 1.00 \\
\hline
\end{tabular}


Table A.1. (contd)

\begin{tabular}{|c|c|}
\hline Cost (\$): & 43686.43 \\
\hline O\&M costs $(\$):$ & 436.86 \\
\hline \multicolumn{2}{|l|}{ 2nd Stage generator cooling coil } \\
\hline Cost (\$): & 13260.88 \\
\hline O\&M costs $(\$):$ & 132.61 \\
\hline \multicolumn{2}{|l|}{ 1st Chilled water circulation cost } \\
\hline Cost $(\mathrm{gpm} / 10,000)^{\wedge} 0.6:$ & 290000.00 \\
\hline O\&M cost (as \% of initial cost): & 3.00 \\
\hline Cost (\$): & 386565.41 \\
\hline O\&M costs $(\$):$ & 11596.96 \\
\hline Cost (\$) [generator loop]: & 64062.66 \\
\hline O\&M costs (\$) [generator loop]: & 1921.88 \\
\hline \multicolumn{2}{|l|}{ Ist Ammonia circulation cost } \\
\hline Cost $(\mathrm{lb} / \mathrm{h} / 15,000)^{\wedge} 0.6$ & 54000.00 \\
\hline O\&M cost (as \% of initial cost): & 3.00 \\
\hline Cost (\$): & 0.00 \\
\hline O\&M costs (\$): & 0.00 \\
\hline Cost (\$) [generator loop]: & 0.00 \\
\hline O\&M costs (\$) [generator loop]: & 0.00 \\
\hline \multicolumn{2}{|l|}{ 2nd Ammonia circulation cost } \\
\hline $\operatorname{Cost}(\mathrm{lb} / \mathrm{h} / 15,000)^{\wedge} 0.6:$ & 108000.00 \\
\hline Cost $(\$):$ & 330543.51 \\
\hline O\&M costs (\$): & 9916.31 \\
\hline Cost (\$) [generator loop]: & 27389.28 \\
\hline O\&M costs (\$) [generator loop]: & 821.68 \\
\hline \multicolumn{2}{|c|}{ Ist stage storage water charging cost (ice loop) } \\
\hline Cost $(\mathrm{gpm} / 10,000)^{\sim} 0.6:$ & 100000.00 \\
\hline O\&M cost (as \% of initial cost): & 3.00 \\
\hline Cost $(\$):$ & 122177.16 \\
\hline O\&M costs $(\$):$ & 3665.31 \\
\hline \multicolumn{2}{|l|}{ lst stage storage water charging cost } \\
\hline Cost $(\mathrm{gpm} / 10,000)^{\wedge} 0.6:$ & 100000.00 \\
\hline O\&M cost (as \% of initial cost): & 3.00 \\
\hline Cost $(\$):$ & 0.00 \\
\hline O\&M costs (\$): & 0.00 \\
\hline \multicolumn{2}{|c|}{ Ist Ammonia circulation cost (chiller-to-storage) } \\
\hline Cost $(\mathrm{lb} / \mathrm{h} / 15,000)^{\wedge} 0.6:$ & 54000.00 \\
\hline O\&M cost (as \% of initial cost): & 3.00 \\
\hline Cost (\$): & 170302.74 \\
\hline O\&M costs $(\$):$ & 5109.08 \\
\hline
\end{tabular}

\section{A. 13}


Table A.1. (contd)

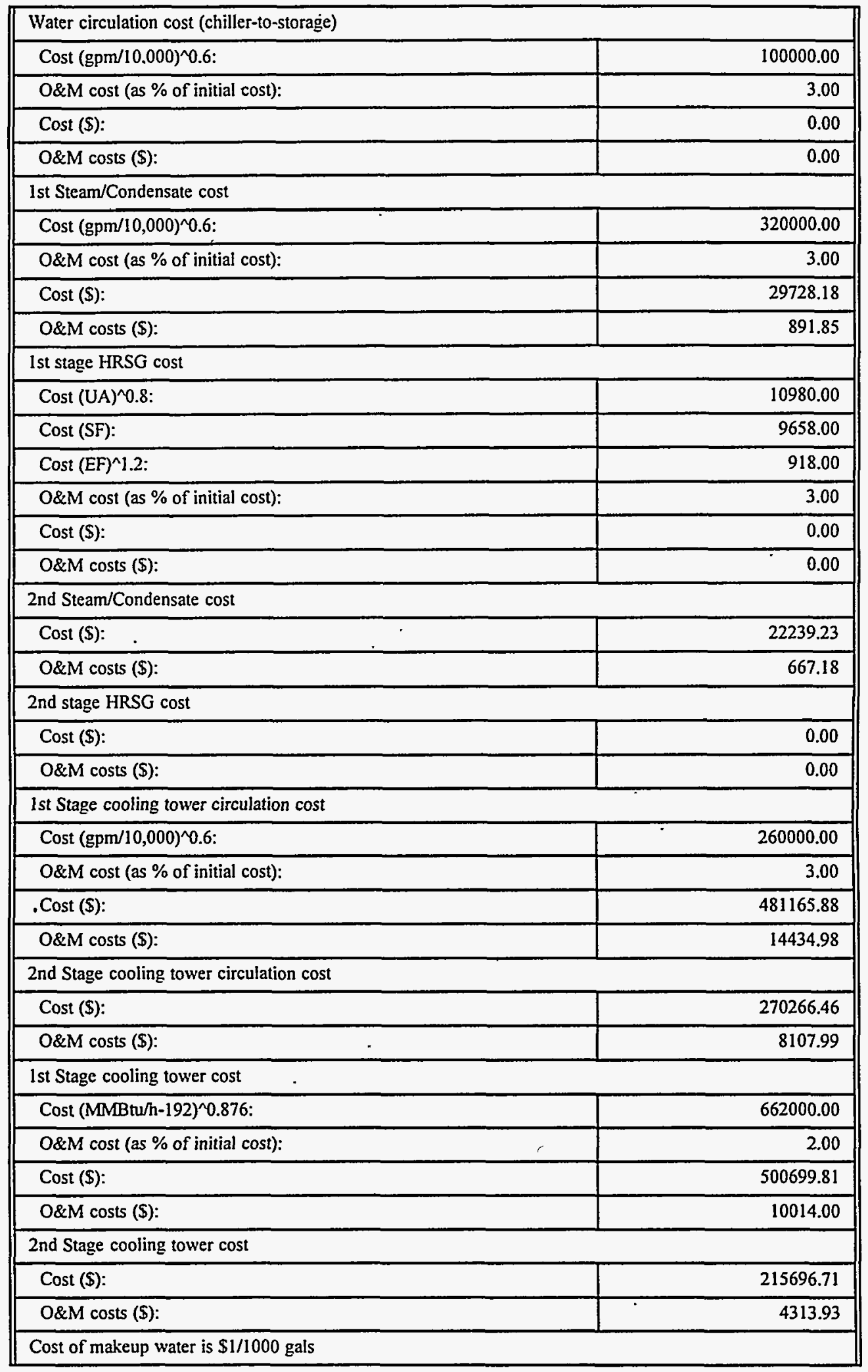


Table A.1. (contd)

\begin{tabular}{|c|c|}
\hline Ist stage makeup water costs & 11623.14 \\
\hline 2nd stage makeup water costs & 6355.572 \\
\hline \multicolumn{2}{|l|}{ System control cost } \\
\hline Fixed Cost (\$): & 250000.00 \\
\hline O\&M cost (as \% of initial cost): & $\cdot$ \\
\hline O\&M costs (\$): & 15000.00 \\
\hline \multicolumn{2}{|l|}{ Plant electric cost } \\
\hline Fixed Cost (\$): & 100000.00 \\
\hline O\&M cost (as \% of initial cost): & 2.00 \\
\hline O\&M costs $(\$):$ & 2000.00 \\
\hline \multicolumn{2}{|l|}{ Peak transformer cost } \\
\hline Cost $(\$ k W)^{\wedge} 0.4359:$ & 5553.00 \\
\hline O\&M cost (as \% of initial cost): & 2.00 \\
\hline Cost (\$): & 106352.24 \\
\hline O\&M costs (S): & 2127.04 \\
\hline Peak auxiliary power consumption (kW) & 790.66 \\
\hline Off-Peak auxiliary power consumption $(k W)$ & 874.07 \\
\hline Peak auxiliary annual energy consumption (kWh) & 591893.12 \\
\hline Off-Peak auxiliary annual energy consumption ( $\mathrm{kWh}$ ) & 584915.87 \\
\hline Total capital cost & 16266450.96 \\
\hline Total O\&M cost & 571759.21 \\
\hline \multicolumn{2}{|l|}{ Echo Input NPV Routine } \\
\hline Reading Parameters from file & npv.cr51 \\
\hline Net $k W h$ reference uncooled plant & 619825508 \\
\hline Net mmBtu reference uncooled plant & 4573613.7 \\
\hline kW/kWh multiplier & 10.391 \\
\hline O\&M and off-peak $k$ Wh multiplier & 10.39100 \\
\hline Fuel multiplier & 14.32600 \\
\hline Capital cost multiplier & 1.00970 \\
\hline Peak kW cost $(\$ / k W)$ & 64.00 \\
\hline Peak kWh cost (\$/kWh) & 0.03800 \\
\hline Off-Peak $k W h$ cost $(\$ k W h)$ & 0.02400 \\
\hline Fuel cost $(\$ / \mathrm{mmBtu})$ & 2.25 \\
\hline Reading Inputs from file & cr5I.npv \\
\hline Gross kW cooled plant & 254541 \\
\hline Net kW@max cooling load condition & 197853 \\
\hline Peak auxiliary $\mathrm{kW}$ & 790.7 \\
\hline Peak auxiliary $\mathrm{kW}$ reduction due to steam extraction & 0.0 \\
\hline Gross kWh cooled plant & 642003000 \\
\hline Net kWh reference uncooled plant & 619825508 \\
\hline
\end{tabular}


Table A.1. (contd)

\begin{tabular}{||r|r|}
\hline Peak auxiliary $k W h$ & 591893 \\
\hline Peak auxiliary kWh lost due to steam extraction & 0 \\
\hline Off-Peak auxiliary $k W h$ & 584916 \\
\hline Off-Peak auxiliary kWh lost due to steam extraction & 5850890 \\
\hline Fuel input & 4716300.000 \\
\hline Net mmBtu reference uncooled plant & 4573613.731 \\
\hline Total capital costs & 16266500.00 \\
\hline Total O\&M costs & 571759.00 \\
\hline Output from NPV routine & 55897.341 \\
\hline Net on-peak $k W$ & 21585599.000 \\
\hline Net on-peak $k W h$ & 6435806.000 \\
\hline Net off-peak $k W h$ & 142686.269 \\
\hline Net fuel & 17126622.037 \\
\hline NPV & 291.007 \\
\hline Incremental $k W$ cost & -37173073.301 \\
\hline On-Peak $k W$ fraction of NPV & 8523246.450 \\
\hline On-Peak $k W h$ fraction of NPV & -1604987.044 \\
\hline Off-Peak $k W h$ fraction of NPV & -5941147.769 \\
\hline O\&M fraction of NPV & -4599277.852 \\
\hline Fuel fraction of NPV & -16424285.050 \\
\hline Capital fraction of NPV & \\
\hline \hline
\end{tabular}

\section{A. 16}


Appendix B

Component Sizing 



\section{Appendix B}

\section{Component Sizing}

The equations and assumptions used to size cooling system components are presented in this Appendix.

\section{B.1 Chiller Sizing}

For direct air cooling applications (without storage) the chiller is sized to meet the peak air cooling load (pacl) and the cooling load required to cool the generator:

$$
1^{\text {st }} \text { Stage Chiller Size }(B t u / h)=1^{\text {st }} \text { Stage pacl } x \text { gcf }
$$

where "gcf," the generator cooling factor, is the amount of additional cooling needed for the generator (a value of 1.05 was for all cases). When the air is cooled to $0^{\circ} \mathrm{F}$, two chillers are sized. The first chiller meets the peak cooling load required to cool air from the ambient condition to $42^{\circ} \mathrm{F}\left(1^{\text {st }}\right.$ stage). The second chiller meets the peak cooling load to cool the air from $42^{\circ} \mathrm{F}$ to $0^{\circ} \mathrm{F}\left(2^{\text {nd }}\right.$ stage).

$$
2^{\text {nd }} \text { Stage Chiller Size }(B t u / h)=2^{\text {nd }} \text { Stage pacl } x \text { gcf }
$$

When daily storage is used, the total load the chiller is required to provide is the sum of the peak daily air cooling load, the daily generator cooling load, and the load required to offset the storage and defrost (ice storage only) losses. For load-shifting storage, the chiller is sized to generate the total load while operating only during the period when there is no inlet air cooling:

\section{Chiller Size, Daily Load-Shifting $($ Btu/h $)=($ pacl $x$ gcf $x$ seff $x$ deff $) / n o p$}

where "seff" and "deff" are storage and defrost efficiencies, respectively, and "nop" is the number of hours the chiller can operate when inlet air is not being cooled. For example, if the inlet air is cooled 4 hours per day with an electrically-driven chiller, "nop" is 20 hours. For thermally-activated chillers "nop" is the difference between the number of plant operating hours and the number of inlet air cooling hours (because the thermal energy required to run the chiller is extracted from the power plant). For load-leveling storage the chiller is sized to provide the total daily load while operating 24 hours a day (for electrically-driven chillers) or while the plant is operating (for thermally-activated chillers). 
where "op" is either 24 or the number of plant operating hours.

When weekly storage is used, the total load the chiller is required to provide is the sum of the peak weekly air cooling load, the weekly generator cooling load and load required to offset the storage and defrost (ice storage only) losses. For load-shifting, the chiller is sized to generate the total load while operating only during the period when there is no inlet air cooling. The same equations used to size chillers for daily load-shifting and load-leveling are used of weekly load-shifting and load-leveling as well. The "nop" for weekly storage is either multiplied by 5 or 7 , for thermally- activated chillers, depending on whether the plant operates on weekends or not. For electrically-driven chillers with the plant operating on weekends the daily "nop" is multiplied by 7; when the plant is not operating on weekends the weekly "nop" is:

$$
\text { weekly nop }=(\text { daily nop } \times 5)+48
$$

\section{B.2 Storage Sizing}

The storage size for daily load-shifting is:

Daily Storage Size, Load-Shifting $(B t u)=(\mathrm{pdcl} \times \mathrm{gcf}) / \mathrm{seff}$

where "pdcl" is the peak daily cooling load. The storage size for daily load-leveling is:

Daily Storage Size, Load-Leveling $($ Btu $)=(\mathrm{pdcl} \times \mathrm{gcf}) / \mathrm{seff}-$

(chiller size $\mathrm{x}$ noc $\mathrm{x}$ deff)

where "noc" is the number of inlet cooling hours. The storage size for weekly load-shifting is:

Weekly Storage Size, Load-Shifting $(B t u)=(\mathrm{pwcl} \times \mathrm{gcf}) / \mathrm{seff}-$

(chiller size $\mathrm{x}$ nop $\mathrm{x} 4 \mathrm{x}$ deff)

where "pwcl" is the peak weekly cooling load. The storage size for weekly load-leveling is:

Weekly Storage Size, Load-Leveling $(B t u)=($ pwcl $x$ gcf $) /$ seff $-($ chiller size $\mathrm{x}$

$($ noc $+24 \times 4) \times$ deff)

\section{B.3 Inlet Air Cooling Coil Sizing}

Both the $1^{\text {st }}$ and $2^{\text {nd }}$ stage inlet air cooling coil UAs are sized as follows:

Coil UA Size $\left(B t u / h-^{\circ} \mathrm{F}\right)=p a c 1 / \Delta T_{\mathrm{lm}}$ 
where " $\Delta \mathrm{T}_{\mathrm{lm}}$ " is the log mean temperature difference. The heat exchangers required to cool the generator are sized as follows:

$$
\text { Generator Cooling Coil Size (sf) }=\operatorname{pacl} \times(\operatorname{gcf}-1) /\left(\Delta \mathrm{T}_{\mathrm{lm}} \times \mathrm{U}\right)
$$

The values used for " $\Delta \mathrm{T}_{\mathrm{Im}}$ " and "UA" are shown in Table B.1.

\section{B.4 Chilled Water Circulation System Sizing}

The chilled water (CW) circulation loop is sized as follows:

$$
\text { CW Circulation System Size }(\mathrm{gpm})=\mathrm{pacl} /\left(500.4 \times\left[\mathrm{T}_{\mathrm{o}}-\mathrm{T}_{\mathrm{i}}\right]\right)
$$

For $\mathrm{LiBr}$ chillers or water storage cases $\mathrm{T}_{\mathrm{o}}$ and $\mathrm{T}_{\mathrm{i}}$ are $56^{\circ} \mathrm{F}$ and $44^{\circ} \mathrm{F}$, respectively; and for ice storage $T_{0}$ and $T_{i}$ are $46^{\circ} \mathrm{F}$ and $34^{\circ} \mathrm{F}$, respectively. The circulation system needed to cool the generator is calculated similarly:

$$
\text { CW Circulation System Size Generator Loop }(\mathrm{gpm})=\operatorname{pacl} \times(\mathrm{gcf}-1) /\left(500.4 \times\left[\mathrm{T}_{\mathrm{o}}-\mathrm{T}_{\mathrm{i}}\right]\right)
$$

The peak pumping pump required to pump water is calculated as follows:

$$
\text { Peak Pumping Power }(\mathrm{kW})=\mathrm{CW} \text { Circulation System Size } \mathrm{x} \text { kW_gpm }
$$

where "kW_gpm" is the power $(\mathrm{kW})$ required to pump 1 gallon of $\mathrm{CW}$ water per minute. The same equation is used for calculating the generator peak pumping power as well. Annual pumping energy for both the main $\mathrm{CW}$ loop and the generator cooling loop is calculated as follows:

\begin{tabular}{|c|c|c|}
\hline Mode & $\Delta \mathrm{T}_{\mathrm{lm}}$ & $\mathrm{U}$ \\
\hline Inlet air cooling to $42^{\circ} \mathrm{F}$ or $52^{\circ} \mathrm{F}$ & 35 & 225 \\
\hline Inlet air cooling to $0^{\circ} \mathrm{F}$ & & \\
\hline $1^{\text {st }}$ Stage & 10 & 225 \\
\hline $2^{\text {nd }}$ Stage & 60 & 225 \\
\hline
\end{tabular}

$$
\text { Annual CW Pumping Energy }(\mathrm{kWh})=\text { Peak Pumping Power } \mathrm{x} \text { acl/pacl }
$$

where "acl" is the annual cooling load.

Table B.1. $\Delta \mathrm{T}_{\mathrm{Im}}$ and $\mathrm{U}$ Values Used for Sizing Generator Cooling Coil 


\section{B.5 Ammonia Circulation System Sizing}

The ammonia circulation loop is sized as follows:

Ammonia Circulation System Sizing $(\mathrm{lbs} / \mathrm{h})=\mathrm{pacl} /$ Ammonia $\mathrm{hfg}$

where "Ammonia hfg" is the latent heat of vaporization for ammonia. For ammonia chillers operating at an evaporator temperature of $32^{\circ} \mathrm{F}$, the hfg is $543 \mathrm{Btu} / \mathrm{lb}$, and for chillers operating at $20^{\circ} \mathrm{F}$ and $-20^{\circ} \mathrm{F}$ evaporator temperatures, hfg values are $549 \mathrm{Btu} / \mathrm{lb}$ and $583 \mathrm{Btu} / \mathrm{lb}$, respectively. Typically, the first $1^{\text {st }}$ stage chiller operates at $32^{\circ} \mathrm{F}$ or $20^{\circ} \mathrm{F}$ evaporator temperature, while the $2^{\text {nd }}$ stage chiller operates at $-20^{\circ} \mathrm{F}$ evaporator temperature. When ice or water storage is used, an additional ammonia loop between the chiller and storage tank is sized similarly:

\section{Ammonia Chiller-to-Storage Sizing $(\mathrm{lb} / \mathrm{h})=$ Storage Size $/$ Ammonia $\mathrm{hfg}$}

The circulation loop needed to cool the generator is calculated as follows:

$$
\text { Ammonia Circulation Size for Generator Loop }(\mathrm{lb} / \mathrm{h})=\operatorname{pacl} \mathrm{x}(\mathrm{gcf}-1) / \text { Ammonia hfg }
$$

The peak pumping pump required to pump ammonia is calculated as follows:

Peak Pumping Power $(\mathrm{kW})=$ Ammonia Circulation System Size $\mathrm{x} \mathrm{kW} \mathrm{l} b \mathrm{bh}$

where " $k W \_l b h "$ is the power $(\mathrm{kW})$ required to pump 1 pound of ammonia per hour. The same equation is used for calculating the generator peak pumping power as well. Annual pumping energy for the main ammonia loop, chiller-to-storage loop, and the generator loop is calculated as follows:

Annual Ammonia Pumping Energy $(\mathrm{kWh})=$ Peak Pumping Power $\mathrm{x}$ acl $/ \mathrm{pacl}$

\section{B.6 Ice Generator Sizing .}

The size of the ice generator is same as the chiller size. The circulation loop for the ice generator is sized as follows:

Ice Generator Circulation Loop Sizing $(\mathrm{gpm})=$ Chiller Size $\mathrm{x}$ ice_gpmpt $/ 12000$

where "ice_gpmpt" is the circulation loop flow rate in gallons per minute per ton of chilling capacity. The peak pumping power is calculated as follows:

Peak Pumping Power for Ice Generator $(\mathrm{kW})=$ Chiller Size $\mathrm{x}$ ikW_ton $/ 12000$ 
where "ikW_ton" is the $\mathrm{kW}$ per ton of chilling capacity. Annual pumping power is calculated as follows:

Annual Pumping Energy $(\mathrm{kWh})=$ Peak Pumping Power $\mathrm{x}$ acl $\mathrm{x}$ gcf $/$ (seff $\mathrm{x}$ Chiller Size)

\section{B.7 Chilled Water Generator Sizing}

The size of the chilled water generator is same as the chiller size. The circulation loop for the chilled water generator is sized as follows:

CW Generator Circulation Loop Sizing $(\mathrm{gpm})=$ Chiller Size $/(12000 \times$ h2o_gpmpt)

where "h2o_gpmpt" is the circulation loop flow rate in gallons per minute per ton of chilling capacity. The peak pumping power is calculated as follows:

Peak Pumping Power for CW Generator $(\mathrm{kW})=$ Chiller Size / (12000 x wkW_ton)

where "wkW_ton" is the $\mathrm{kW}$ per ton of chiller capacity. Annual pumping power is calculated as follows:

Annual Pumping Power $(\mathrm{kWh})=$ Peak Pumping Power $\mathrm{x}$ acl $\mathrm{x}$ gcf $/($ seff $\mathrm{x}$ Chiller Size $)$

\section{B.8 Cooling Tower Sizing}

The peak heat rejection rate at the cooling tower for both $1^{\text {st }}$ and $2^{\text {nd }}$ stage is calculated as follows:

Peak Heat Rejection Rate $(B t u / h)=$ Chiller Size x Chiller Heat Rejection Rate / 12000

where the chiller heat rejection rate varies by chiller technology. The water pipe sizing for the cooling tower is:

Cooling Water Sizing $(\mathrm{gpm})=$ Peak Heat Rejection Rate $/\left(500.4 \times \Delta \mathrm{T}_{\mathrm{e}}\right)$

where, $\Delta \mathrm{T}_{e}$, is assumed to be $10^{\circ} \mathrm{F}$. The peak pumping power is calculated as follows:

Peak Pumping Power $(\mathrm{kW})=$ Cooling Water Sizing $\mathrm{x}$ ckW_gpm

where "ckW_gpm" is 0.02 . Annual pumping energy is calculated as follows:

Annual Pumping Energy $(\mathrm{kWh})=$ Peak Pumping Power $\mathrm{x}$ acl $\mathrm{x}$ gcf $/($ seff $\mathrm{x}$ Chiller Size) 
The peak fan power for the cooling tower is calculated as follows:

Peak Fan Power $(\mathrm{kW})=$ Peak Heat Rejection Rate $\mathrm{x} \mathrm{kW}$ _mmBtu/1E6

where " $k W \_m m B t u "$ is 1.25 . The annual fan energy consumption is calculated as follows:

Annual Fan Energy $(\mathrm{kWh})=($ Peak Fan Power $\mathrm{x}$ acl $\mathrm{x}$ gcf $) /($ seff $\mathrm{x}$ Chiller Size $)$

\section{B.9 Chiller Parasitic Energy}

The $\mathrm{LiBr}$ chiller has additional parasitic consumption, which is calculated as follows:

Annual Parasitic $(\mathrm{kWh})=($ Chiller Size $/ 12000 \times \mathrm{kW}$ _ton $) \times$ acl $\mathrm{x}$ gcf $/$ Chiller Size

where "kW_ton" is $0.0136 \mathrm{~kW} /$ ton for a single stage $\mathrm{LiBr}$ chiller and $0.028 \mathrm{~kW} /$ ton for a double stage $\mathrm{LiBr}$ chiller.

\section{B.10 Heat Recovery Steam Generator (HRSG) Sizing}

The heat recovery steam generator for thermally-activated chillers with a simple-cycle power plant is sized as follows:

$$
\text { HRSG UA }\left(B t u / h-^{\circ} \mathrm{F}\right)=\text { Peak Chiller Energy Consumption } / \Delta \mathrm{T}_{\mathrm{Im}}
$$

where $" \Delta T_{1 m}$ " is the log mean temperature difference:

$$
\Delta T_{1 m}=\left(\left[g t \_f e x-\text { feed_t }\right]-\left[g t \_e x-f e e d \_t\right]\right) /\left(\log \left[\left\{g t \_f e x-f e e d \_t\right\} /\left\{g t \_e x-f e e d \_t\right\}\right]\right)
$$

where "gt_ex" is the temperature of the exhaust gas leaving the gas turbine $\left(1000^{\circ} \mathrm{F}\right)$ and "gt_fex" is the temperature of the exhaust gas leaving the HRSG. The exhaust gas leaving the HRSG is calculated as follows:

$$
\text { gt_fex }\left({ }^{\circ} \mathrm{F}\right)=\mathrm{gt} \_\mathrm{ex}-\text { Peak Chiller Energy Consumption/(mass } x \mathrm{C}_{\mathrm{p}} \text { Gas) }
$$

where "mass" is the mass flow rate of the exhaust gas and a value of $0.25 \mathrm{Btu} /{ }^{\circ} \mathrm{F}-\mathrm{lb}$ is assumed for the exhaust gas $\mathrm{C}_{\mathrm{p}}$. The required steam flow is calculated as follows:

Steam Flow $(\mathrm{lb} / \mathrm{h})=$ Peak Chiller Energy Consumption/(Steam $\mathrm{hfg})$ 
A maximum pressure drop equivalent to 10 inches of water is assumed to occur in the HRSG, if all the energy from the exhaust gas is extracted to generate steam (i.e., if gt_fex $=300^{\circ} \mathrm{F}$ ). However, only a fraction of the exhaust flow energy is required in most cases to meet the peak energy requirements of the thermally-activated chiller:

$$
\text { Fraction of Energy Required }=\left(g t \text { ex }-g t \_f e x\right) /\left(g t \_e x-300\right)
$$

The required exhaust air flow to meet the peak chiller energy consumption is calculated as follows:

$$
\text { Exhaust Flow Rate (lbs/h) }=\text { Chiller Energy Consumption/(Cp Gas x [gt_ex - gt_fex]) }
$$

\section{B.11 Power Reduction Due to Steam Extraction}

Power is lost when a thermally-activated chiller is used with a combined-cycle power plant because the steam extracted from the combined-cycle to run the chiller would otherwise be used to generated electricity. The foregone electricity production is calculated as follows:

$$
\text { Power Reduction }(\mathrm{kW})=\left(-0.0079+0.0172 \times \log _{\mathrm{e}} \text { [Steam Pressure, psia] }\right)
$$

The amount of steam that has to be extracted is calculated as follows:

$$
\text { Steam Flow }(\mathrm{lb} / \mathrm{h})=\text { Peak Chiller Energy Consumption/(Steam hfg) }
$$





\section{Appendix C}

Complete Results 
$\pi$

.

. 


\section{Appendix C}

\section{Complete Results}

NPV and $\$ / \mathrm{kW}$ results are presented for each case evaluated in the tables that follow. The nomenclature used to define each case is the same as that described in Section 9, but is repeated here.

Each case is distinguished by its case number, chiller type, plant operating hours per day, cooling hours per day, and storage type. The case number uniquely defines one of 356 cases. Industrial turbine cases begin with an " $i$," aeroderivative turbine cases with an "a," and combined-cycle cases with a "c,", "d," "e," or "f." The four combined-cycle groups represent different combinations of plant operating hours and cooling system operating hours. The second letter of the case number, an "e" or an "r," designates a case as being evaporatively or refrigeratively cooled. The chiller type can be either aquaammonia (AA), complex compound (CC), lithium bromide $(\mathrm{LiBr})$, or vapor compression (VC). The chiller numbers refer to the specific versions of each chiller type defined in Section 6. Plant operating hours and cooling system operating hours are designated by two numbers separated by a backslash. For example, "12/4" would mean the plant runs 12 hours per day while the cooling system runs 4 hours per day. The specific power plant and cooling system schedule assumptions were defined in Section 4 . The storage type is defined by a four letter code. The first letter refers to ice or water storage, the second letter to a daily or weekly cycle, and the final two letters to a load-shifting or load-leveling design basis. 
Table C.1. Aeroderivative Turbine $\$ / \mathrm{kW}$; Uncooled Base

\begin{tabular}{||l|l|r|c|r|r|r|r|r||}
\hline \hline Case & Chiller & Ophrs & Storage & Nash. & Hous. & Minn. & Phoe. & San Fran. \\
\hline ae1 & NA & $4 / 4$ & NA & 52 & 65 & 49 & 27 & 95 \\
\hline ae2 & NA & $8 / 8$ & NA & 52 & 115 & 62 & 43 & 35 \\
\hline ar1 & AA-2 & $4 / 4$ & NA & 881 & 941 & 845 & 628 & 708 \\
\hline ar2 & AA-2 & $8 / 8$ & NA & 881 & 1034 & 921 & 738 & 530 \\
\hline ar3 & CC-2 & $4 / 4$ & NA & 313 & 331 & 304 & 232 & 306 \\
\hline ar4 & CC-2 & $8 / 8$ & NA & 313 & 364 & 328 & 273 & 221 \\
\hline ar5 & LiBr-1 & $4 / 4$ & NA & 350 & 379 & 334 & 233 & 387 \\
\hline ar6 & LiBr-1 & $8 / 8$ & NA & 350 & 430 & 372 & 286 & 220 \\
\hline ar7 & VC-2 & $4 / 4$ & NA & 273 & 291 & 262 & 193 & 254 \\
\hline ar8 & VC-2 & $8 / 8$ & NA & 273 & 326 & 288 & 231 & 180 \\
\hline ar9 & VC-1 & $4 / 4$ & IWLS & 159 & 173 & 150 & 128 & 179 \\
\hline ar10 & VC-1 & $4 / 4$ & IWLL & 156 & 170 & 147 & 125 & 177 \\
\hline ar11 & VC-1 & $4 / 4$ & IDLS & 179 & 191 & 180 & 139 & 198 \\
\hline ar12 & VC-1 & $4 / 4$ & IDLL & 172 & 184 & 173 & 133 & 192 \\
\hline ar13 & VC-1 & $8 / 8$ & IWLS & 238 & 287 & 230 & 224 & 167 \\
\hline ar14 & VC-1 & $8 / 8$ & IWLL & 217 & 263 & 209 & 203 & 152 \\
\hline ar15 & VC-1 & $8 / 8$ & IDLS & 298 & 350 & 315 & 268 & 203 \\
\hline ar16 & VC-1 & $8 / 8$ & IDLL & 251 & 301 & 267 & 225 & 172 \\
\hline ar17 & VC-2 & $4 / 4$ & WWLS & 225 & 251 & 207 & 173 & 267 \\
\hline ar18 & VC-2 & $4 / 4$ & WWLL & 219 & 244 & 201 & 167 & 261 \\
\hline ar19 & VC-2 & $4 / 4$ & WDLS & 203 & 220 & 205 & 151 & 269 \\
\hline ar20 & VC-2 & $4 / 4$ & WDLL & 196 & 212 & 198 & 144 & 261 \\
\hline ar21 & VC-2 & $8 / 8$ & WWLS & 335 & 423 & 320 & 312 & 210 \\
\hline ar22 & VC-2 & $8 / 8$ & WWLL & 302 & 385 & 288 & 280 & 191 \\
\hline ar23 & VC-2 & $8 / 8$ & WDLS & 304 & 371 & 326 & 269 & 215 \\
\hline ar24 & VC-2 & $8 / 8$ & WDLL & 263 & 326 & 283 & 231 & 185 \\
\hline \hline
\end{tabular}


Table C.2. Combined-Cycle $\$ / \mathrm{kW}$; Uncooled Base; $12 \mathrm{hr} /$ day plant; 4 or $8 \mathrm{hr} /$ day cooling

\begin{tabular}{|c|c|c|c|c|c|c|c|c|}
\hline Case & Chiller & Ophrs & Storage & Nash. & Hous. & Minn. & Phoe. & San Fran. \\
\hline cel & NA & $12 / 4$ & NA & 65 & 82 & 61 & 34 & 119 \\
\hline ce2 & NA & $12 / 8$ & NA & 65 & 145 & 78 & 54 & 44 \\
\hline ce3 & NA & $12 / 12$ & $\mathrm{NA}$ & 77 & 236 & 78 & 54 & 60 \\
\hline ce4 & NA & $24 / 4$ & $\overline{N A}$ & 65 & 82 & 61 & 34 & 119 \\
\hline $\operatorname{ce} 5$ & NA & $24 / 8$ & NA & 65 & 145 & 78 & 54 & 44 \\
\hline ce6 & NA & $24 / 12$ & NA & 77 & 1200 & 78 & 54 & 46 \\
\hline ce7. & NA & $24 / 24$ & NA & 77 & 1200 & 78 & 54 & 46 \\
\hline crl & $\mathrm{CC}-4$ & $12 / 4$ & $\mathrm{NA}$ & 392 & 434 & 368 & 241 & 302 \\
\hline cr2 & $\mathrm{CC}-4$ & $12 / 8$ & NA & 392 & 514 & 422 & 304 & 203 \\
\hline $\mathrm{cr} 3$ & $\mathrm{CC}-4$ & $12 / 4$ & WDLS & 233 & 258 & 237 & 167 & 262 \\
\hline $\mathrm{cr} 4$ & $\mathrm{CC}-4$ & $12 / 4$ & WDLL & 218 & 246 & 222 & 148 & 247 \\
\hline cr5 & $\mathrm{CC}-4$ & $12 / 8$ & WDLS & 578 & 716 & 617 & 491 & 337 \\
\hline cr6 & $\mathrm{CC}-4$ & $12 / 8$ & WDLL & 374 & 522 & 414 & 299 & 192 \\
\hline cr7 & $\mathrm{CC}-3$ & $12 / 4$ & IDLS & 269 & 294 & 273 & 205 & 246 \\
\hline cr8 & $\mathrm{CC}-3$ & $12 / 4$ & IDLL & 244 & 271 & 248 & 177 & 221 \\
\hline cr9 & $\mathrm{CC}-3$ & $12 / 8$ & IDLS & 836 & 992 & 877 & 727 & 477 \\
\hline crlo & $\mathrm{CC}-3$ & $12 / 8$ & IDLL & 501 & 660 & 544 & 410 & 244 \\
\hline $\operatorname{crl1}$ & $\mathrm{LiBr}-2$ & $12 / 4$ & NA & 432 & 489 & 399 & 243 & 381 \\
\hline $\operatorname{crl2}$ & LiBr-2 & $12 / 8$ & $\mathrm{NA}$ & 432 & 581 & 467 & 311 & 198 \\
\hline cr13 & LiBr-2 & $12 / 4$ & WDLS & 250 & 279 & 250 & 171 & 257 \\
\hline cr14 & LiBr-2 & $12 / 4$ & WDLL & 215 & 244 & 217 & 144 & 228 \\
\hline cr15 & $\mathrm{LiBr}-2$ & $12 / 8$ & WDLS & 663 & 823 & 670 & 519 & 336 \\
\hline crl6 & LiBr-2 & $12 / 8$ & WDLL & 358 & 489 & 386 & 276 & 176 \\
\hline crl7 & VC-2 & $12 / 4$ & NA & 245 & 264 & 234 & 169 & 204 \\
\hline cr18 & VC-2 & $12 / 8$ & $\mathrm{NA}$ & 245 & 296 & 259 & 203 & 148 \\
\hline cr19 & VC-1 & $12 / 4$ & IWLS & 127 & 139 & 117 & 100 & 130 \\
\hline $\operatorname{cr} 20$ & VC-1 & $12 / 4$ & IWLL & 123 & 136 & 114 & 96 & 127 \\
\hline $\mathrm{cr} 21$ & VC-1 & $12 / 4$ & IDLS & 148 & 159 & 149 & 113 & 149 \\
\hline cr22 & VC-1 & $12 / 4$ & IDLL & 140 & 151 & 141 & 105 & 142 \\
\hline $\operatorname{cr} 23$ & VC-1 & $12 / 8$ & IWLS & 202 & 247 & 193 & 188 & 130 \\
\hline cr24 & VC-1 & $12 / 8$ & IWLL & 180 & 223 & 172 & 167 & 115 \\
\hline cr25 & VC-1 & $12 / 8$ & IDLS & 267 & 317 & 282 & 237 & 169 \\
\hline cr26 & VC-1 & $12 / 8$ & IDLL & 219 & 265 & 233 & 192 & 137 \\
\hline
\end{tabular}

C. 3 
Table C.2. (contd)

\begin{tabular}{|c|c|c|c|c|c|c|c|c|}
\hline Case & Chiller & Ophrs & Storage & Nash. & Hous. & Minn. & Phoe. & San Fran. \\
\hline cr27 & $\overline{\text { VC-2 }}$ & $12 / 4$ & WWLS & 175 & 198 & 159 & 132 & 185 \\
\hline cr28 & VC-2 & $12 / 4$ & WWLL & 169 & 191 & 154 & 126 & 179 \\
\hline cr29 & $\mathrm{VC}-2$ & $12 / 4$ & WDLS & 159 & 174 & 160 & 114 & 189 \\
\hline cr30 & VC-2 & $12 / 4$ & WDLL & 152 & 166 & 153 & 108 & 180 \\
\hline cr31 & VC-2 & $12 / 8$ & WWLS & 271 & 346 & 256 & 250 & 155 \\
\hline $\operatorname{cr} 32$ & VC-2 & $12 / 8$ & WWLL & 242 & 313 & 229 & 221 & 138 \\
\hline cr33 & VC-2 & $12 / 8$ & WDLS & 252 & 311 & 270 & 219 & 163 \\
\hline cr34 & $\overline{V C-2}$ & $12 / 8$ & WDLL & 213 & 269 & 230 & 183 & 135 \\
\hline cr35 & $\overline{\mathrm{AA}-2}$ & $12 / 4$ & $\mathrm{NA}$ & 1176 & 1294 & 1105 & 745 & 800 \\
\hline$\overline{c r 36}$ & $\overline{A A-2}$ & $12 / 8$ & $\mathrm{NA}$ & 1176 & 1482 & 1249 & 912 & 578 \\
\hline$\overline{c r 37}$ & $\overline{\mathrm{AA}-2}$ & $12 / 4$ & WDLS & 540 & 607 & 551 & 378 & 513 \\
\hline$\overline{c r 38}$ & $\overline{\mathrm{AA}-2}$ & $12 / 4$ & WDLL & 439 & 502 & 450 & 297 & 422 \\
\hline cr39 & $\overline{\mathrm{AA}-2}$ & $12 / 8$ & WDLS & 1817 & 2265 & 1913 & 1487 & .898 \\
\hline cr40 & $\overline{A A-2}$ & $12 / 8$ & WDLL & 872 & 1183 & 952 & 686 & 392 \\
\hline cr41 & $\overline{\mathrm{AA}-1}$ & $12 / 4$ & IDLS & 602 & 663 & 612 & 451 & 485 \\
\hline cr42 & $\overline{\mathrm{AA}-1}$ & $12 / 4$ & IDLL & 491 & 552 & 503 & 355 & 391 \\
\hline cr43 & $\overline{A A-1}$ & $12 / 8$ & IDLS & 2177 & 2591 & 2262 & 1853 & 1136 \\
\hline cr44 & $\overline{\mathrm{AA}-1}$ & $12 / 8$ & IDLL & 1075 & 1391 & 1155 & 875 & 489 \\
\hline cr45 & CC-4/CC-5 & $12 / 4$ & $\mathrm{NA}$ & 403 & 429 & 387 & 296 & 334 \\
\hline cr46 & CC-4/CC-5 & $12 / 8$ & $N A$ & 403 & 471 & 421 & 343 & 270 \\
\hline cr47 & $\mathrm{AA}-2 / \mathrm{AA}-3$ & $12 / 4$ & $\mathrm{NA}$ & 1351 & 1450 & 1288 & 976 & 967 \\
\hline$\overline{c r 48}$ & $\mathrm{AA}-2 / \mathrm{AA}-3$ & $12 / 8$ & $\mathrm{NA}$ & 1351 & 1577 & 1405 & 1116 & 818 \\
\hline cr49 & VC-2/VC-3 & $12 / 4$ & $\mathrm{NA}$ & 287 & 300 & 279 & 229 & 257 \\
\hline cr50 & VC-2/VC-3 & $12 / 8$ & $\mathrm{NA}$ & 287 & 321 & 297 & 256 & 218 \\
\hline cr51 & $\mathrm{CC}-3 / \mathrm{CC}-6$ & $12 / 4$ & IDLS & 291 & 305 & 293 & 251 & 280 \\
\hline cr52 & $\mathrm{CC}-3 / \mathrm{CC}-6$ & $12 / 8$ & IDLS & 759 & 839 & 781 & 695 & 548 \\
\hline cr53 & $\mathrm{AA}-1 / \mathrm{AA}-3$ & $12 / 4$ & IDLS & 673 & 710 & 675 & 567 & 587 \\
\hline cr54 & AA-1/AA-3 & $12 / 8$ & IDLS & 1610 & 1799 & 1635 & 1408 & 935 \\
\hline cr55 & VC-1/VC-3 & $12 / 4$ & IWLS & 202 & 212 & 195 & 175 & 216 \\
\hline cr56 & VC-1/VC-3 & $12 / 8$ & IWLS & 252 & 284 & 247 & 241 & 203 \\
\hline cr57 & $\mathrm{VC}-1 / \mathrm{VC}-3$ & $12 / 4$ & IWLL & 201 & 211 & 194 & 173 & 215 \\
\hline cr58 & VC-1/VC-3 & $12 / 8$ & IWLL & 240 & 271 & 235 & 229 & 195 \\
\hline cr59 & VC-1/VC-3 & $12 / 4$ & IDLS & 216 & 225 & 216 & 184 & 226 \\
\hline
\end{tabular}


Table C.2. (contd)

\begin{tabular}{|l|l|r|l|r|r|r|r|r||}
\hline \hline Case & Chiller & Ophrs & Storage & Nash. & Hous. & Minn. & Phoe. & San Fran. \\
\hline \hline cr60 & VC-1/VC-3 & $12 / 8$ & IDLS & 296 & 329 & 306 & 273 & 227 \\
\hline cr61 & VC-1/VC-3 & $12 / 4$ & IDLL & 213 & 222 & 213 & 181 & 223 \\
\hline cr62 & VC-1/VC-3 & $12 / 8$ & IDLL & 267 & 299 & 277 & 246 & 209 \\
\hline cr63 & CC-3/CC-6 & $12 / 4$ & IDLL & 285 & 301 & 288 & 242 & 279 \\
\hline cr64 & CC-3/CC-6 & $12 / 8$ & IDLL & 589 & 669 & 613 & 537 & 446 \\
\hline cr65 & AA-1/AA-3 & $12 / 4$ & IDLL & 815 & 875 & 817 & 651 & 724 \\
\hline cr66 & AA-1/AA-3 & $12 / 8$ & IDLL & 1269 & 1508 & 1326 & 1081 & 745 \\
\hline cr67 & CC-2 & $12 / 4$ & NA & 266 & 286 & 254 & 181 & 229 \\
\hline cr68 & CC-2 & $12 / 8$ & NA & 266 & 325 & 282 & 220 & 161 \\
\hline cr69 & CC-2 & $12 / 4$ & WDLS & 221 & 243 & 224 & 159 & 253 \\
\hline cr70 & CC-2 & $12 / 4$ & WDLL & 195 & 216 & 197 & 136 & 226 \\
\hline cr71 & CC-2 & $12 / 8$ & WDLS & 519 & 641 & 554 & 443 & 310 \\
\hline cr72 & CC-2 & $12 / 8$ & WDLL & 295 & 386 & 321 & 245 & 170 \\
\hline cr73 & CC-1 & $12 / 4$ & IDLS & 254 & 276 & 258 & 194 & 236 \\
\hline cr74 & CC-1 & $12 / 4$ & IDLL & 214 & 235 & 218 & 159 & 202 \\
\hline cr75 & CC-1 & $12 / 8$ & IDLS & 766 & 908 & 805 & 668 & 444 \\
\hline cr76 & CC-1 & $12 / 8$ & IDLL & 389 & 482 & 415 & 330 & 214 \\
\hline cr77 & CC-2/CC-5 & $12 / 4$ & NA & 314 & 329 & 305 & 245 & 290 \\
\hline cr78 & CC-2/CC-5 & $12 / 8$ & NA & 314 & 355 & 325 & 279 & 237 \\
\hline cr79 & CC-1/CC-6 & $12 / 4$ & IDLS & 282 & 295 & 284 & 244 & 276 \\
\hline cr80 & CC-1/CC-6 & $12 / 8$ & IDLS & 718 & 791 & 738 & 659 & 530 \\
\hline cr81 & CC-1/CC-6 & $12 / 4$ & IDLL & 227 & 238 & 229 & 193 & 219 \\
\hline cr82 & CC-1/CC-6 & $12 / 8$ & IDLL & 339 & 383 & 352 & 307 & 240 \\
\hline cr83 & VC-2/CC-5 & $12 / 4$ & NA & 299 & 313 & 291 & 235 & 276 \\
\hline cr84 & VC-2/CC-5 & $12 / 8$ & NA & 299 & 337 & 310 & 266 & 227 \\
\hline cr85 & VC-1/CC-6 & $12 / 4$ & IWLL & 213 & 222 & 208 & 189 & 238 \\
\hline cr86 & VC-2/CC-6 & $12 / 8$ & IWLL & 380 & 418 & 379 & 371 & 357 \\
\hline \hline
\end{tabular}


Table C.3. Combined-Cycle $\$ / \mathrm{kW}$; Uncooled Base; $12 \mathrm{hr} /$ day plant; $12 \mathrm{hr} /$ day cooling

\begin{tabular}{|l|l|r|c|r|r|r|r|r||}
\hline Case & Chiller & Ophrs & Storage & Nash. & Hous. & Minn. & Phoe. & San Fran. \\
\hline \hline dr1 & CC-4 & $12 / 12$ & NA & 435 & 566 & 422 & 304 & 251 \\
\hline dr2 & LiBr-2 & $12 / 12$ & NA & 520 & 693 & 491 & 317 & 233 \\
\hline dr3 & AA-2 & $12 / 12$ & NA & 1295 & 1599 & 1249 & 912 & 704 \\
\hline dr4 & VC-2 & $12 / 12$ & NA & 265 & 316 & 259 & 203 & 175 \\
\hline dr5 & VC-1 & $12 / 12$ & IWLS & 309 & 388 & 281 & 278 & 209 \\
\hline dr6 & VC-1 & $12 / 12$ & IWLL & 246 & 316 & 223 & 219 & 165 \\
\hline dr7 & VC-1 & $12 / 12$ & IDLS & 465 & 555 & 462 & 393 & 307 \\
\hline dr8 & VC-1 & $12 / 12$ & IDLL & 310 & 382 & 308 & 256 & 200 \\
\hline dr9 & VC-2 & $12 / 12$ & WWLS & 396 & 525 & 355 & 350 & 236 \\
\hline dr10 & VC-2 & $12 / 12$ & WWLL & 320 & 434 & 286 & 278 & 189 \\
\hline dr11 & VC-2 & $12 / 12$ & WDLS & 386 & 483 & 384 & 315 & 260 \\
\hline dr12 & VC-2 & $12 / 12$ & WDLL & 274 & 356 & 273 & 219 & 180 \\
\hline dr13 & CC-4/CC-5 & $12 / 12$ & NA & 430 & 495 & 421 & 343 & 304 \\
\hline dr14 & AA-2/AA-3 & $12 / 12$ & NA & 1450 & 1650 & 1406 & 1116 & 918 \\
\hline dr15 & VC-2/VC-3 & $12 / 12$ & NA & 301 & 332 & 297 & 256 & 238 \\
\hline dr16 & VC-1/VC-3 & $12 / 12$ & IWLL & 285 & 331 & 270 & 264 & 229 \\
\hline dr17 & CC-2 & $12 / 12$ & NA & 287 & 348 & 282 & 220 & 193 \\
\hline dr18 & CC-2/CC-5 & $12 / 12$ & NA & 330 & 370 & 326 & 279 & 262 \\
\hline dr19 & VC-2/CC-5 & $12 / 12$ & NA & 314 & 350 & 310 & 266 & 251 \\
\hline dr20 & VC-2/CC-5 & $12 / 12$ & IWLL & 297 & 348 & 280 & 274 & 241 \\
\hline \hline
\end{tabular}


Table C.4. Combined-Cycle \$/kW; Uncooled Base; $24 \mathrm{hr} /$ day plant; 4 or 8 or $12 \mathrm{hr} /$ day cooling

\begin{tabular}{|c|c|c|c|c|c|c|c|c|}
\hline Case & Chiller & Ophrs & Storage & Nash. & Hous. & Minn. & Phoe. & San Fran. \\
\hline erl & CC-4 & $24 / 4$ & NA & 392 & 434 & 368 & 241 & 302 \\
\hline er2 & CC-4 & $24 / 8$ & NA & 392 & 514 & 422 & 304 & 203 \\
\hline er3 & $\mathrm{CC}-4$ & $24 / 12$ & NA & 435 & 723 & 422 & 304 & 223 \\
\hline er4 & CC-4 & $24 / 4$ & WDLS & 167 & 182 & 168 & 120 & 197 \\
\hline er5 & CC-4 & $24 / 4$ & WDLL & 166 & 183 & 168 & 116 & 197 \\
\hline er6 & CC-4 & $24 / 8$ & WDLS & 268 & 332 & 288 & 233 & 172 \\
\hline er7 & CC-4 & $24 / 8$ & WDLL & 249 & 322 & 271 & 210 & 150 \\
\hline er8 & CC-4 & $24 / 12$ & WDLS & 417 & 584 & 415 & 341 & 239 \\
\hline er9 & $\mathrm{CC}-4$ & $24 / 12$ & WDLL & 345 & 553 & 342 & 265 & 178 \\
\hline er10 & $\mathrm{CC}-3$ & $24 / 4$ & IDLS & 153 & 166 & 154 & 117 & 153 \\
\hline er11 & $\mathrm{CC}-3$ & $24 / 4$ & IDLL & 152 & 165 & 153 & 113 & 151 \\
\hline er12 & $\mathrm{CC}-3$ & $24 / 8$ & IDLS & 278 & 331 & 294 & 246 & 173 \\
\hline er13 & $\mathrm{CC}-3$ & $24 / 8$ & IDLL & 252 & 312 & 270 & 218 & 148 \\
\hline er14 & $\mathrm{CC}-3$ & $24 / 12$ & IDLS & 484 & 631 & 481 & 408 & 282 \\
\hline er15 & CC-3 & $24 / 12$ & IDLL & 381 & 554 & 378 & 304 & 200 \\
\hline er16 & $\mathrm{LiBr}-2$ & $24 / 4$ & NA & 432 & 489 & 399 & 243 & 381 \\
\hline er17 & $\mathrm{LiBr}-2$ & $24 / 8$ & NA & 432 & 581 & 467 & 311 & 198 \\
\hline er18 & $\mathrm{LiBr}-2$ & $24 / 12$ & NA & 520 & 932 & 491 & 317 & 200 \\
\hline er19 & LiBr-2 & $24 / 4$ & WDLS & 168 & 187 & 170 & 119 & 193 \\
\hline er20 & $\mathrm{LiBr}-2$ & $24 / 4$ & WDLL & 162 & 181 & 164 & 113 & 187 \\
\hline er21 & $\mathrm{LiBr}-2$ & $24 / 8$ & WDLS & 274 & 352 & 293 & 235 & 169 \\
\hline er22 & $\mathrm{LiBr}-2$ & $24 / 8$ & WDLL & 240 & 317 & 260 & 201 & 143 \\
\hline er23 & $\mathrm{LiBr}-2$ & $24 / 12$ & WDLS & 428 & 638 & 429 & 344 & 237 \\
\hline er24 & LiBr-2 & $24 / 12$ & WDLL & 324 & 515 & 321 & 247 & 167 \\
\hline er25 & VC-2 & $24 / 4$ & $\mathrm{NA}$ & 245 & 264 & 234 & 169 & 204 \\
\hline er26 & VC-2 & $24 / 8$ & NA & 245 & 296 & 259 & 203 & 148 \\
\hline er27 & VC-2 & $24 / 12$ & NA & 265 & 368 & 259 & 203 & 159 \\
\hline er28 & VC-1 & $24 / 4$ & IWLS & 128 & 141 & 119 & 101 & 131 \\
\hline er29 & VC-1 & $24 / 4$ & IWLL & 123 & 136 & 114 & 96 & 127 \\
\hline er30 & VC-1 & $24 / 4$ & IDLS & 148 & 159 & 149 & 113 & 149 \\
\hline er31 & VC-1 & $24 / 4$ & IDLL & 140 & 151 & 141 & 105 & 142 \\
\hline er32 & VC-1 & $24 / 8$ & IWLS & 213 & 260 & 202 & 198 & 135 \\
\hline er33 & VC-1 & $24 / 8$ & IWLL & 180 & 223 & 172 & 167 & 115 \\
\hline
\end{tabular}

C. 7 
Table C.4. (contd)

\begin{tabular}{|c|c|c|c|c|c|c|c|c|}
\hline Case & Chiller & Ophrs & Storage & Nash. & Hous. & Minn. & Phoe. & San Fran \\
\hline er34 & VC-1 & $24 / 8$ & IDLS & 267 & 317 & 282 & 237 & 169 \\
\hline er35 & VC-1 & $24 / 8$ & IDLL & 219 & 265 & 233 & 192 & 137 \\
\hline er36 & VC-1 & $24 / 12$ & IWLS & 462 & 620 & 422 & 403 & 256 \\
\hline er37 & VC-1 & $24 / 12$ & IWLL & 325 & 458 & 295 & 279 & 178 \\
\hline er38 & VC-1 & $24 / 12$ & IDLS & 465 & 601 & 462 & 393 & 277 \\
\hline er39 & VC-1 & $24 / 12$ & IDLL & 310 & 422 & 308 & 256 & 179 \\
\hline er40 & VC-2 & $24 / 4$ & WWLS & 172 & 194 & 157 & 130 & 182 \\
\hline er4l & VC-2 & $24 / 4$ & WWLL & 169 & 191 & 154 & 126 & 179 \\
\hline er42 & VC-2 & $24 / 4$ & WDLS & 159 & 174 & 160 & 114 & 189 \\
\hline er43 & VC-2 & $24 / 4$ & WDLL & 152 & 166 & 153 & 108 & 180 \\
\hline er44 & VC-2 & $24 / 8$ & WWLS & 263 & 335 & 248 & 241 & 150 \\
\hline er45 & VC-2 & $24 / 8$ & WWLL & 242 & 313 & 229 & 221 & 138 \\
\hline er46 & VC-2 & $24 / 8$ & WDLS & 252 & 311 & 270 & 219 & 163 \\
\hline er47 & VC-2 & $24 / 8$ & WDLL & 213 & 269 & 230 & 183 & 135 \\
\hline er48 & VC-2 & $24 / 12$ & WWLS & 487 & 708 & 441 & 416 & 226 \\
\hline er49 & VC-2 & $24 / 12$ & WWLL & 411 & 629 & 369 & 345 & 188 \\
\hline er50 & VC-2 & $24 / 12$ & WDLS & 386 & 540 & 384 & 315 & 223 \\
\hline er51 & VC-2 & $24 / 12$ & WDLL & 274 & 407 & 273 & 219 & 155 \\
\hline er52 & AA-2 & $24 / 4$ & $\mathrm{NA}$ & 1176 & 1294 & 1105 & 745 & $\overline{800}$ \\
\hline er53 & AA-2 & $24 / 8$ & NA & 1176 & 1482 & 1249 & 912 & 578 \\
\hline er54 & $\mathrm{AA}-2$ & $24 / 12$ & NA & 1295 & 1944 & 1249 & 912 & 642 \\
\hline er55 & $\widehat{A A-2}$ & $24 / 4$ & WDLS & 286 & 320 & 292 & 204 & 297 \\
\hline er56 & $\widehat{A A-2}$ & $24 / 4$ & WDLL & 268 & 302 & 274 & 188 & 280 \\
\hline er57 & AA-2 & $24 / 8$ & WDLS & 568 & 719 & 610 & 482 & 311 \\
\hline er58 & $\mathrm{AA}-2$ & $24 / 8$ & WDLL & 466 & 607 & 505 & 386 & 245 \\
\hline er59 & AA-2 & $24 / 12$ & WDLS & 1029 & 1470 & 1022 & 820 & 500 \\
\hline er60 & $\widehat{A A-2}$ & $24 / 12$ & WDLL & 699 & 1083 & 690 & 531 & $\overline{314}$ \\
\hline er61 & $A A-1$ & $24 / 4$ & IDLS & 283 & 312 & 288 & 215 & 247 \\
\hline er62 & $\mathrm{AA}-1$ & $24 / 4$ & IDLL & 266 & 295 & 271 & 198 & 232 \\
\hline er63 & AA-1 & $24 / 8$ & IDLS & 604 & 731 & 638 & 528 & 335 \\
\hline er64 & $\widehat{A A-1}$ & $24 / 8$ & IDLL & 497 & 619 & 530 & 424 & 262 \\
\hline er65 & AA-1 & $24 / 12$ & IDLS & 1144 & 1514 & 1137 & 954 & 600 \\
\hline er66 & AA-1 & $24 / 12$ & IDLL & 784 & 1119 & 775 & 622 & 376 \\
\hline
\end{tabular}

C.8 
Table C.4. (contd)

\begin{tabular}{|c|c|c|c|c|c|c|c|c|}
\hline Case & Chiller & Ophrs & Storage & Nash. & Hous. & Minn. & Phoe. & San Fran. \\
\hline er67 & CC-4/CC-5 & $24 / 4$ & NA & 403 & 429 & 387 & 296 & 334 \\
\hline er68 & CC-4/CC-5 & $24 / 8$ & $\overline{N A}$ & 403 & 471 & 421 & 343 & 270 \\
\hline er69 & CC- $4 / C C-5$ & $24 / 12$ & $\mathrm{NA}$ & 430 & 562 & 421 & 343 & 284 \\
\hline er70 & $\mathrm{AA}-2 / \mathrm{AA}-3$ & $24 / 4$ & $\mathrm{NA}$ & 1351 & 1450 & 1288 & 976 & 967 \\
\hline er71 & AA-2/AA-3 & $24 / 8$ & $\mathrm{NA}$ & 1351 & 1577 & 1405 & 1116 & 818 \\
\hline er72 & $\mathrm{AA}-2 / \mathrm{AA}-3$ & $24 / 12$ & NA & 1450 & 1872 & 1406 & 1116 & 872 \\
\hline er73 & VC-2/VC-3 & $24 / 4$ & $\mathrm{NA}$ & 287 & 300 & 279 & 229 & 257 \\
\hline er74 & $\mathrm{VC}-2 / \mathrm{VC}-3$ & $24 / 8$ & NA & 287 & 321 & 297 & 256 & 218 \\
\hline er75 & VC-2/VC-3 & $24 / 12$ & NA & 301 & 362 & 297 & 256 & 226 \\
\hline er76 & $\mathrm{CC}-3$ & $24 / 4$ & IWLS & 132 & 146 & 122 & 104 & 134 \\
\hline er77 & $\mathrm{CC}-3$ & $24 / 4$ & IWLL & 130 & 144 & 120 & 101 & 132 \\
\hline er78 & $\mathrm{CC}-3$ & $24 / 8$ & IWLS & 220 & 269 & 208 & 204 & 138 \\
\hline er79 & $\mathrm{CC}-3$ & $24 / 8$ & IWLL & 198 & 249 & 187 & .182 & 121 \\
\hline er80 & $\mathrm{CC}-3$ & $24 / 12$ & IWLS & 479 & 645 & 435 & 418 & 261 \\
\hline er81 & $\mathrm{CC}-3$ & $24 / 12$ & IWLL & 390 & 588 & 347 & 327 & 194 \\
\hline er82 & AA-1 & $24 / 4$ & IWLS & 215 & 243 & 193 & 171 & 190 \\
\hline er83 & AA-1 & $24 / 4$ & IWLL & 201 & 229 & 180 & 158 & 180 \\
\hline er84 & $\mathrm{AA}-1$ & $24 / 8$ & IWLS & 424 & 531 & 387 & 393 & 234 \\
\hline er85 & AA-1 & $24 / 8$ & IWLL & 344 & 438 & 313 & 315 & 187 \\
\hline er86 & AA-1 & $24 / 12$ & IWLS & 1072 & 1467 & 953 & 928 & 520 \\
\hline er87 & $\mathrm{AA}^{*}-1$ & $24 / 12$ & IWLL. & 739 & 1100 & 643 & 618 & 332 \\
\hline er88 & $\mathrm{CC}-3 / \mathrm{CC}-6$ & $24 / 4$ & IWLS & 641 & 655 & 635 & 583 & 785 \\
\hline er89 & $\mathrm{CC}-3 / \mathrm{CC}-6$ & $24 / 8$ & IWLS & 1244 & 1330 & 1260 & .1233 & 1290 \\
\hline er90 & $\mathrm{CC}-3 / \mathrm{CC}-6$ & $24 / 12$ & IWLS & 2647 & 2973 & 2645 & 2583 & 2667 \\
\hline er91 & $\mathrm{CC}-3 / \mathrm{CC}-6$ & $24 / 4$ & IWLL & 662 & 679 & 654 & 599 & 804 \\
\hline er92 & $\mathrm{CC}-3 / \mathrm{CC}-6$ & $24 / 8$ & IWLL & 1323 & 1432 & 1332 & 1306 & 1340 \\
\hline er93 & $\mathrm{CC}-3 / \mathrm{CC}-6$ & $24 / 12$ & IWLL & 3061 & 3578 & 3013 & 2935 & 2895 \\
\hline er94 & $\mathrm{CC}-3 / \mathrm{CC}-6$ & $24 / 4$ & IDLS & 218 & 226 & 219 & 191 & 233 \\
\hline er95 & $\mathrm{CC}-3 / \mathrm{CC}-6$ & $24 / 8$ & IDLS & 405 & 441 & 417 & 387 & 358 \\
\hline er96 & $\mathrm{CC}-3 / \mathrm{CC}-6$ & $24 / 12$ & IDLS & 646 & 737 & 646 & 600 & 543 \\
\hline er97 & CC-3/CC-6 & $24 / 4$ & IDLL & 223 & 232 & 224 & 194 & 238 \\
\hline er98 & $\mathrm{CC}-3 / \mathrm{CC}-6$ & $24 / 8$ & IDLL & 415 & 457 & 428 & 393 & 363 \\
\hline er99 & CC-3/CC-6 & $24 / 12$ & $\overline{\text { IDLL }}$ & 644 & 757 & 643 & 590 & 537 \\
\hline
\end{tabular}


Table C.4. (contd)

\begin{tabular}{|c|c|c|c|c|c|c|c|c|}
\hline Case & Chiller & Ophrs & Storage & Nash. & Hous. & Minn. & Phoe. & San Fran. \\
\hline er100 & AA-1/AA-3 & $24 / 4$ & IWLS & 433 & 457 & 414 & 385 & 445 \\
\hline er101 & AA-1/AA-3 & $24 / 8$ & IWLS & 556 & 629 & 531 & 534 & 430 \\
\hline er102 & $\mathrm{AA}-1 / \mathrm{AA}-3$ & $24 / 12$ & IWLS & 556 & 629 & 531 & 534 & 430 \\
\hline er103 & $\mathrm{AA}-1 / \mathrm{AA}-3$ & $24 / 4$ & IWLL & 558 & 597 & 531 & 475 & 576 \\
\hline er104 & AA-1/AA-3 & $24 / 8$ & IWLL & 677 & 789 & 653 & 636 & 514 \\
\hline er105 & AA-1/AA-3 & $24 / 12$ & IWLL & 677 & 789 & 653 & 636 & $\overline{514}$ \\
\hline er106 & AA-1/AA-3 & $24 / 4$ & IDLS & 477 & 500 & 479 & 417 & 476 \\
\hline er107 & AA-1/AA-3 & $24 / 8$ & IDLS & 665 & 746 & 685 & 618 & 491 \\
\hline er108 & AA-1/AA-3 & $24 / 12$ & IDLS & 981 & 1161 & 976 & 868 & 627 \\
\hline er109 & AA-1/AA-3 & $24 / 4$ & IDLL & 620 & 658 & 621 & 515 & 618 \\
\hline er110 & AA-1/AÁ-3 & $24 / 8$ & IDLL & 811 & 941 & 844 & 732 & 577 \\
\hline er111 & AA-1/AA-3 & $24 / 12$ & IDLL & 1048 & 1329 & 1037 & 885 & 657 \\
\hline er112 & VC-1/VC-3 & $24 / 4$ & IWLS & 203 & 213 & 196 & 176 & 217 \\
\hline er113 & VC-1/VC-3 & $24 / 8$ & IWLS & 259 & 293 & 253 & 247 & 206 \\
\hline er114 & VC-1/VC-3 & $24 / 12$ & IWLS & 427 & 517 & 399 & 384 & 281 \\
\hline er115 & VC-1/VC-3 & $24 / 4$ & IWLL & 201 & 211 & 194 & 173 & 215 \\
\hline er116 & VC-1/VC-3 & $24 / 8$ & IWLL & 240 & 271 & 235 & 229 & 195 \\
\hline er117 & VC-1/VC-3 & $24 / 12$ & IWLL & 337 & 414 & 317 & 303 & 234 \\
\hline erl18 & VC-1/VC-3 & $24 / 4$ & IDLS & 216 & 225 & 216 & 184 & 226 \\
\hline er119 & VC-1/VC-3 & $24 / 8$ & IDLS & 296 & 329 & 306 & 273 & 227 \\
\hline er120 & VC-1/VC-3 & $24 / 12$ & IDLS & 429 & 506 & 426 & 377 & 294 \\
\hline er121 & VC-1/VC-3 & $24 / 4$ & IDLL & 213 & 222 & 213 & 181 & 223 \\
\hline er122 & $\mathrm{VC}-1 / \mathrm{VC}-3$ & $24 / 8$ & IDLL & 267 & 299 & 277 & 246 & 209 \\
\hline er123 & $\mathrm{VC}-1 / \mathrm{VC}-3$ & $24 / 12$ & IDLL & 328 & 394 & 326 & 289 & 236 \\
\hline er124 & $\mathrm{CC}-2$ & $24 / 4$ & $\overline{\mathrm{NA}}$ & 266 & 286 & 254 & 181 & 229 \\
\hline er125 & CC-2 & $24 / 8$ & $\mathrm{NA}$ & 266 & 325 & 282 & 220 & 161 \\
\hline er126 & $\mathrm{CC}-2$ & $24 / 12$ & $\mathrm{NA}$ & 287 & 409 & 282 & 220 & 174 \\
\hline er127 & $C C-2$ & $24 / 4$ & WDLS & 162 & 177 & 164 & 117 & 194 \\
\hline er128 & CC-2. & $24 / 4$ & WDLL & 157 & 172 & 158 & 111 & 189 \\
\hline er129 & $\overline{C C}-2$ & $24 / 8$ & WDLS & 256 & 316 & 274 & 223 & 167 \\
\hline er130 & $\mathrm{CC}-2$ & $24 / 8$ & WDLL & 223 & 282 & 241 & 191 & 142 \\
\hline er131 & $\mathrm{CC}-2$ & $24 / 12$ & WDLS & 389 & 545 & 388 & 319 & 228 \\
\hline er132 & CC-2 & $24 / 12$ & $\overline{\text { WDLL }}$ & 291 & 437 & 290 & 231 & 164 \\
\hline
\end{tabular}

C. 10 
Table C.4. (contd)

\begin{tabular}{|c|c|c|c|c|c|c|c|c|}
\hline Case & Chiller & Ophrs & Storage & Nash. & Hous. & Minn. & Phoe. & San Fran. \\
\hline er133 & CC-1 & $24 / 4$ & IDLS & 148 & 159 & 149 & 113 & 149 \\
\hline er134 & $\mathrm{CC}-1$ & $24 / 4$ & IDLL & 142 & 154 & 143 & 107 & 144 \\
\hline er135 & CC-1 & $24 / 8$ & IDLS & 263 & 312 & 278 & 233 & 166 \\
\hline er136 & CC-1 & $24 / 8$ & IDLL & 222 & 269 & 236 & 194 & 138 \\
\hline er137 & CC-1 & $24 / 12$ & IDLS & 451 & 586 & 448 & 381 & 268 \\
\hline er138 & CC-1 & $24 / 12$ & IDLL & 315 & 433 & 313 & 259 & 181 \\
\hline er139 & CC-2/CC-5 & $24 / 4$ & $\mathrm{NA}$ & 314 & 329 & 305 & 245 & 290 \\
\hline er140 & CC-2/CC-5 & $24 / 8$ & $\mathrm{NA}$ & 314 & 355 & 325 & 279 & 237 \\
\hline er14I & CC-2/CC-5 & $24 / 12$ & $\mathrm{NA}$ & 330 & 407 & 326 & 279 & $\overline{246}$ \\
\hline er142 & $\mathrm{CC}-1$ & $24 / 4$ & IWLS & 129 & 142 & 120 & 102 & 132 \\
\hline er143 & CC-1 & $24 / 4$ & IWLL & 125 & 137 & 115 & 97 & 129 \\
\hline er144 & $\mathrm{CC}-1$ & $24 / 8$ & IWLS & 211 & 258 & 200 & 196 & 134 \\
\hline er145 & CC-1 & $24 / 8$ & IWLL & 183 & 226 & 174 & 169 & 117 \\
\hline er146 & $\mathrm{CC}-1$ & $24 / 12$ & IWLS & 449 & 605 & 410 & 393 & 249 \\
\hline er147 & CC-1 & $24 / 12$ & IWLL & 331 & 471 & 300 & 283 & 179 \\
\hline er148 & CC-1/CC- 6 & $24 / 4$ & IWLS & 639 & 653 & 634 & 581 & 784 \\
\hline er149 & CC-1/CC-6 & $24 / 8$ & IWLS & 1239 & 1324 & 1255 & 1228 & 1288 \\
\hline er150 & CC-1/CC-6 & $24 / 12$ & IWLS & 2630 & 2952 & 2630 & 2568 & 2660 \\
\hline er151 & CC-1/CC-6 & $24 / 4$ & IWLL & 652 & 667 & 645 & 591 & 798 \\
\hline er152 & $\mathrm{CC}-1 / \mathrm{CC}-6$ & $24 / 8$ & IWLL & 1284 & 1381 & 1298 & 1271 & 1322 \\
\hline erl53 & CC-1/CC-6 & $24 / 12$ & IWLL & 2859 & 3281 & 2841 & 2768 & 2816 \\
\hline er154 & CC-1/CC-6 & $24 / 4$ & IDLS & 215 & 222 & 216 & 189 & 231 \\
\hline er155 & CC-1/CC-6 & $24 / 8$ & IDLS & 396 & 431 & 408 & 379 & 354 \\
\hline er156 & CC-1/CC-6 & $24 / 12$ & IDLS & 627 & 714 & 627 & 584 & 535 \\
\hline er157 & CC-1/CC-6 & $24 / 4$ & IDLL & 216 & 224 & 217 & 189 & 234 \\
\hline er158 & $\mathrm{CC}-1 / \mathrm{CC}-6$ & $24 / 8$ & IDLL & 390 & 426 & 402 & 373 & 353 \\
\hline er159 & CC-1/CC-6 & $24 / 12$ & IDLL & 587 & 680 & 588 & 547 & 516 \\
\hline er160 & VC-2/CC-5 & $24 / 4$ & $\overline{N A}$ & 299 & 313 & 291 & 235 & 276 \\
\hline er161 & VC-2/CC-5 & $24 / 8$ & $\mathrm{NA}$ & 299 & 337 & 310 & 266 & 227 \\
\hline er162 & VC-2/CC-5 & $24 / 12$ & $\mathrm{NA}$ & 314 & 384 & 310 & 266 & 235 \\
\hline er163 & VC-1/CC-5 & $24 / 4$ & IWLL & 207 & 215 & 202 & 184 & 229 \\
\hline er164 & $V C-1 / C C-5$ & $24 / 8$ & IWLL & 364 & 398 & 362 & 355 & 340 \\
\hline er165 & VC-1/CC-5 & $24 / 12$ & IWLL & 588 & 688 & 571 & 555 & 510 \\
\hline
\end{tabular}

C. 11 
Table C.5. Combined-Cycle \$/kW; Uncooled Base; $24 \mathrm{hr} /$ day plant; $24 \mathrm{hr} /$ day cooling

\begin{tabular}{|l|l|r|r|r|r|r|r|r||}
\hline \hline Case & Chiller & Ophrs & Storage & Nash. & Hous. & . Minn. & Phoe. & San Fran. \\
\hline \hline fr1 & CC-4 & $24 / 24$ & NA & 435 & 723 & 422 & 304 & 223 \\
\hline fr2 & LiBr-2 & $24 / 24$ & NA & 520 & 932 & 491 & 317 & 200 \\
\hline fr3 & AA-2 & $24 / 24$ & NA & 1295 & 1944 & 1249 & 912 & 642 \\
\hline fr4 & VC-2 & $24 / 24$ & NA & 265 & 368 & 259 & 203 & 159 \\
\hline fr5 & CC-4/CC-5 & $24 / 24$ & NA & 430 & 563 & 421 & 343 & 285 \\
\hline fr6 & AA-2/AA-3 & $24 / 24$ & NA & 1451 & 1873 & 1406 & 1116 & 874 \\
\hline fr7 & VC-2/VC-3 & $24 / 24$ & NA & 301 & 362 & 297 & 256 & 226 \\
\hline fr8 & CC-2 & $24 / 24$ & NA & 287 & 409 & 282 & 220 & 174 \\
\hline fr9 & CC-2/CC-5 & $24 / 24$ & NA & 330 & 407 & 326 & 279 & 246 \\
\hline fr10 & VC-2/CC-5 & $24 / 24$ & NA & 314 & 385 & 310 & 266 & 235 \\
\hline
\end{tabular}


Table C.6. Industrial Turbine \$/kW; Uncooled Base

\begin{tabular}{|c|c|c|c|c|c|c|c|c|}
\hline Case & Chiller & Ophrs & Storage & Nash. & Hous. & Minn. & Phoe. & San Fran. \\
\hline iel & NA & $4 / 4$ & NA & 68 & 85 & 64 & 36 & 124 \\
\hline ie2 & $\mathrm{NA}$ & $8 / 8$ & $\mathrm{NA}$ & 68 & 151 & 81 & 56 & 46 \\
\hline irl & $\overline{A A-2}$ & $4 / 4$ & $\mathrm{NA}$ & 1075 & 1151 & 1029 & 758 & 843 \\
\hline ir2 & $\overline{\mathrm{AA}-2}$ & $8 / 8$ & $\mathrm{NA}$ & 1075 & 1268 & 1125 & 893 & 628 \\
\hline ir3 & $\mathrm{CC}-2$ & $4 / 4$ & $\mathrm{NA}$ & 353 & 375 & 341 & 257 & 327 \\
\hline ir4 & $\overline{C C-2}$ & $8 / 8$ & $\overline{\mathrm{NA}}$ & 353 & 414 & 371 & 304 & 236 \\
\hline ir5 & $\mathrm{LiBr}-\mathrm{I}$ & $4 / 4$ & $\mathrm{NA}$ & 397 & 432 & 376 & 255 & 407 \\
\hline$\overline{i r 6}$ & LiBr-l & $8 / 8$ & NA & 397 & 493 & 422 & 315 & 227 \\
\hline ir7 & VC-2 & $4 / 4$ & $\mathrm{NA}$ & 307 & 331 & 293 & 209 & 263 \\
\hline ir8 & VC-2 & $8 / 8$ & $\mathrm{NA}$ & 307 & 374 & 325 & 253 & 186 \\
\hline ir9 & VC-1 & $4 / 4$ & IWLS & 158 & 174 & 147 & 125 & 169 \\
\hline $\operatorname{ir} 10$ & $\mathrm{VC}-1$ & $4 / 4$ & IWLL & 155 & 170 & 144 & 122 & 165 \\
\hline irl1 & VC-1 & $4 / 4$ & IDLS & 182 & 196 & 184 & 140 & 191 \\
\hline ir12 & VC-1 & $4 / 4$ & IDLL & 175 & 189 & 176 & 132 & 184 \\
\hline ir13 & VC-1 & $8 / 8$ & IWLS & 249 & 302 & 237 & 232 & 164 \\
\hline irl4 & VC-1 & $8 / 8$ & IWLL & 225 & 277 & 215 & 208 & 147 \\
\hline ir15 & VC-1 & $8 / 8$ & IDLS & 323 & 382 & 341 & 287 & 209 \\
\hline ir16 & VC-1 & $8 / 8$ & IDLL & 271 & 328 & 288 & 238 & 172 \\
\hline ir17 & $\mathrm{VC}-2$ & $4 / 4$ & WWLS & 221 & 248 & 202 & 167 & 243 \\
\hline ir18 & VC-2 & $4 / 4$ & WWLL & 214 & 242 & 195 & 161 & 237 \\
\hline ir19 & VC-2 & $4 / 4$ & WDLS & 200 & 218 & 201 & 144 & 247 \\
\hline ir20 & VC-2 & $4 / 4$ & WDLL & 192 & 210 & 194 & 137 & 238 \\
\hline ir21 & VC-2 & $8 / 8$ & WWLS & 339 & 431 & 321 & 313 & 199 \\
\hline ir22 & VC-2 & $8 / 8$ & WWLL & 305 & 394 & 289 & 279 & 178 \\
\hline ir23 & VC-2 & $8 / 8$ & WDLS & 311 & 384 & 334 & 272 & 206 \\
\hline ir24 & VC-2 & $8 / 8$ & WDLL & 268 & 339 & 290 & 231 & 174 \\
\hline ir 25 & $\mathrm{CC}-2 / \mathrm{CC}-5$ & $4 / 4$ & $\mathrm{NA}$ & 413 & 425 & 407 & 352 & $\overline{425}$ \\
\hline ir26 & $\mathrm{CC}-2 / \mathrm{CC}-5$ & $8 / 8$ & NA & 413 & 448 & 424 & 387 & 362 \\
\hline ir27 & $\mathrm{AA}-2 / \mathrm{AA}-3$ & $4 / 4$ & $\mathrm{NA}$ & 1126 & 1172 & 1096 & 919 & 963 \\
\hline ir28 & AA-2/AA-3 & $8 / 8$ & $\overline{\mathrm{NA}}$ & 1126 & 1234 & 1154 & 1008 & 842 \\
\hline ir29 & VC-2/VC-3 & $4 / 4$ & NA & 367 & 385 & 356 & 289 & 330 \\
\hline ir30 & VC-2/VC-3 & $8 / 8$ & NA & 367 & 413 & 380 & 325 & 276 \\
\hline ir31 & VC-1/VC-3 & $4 / 4$ & IWLS & 254 & 266 & 246 & 219 & 276 \\
\hline
\end{tabular}

C. 13 
Table C.6. (contd)

\begin{tabular}{||c|c|r|r|r|r|r|r|r||}
\hline Case & Chiller & Ophrs & Storage & Nash. & Hous. & Minn. & Phoe. & San Fran. \\
\hline \hline ir32 & VC-1/VC-3 & $8 / 8$ & IWLS & 316 & 357 & 310 & 301 & 256 \\
\hline ir33 & VC-1/VC-3 & $4 / 4$ & IWLL & 253 & 266 & 245 & 218 & 275 \\
\hline ir34 & VC-1/VC-3 & $8 / 8$ & IWLL & 303 & 344 & 298 & 289 & 247 \\
\hline ir35 & VC-1/VC-3 & $4 / 4$ & IDLS & 270 & 282 & 271 & 229 & 288 \\
\hline ir36 & VC-1/VC-3 & $8 / 8$ & IDLS & 368 & 411 & 381 & 339 & 284 \\
\hline ir37 & VC-1/VC-3 & $4 / 4$ & IDLL & 268 & 280 & 269 & 226 & 286 \\
\hline ir38 & VC-1/VC-3 & $8 / 8$ & IDLL & 337 & 380 & 350 & 311 & 264 \\
\hline ir39 & VC-2/CC-5 & $4 / 4$ & NA & 410 & 426 & 401 & 339 & 402 \\
\hline ir40 & VC-2/CC-5 & $8 / 8$ & NA & 410 & 451 & 422 & 376 & 341 \\
\hline ir41 & VC-1/CC-5 & $4 / 4$ & IWLL & 309 & 320 & 301 & 274 & 352 \\
\hline ir42 & VC-1/CC-5 & $8 / 8$ & IWLL & 352 & 390 & 349 & 341 & 314 \\
\hline \hline
\end{tabular}


Table C.7. Aeroderivative Turbine NPV (\$M); Uncooled Base

\begin{tabular}{|l|l|r|c|r|r|r|r|r||}
\hline Case & Chiller & Ophrs & Storage & Nash. & Hous. & Minn. & Phoe. & San Fran. \\
\hline \hline ae1 & NA & $4 / 4$ & NA & 2.91 & 2.31 & 3.09 & 6.41 & 1.47 \\
\hline ae2 & NA & $8 / 8$ & NA & 3.00 & 1.36 & 2.51 & 4.45 & 4.22 \\
\hline ar1 & AA-2 & $4 / 4$ & NA & -0.69 & -1.52 & -0.33 & 5.31 & 0.80 \\
\hline ar2 & AA-2 & $8 / 8$ & NA & -0.43 & -2.31 & -1.17 & 3.49 & 3.51 \\
\hline ar3 & CC-2 & $4 / 4$ & NA & 7.66 & 7.40 & 7.59 & 12.02 & 4.28 \\
\hline ar4 & CC-2 & $8 / 8$ & NA & 7.91 & 6.62 & 7.11 & 10.21 & 7.44 \\
\hline ar5 & LiBr-1 & $4 / 4$ & NA & 5.60 & 5.24 & 5.62 & 9.89 & 2.26 \\
\hline ar6 & LiBr-1 & $8 / 8$ & NA & 5.79 & 4.39 & 5.02 & 7.98 & 5.58 \\
\hline ar7 & VC-2 & $4 / 4$ & NA & 7.19 & 6.82 & 7.23 & 11.65 & 4.44 \\
\hline ar8 & VC-2 & $8 / 8$ & NA & 7.36 & 5.92 & 6.67 & 9.77 & 7.57 \\
\hline ar9 & VC-1 & $4 / 4$ & IWLS & 10.41 & 10.18 & 10.33 & 14.30 & 5.66 \\
\hline ar10 & VC-1 & $4 / 4$ & IWLL & 10.21 & 9.93 & 10.17 & 14.10 & 5.60 \\
\hline ar11 & VC-1 & $4 / 4$ & IDLS & 10.12 & 9.90 & 9.88 & 14.10 & 5.50 \\
\hline ar12 & VC-1 & $4 / 4$ & IDLL & 9.84 & 9.58 & 9.61 & 13.83 & 5.41 \\
\hline ar13 & VC-1 & $8 / 8$ & IWLS & 9.49 & 8.07 & 9.01 & 11.44 & 8.49 \\
\hline ar14 & VC-1 & $8 / 8$ & IWLL & 9.34 & 7.85 & 8.92 & 11.26 & 8.49 \\
\hline ar15 & VC-1 & $8 / 8$ & IDLS & 8.61 & 7.20 & 7.83 & 10.79 & 8.02 \\
\hline ar16 & VC-1 & $8 / 8$ & IDLL & 8.57 & 7.09 & 7.82 & 10.70 & 8.12 \\
\hline ar17 & VC-2 & $4 / 4$ & WWLS & 7.66 & 7.33 & 7.66 & 11.32 & 3.22 \\
\hline ar18 & VC-2 & $4 / 4$ & WWLL & 7.59 & 7.23 & 7.61 & 11.24 & 3.22 \\
\hline ar19 & VC-2 & $4 / 4$ & WDLS & 7.85 & 7.61 & 7.65 & 11.57 & 3.19 \\
\hline ar20 & VC-2 & $4 / 4$ & WDLL & 7.70 & 7.42 & 7.49 & 11.42 & 3.16 \\
\hline ar21 & VC-2 & $8 / 8$ & WWLS & 6.65 & 5.11 & 6.27 & 8.35 & 6.08 \\
\hline ar22 & VC-2 & $8 / 8$ & WWLL & 6.75 & 5.19 & 6.39 & 8.43 & 6.18 \\
\hline ar23 & VC-2 & $8 / 8$ & WDLS & 6.89 & 5.49 & 6.12 & 8.72 & 6.00 \\
\hline ar24 & VC-2 & $8 / 8$ & WDLL & 6.91 & 5.46 & 6.15 & 8.71 & 6.11 \\
\hline
\end{tabular}

C. 15 
Table C.8. Combined-Cycle NPV (\$M); Uncooled Base; 12 hr/day plant; 4 or 8 hr/day cooling

\begin{tabular}{|c|c|c|c|c|c|c|c|c|}
\hline Case & Chiller & Ophrs & Storage & Nash. & Hous. & Minn. & Phoe. & San Fran. \\
\hline cel & NA & $12 / 4$ & NA & 4.40 & 3.36 & 4.71 & 10.28 & 1.98 \\
\hline ce2 & $\mathrm{NA}$ & $12 / 8$ & NA & 4.90 & $2.2 \mathrm{I}$ & 4.12 & 8.21 & 6.62 \\
\hline ce3 & NA & $12 / 12$ & NA & 5.95 & 1.89 & 5.77 & 10.09 & 7.38 \\
\hline ce4 & NA & $24 / 4$ & NA & 3.71 & 2.69 & 4.03 & 9.61 & 1.31 \\
\hline ce5 & NA & $24 / 8$ & NA & 4.21 & 1.54 & 3.44 & 7.54 & 5.94 \\
\hline ce6 & $\mathrm{NA}$ & $24 / 12$ & NA & 5.89 & -0.53 & 5.62 & 10.39 & 9.47 \\
\hline ce7 & NA & $24 / 24$ & NA & 6.17 & -0.24 & 5.84 & 11.55 & 9.69 \\
\hline $\mathrm{crl}$ & $\mathrm{CC}-4$ & $12 / 4$ & NA & 2.20 & 0.72 & 2.89 & 10.49 & 2.95 \\
\hline cr2 & $\mathrm{CC}-4$ & $12 / 8$ & NA & 2.62 & -0.74 & 1.86 & 8.43 & 7.72 \\
\hline cr3 & $\mathrm{CC}-4$ & $12 / 4$ & WDLS & 8.97 & 7.79 & 8.66 & 15.49 & 3.63 \\
\hline cr4 & $\mathrm{CC}-4$ & $12 / 4$ & WDLL & 8.08 & 6.75 & 7.78 & 14.60 & 3.37 \\
\hline cr5 & $\overline{C C}-4$ & $12 / 8$ & WDLS & -2.12 & -6.16 & -3.35 & 3.94 & $\overline{4.21}$ \\
\hline cr6 & $\mathrm{CC}-4$ & $12 / 8$ & WDLL & 3.26 & -0.46 & 2.25 & 7.98 & .6 .95 \\
\hline cr7 & $\mathrm{CC}-3$ & $12 / 4$ & IDLS & 9.85 & 8.41 & 9.55 & 17.06 & 6.12 \\
\hline cr8 & $\mathrm{CC}-3$ & $12 / 4$ & IDLL & 9.09 & 7.52 & 8.83 & 16.18 & 5.90 \\
\hline cr9 & $\mathrm{CC}-3$ & $12 / 8$ & IDLS & -12.61 & -17.73 & -13.62 & -4.25 & 1.11 \\
\hline $\operatorname{cr} 10$ & $\mathrm{CC}-3$ & $12 / 8$ & IDLL & 0.42 & -3.80 & -0.34 & 6.31 & 7.49 \\
\hline cr11 & $\mathrm{LiBr}-2$ & $12 / 4$ & NA & 1.36 & -0.28 & 2.05 & 10.22 & 1.15 \\
\hline $\mathrm{cr} 12$ & $\mathrm{LiBr}-2$ & $12 / 8$ & $\mathrm{NA}$ & 2.10 & -1.29 & 0.88 & 8.27 & 6.76 \\
\hline cr13 & $\mathrm{LiBr}-2$ & $12 / 4$ & WDLS & 8.55 & 7.30 & 8.25 & 15.53 & 3.74 \\
\hline cr14 & $\mathrm{LiBr}-2$ & $12 / 4$ & WDLL & 8.87 & 7.62 & 8.49 & 15.59 & 3.87 \\
\hline crl5 & $\mathrm{LiBr}-2$ & $12 / 8$ & WDLS & -5.04 & -9.27 & -5.28 & 3.14 & 4.17 \\
\hline cr16 & $\mathrm{LiBr}-2$ & $12 / 8$ & WDLL & 4.50 & 0.77 & 3.30 & 9.80 & 7.86 \\
\hline crl7 & VC-2 & $12 / 4$ & NA & 9.46 & 8.45 & 9.57 & 17.07 & 6.60 \\
\hline cr18 & VC-2 & $12 / 8$ & NA & 10.82 & 8.17 & 9.34 & 15.88 & 12.14 \\
\hline cr19 & VC-1 & $12 / 4$ & IWLS & 16.61 & 15.84 & 16.50 & 22.79 & $\overline{9.36}$ \\
\hline cr20 & VC-1 & $12 / 4$ & IWLL & 16.36 & 15.53 & 16.30 & 22.54 & 9.30 \\
\hline $\mathrm{cr} 21$ & $\mathrm{VC}-1$ & $12 / 4$ & IDLS & 15.74 & 15.00 & 15.22 & 22.17 & 8.89 \\
\hline cr22 & VC-1 & $12 / 4$ & IDLL & 15.45 & 14.66 & 14.94 & 21.89 & 8.84 \\
\hline cr23 & VC-1 & $12 / 8$ & IWLS & 15.17 & 12.46 & 14.24 & 19.03 & 14.12 \\
\hline cr24 & VC-1 & $12 / 8$ & IWLL & 15.28 & 12.48 & 14.41 & 19.10 & 14.30 \\
\hline cr25 & VC-1 & $12 / 8$ & IDLS & 12.53 & 9.83 & 10.80 & 17.08 & 12.75 \\
\hline cr26 & VC-1 & $12 / 8$ & IDLL & 13.37 & 10.59 & 11.73 & 17.74 & 13.36 \\
\hline
\end{tabular}


Table C.8. (contd)

\begin{tabular}{|c|c|c|c|c|c|c|c|c|}
\hline Case & Chiller & Ophrs & Storage & Nash. & Hous. & Minn. & Phoe. & San Fran. \\
\hline cr27 & VC-2 & $12 / 4$ & WWLS & 11.78 & 10.89 & 11.80 & 17.72 & 5.12 \\
\hline cr28 & VC-2 & $12 / 4$ & WWLL & 11.73 & 10.81 & 11.78 & 17.67 & 5.15 \\
\hline cr29 & VC-2 & $12 / 4$ & WDLS & 12.15 & 11.47 & 11.67 & 18.25 & 5.02 \\
\hline cr30 & $\mathrm{VC}-2$ & $12 / 4$ & WDLL & 11.99 & 11.27 & 11.51 & 18.10 & 5.02 \\
\hline cr31 & VC-2 & $12 / 8$ & WWLS & 10.10 & 7.26 & 9.34 & 13.67 & 9.73 \\
\hline cr32 & VC-2 & $12 / 8$ & WWLL & 10.58 & 7.72 & 9.80 & 14.09 & 10.03 \\
\hline cr33 & VC-2 & $12 / 8$ & WDLS & 10.42 & 7.90 & 8.70 & 14.36 & 9.44 \\
\hline cr34 & $\mathrm{VC}-2$ & $12 / 8$ & WDLL & 10.93 & 8.35 & 9.25 & 14.76 & 9.87 \\
\hline cr35 & AA-2 & $12 / 4$ & NA & -20.11 & -23.10 & -18.33 & -7.19 & -6.23 \\
\hline cr36 & $\overline{A A-2}$ & $12 / 8$ & $\mathrm{NA}$ & -19.28 & -24.12 & -20.14 & -8.94 & -2.52 \\
\hline cr37 & AA-2 & $12 / 4$ & WDLS & -1.09 & -3.56 & -1.66 & 7.30 & -0.36 \\
\hline cr38 & AA-2 & $12 / 4$ & WDLL & 2.08 & -0.04 & 1.54 & 9.78 & 1.01 \\
\hline $\operatorname{cr} 39$ & AA-2 & $12 / 8$ & WDLS & -43.27 & -51.70 & -43.99 & -28.56 & -11.10 \\
\hline $\mathrm{cr} 40$ & $\overline{A A-2}$ & $12 / 8$ & WDLL & -8.82 & -13.90 & -10.11 & -1.41 & 2.50 \\
\hline $\mathrm{cr} 41$ & AA-1 & $12 / 4$ & IDLS & -3.99 & -6.91 & -4.51 & 5.33 & 0.21 \\
\hline cr42 & AA-1 & $12 / 4$ & IDLL & 0.57 & -1.94 & 0.09 & 9.02 & 2.32 \\
\hline $\operatorname{cr} 43$ & AA-1 & $12 / 8$ & IDLS & -68.93 & -79.01 & -69.06 & -50.76 & -22.72 \\
\hline cr44 & AA-1 & $12 / 8$ & IDLL & -16.68 & -22.55 & -17.65 & -7.73 & 0.37 \\
\hline cr45 & $\mathrm{CC}-4 / \mathrm{CC}-5$ & $12 / 4$ & NA & 2.78 & 1.05 & 3.60 & 12.23 & 4.55 \\
\hline cr46 & $\mathrm{CC}-4 / \mathrm{CC}-5$ & $12 / 8$ & $\mathrm{NA}$ & 3.14 & -0.53 & 2.50 & 10.28 & 9.20 \\
\hline cr47 & AA-2/AA-3 & $12 / 4$ & NA & -40.11 & -44.23 & -37.51 & -24.19 & -20.34 \\
\hline cr48 & AA-2/AA-3 & $12 / 8$ & $\mathrm{NA}$ & -39.21 & -45.36 & -39.48 & -25.63 & -16.87 \\
\hline $\operatorname{cr} 49$ & VC-2/VC-3 & $12 / 4$ & $\mathrm{NA}$ & 13.30 & 11.98 & 13.57 & 22.38 & 11.85 \\
\hline cr50 & $\mathrm{VC}-2 / \mathrm{VC}-3$ & $12 / 8$ & NA & 15.66 & 12.61 & 14.29 & 22.34 & 18.38 \\
\hline cr51 & $\mathrm{CC}-3 / \mathrm{CC}-6$ & $12 / 4$ & IDLS & 17.13 & 15.46 & 16.68 & 25.77 & 13.40 \\
\hline $\operatorname{cr} 52$ & $\mathrm{CC}-3 / \mathrm{CC}-6$ & $12 / 8$ & IDLS & -15.79 & -21.47 & $-16: 95$ & -5.43 & -1.22 \\
\hline $\operatorname{cr} 53$ & AA-1/AA-3 & $12 / 4$ & IDLS & -13.45 & -17.17 & -13.58 & -1.51 & -6.29 \\
\hline $\operatorname{cr} 54$ & $\mathrm{AA}-1 / \mathrm{AA}-3$ & $12 / 8$ & IDLS & -83.09 & -94.47 & -82.42 & -61.06 & -30.64 \\
\hline cr55 & VC-1/VC-3 & $12 / 4$ & IWLS & 21.03 & 19.96 & 21.04 & 28.54 & 14.81 \\
\hline $\operatorname{cr} 56$ & VC-1/VC-3 & $12 / 8$ & IWLS & 20.42 & 17.29 & 19.64 & 25.79 & 20.54 \\
\hline cr57 & VC-1/VC-3 & $12 / 4$ & IWLL & 21.41 & 20.31 & 21.39 & 28.90 & 15.31 \\
\hline cr58 & VC-1/VC-3 & $12 / 8$ & IWLL & 21.72 & 18.51 & 20.85 & 27.03 & 21.75 \\
\hline $\operatorname{cr} 59$ & VC-1/VC-3 & $12 / 4$ & IDLS & 20.10 & 19.07 & 19.68 & 27.88 & 14.31 \\
\hline
\end{tabular}


Table C.8. (contd)

\begin{tabular}{|l|l|r|r|r|r|r|r|r||}
\hline \hline Case & Chiller & Ophrs & Storage & Nash. & Hous. & Minn. & Phoe. & San Fran. \\
\hline \hline cr60 & VC-1/VC-3 & $12 / 8$ & IDLS & 17.60 & 14.49 & 15.96 & 23.71 & 19.09 \\
\hline cr61 & VC-1/VC-3 & $12 / 4$ & IDLL & 20.43 & 19.37 & 19.91 & 28.19 & 14.80 \\
\hline cr62 & VC-1/VC-3 & $12 / 8$ & IDLL & 19.60 & 16.39 & 17.94 & 25.48 & 20.74 \\
\hline cr63 & CC-3/CC-6 & $12 / 4$ & IDLL & 15.52 & 13.71 & 15.14 & 23.99 & 12.42 \\
\hline cr64 & CC-3/CC-6 & $12 / 8$ & IDLL & -2.38 & -7.11 & -3.17 & 5.20 & 5.04 \\
\hline cr65 & AA-1/AA-3 & $12 / 4$ & IDLL & -16.69 & -20.28 & -16.65 & -5.69 & -10.31 \\
\hline cr66 & AA-1/AA-3 & $12 / 8$ & IDLL & -35.31 & -42.64 & -35.52 & -23.33 & -12.62 \\
\hline cr67 & CC-2 & $12 / 4$ & NA & 7.72 & 6.66 & 7.95 & 15.31 & 5.37 \\
\hline cr68 & CC-2 & $12 / 8$ & NA & 8.74 & 5.98 & 7.48 & 13.78 & 10.65 \\
\hline cr69 & CC-2 & $12 / 4$ & WDLS & 9.78 & 8.79 & 9.35 & 16.19 & 3.91 \\
\hline cr70 & CC-2 & $12 / 4$ & WDLL & 9.72 & 8.69 & 9.31 & 16.07 & 3.99 \\
\hline cr71 & CC-2 & $12 / 8$ & WDLS & 0.79 & -2.75 & -0.68 & 6.35 & 5.24 \\
\hline cr72 & CC-2 & $12 / 8$ & WDLL & 6.76 & 3.65 & 5.39 & 11.07 & 8.17 \\
\hline cr73 & CC-1 & $12 / 4$ & IDLS & 11.09 & 9.87 & 10.63 & 18.12 & 6.63 \\
\hline cr74 & CC-1 & $12 / 4$ & IDLL & 11.48 & 10.27 & 11.06 & 18.33 & 6.91 \\
\hline cr75 & CC-1 & $12 / 8$ & IDLS & -8.26 & -12.79 & -9.66 & -0.62 & 2.93 \\
\hline cr76 & CC-1 & $12 / 8$ & IDLL & 5.52 & 2.03 & 4.26 & 10.83 & 9.64 \\
\hline cr77 & CC-2/CC-5 & $12 / 4$ & NA & 8.79 & 7.52 & 9.11 & 17.48 & 7.18 \\
\hline cr78 & CC-2/CC-5 & $12 / 8$ & NA & 9.80 & 6.78 & 8.62 & 16.11 & 12.40 \\
\hline cr79 & CC-1/CC-6 & $12 / 4$ & IDLS & 18.66 & 17.29 & 17.98 & 27.09 & 14.05 \\
\hline cr80 & CC-1/CC-6 & $12 / 8$ & IDLS & -10.69 & -15.63 & -12.39 & -1.16 & 0.92 \\
\hline cr81 & CC-1/CC-6 & $12 / 4$ & IDLL & 21.04 & 19.66 & 20.45 & 29.19 & 16.49 \\
\hline cr82 & CC-1/CC-6 & $12 / 8$ & IDLL & 14.80 & 11.08 & 13.36 & 21.53 & 19.24 \\
\hline cr83 & VC-2/CC-5 & $12 / 4$ & NA & 10.56 & 9.34 & 10.76 & 19.28 & 8.40 \\
\hline cr84 & VC-2/CC-5 & $12 / 8$ & NA & 11.95 & 9.05 & 10.53 & 18.27 & 13.89 \\
\hline cr85 & VC-1/CC-6 & $12 / 4$ & IWLL & 23.09 & 22.04 & 22.96 & 30.59 & 15.85 \\
\hline cr86 & VC-2/CC-6 & $12 / 8$ & IWLL & 13.37 & 10.12 & 12.51 & 18.73 & 12.16 \\
\hline \hline
\end{tabular}

C. 18 
Table C.9. Combined-Cycle NPV (\$M); Uncooled Base; 12 hr/day plant; 12 hr/day cooling

\begin{tabular}{||l|l|r|r|r|r|r|r|r||}
\hline Case & Chiller & Ophrs & Storage & Nash. & Hous. & Minn. & Phoe. & San Fran. \\
\hline \hline dr1 & CC-4 & $12 / 12$ & NA & 4.45 & -0.56 & 5.74 & 11.63 & 9.58 \\
\hline dr2 & LiBr-2 & $12 / 12$ & NA & 3.62 & -0.84 & 4.58 & 11.80 & 9.39 \\
\hline dr3 & AA-2 & $12 / 12$ & NA & -17.28 & -22.39 & -15.11 & -4.49 & -0.48 \\
\hline dr4 & VC-2 & $12 / 12$ & NA & 15.81 & 11.99 & 15.74 & 21.90 & 16.17 \\
\hline dr5 & VC-1 & $12 / 12$ & IWLS & 18.31 & 13.28 & 18.98 & 22.71 & 17.16 \\
\hline dr6 & VC-1 & $12 / 12$ & IWLL & 18.98 & 13.90 & 19.70 & 23.25 & 17.76 \\
\hline dr7 & VC-1 & $12 / 12$ & IDLS & 12.10 & 7.33 & 12.07 & 18.10 & 14.06 \\
\hline dr8 & VC-1 & $12 / 12$ & IDLL & 15.69 & 10.94 & 15.61 & 21.05 & 16.22 \\
\hline dr9 & VC-2 & $12 / 12$ & WWLS & 12.44 & 7.33 & 13.19 & 16.41 & 12.10 \\
\hline dr10 & VC-2 & $12 / 12$ & WWLL & 13.68 & 8.62 & 14.36 & 17.51 & 12.81 \\
\hline dr11 & VC-2 & $12 / 12$ & WDLS & 12.23 & 7.80 & 11.91 & 17.01 & 11.39 \\
\hline dr12 & VC-2 & $12 / 12$ & WDLL & 13.95 & 9.50 & 13.63 & 18.40 & 12.54 \\
\hline dr13 & CC-4/CC-5 & $12 / 12$ & NA & 4.48 & -1.12 & 7.16 & 13.29 & 10.39 \\
\hline dr14 & AA-2/AA-3 & $12 / 12$ & NA & -37.66 & -44.14 & -33.43 & -20.69 & -14.55 \\
\hline dr15 & VC-2/VC-3 & $12 / 12$ & NA & 23.73 & 19.48 & 24.39 & 31.88 & 25.89 \\
\hline dr16 & VC-1/VC-3 & $12 / 12$ & IWLL & 27.89 & 22.35 & 29.24 & 34.06 & 28.35 \\
\hline dr17 & CC-2 & $12 / 12$ & NA & 12.90 & 8.68 & 13.23 & 18.86 & 13.90 \\
\hline dr18 & CC-2/CC-5 & $12 / 12$ & NA & 13.66 & 8.93 & 15.30 & 21.16 & 15.09 \\
\hline dr19 & VC-2/CC-5 & $12 / 12$ & NA & 16.71 & 12.40 & 17.92 & 24.35 & 17.45 \\
\hline dr20 & VC-2/CC-5 & $12 / 12$ & IWLL & 19.83 & 14.00 & 22.02 & 25.50 & 18.98 \\
\hline \hline
\end{tabular}


Table C.10. Combined-Cycle NPV (\$M); Uncooled Base; 24 hr/day plant; 4 or 8 or 12 hr/day cooling

\begin{tabular}{|c|c|c|c|c|c|c|c|c|}
\hline Case & Chiller & Ophrs & Storage & Nash. & Hous. & Minn. & Phoe. & San Fran. \\
\hline er1 & $\mathrm{CC}-4$ & $24 / 4$ & $\mathrm{NA}$ & .2 .90 & 1.87 & 2.84 & 12.05 & 3.36 \\
\hline er2 & $C C-4$ & $24 / 8$ & NA & 4.26 & 1.80 & 2.04 & 11.71 & 8.84 \\
\hline er3 & $\mathrm{CC}-4$ & $24 / 12$ & NA & 3.59 & -4.83 & 5.14 & 11.10 & 11.55 \\
\hline er4 & $\mathrm{CC}-4$ & $24 / 4$ & WDLS & 11.51 & 11.05 & 10.53 & 18.51 & 4.68 \\
\hline er5 & $\overline{\mathrm{CC}-4}$ & $24 / 4$ & WDLL & 10.72 & 10.15 & 9.72 & 17.77 & 4.38 \\
\hline er6 & $\mathrm{CC}-4$ & $24 / 8$ & WDLS & 9.34 & 7.22 & 6.67 & 15.06 & 9.09 \\
\hline er7 & $\mathrm{CC}-4$ & $24 / 8$ & WDLL & 8.63 & 6.34 & 6.03 & 14.34 & 8.96 \\
\hline er8 & $\mathrm{CC}-4$ & $24 / 12$ & WDLS & 8.26 & 0.08 & 9.16 & 13.37 & 12.91 \\
\hline er9 & $\mathrm{CC}-4$ & $24 / 12$ & WDLL & 7.47 & -0.78 & 8.46 & 12.55 & 12.91 \\
\hline er10 & $\mathrm{CC}-3$ & $24 / 4$ & IDLS & 15.30 & 14.77 & 14.32 & 22.73 & 8.79 \\
\hline er11 & $\mathrm{CC}-3$ & $24 / 4$ & IDLL & 14.18 & 13.53 & 13.19 & 21.65 & 8.33 \\
\hline er12 & $\mathrm{CC}-3$ & $24 / 8$ & IDLS & 11.88 & 9.53 & 9.25 & 18.36 & 12.89 \\
\hline er13 & $\mathrm{CC}-3$ & $24 / 8$ & IDLL & 11.07 & 8.54 & 8.57 & 17.48 & 12.68 \\
\hline erl4 & $\mathrm{CC}-3$ & $24 / 12$ & IDLS & 6.71 & -2.48 & 8.42 & 13.28 & 14.03 \\
\hline er15 & $\mathrm{CC}-3$ & $24 / 12$ & IDLL & 6.85 & -2.26 & 8.62 & 13.05 & 14.36 \\
\hline er16 & $\mathrm{LiBr}-2$ & $24 / 4$ & NA & 1.60 & 0.42 & 1.59 & 11.30 & 1.13 \\
\hline er17 & $\mathrm{LiBr}-2$ & $24 / 8$ & $\mathrm{NA}$ & 2.85 & 0.33 & 0.22 & 10.63 & 7.03 \\
\hline er18 & $\mathrm{LiBr}-2$ & $24 / 12$ & $\overline{N A}$ & 3.34 & -4.73 & 4.36 & 11.81 & 12.05 \\
\hline erI9 & $\mathrm{LiBr}-2$ & $24 / 4$ & WDLS & 11.71 & 11.26 & 10.60 & 18.77 & 4.80 \\
\hline er20 & $\mathrm{LiBr}-2$ & $24 / 4$ & WDLL & 11.39 & 10.90 & 10.27 & 18.46 & 4.69 \\
\hline er21 & LiBr-2 & $24 / 8$ & WDLS & 9.61 & 7.26 & 6.69 & 15.43 & 9.26 \\
\hline er22 & $\mathrm{LiBr}-2$ & $24 / 8$ & WDLL & 9.80 & 7.45 & 6.93 & 15.57 & 9.52 \\
\hline er23 & LiBr-2 & $24 / 12$ & WDLS & 9.03 & 0.62 & 9.20 & 14.52 & 13.29 \\
\hline er24 & $\mathrm{LiBr}-2$ & $24 / 12$ & WDLL & 10.25 & 2.32 & 10.56 & 15.53 & 14.17 \\
\hline er25 & $\mathrm{VC}-2$ & $24 / 4$ & $\mathrm{NA}$ & 10.15 & 9.60 & 9.52 & 18.63 & 7.00 \\
\hline er26 & VC-2 & $24 / 8$ & $\mathrm{NA}$ & 12.46 & 10.71 & 9.52 & 19.16 & 13.26 \\
\hline er27 & VC-2 & $24 / 12$ & NA & 15.78 & 9.28 & 15.68 & 22.29 & 18.94 \\
\hline er28 & VC-1 & $24 / 4$ & IWLS & 17.14 & 16.78 & 16.33 & 24.20 & 9.70 \\
\hline er29 & $\mathrm{VC}-1$ & $24 / 4$ & IWLL & 16.95 & 16.53 & 16.19 & 24.00 & 9.66 \\
\hline er30 & VC-1 & $24 / 4$ & IDLS & 16.33 & 16.02 & 15.11 & 23.64 & $9 . \overline{26}$ \\
\hline er31 & $\mathrm{VC}-1$ & $24 / 4$ & IDLL & 16.05 & 15.68 & 14.83 & 23.36 & 9.20 \\
\hline er32 & VC-1 & $24 / 8$ & IWLS & 16.17 & 14.22 & 13.92 & 21.75 & 14.97 \\
\hline er33 & $\overline{V C}-1$ & $24 / 8$ & IWLL & 16.68 & 14.70 & 14.45 & 22.19 & 15.33 \\
\hline
\end{tabular}


Table C.10. (contd)

\begin{tabular}{|c|c|c|c|c|c|c|c|c|}
\hline Case & Chiller & Ophrs & Storage & Nash. & Hous. & Minn. & Phoe. & San Fran. \\
\hline er34 & VC-1 & $24 / 8$ & IDLS & 13.97 & 12.09 & 10.85 & 20.19 & 13.80 \\
\hline er35 & VC-1 & $24 / 8$ & IDLL & 14.83 & 12.91 & 11.79 & 20.87 & 14.42 \\
\hline er36 & VC-1 & $24 / 12$ & IWLS & 11.78 & 3.84 & 13.30 & 17.63 & 17.42 \\
\hline er37 & VC-1 & $24 / 12$ & IWLL & 15.08 & 7.39 & 16.32 & 20.41 & 19.25 \\
\hline er38 & VC-1 & $24 / 12$ & IDLS & 11.48 & 4.24 & 11.67 & 17.92 & 16.62 \\
\hline er39 & VC-1 & $24 / 12$ & IDLL & 15.14 & 7.98 & 15.23 & 20.91 & 18.89 \\
\hline er40 & VC-2 & $24 / 4$ & WWLS & 12.04 & 11.58 & 11.36 & 18.82 & 5.12 \\
\hline er41 & VC-2 & $.24 / 4$ & WWLL & 11.92 & 11.42 & 11.28 & 18.70 & 5.11 \\
\hline er42 & VC-2 & $24 / 4$ & WDLS & 12.34 & 12.07 & 11.16 & 19.28 & 4.98 \\
\hline er43 & VC-2 & $24 / 4$ & WDLL & 12.18 & 11.88 & 11.01 & 19.13 & 4.99 \\
\hline er44 & $\mathrm{VC}-2$ & $24 / 8$ & WWLS & 10.93 & 8.93 & 8.79 & 16.11 & 10.07 \\
\hline er45 & VC-2 & $24 / 8$ & WWLL & 11.19 & 9.14 & 9.07 & 16.32 & 10.26 \\
\hline er46 & $V C-2$ & $24 / 8$ & WDLS & 11.05 & 9.35 & 7.98 & 16.61 & 9.68 \\
\hline er47. & VC-2 & $24 / 8$ & WDLL & 11.56 & 9.82 & 8.53 & 17.02 & 10.11 \\
\hline er48 & VC-2 & $24 / 12$ & WWLS & 9.30 & 1.75 & 10.44 & 14.31 & 14.35 \\
\hline er49 & VC-2 & $24 / 12$ & WWLL & 10.61 & 3.13 & 11.67 & 15.40 & 15.01 \\
\hline er50 & VC-2 & $24 / 12$ & WDLS & 11.93 & 5.19 & 11.70 & 17.03 & 14.28 \\
\hline er5l & VC-2 & $24 / 12$ & WDLL & 13.67 & 6.96 & 13.43 & 18.46 & 15.43 \\
\hline er52 & AA-2 & $24 / 4$ & NA & -19.41 & -21.95 & -18.38 & -5.64 & -5.83 \\
\hline er53 & AA-2 & $24 / 8$ & $\mathrm{NA}$ & -17.64 & -21.58 & -19.96 & -5.65 & -1.39 \\
\hline er54 & AA-2 & $24 / 12$ & $\mathrm{NA}$ & -17.80 & -27.29 & -15.49 & -4.64 & 1.11 \\
\hline er55 & AA-2 & $24 / 4$ & WDLS & 7.71 & 6.74 & 6.54 & 15.37 & 3.13 \\
\hline er56 & AA-2 & $24 / 4$ & WDLL & 7.89 & 6.93 & 6.72 & 15.47 & 3.24 \\
\hline er57 & $\mathrm{AA}-2$ & $24 / 8$ & WDLS & -0.32 & -3.76 & \begin{tabular}{|c|}
-3.24 \\
\end{tabular} & 7.22 & 5.39 \\
\hline er58 & AA-2 & $24 / 8$ & WDLL & 2.91 & -0.10 & 0.06 & 9.82 & 6.81 \\
\hline er59 & AA-2 & $24 / 12$ & WDLS & -10.76 & -20.88 & -9.46 & -1.39 & 5.87 \\
\hline er60 & AA-2 & $24 / 12$ & WDLL & -0.34 & -9.05 & 0.64 & 6.86 & 10.15 \\
\hline er61 & AA-1 & $24 / 4$ & IDLS & 10.03 & 8.89 & 8.86 & 18.17 & 6.53 \\
\hline er62 & AA-1 & $24 / 4$ & IDLL & 10.13 & 9.00 & 8.96 & 18.18 & 6.61 \\
\hline er63 & AA-1 & $24 / 8$ & IDLS & -1.45 & -5.38 & -4.29 & 7.03 & 7.19 \\
\hline er64 & $\mathrm{AA}-1$ & $24 / 8$ & IDLL & 2.91 & -0.54 & 0.18 & 10.65 & 9.25 \\
\hline er65 & AA-1 & $24 / 12$ & IDLS & -19.49 & -31.09 & -17.33 & -8.26 & 2.93 \\
\hline er66 & AA-1 & $24 / 12$ & IDLL & -4.51 & -14.32 & -2.72 & 4.07 & 9.76 \\
\hline
\end{tabular}


Table C.10. (contd)

\begin{tabular}{|c|c|c|c|c|c|c|c|c|}
\hline Case & Chiller & Ophrs & Storage & Nash. & Hous. & Minn. & Phoe. & San Fran. \\
\hline er67 & CC-4/CC-5 & $24 / 4$ & NA & 4.92 & 3.69 & 4.88 & 15.31 & 6.34 \\
\hline er68 & $\mathrm{CC}-4 / \mathrm{CC}-5$ & $24 / 8$ & NA & 8.22 & 5.51 & 5.88 & 17.14 & 13.63 \\
\hline er69 & CC-4/CC-5 & $24 / 12$ & NA & 1.34 & -8.05 & 4.80 & 10.61 & 9.83 \\
\hline er70 & AA-2/AA-3 & $24 / 4$ & $\mathrm{NA}$ & -37.97 & -41.59 & -36.23 & -21.12 & -18.55 \\
\hline er71 & $\mathrm{AA}-2 / \mathrm{AA}-3$ & $24 / 8$ & NA & -34.13 & -39.32 & -36.10 & -18.77 & -12.44 \\
\hline er72 & $\mathrm{AA}-2 / \mathrm{AA}-3$ & $24 / 12$ & $\mathrm{NA}$ & -40.00 & -51.89 & -35.14 & -22.53 & -15.15 \\
\hline er73 & $\mathrm{VC}-2 / \mathrm{VC}-3$ & $24 / 4$ & NA & 15.44 & 14.62 & 14.85 & 25.45 & 13.64 \\
\hline er74 & VC-2/VC-3 & $24 / 8$ & $\mathrm{NA}$ & 20.73 & 18.65 & 17.67 & 29.20 & 22.81 \\
\hline er75 & VC-2/VC-3 & $24 / 12$ & $\mathrm{NA}$ & 23.10 & 15.75 & 23.91 & 31.74 & 27.95 \\
\hline er76 & $\mathrm{CC}-3$ & $24 / 4$ & IWLS & 16.20 & 15.63 & 15.66 & 23.36 & 9.27 \\
\hline er77 & $\mathrm{CC}-3$ & $24 / 4$ & IWLL & 15.46 & 14.76 & 15.05 & 22.61 & 8.98 \\
\hline er78 & $\mathrm{CC}-3$ & $24 / 8$ & IWLS & 14.32 & 11.93 & 12.64 & 20.10 & 14.15 \\
\hline er79 & $\mathrm{CC}-3$ & $24 / 8$ & IWLL & 13.67 & 11.09 & 12.22 & 19.41 & 13.96 \\
\hline er80 & $\overline{\mathrm{CC}-3}$ & $24 / 12$ & IWLS & 7.13 & -2.69 & 10.36 & 13.07 & 14.87 \\
\hline er81 & $\mathrm{CC}-3$ & $24 / 12$ & IWLL & 7.22 & -2.61 & 10.51 & 12.80 & 15.15 \\
\hline er82 & $\overline{A A-1}$ & $24 / 4$ & IWLS & 12.94 & 11.80 & 12.86 & 20.35 & 7.96 \\
\hline er83 & AA-1 & $24 / 4$ & IWLL & 12.99 & 11.84 & 12.92 & 20.35 & 8.00 \\
\hline er84 & $\mathrm{AA}-1$ & $24 / 8$ & IWLS & 6.12 & 2.36 & 5.72 & 12.67 & 10.88 \\
\hline er85 & $A A-1$ & $24 / 8$ & IWLL & 8.78 & 5.40 & 8.06 & 15.02 & 12.05 \\
\hline er86 & AA-1 & $24 / 12$ & IWLS & -16.30 & -29.18 & -9.79 & -7.01 & 5.96 \\
\hline er87 & $\mathrm{AA}-1$ & $24 / 12$ & IWLL & -2.78 & -13.74 & 1.81 & 4.52 & 11.61 \\
\hline er88 & $\mathrm{CC}-3 / \mathrm{CC}-6$ & $24 / 4$ & IWLS & -8.87 & -10.17 & -9.40 & 0.35 & -16.84 \\
\hline er89 & $\mathrm{CC}-3 / \mathrm{CC}-6$ & $24 / 8$ & IWLS & -50.99 & -54.87 & -52.52 & -42.15 & -53.06 \\
\hline er90 & $\mathrm{CC}-3 / \mathrm{CC}-6$ & $24 / 12$ & IWLS & -152.30 & -165.10 & -147.81 & -141.25 & -147.73 \\
\hline er91 & $\mathrm{CC}-3 / \mathrm{CC}-6$ & $24 / 4$ & IWLL & -10.08 & -11.57 & -10.42 & -0.87 & -17.48 \\
\hline er92 & $\mathrm{CC}-3 / \mathrm{CC}-6$ & $24 / 8$ & IWLL & -52.49 & -56.67 & -53.64 & -43.69 & -53.88 \\
\hline er93 & $\mathrm{CC}-3 / \mathrm{CC}-6$ & $24 / 12$ & IWLL & -154.56 & -167.76 & -149.70 & -144.03 & -149.45 \\
\hline er94 & CC-3/CC-6 & $24 / 4$ & IDLS & 24.81 & 24.15 & 23.57 & 33.71 & 18.06 \\
\hline er95 & $\mathrm{CC}-3 / \mathrm{CC}-6$ & $24 / 8$ & IDLS & 15.70 & 13.04 & 12.67 & 24.05 & 16.41 \\
\hline er96 & $\mathrm{CC}-3 / \mathrm{CC}-6$ & $24 / 12$ & IDLS & 3.54 & -6.13 & 5.39 & 12.38 & 10.99 \\
\hline er97 & $\mathrm{CC}-3 / \mathrm{CC}-6$ & $24 / 4$ & IDLL & 23.21 & 22.40 & 21.95 & 32.11 & 17.17 \\
\hline er98 & $\mathrm{CC}-3 / \mathrm{CC}-6$ & $24 / 8$ & IDLL & 14.09 & 11.19 & 11.23 & 22.29 & 15.49 \\
\hline er99 & CC-3/CC-6 & $24 / 12$ & IDLL & 2.04 & -7.58 & 3.97 & 10.36 & 9.73 \\
\hline
\end{tabular}


Table C.10. (contd)

\begin{tabular}{|c|c|c|c|c|c|c|c|c|}
\hline Case & Chiller & Ophrs & Storage & Nash. & Hous. & Minn. & Phoe. & San Fran. \\
\hline er100 & AA-1/AA-3 & $24 / 4$ & IWLS & 7.07 & 4.93 & 7.51 & 16.50 & 4.08 \\
\hline er101 & AA-1/AA-3 & $24 / 8$ & IWLS & 2.42 & -2.61 & 2.57 & 11.29 & 9.65 \\
\hline er102 & $\mathrm{AA}-1 / \mathrm{AA}-3$ & $24 / 12$ & IWLS & 10.43 & 3.18 & 13.20 & 16.97 & 17.66 \\
\hline er103 & $\mathrm{AA}-1 / \mathrm{AA}-3$ & $24 / 4$ & IWLL & -1.05 & -3.39 & -0.38 & 8.43 & -2.17 \\
\hline er104 & $\mathrm{AA}-1 / \mathrm{AA}-3$ & $24 / 8$ & IWLL & -3.13 & -7.99 & -3.12 & 5.60 & 4.26 \\
\hline er105 & AA-1/AA-3 & $24 / 12$ & IWLL & -0.08 & -7.39 & 2.50 & 6.37 & 8.59 \\
\hline er106 & AA-1/AA-3 & $24 / 4$ & IDLS & 3.63 & 1.61 & 2.50 & 13.84 & 2.16 \\
\hline er107 & AA-1/AA-3 & $24 / 8$ & IDLS & -6.01 & -11.33 & -8.86 & 4.90 & 5.29 \\
\hline er108 & AA-1/AA-3 & $24 / 12$ & IDLS & -27.73 & -42.09 & -23.64 & -13.43 & -1.16 \\
\hline er109 & AA-1/AA-3 & $24 / 4$ & IDLL & -4.45 & -6.63 & -5.38 & 5.78 & -4.03 \\
\hline $\operatorname{erl10}$ & AA-1/AA-3 & $24 / 8$ & IDLL & -9.73 & -14.71 & -12.30 & 0.60 & 0.97 \\
\hline er111 & AA-1/AA-3 & $24 / 12$ & IDLL & -24.68 & -37.25 & -20.55 & -12.62 & -4.55 \\
\hline er112 & VC-1/VC-3 & $24 / 4$ & IWLS & 22.98 & 22.37 & 22.19 & 31.45 & 16.53 \\
\hline er113 & VC-1/VC-3 & $24 / 8$ & IWLS & 24.81 & 22.51 & 22.49 & 32.05 & 24.69 \\
\hline er114 & VC-1/VC-3 & $24 / 12$ & IWLS & 18.98 & 10.08 & 21.52 & 26.87 & 26.44 \\
\hline er115 & VC-1/VC-3 & $24 / 4$ & IWLL & 23.26 & 22.60 & 22.45 & 31.72 & 16.90 \\
\hline er116 & VC-1/VC-3 & $24 / 8$ & IWLL & 26.15 & 23.82 & 23.75 & 33.32 & 25.75 \\
\hline er117 & VC-1/VC-3 & $24 / 12$ & IWLL & 22.40 & 13.75 & 24.66 & 29.74 & 28.33 \\
\hline er118 & $\mathrm{VC}-1 / \mathrm{VC}-3$ & $24 / 4$ & IDLS & 22.12 & 21.56 & 20.89 & 30.86 & 16.06 \\
\hline er119 & VC-1/VC-3 & $24 / 8$ & IDLS & 22.46 & 20.23 & 19.21 & 30.38 & 23.43 \\
\hline er120 & VC-1/VC-3 & $24 / 12$ & IDLS & 18.64 & 10.48 & 19.75 & 27.17 & 25.58 \\
\hline er121 & VC-1/VC-3 & $24 / 4$ & IDLL & 22.30 & 21.70 & 20.98 & 31.02 & 16.41 \\
\hline er122 & VC-1/VC-3 & $24 / 8$ & IDLL & 24.19 & 21.91 & 20.92 & 31.92 & 24.83 \\
\hline er123 & VC-1/VC-3 & $24 / 12$ & IDLL & 22.44 & 14.36 & 23.45 & 30.27 & 27.93 \\
\hline er124 & CC-2 & $24 / 4$ & NA & 8.42 & 7.81 & 7.90 & 16.87 & 5.77 \\
\hline er125 & $\mathrm{CC}-2$ & $24 / 8$ & $\mathrm{NA}$ & 10.38 & 8.52 & 7.66 & 17.07 & 11.78 \\
\hline er126 & CC-2 & $24 / 12$ & NA & 12.52 & 5.48 & 12.94 & 18.84 & 16.36 \\
\hline er127 & $\overline{\mathrm{CC}-2}$ & $24 / 4$ & WDLS & 11.99 & 11.67 & 10.90 & 18.95 & 4.82 \\
\hline er128 & $\mathrm{CC}-2$ & $24 / 4$ & WDLL & 11.66 & 11.29 & 10.55 & 18.62 & 4.71 \\
\hline er129 & $\overline{C C-2}$ & $24 / 8$ & WDLS & 10.43 & 8.62 & 7.52 & 16.01 & 9.41 \\
\hline er130 & CC-2 & $24 / 8$ & WDLL & 10.58 & 8.72 & 7.71 & 16.07 & 9.62 \\
\hline er131 & $\mathrm{CC}-2$ & $24 / 12$ & WDLS & 10.69 & 3.44 & 10.91 & 15.63 & 13.72 \\
\hline er132 & CC-2 & $24 / 12$ & WDLL & 11.64 & 4.47 & 11.86 & 16.33 & 14.39 \\
\hline
\end{tabular}


Table C.10. (contd)

\begin{tabular}{|c|c|c|c|c|c|c|c|c|}
\hline Case & Chiller & Ophrs & Storage & Nash. & Hous. & Minn. & Phoe. & San Fran. \\
\hline erl33 & $\mathrm{CC}-1$ & $24 / 4$ & IDLS & 16.05 & 15.69 & 14.91 & 23.38 & 9.10 \\
\hline er134 & CC-1 & $24 / 4$ & IDLL & 15.57 & 15.16 & 14.42 & 22.90 & 8.91 \\
\hline erl35 & $\mathrm{CC}-1$ & $24 / 8$ & IDLS & 13.56 & 11.58 & 10.60 & 19.80 & 13.58 \\
\hline er136 & CC-1 & $24 / 8$ & IDLL & 13.95 & 11.95 & 11.07 & 20.03 & 13.89 \\
\hline er137 & $\mathrm{CC}-1$ & $24 / 12$ & IDLS & 10.54 & 2.68 & 11.23 & 16.79 & 15.97 \\
\hline er138 & $\mathrm{CC}-1$ & $24 / 12$ & $\overline{\text { IDLL }}$ & 13.08 & 5.45 & 13.72 & 18.74 & 17.39 \\
\hline er139 & $\mathrm{CC}-2 / \mathrm{CC}-5$ & $24 / 4$ & NA & 10.93 & 10.16 & 10.39 & 20.55 & 8.97 \\
\hline er140 & CC-2/CC-5 & $24 / 8$ & $\mathrm{NA}$ & 14.88 & 12.82 & 12.00 & 22.96 & 16.83 \\
\hline er141 & CC-2/CC-5 & $24 / 12$ & $\overline{N A}$ & 11.05 & 3.16 & 13.28 & 19.03 & 15.07 \\
\hline erl42 & CC-1 & $24 / 4$ & IWLS & 16.83 & 16.43 & 16.09 & 23.92 & 9.53 \\
\hline er143 & $\overline{\mathrm{CC}-1}$ & $24 / 4$ & IWLL & 16.51 & 16.05 & 15.84 & 23.58 & 9.41 \\
\hline er144 & $\overline{\mathrm{CC}-1}$ & $24 / 8$ & IWLS & 15.69 & 13.66 & 13.59 & 21.31 & 14.71 \\
\hline er145 & $\mathrm{CC}-1$ & $24 / 8$ & IWLL & 15.86 & 13.80 & 13.82 & 21.41 & 14.86 \\
\hline erl46 & $\mathrm{CC}-1$ & $24 / 12$ & IWLS & 10.77 & 2.32 & 12.83 & 16.49 & 16.68 \\
\hline er147 & $\overline{\mathrm{CC}}-1$ & $24 / 12$ & IWLL & 13.02 & 4.81 & 14.82 & 18.25 & $17: 84$ \\
\hline erl48 & $\mathrm{CC}-1 / \mathrm{CC}-6$ & $24 / 4$ & IWLS & -8.15 & -9.25 & -8.90 & 0.99 & -16.54 \\
\hline er149 & CC-1/CC- 6 & $24 / 8$ & IWLS & -49.41 & -52.88 & -51.42 & -40.77 & -52.41 \\
\hline er150 & $\mathrm{CC}-1 / \mathrm{CC}-6$ & $24 / 12$ & IWLS & -148.14 & -159.38 & -145.01 & -137.35 & -145.64 \\
\hline er151 & CC-1/CC-6 & $24 / 4$ & IWLL & -8.94 & -10.16 & -9.56 & 0.19 & -17.01 \\
\hline er152 & CC-1/CC-6 & $24 / 8$ & IWLL & -50.10 & -53.73 & -51.90 & -41.52 & -52.90 \\
\hline er153 & CC-1/CC-6 & $24 / 12$ & IWLL & -148.26 & -159.70 & -145.01 & -138.10 & -146.54 \\
\hline er154 & CC-1/CC-6 & $24 / 4$ & IDLS & 25.63 & 25.15 & 24.21 & 34.41 & 18.40 \\
\hline er155 & $\mathrm{CC}-1 / \mathrm{CC}-6$ & $24 / 8$ & IDLS & 17.53 & 15.27 & 14.14 & 25.61 & 17.18 \\
\hline er156 & CC-1/CC-6 & $24 / 12$ & IDLS & 7.72 & -0.51 & 8.45 & 16.20 & 13.10 \\
\hline er157 & $\mathrm{CC}-1 / \mathrm{CC}-6$ & $24 / 4$ & IDLL & 24.71 & 24.17 & 23.30 & 33.47 & 17.81 \\
\hline er158 & $\mathrm{CC}-1 / \mathrm{CC}-6$ & $24 / 8$ & IDLL & 17.22 & 14.89 & 13.94 & 25.06 & 16.81 \\
\hline erl59 & CC-1/CC-6 & $24 / 12$ & IDLL & 8.81 & 0.80 & 9.51 & 16.54 & 13.03 \\
\hline er160 & VC-2/CC-5 & $24 / 4$ & $\mathrm{NA}$ & 12.70 & 11.98 & 12.04 & 22.35 & 10.19 \\
\hline er161 & VC-2/CC-5 & $24 / 8$ & $\mathrm{NA}$ & 17.02 & 15.09 & 13.91 & 25.13 & 18.32 \\
\hline er162 & VC-2/CC-5 & $24 / 12$ & $\mathrm{NA}$ & 14.48 & 7.18 & 16.15 & 22.67 & 17.75 \\
\hline er163 & VC-1/CC-5 & $24 / 4$ & IWLL & 26.00 & 25.45 & 24.99 & 34.46 & 18.40 \\
\hline er164 & VC-1/CC-5 & $24 / 8$ & IWLL & 20.00 & 17.70 & 17.42 & 27.23 & 18.17 \\
\hline er165 & VC-1/CC-5 & $24 / 12$ & IWLL & 10.84 & 2.77 & 12.18 & 18.22 & 14.87 \\
\hline
\end{tabular}


Table C.11. Combined-Cycle NPV (\$M); Uncooled Base; 24 hr/day plant; 24 hr/day cooling

\begin{tabular}{|l|l|r|r|r|r|r|r|r||}
\hline Case & Chiller & Ophrs & Storage & Nash. & Hous. & Minn. & Phoe. & San Fran. \\
\hline \hline fr1 & CC-4 & $24 / 24$ & NA & 1.18 & -9.09 & 3.86 & 9.85 & 10.55 \\
\hline fr2 & LiBr-2 & $24 / 24$ & NA & 2.71 & -6.15 & 4.12 & 11.95 & 12.04 \\
\hline fr3 & AA-2 & $24 / 24$ & NA & -19.22 & -29.94 & -16.20 & -4.97 & 0.64 \\
\hline fr4 & VC-2 & $24 / 24$ & NA & 15.78 & 8.93 & 15.79 & 23.30 & 19.23 \\
\hline fr5 & CC-4/CC-5 & $24 / 24$ & NA & -7.92 & -20.30 & -1.50 & 2.66 & 1.31 \\
\hline fr6 & AA-2/AA-3 & $24 / 24$ & NA & -46.51 & -61.29 & -39.20 & -27.64 & -20.66 \\
\hline fr7 & VC-2/VC-3 & $24 / 24$ & NA & 22.00 & 13.40 & 23.62 & 31.88 & 27.32 \\
\hline fr8 & CC-2 & $24 / 24$ & NA & 11.49 & 3.54 & 12.44 & 18.85 & 16.03 \\
\hline fr9 & CC-2/CC-5 & $24 / 24$ & NA & 3.29 & -6.57 & 7.83 & 12.43 & 7.27 \\
\hline fr10 & VC-2/CC-5 & $24 / 24$ & NA & 7.83 & -0.83 & 11.36 & 17.15 & 10.63 \\
\hline \hline
\end{tabular}


Table C.12. Industrial Turbine NPV (\$M); Uncooled Base

\begin{tabular}{|c|c|c|c|c|c|c|c|c|}
\hline Case & Chiller & Ophrs & Storage & Nash. & Hous. & Minn. & Phoe. & San Fran. \\
\hline iel & $\mathrm{NA}$ & $4 / 4$ & NA & 2.86 & 2.22 & 3.04 & 6.43 & 1.35 \\
\hline ie2 & $\mathrm{NA}$ & $8 / 8$ & $\mathrm{NA}$ & 3.10 & 1.44 & 2.59 & 5.02 & 4.17 \\
\hline irl & AA-2 & $4 / 4$ & $\mathrm{NA}$ & -14.03 & $\mid-15.84$ & -13.04 & -5.78 & -5.16 \\
\hline ir2 & $\overline{A A-2}$ & $8 / 8$ & $\overline{N A}$ & -13.38 & $\mid-16.19$ & -14.24 & -6.84 & -3.01 \\
\hline ir3 & $\mathrm{CC}-2$ & $4 / 4$ & $\mathrm{NA}$ & 3.75 & 3.13 & 3.81 & 8.54 & 2.24 \\
\hline ir4 & $\mathrm{CC}-2$ & $8 / 8$ & $\mathrm{NA}$ & 4.36 & 2.79 & 3.39 & 7.47 & 5.35 \\
\hline ir5 & $\mathrm{LiBr}-1$ & $4 / 4$ & $\mathrm{NA}$ & 2.05 & 1.30 & 2.25 & 7.05 & 0.65 \\
\hline$\overline{\text { ir6 }}$ & $\mathrm{LiBr}-1$ & $8 / 8$ & NA & 2.53 & 0.80 & 1.59 & 5.80 & 4.02 \\
\hline ir7 & VC-2 & $4 / 4$ & NA & 4.07 & 3.34 & 4.27 & 8.90 & 2.95 \\
\hline ir8 & $\overline{V C-2}$ & $8 / 8$ & NA & 4.51 & 2.71 & 3.75 & 7.70 & 6.06 \\
\hline ir 9 & VC-1 & $4 / 4$ & IWLS & 9.09 & 8.52 & 9.13 & 12.90 & 4.89 \\
\hline irlo & VC-1 & $4 / 4$ & IWLL & 8.92 & 8.30 & 9.00 & 12.73 & 4.85 \\
\hline ir11 & VC-1 & $4 / 4$ & IDLS & 8.48 & 7.94 & 8.23 & 12.47 & 4.56 \\
\hline irl2 & VC-1 & $4 / 4$ & IDLL & 8.28 & 7.71 & 8.04 & 12.28 & 4.52 \\
\hline irl3 & VC-1 & $8 / 8$ & IWLS & 7.49 & 5.64 & 7.13 & 9.85 & 7.41 \\
\hline irl4 & VC-1 & $8 / 8$ & IWLL & 7.59 & 5.68 & 7.27 & 9.92 & 7.55 \\
\hline ir15 & VC-1 & $8 / 8$ & IDLS & 5.64 & 3.80 & 4.70 & 8.48 & 6.45 \\
\hline ir16 & VC-1 & $8 / 8$ & IDLL & 6.26 & 4.38 & 5.38 & 8.98 & 6.90 \\
\hline ir17 & VC-2 & $4 / 4$ & WWLS & 6.25 & 5.60 & 6.39 & 9.93 & 2.53 \\
\hline ir18 & VC-2 & $4 / 4$ & WWLL & 6.24 & 5.56 & 6.39 & 9.91 & 2.56 \\
\hline ir19 & VC-2 & $4 / 4$ & WDLS & 6.56 & 6.06 & 6.32 & 10.35 & 2.46 \\
\hline ir20 & VC-2 & $4 / 4$ & WDLL & 6.46 & 5.93 & 6.22 & 10.26 & 2.47 \\
\hline ir21 & VC-2 & $8 / 8$ & WWLS & 4.60 & 2.65 & 4.37 & 6.79 & 5.12 \\
\hline ir22 & VC-2 & $8 / 8$ & WWLL & 4.99 & 3.04 & 4.74 & 7.14 & 5.35 \\
\hline ir23 & VC-2 & $8 / 8$ & WDLS & 4.91 & 3.21 & 3.96 & 7.36 & 4.93 \\
\hline ir24 & VC-2 & $8 / 8$ & WDLL & 5.32 & 3.59 & 4.40 & 7.69 & 5.26 \\
\hline ir 25 & $\mathrm{CC}-2 / \mathrm{CC}-5$ & $4 / 4$ & NA & 4.48 & 3.72 & 4.46 & 10.06 & 2.51 \\
\hline ir26 & CC-2/CC-5 & $8 / 8$ & $\mathrm{NA}$ & 5.78 & 4.06 & 4.65 & 9.76 & 6.25 \\
\hline ir27 & AA-2/AA-3 & $4 / 4$ & $\mathrm{NA}$ & -27.70 & -30.13 & $|-26.47|$ & -17.56 & -16.53 \\
\hline ir28 & $\mathrm{AA}-2 / \mathrm{AA}-3$ & $8 / 8$ & NA & -26.35 & -29.77 & -27.25 & -17.85 & -14.04 \\
\hline ir29 & $\mathrm{VC}-2 / \mathrm{VC}-3$ & $4 / 4$ & $\mathrm{NA}$ & 4.20 & 3.21 & 4.54 & 9.94 & 4.05 \\
\hline ir30 & $\mathrm{VC}-2 / \mathrm{VC}-3$ & $8 / 8$ & $\mathrm{NA}$ & 4.50 & 2.35 & 3.89 & 8.75 & 7.02 \\
\hline ir31 & VC-1/VC-3 & $4 / 4$ & IWLS & 9.60 & 8.78 & 9.77 & 14.25 & 6.12 \\
\hline
\end{tabular}


Table C.12. (contd)

\begin{tabular}{||c|c|r|c|r|r|r|r|r||}
\hline Case & Chiller & Ophrs & Storage & Nash. & Hous. & Minn. & Phoe. & San Fran. \\
\hline \hline ir32 & VC-1/VC-3 & $8 / 8$ & IWLS & 7.76 & 5.55 & 7.57 & 11.09 & 8.49 \\
\hline ir33 & VC-1/VC-3 & $4 / 4$ & IWLL & 9.91 & 9.08 & 10.05 & 14.54 & 6.50 \\
\hline ir34 & VC-1/VC-3 & $8 / 8$ & IWLL & 8.76 & 6.52 & 8.49 & 12.04 & 9.41 \\
\hline ir35 & VC-1/VC-3 & $4 / 4$ & IDLS & 8.95 & 8.17 & 8.81 & 13.79 & 5.77 \\
\hline ir36 & VC-1/VC-3 & $8 / 8$ & IDLS & 5.79 & 3.60 & 4.98 & 9.64 & 7.47 \\
\hline ir37 & VC-1/VC-3 & $4 / 4$ & IDLL & 9.22 & 8.43 & 9.01 & 14.05 & 6.15 \\
\hline ir38 & VC-1/VC-3 & $8 / 8$ & IDLL & 7.29 & 5.05 & 6.45 & 10.98 & 8.71 \\
\hline ir39 & VC-2/CC-5 & $4 / 4$ & NA & 4.08 & 3.14 & 4.26 & 9.86 & 3.12 \\
\hline ir40 & VC-2/CC-5 & $8 / 8$ & NA & 5.10 & 3.09 & 4.23 & 9.34 & 6.74 \\
\hline ir41 & VC-1/CC-5 & $4 / 4$ & IWLL & 9.27 & 8.46 & 9.32 & 13.96 & 5.13 \\
\hline ir42 & VC-1/CC-5 & $8 / 8$ & IWLL & 8.42 & 6.29 & 8.01 & 11.72 & 8.32 \\
\hline \hline
\end{tabular}


Table C.13. Aeroderivative Turbine $\$ / \mathrm{kW}$; Evaporatively-Cooled Base

\begin{tabular}{|l|l|r|r|r|r|r|r|r||}
\hline Case & Chiller & Ophrs & Storage & Nash. & Hous. & Minn. & Phoe. & San Fran. \\
\hline ar1 & AA-2 & $4 / 4$ & NA & 1153 & 1157 & 1133 & 1039 & 894 \\
\hline ar2 & AA-2 & $8 / 8$ & NA & 1153 & 1161 & 1161 & 1043 & 899 \\
\hline ar3 & CC-2 & $4 / 4$ & NA & 411 & 407 & 408 & 385 & 386 \\
\hline ar4 & CC-2 & $8 / 8$ & NA & 411 & 410 & 414 & 388 & 376 \\
\hline ar5 & LiBr-1 & $4 / 4$ & NA & 500 & 497 & 493 & 449 & 575 \\
\hline ar6 & LiBr-1 & $8 / 8$ & NA & 500 & 502 & 506 & 454 & 483 \\
\hline ar7 & VC-2 & $4 / 4$ & NA & 374 & 372 & 369 & 340 & 327 \\
\hline ar8 & VC-2 & $8 / 8$ & NA & 374 & 375 & 378 & 343 & 318 \\
\hline ar9 & VC-1 & $4 / 4$ & IWLS & 206 & 210 & 198 & 207 & 224 \\
\hline ar10 & VC-1 & $4 / 4$ & IWLL & 203 & 208 & 196 & 205 & 222 \\
\hline ar11 & VC-1 & $4 / 4$ & IDLS & 231 & 232 & 238 & 226 & 247 \\
\hline ar12 & VC-1 & $4 / 4$ & IDLL & 224 & 226 & 232 & 219 & 241 \\
\hline ar13 & VC-1 & $8 / 8$ & IWLS & 308 & 320 & 286 & 313 & 277 \\
\hline ar14 & VC-1 & $8 / 8$ & IWLL & 284 & 296 & 263 & 288 & 256 \\
\hline ar15 & VC-1 & $8 / 8$ & IDLS & 385 & 391 & 392 & 373 & 338 \\
\hline ar16 & VC-1 & $8 / 8$ & IDLL & 333 & 340 & 340 & 322 & 292 \\
\hline ar17 & VC-2 & $4 / 4$ & WWLS & 314 & 324 & 299 & 323 & 384 \\
\hline ar18 & VC-2 & $4 / 4$ & WWLL & 307 & 317 & 292 & 315 & 377 \\
\hline ar19 & VC-2 & $4 / 4$ & WDLS & 284 & 284 & 296 & 280 & 387 \\
\hline ar20 & VC-2 & $4 / 4$ & WDLL & 277 & 277 & 289 & 273 & 379 \\
\hline ar21 & VC-2 & $8 / 8$ & WWLS & 468 & 488 & 426 & 483 & 441 \\
\hline ar22 & VC-2 & $8 / 8$ & WWLL & 427 & 448 & 388 & 441 & 405 \\
\hline ar23 & VC-2 & $8 / 8$ & WDLS & 424 & 429 & 434 & 416 & 450 \\
\hline ar24 & VC-2 & $8 / 8$ & WDLL & 376 & 382 & 386 & 368 & 399 \\
\hline
\end{tabular}


Table C.14. Combined-Cycle $\$ / \mathrm{kW}$; Evaporatively-Cooled Base; $12 \mathrm{hr} /$ day plant; $4 \mathrm{or} 8 \mathrm{hr} /$ day cooling

\begin{tabular}{|c|c|c|c|c|c|c|c|c|}
\hline Case & Chiller & Ophrs & Storage & Nash. & Hous. & Minn. & Phoe. & San Fran. \\
\hline crl & $\mathrm{CC}-4$ & $12 / 4$ & $\mathrm{NA}$ & 629 & 631 & 610 & 522 & 420 \\
\hline cr2 & $\mathrm{CC}-4$ & $12 / 8$ & NA & 629 & 636 & 667 & 528 & 498 \\
\hline cr3 & $\mathrm{CC}-4$ & $12 / 4$ & WDLS & 324 & 331 & 340 & 310 & 373 \\
\hline cr4 & CC-4 & $12 / 4$ & WDLL & 325 & 336 & 346 & 306 & 377 \\
\hline $\operatorname{cr} 5$ & CC-4 & $12 / 8$ & WDLS & 803 & 823 & 842 & 754 & 825 \\
\hline$\overline{c r 6}$ & CC-4 & $12 / 8$ & WDLL & 627 & 661 & 689 & 562 & 639 \\
\hline cr7 & $\mathrm{CC}-3$ & $12 / 4$ & IDLS & 346 & 356 & 359 & 329 & 304 \\
\hline cr8 & $\mathrm{CC}-3$ & $12 / 4$ & IDLL & 332 & 345 & 349 & 312 & 283 \\
\hline cr9 & $\mathrm{CC}-3$ & $12 / 8$ & IDLS & 1074 & 1102 & 1110 & 1005 & 861 \\
\hline $\mathrm{cr} 10$ & $\mathrm{CC}-3$ & $12 / 8$ & IDLL & 751 & 793 & 806 & 672 & 533 \\
\hline crll & $\mathrm{LiBr}-2$ & $12 / 4$ & $\mathrm{NA}$ & 698 & 710 & 669 & 549 & 627 \\
\hline $\mathrm{cr} 12$ & $\mathrm{LiBr}-2$ & $12 / 8$ & $\mathrm{NA}$ & 698 & 719 & 742 & 558 & 642 \\
\hline crl3 & $\mathrm{LiBr}-2$ & $12 / 4$ & WDLS & 347 & 358 & 358 & 316 & 365 \\
\hline crl4 & $\mathrm{LiBr}-2$ & $12 / 4$ & WDLL & 311 & 324 & 326 & 284 & 338 \\
\hline crl5 & $\mathrm{LiBr}-2$ & $12 / 8$ & WDLS & 920 & 945 & 914 & 797 & 823 \\
\hline crl6 & $\mathrm{LiBr}-2$ & $12 / 8$ & WDLL & 555 & 595 & 589 & 476 & 510 \\
\hline $\operatorname{crl7}$ & VC-2 & $12 / 4$ & $\mathrm{NA}$ & 336 & 337 & 320 & 296 & 232 \\
\hline cr18 & VC-2 & $12 / 8$ & $\overline{\mathrm{NA}}$ & 336 & 339 & 339 & 299 & 257 \\
\hline crl9 & $V C-1$ & $12 / 4$ & IWLS & 163 & 169 & 151 & 160 & 145 \\
\hline cr20 & VC-1 & $12 / 4$ & IWLL & 159 & 165 & 148 & 157 & 142 \\
\hline cr21 & VC-1 & $12 / 4$ & IDLS & 190 & 193 & 192 & 181 & 167 \\
\hline cr22 & VC-1 & $12 / 4$ & IDLL & 182 & 185 & 184 & 173 & 159 \\
\hline cr23 & VC-1 & $12 / 8$ & IWLS & 260 & 274 & 239 & 260 & 212 \\
\hline$\overline{c r 24}$ & VC-1 & $12 / 8$ & IWLL & 235 & 249 & 215 & 235 & 191 \\
\hline cr25 & VC-1 & $12 / 8$ & IDLS & 343 & 352 & 350 & 327 & 276 \\
\hline cr26 & VC-1 & $12 / 8$ & IDLL & 289 & 298 & 295 & 273 & 228 \\
\hline cr27 & VC-2 & $12 / 4$ & WWLS & 243 & 254 & 222 & 244 & 221 \\
\hline cr28 & $\overline{V C-2}$ & $12 / 4$ & WWLL & 236 & 247 & 215 & 237 & 214 \\
\hline cr29 & VC-2 & $12 / 4$ & WDLS & 221 & 223 & 223 & 211 & 226 \\
\hline $\operatorname{cr} 30$ & $\overline{V C-2}$ & $12 / 4$ & WDLL & 213 & 216 & 216 & 203 & 217 \\
\hline cr31 & VC-2 & $12 / 8$ & WWLS & 376 & 398 & 340 & 384 & 319 \\
\hline cr32 & $\mathrm{VC}-2$ & $12 / 8$ & WWLL & 341 & 362 & 306 & 346 & 287 \\
\hline$\overline{c r 33}$ & VC-2 & $12 / 8$ & WDLS & 349 & 358 & 358 & 336 & 334 \\
\hline
\end{tabular}


Table C.14. (contd)

\begin{tabular}{|c|c|c|c|c|c|c|c|c|}
\hline Case & Chiller & Ophrs & Storage & Nash. & Hous. & Minn. & Phoe. & San Fran. \\
\hline cr34 & VC-2 & $12 / 8$ & WDLL & 304 & 314 & 313 & 290 & 287 \\
\hline $\operatorname{cr} 35$ & AA-2 & $12 / 4$ & NA & 1724 & 1745 & 1669 & 1440 & 1061 \\
\hline $\mathrm{cr} 36$ & $A A-2$ & $12 / 8$ & NA & 1724 & 1754 & 1801 & 1448 & 1256 \\
\hline cr37 & AA-2 & $12 / 4$ & WDLS & 749 & 780 & 789 & 701 & 730 \\
\hline cr38 & $\overline{\mathrm{AA}-2}$ & $12 / 4$ & WDLL & 640 & 673 & 684 & 594 & 629 \\
\hline $\operatorname{cr} 39$ & $\overline{\mathrm{AA}-2}$ & $12 / 8$ & WDLS & 2522 & 2603 & 2610 & 2285 & 2201 \\
\hline $\mathrm{cr} 40$ & $\mathrm{AA}-2$ & $12 / 8$ & WDLL & 1367 & 1447 & 1472 & 1203 & 1169 \\
\hline cr4l & $\mathrm{AA}-1$ & $12 / 4$ & IDLS & 773 & 804 & 804 & 726 & 599 \\
\hline cr42 & $\overline{\mathrm{AA}-1}$ & $12 / 4$ & IDLL & 661 & 694 & 696 & 614 & 496 \\
\hline $\mathrm{cr} 43$ & AA-1 & $12 / 8$ & IDLS & 2796 & 2878 & 2861 & 2563 & 2050 \\
\hline $\mathrm{cr} 44$ & $\overline{A A-1}$ & $12 / 8$ & IDLL & 1547 & 1635 & 1638 & 1370 & 1014 \\
\hline cr45 & CC-4/CC-5 & $12 / 4$ & $\mathrm{NA}$ & 517 & 522 & 506 & 459 & 385 \\
\hline $\mathrm{cr} 46$ & CC-4/CC-5 & $12 / 8$ & $\overline{\mathrm{NA}}$ & 517 & 525 & 532 & 462 & 415 \\
\hline cr4.7 & $\mathrm{AA}-2 / \mathrm{AA}-3$ & $12 / 4$ & NA & 1700 & 1736 & 1646 & 1460 & 1098 \\
\hline cr48 & $\mathrm{AA}-2 / \mathrm{AA}-3$ & $12 / 8$ & NA & 1700 & 1742 & 1741 & 1465 & 1203 \\
\hline cr49 & $\mathrm{VC}-2 / \mathrm{VC}-3$ & $12 / 4$ & NA & 342 & 344 & 332 & 315 & 272 \\
\hline cr50 & VC-2/VC-3 & $12 / 8$ & NA & 342 & 346 & 344 & 317 & 285 \\
\hline $\mathrm{cr} 51$ & $\mathrm{CC}-3 / \mathrm{CC}-6$ & $12 / 4$ & IDLS & 331 & 337 & 337 & 321 & 304 \\
\hline cr52 & CC-3/CC-6 & $12 / 8$ & IDLS & 865 & 886 . & 880 & 820 & 709 \\
\hline cr53 & AA-1/AA-3 & $12 / 4$ & IDLS & 766 & 786 & 778 & 730 & 638 \\
\hline $\operatorname{cr} 54$ & $\mathrm{AA}-1 / \mathrm{AA}-3$ & $12 / 8$ & IDLS & 1834 & 1900 & 1845 & 1662 & 1209 \\
\hline cr55 & VC-1/VC-3 & $12 / 4$ & IWLS & 235 & 238 & 227 & 234 & 228 \\
\hline $\operatorname{cr} 56$ & VC-1/VC-3 & $12 / 8$ & IWLS & 294 & 303 & 281 & 291 & 261 \\
\hline cr57 & $V C-1 / V C-3$ & $12 / 4$ & IWLL & 234 & 237 & 226 & 233 & 227 \\
\hline cr58 & VC-1/VC-3 & $12 / 8$ & IWLL & 281 & 290 & 269 & 279 & 252 \\
\hline $\operatorname{cr} 59$ & VC-1/VC-3 & $12 / 4$ & IDLS & 251 & 253 & 252 & 245 & 238 \\
\hline cr60 & $\mathrm{VC}-1 / \mathrm{VC}-3$ & $12 / 8$ & IDLS & 344 & 351 & 348 & 330 & 292 \\
\hline cr61 & VC-1/VC-3 & $12 / 4$ & IDLL & 249 & 250 & 249 & 243 & 236 \\
\hline cr62 & VC-1/VC-3 & $12 / 8$ & IDLL & 314 & 320 & 317 & 302 & 271 \\
\hline cr63 & $\mathrm{CC}-3 / \mathrm{CC}-6$ & $12 / 4$ & IDLL & 331 & 337 & 338 & 320 & 305 \\
\hline cr64 & $\mathrm{CC}-3 / \mathrm{CC}-6$ & $12 / 8$ & IDLL & 702 & 721 & 722 & 667 & 606 \\
\hline cr65 & $\mathrm{AA}-1 / \mathrm{AA}-3$ & $12 / 4$ & IDLL & 988 & 1018 & 1008 & 928 & 813 \\
\hline cr66 & $\mathrm{AA}-1 / \mathrm{AA}=3$ & $12 / 8$ & IDLL & 1584 & 1661 & 1633 & 1412 & 1083 \\
\hline
\end{tabular}


Table C.14. (contd)

\begin{tabular}{|l|l|r|r|r|r|r|r|r||}
\hline Case & \multicolumn{1}{|c|}{ Chiller } & Ophrs & Storage & Nash. & Hous. & Minn. & Phoe. & San Fran. \\
\hline \hline cr67 & CC-2 & $12 / 4$ & NA & 374 & 373 & 368 & 332 & 299 \\
\hline cr68 & CC-2 & $12 / 8$ & NA & 374 & 376 & 390 & 336 & 335 \\
\hline cr69 & CC-2 & $12 / 4$ & WDLS & 307 & 313 & 321 & 294 & 360 \\
\hline cr70 & CC-2 & $12 / 4$ & WDLL & 281 & 287 & 296 & 267 & 334 \\
\hline cr71 & CC-2 & $12 / 8$ & WDLS & 721 & 737 & 756 & 681 & 759 \\
\hline cr72 & CC-2 & $12 / 8$ & WDLL & 448 & 464 & 481 & 417 & 488 \\
\hline cr73 & CC-1 & $12 / 4$ & IDLS & 326 & 335 & 339 & 311 & 292 \\
\hline cr74 & CC-1 & $12 / 4$ & IDLL & 284 & 292 & 296 & 269 & 254 \\
\hline cr75 & CC-1 & $12 / 8$ & IDLS & 984 & 1009 & 1018 & 924 & 801 \\
\hline cr76 & CC-1 & $12 / 8$ & IDLL & 534 & 555 & 564 & 495 & 426 \\
\hline cr77 & CC-2/CC-5 & $12 / 4$ & NA & 385 & 386 & 381 & 357 & 329 \\
\hline cr78 & CC-2/CC-5 & $12 / 8$ & NA & 385 & 387 & 394 & 359 & 348 \\
\hline cr79 & CC-1/CC-6 & $12 / 4$ & IDLS & 321 & 326 & 327 & 312 & 299 \\
\hline cr80 & CC-1/CC-6 & $12 / 8$ & IDLS & 818 & 836 & 832 & 779 & 685 \\
\hline cr81 & CC-1/CC-6 & $12 / 4$ & IDLL & 261 & 266 & 267 & 252 & 239 \\
\hline cr82 & CC-1/CC-6 & $12 / 8$ & IDLL & 397 & 409 & 408 & 374 & 321 \\
\hline cr83 & VC-2/CC-5 & $12 / 4$ & NA & 363 & 364 & 359 & 336 & 312 \\
\hline cr84 & VC-2/CC-5 & $12 / 8$ & NA & 363 & 366 & 366 & 338 & 310 \\
\hline cr85 & VC-1/CC-6 & $12 / 4$ & IWLL & 244 & 246 & 240 & 245 & 259 \\
\hline cr86 & VC-2/CC-6 & $12 / 8$ & IWLL & 438 & 443 & 427 & 444 & 451 \\
\hline \hline
\end{tabular}


Table C.15. Combined-Cycle \$/kW; Evaporatively-Cooled Base; 12 hr/day plant; $12 \mathrm{hr} /$ day cooling

\begin{tabular}{|c|c|c|c|c|c|c|c|c|}
\hline Case & Chiller & Ophrs & Storage & Nash. & \begin{tabular}{|l|} 
Hous. \\
\end{tabular} & Minn. & Phoe. & San Fran. \\
\hline $\mathrm{dr} 1$ & $\overline{\mathrm{CC}-4}$ & $12 / 12$ & $\overline{N A}$ & 656 & 640 & 638 & 528 & $\overline{444}$ \\
\hline $\mathrm{dr} 2$ & $\mathrm{LiBr}-2$ & $12 / 12$ & NA & 810 & 792 & 766 & 578 & 474 \\
\hline $\mathrm{dr} 3$ & $\mathrm{AA}-2$ & $12 / 12$ & NA & 1797 & 1760 & 1740 & 1448 & 1152 \\
\hline $\mathrm{dr} 4$ & VC-2 & $12 / 12$ & $\mathrm{NA}$ & 345 & 341 & 339 & 299 & 268 \\
\hline $\mathrm{dr} 5$ & VC-I & $12 / 12$ & IWLS & 381 & 411 & 348 & 384 & 302 \\
\hline $\mathrm{dr} 6$ & VC-1 & $12 / 12$ & IWLL & 310 & 338 & 281 & 311 & 244 \\
\hline $\mathrm{dr} 7$ & VC-1 & $12 / 12$ & IDLS & 573 & 588 & 572 & 543 & $\overline{445}$ \\
\hline $\mathrm{dr} 8$ & VC-1 & $12 / 12$ & IDLL & 395 & 410 & 394 & 369 & 299 \\
\hline $\mathrm{dr} 9$ & VC-2 & $12 / 12$ & WWLS & 521 & 567 & 471 & 537 & $\overline{411}$ \\
\hline $\mathrm{dr} 10$ & VC-2 & $12 / 12$ & WWLL & 430 & 474 & 385 & 441 & 334 \\
\hline drl1 & VC-2 & $12 / 12$ & WDLS & 507 & 523 & 509 & 485 & 452 \\
\hline $\operatorname{dr} 12$ & VC-2 & $12 / 12$ & WDLL & 374 & 390 & 376 & 352 & 325 \\
\hline $\operatorname{dr} 13$ & CC-4/CC-5 & $12 / 12$ & $\mathrm{NA}$ & 533 & 527 & 522 & 462 & $\overline{40.1}$ \\
\hline dr14 & AA-2/AA-3 & $12 / 12$ & $\overline{N A}$ & 1766 & 1746 & 1711 & 1465 & 1175 \\
\hline $\mathrm{dr} 15$ & VC-2/VC-3 & $12 / 12$ & $\overline{\mathrm{NA}}$ & 349 & 347 & 344 & 317 & 291 \\
\hline $\mathrm{dr} 16$ & VC-1/VC-3 & $12 / 12$ & IWLL & 327 & 344 & 309 & 322 & 278 \\
\hline $\mathrm{dr} 17$ & $\mathrm{CC}-2$ & $12 / 12$ & $\mathrm{NA}$ & 384 & 378 & 378 & 336 & 307 \\
\hline $\operatorname{dr} 18$ & CC-2/CC-5 & $12 / 12$ & $\overline{\mathrm{NA}}$ & 392 & 389 & 388 & 359 & $\overline{335}$ \\
\hline $\mathrm{dr} 19$ & VC-2/CC-5 & $12 / 12$ & $\mathrm{NA}$ & 370 & 367 & 366 & 338 & $\overline{316}$ \\
\hline $\operatorname{dr} 20$ & $\mathrm{VC}-2 / \mathrm{CC}-5$ & $12 / 12$ & IWLL & 344 & 363 & 325 & 343 & 300 \\
\hline
\end{tabular}


Table C.16. Combined-Cycle $\$ / \mathrm{kW}$; Evaporatively-Cooled Base; $24 \mathrm{hr} /$ day plant; 4 or 8 or $12 \mathrm{hr} /$ day cooling

\begin{tabular}{|c|c|c|c|c|c|c|c|c|}
\hline Case & Chiller & Ophrs & Storage & Nash. & Hous. & Minn. & Phoe. & San Fran. \\
\hline erl & $\overline{C C}-4$ & $24 / 4$ & NA & 629 & 631 & 610 & 522 & 420 \\
\hline er2 & $\mathrm{CC}-4$ & $24 / 8$ & $\mathrm{NA}$ & 629 & 636 & 638 & 528 & 418 \\
\hline er3 & $\mathrm{CC}-4$ & $24 / 12$ & NA & 656 & 669 & 638 & 528 & 436 \\
\hline er4 & CC-4 & $24 / 4$ & WDLS & 231 & 234 & 241 & 222 & 280 \\
\hline er5 & $\mathrm{CC}-4$ & $24 / 4$ & WDLL & 238 & 242 & 249 & 226 & 289 \\
\hline er6 & $\mathrm{CC}-4$ & $24 / 8$ & WDLS & 372 & 381 & 381 & 357 & 354 \\
\hline er7 & CC-4 & $24 / 8$ & WDLL & 371 & 384 & 384 & 350 & 339 \\
\hline er8 & $\mathrm{CC}-4$ & $24 / 12$ & WDLS & 548 & 558 & 550 & 524 & 452 \\
\hline er9 & $\mathrm{CC}-4$ & $24 / 12$ & WDLL & 503 & 517 & 504 & 464 & 377 \\
\hline er10 & $\mathrm{CC}-3$ & $24 / 4$ & IDLS & 197 & 201 & 203 & 188 & 189 \\
\hline er11 & $\overline{\mathrm{CC}-3}$ & $24 / 4$ & IDLL & 200. & 205 & 208 & 189 & 189 \\
\hline$\overline{\mathrm{er} 12}$ & $\mathrm{CC}-3$ & $24 / 8$ & IDLS & 357 & 368 & 364 & 340 & 282 \\
\hline er13 & $\mathrm{CC}-3$ & $24 / 8$ & IDLL & 343 & 357 & 352 & 322 & 257 \\
\hline er14 & $\overline{C C}-3$ & $24 / 12$ & IDLS & 596 & 609 & 595 & 564 & 440 \\
\hline er15 & CC-3 & $24 / 12$ & IDLL & 511 & 527 & 509 & 469 & 341 \\
\hline er16 & $\mathrm{LiBr}-2$ & $24 / 4$ & $\overline{\mathrm{NA}}$ & 698 & 710 & 669 & 549 & 627 \\
\hline er17 & $\mathrm{LiBr}-2$ & $24 / 8$ & NA & 698 & 719 & 709 & 558 & 495 \\
\hline er18 & $\mathrm{LiBr}-2$ & $24 / 12$ & $\mathrm{NA}$ & 810 & 857 & 766 & 578 & 445 \\
\hline er19 & $\mathrm{LiBr}-2$ & $24 / 4$ & WDLS & 233 & 240 & 243 & 221 & 274 \\
\hline er20 & $\mathrm{LiBr}-2$ & $24 / 4$ & WDLL & 229 & 236 & 240 & 217 & 271 \\
\hline er21 & $\mathrm{LiBr}-2$ & $24 / 8$ & WDLS & 380 & 405 & 389 & 361 & 347 \\
\hline er22 & $\mathrm{LiBr}-2$ & $24 / 8$ & WDLL & 349 & 373 & 359 & 325 & 310 \\
\hline er23 & $\mathrm{LiBr}-2$ & $24 / 12$ & WDLS & 563 & 609 & 569 & 529 & 448 \\
\hline er24 & $\mathrm{LiBr}-2$ & $24 / 12$ & WDLL & 453 & 486 & 453 & 410 & 338 \\
\hline er25 & VC-2 & $24 / 4$ & $\mathrm{NA}$ & 336 & 337 & 329 & 296 & 260 \\
\hline er26 & VC-2. & $24 / .8$ & NA & 336 & 339 & 339 & 299 & 257 \\
\hline er27 & VC-2 & $24 / 12$ & NA & 345 & 352 & 339 & 299 & 264 \\
\hline er28 & VC-1 & $24 / 4$ & IWLS & 165 & 171 & 156 & 163 & 162 \\
\hline er29 & VC-1 & $24 / 4$ & IWLL & 159 & 165 & 151 & 157 & 157 \\
\hline er30 & VC-1 & $24 / 4$ & IDLS & 190 & 193 & 196 & 181 & 184 \\
\hline er31 & VC-1 & $24 / 4$ & IDLL & 182 & 185 & 188 & 173 & 176 \\
\hline er32 & VC-1 & $24 / 8$ & IWLS & 274 & 289 & 250 & 274 & 221 \\
\hline er33 & VC-1 & $24 / 8$ & IWLL & 235 & 249 & 215 & 235 & 191 \\
\hline
\end{tabular}


Table C.16. (contd)

\begin{tabular}{|c|c|c|c|c|c|c|c|c|}
\hline Case & Chiller & Ophrs & Storage & Nash. & Hous. & Minn. & Phoe. & San Fran. \\
\hline er34 & VC-1 & $24 / 8$ & IDLS & 343 & 352 & 350 & 327 & 276 \\
\hline$\overline{\text { er35 }}$ & $\overline{V C-1}$ & $24 / 8$ & IDLL & 289 & 298 & 295 & 273 & 228 \\
\hline er36 & VC-1 & $24 / 12$ & IWLS & 570 & 600 & 523 & 558 & 399 \\
\hline er37 & VC-1 & $24 / 12$ & IWLL & 412 & 440 & 375 & 401 & 284 \\
\hline er38 & $\mathrm{VC}-1$ & $24 / 12$ & IDLS & 573 & 581 & 572 & 543 & 432 \\
\hline er39 & VC-1 & $24 / 12$ & IDLL & 395 & 406 & 394 & 369 & 289 \\
\hline er40 & $\mathrm{VC}-2$ & $24 / 4$ & WWLS & 239 & 250 & 225 & 240 & 259 \\
\hline$\overline{\mathrm{er} 41}$ & $\mathrm{VC}-2$ & $24 / 4$ & WWLL & 236 & 247 & 222 & 237 & 256 \\
\hline er42 & VC-2 & $24 / 4$ & WDLS & 221 & 223 & 230 & 211 & 268 \\
\hline er43 & VC-2 & $24 / 4$ & WDLL & 213 & 216 & 222 & 203 & 259 \\
\hline er44 & VC-2 & $24 / 8$ & WWLS & 365 & 386 & 329 & 371 & 308 \\
\hline er45 & VC-2 & $24 / 8$ & WWLL & 341 & 362 & 306 & 346 & 287 \\
\hline er46 & VC-2 & $24 / 8$ & WDLS & 349 & 358 & 358 & 336 & $\overline{334}$ \\
\hline er47 & VC-2 & $24 / 8$ & WDLL & 304 & 314 & 313 & 290 & 287 \\
\hline er48 & $\mathrm{VC}-2$ & $24 / 12$ & WWLS & 641 & 676 & 584 & 640 & 428 \\
\hline er49 & VC-2 & $24 / 12$ & WWLL & 558 & 596 & 502 & 554 & 363 \\
\hline er50 & $V C-2$ & $24 / 12$ & WDLS & 507 & 516 & 509 & 485 & 422 \\
\hline er51 & $\mathrm{VC}-2$ & $24 / 12$ & WDLL & 374 & 386 & 376 & 352 & 304 \\
\hline er52 & $\overline{\mathrm{AA}-2}$ & $24 / 4$ & NA & 1724 & 1745 & 1669 & 1440 & 1061 \\
\hline er53 & $\overline{\mathrm{AA}-2}$ & $24 / 8$ & NA & 1724 & 1754 & 1740 & 1448 & 1088 \\
\hline er54 & $\mathrm{AA}-2$ & $24 / 12$ & $\mathrm{NA}$ & 1797 & 1834 & 1740 & 1448 & 1150 \\
\hline er55 & $\overline{A A-2}$ & $24 / 4$ & WDLS & 397 & 412 & 418 & 378 & 422 \\
\hline er56 & AA-2 & $24 / 4$ & WDLL & 381 & 396 & 404 & 360 & 407 \\
\hline er57 & $\mathrm{AA}-2$ & $24 / 8$ & WDLS & .789 & 827 & 808 & 741 & 639 \\
\hline er58 & $A A-2$ & $24 / 8$ & WDLL & 680 & 716 & 701 & 629 & 537 \\
\hline er59 & $\overline{A A-2}$ & $24 / 12$ & WDLS & 1354 & 1404 & 1355 & 1260 & 945 \\
\hline er60 & $\overline{A A-2}$ & $24 / 12$ & WDLL & 984 & 1020 & 981 & 891 & 642 \\
\hline er61 & AA-1 & $24 / 4$ & IDLS & 364 & 378 & 379 & 346 & 305 \\
\hline er62 & AA-1 & $24 / 4$ & IDLL & 348 & 363 & 365 & 329 & 290 \\
\hline er63 & $\overline{\mathrm{AA}-1}$ & $24 / 8$ & IDLS & 775 & 812 & 790 & 730 & 547 \\
\hline er64 & $\overline{A A-1}$ & $24 / 8$ & IDLL & 668 & 704 & 684 & 618 & 448 \\
\hline$\overline{\mathrm{er} 65}$ & $\overline{A A-1}$ & $24 / 12$ & IDLS & 1411 & 1463 & 1408 & 1319 & 934 \\
\hline er66 & AA-1 & $24 / 12$ & IDLL & 1030 & 1068 & 1022 & 934 & 626 \\
\hline er67 & CC-4/CC-5 & $24 / 4$ & $\mathrm{NA}$ & 517 & 522 & 506 & 459 & 385 \\
\hline
\end{tabular}


Table C.16. (contd)

\begin{tabular}{|c|c|c|c|c|c|c|c|c|}
\hline Case & Chiller & Ophrs & Storage & Nash. & Hous. & Minn. & Phoe. & San Fran. \\
\hline er68 & CC-4/CC-5 & $24 / 8$ & NA & 517 & 525 & 521 & 462 & 388 \\
\hline er69 & CC-4/CC-5 & $24 / 12$ & $\mathrm{NA}$ & 533 & 543 & 522 & 462 & 400 \\
\hline er70 & AA-2/AA-3 & $24 / 4$ & NA & 1700 & 1736 & 1646 & 1460 & 1098 \\
\hline er71 & AA-2/AA-3 & $24 / 8$ & $\mathrm{NA}$ & 1700 & 1742 & 1709 & 1465 & 1133 \\
\hline er72 & $\mathrm{AA}-2 / \mathrm{AA}-3$ & $24 / 12$ & $\overline{N A}$ & 1766 & 1814 & 1711 & 1465 & 1187 \\
\hline er73 & $\mathrm{VC}-2 / \mathrm{VC}-3$ & $24 / 4$ & NA & 342 & 344 & 337 & 315 & 285 \\
\hline er74 & $\mathrm{VC}-2 / \mathrm{VC}-3$ & $24 / 8$ & NA & 342 & 346 & 344 & 317 & 285 \\
\hline er75 & $\mathrm{VC}-2 / \mathrm{VC}-3$ & $24 / 12$ & $\mathrm{NA}$ & 349 & 354 & 344 & 317 & 290 \\
\hline er76 & $\mathrm{CC}-3$ & $24 / 4$ & IWLS & 170 & 177 & 161 & 168 & 165 \\
\hline er77 & $\mathrm{CC}-3$ & $24 / 4$ & IWLL & 170 & 177 & 160 & 167 & 165 \\
\hline er78 & $\overline{C C-3}$ & $24 / 8$ & IWLS & 282 & 299 & 257 & 283 & 225 \\
\hline er79 & $\mathrm{CC}-3$ & $24 / 8$ & IWLL & 263 & 281 & 237 & 263 & 205 \\
\hline er80 & $\mathrm{CC}-3$ & $24 / 12$ & IWLS & 590 & 624 & 539 & 578 & 407 \\
\hline$\overline{\mathrm{er} 81}$ & $\mathrm{CC}-3$ & $24 / 12$ & IWLL & 517 & 560 & 457 & 499 & 324 \\
\hline er82 & AA-1 & $24 / 4$ & IWLS & 276 & 295 & 253 & 274 & $\overline{235}$ \\
\hline er83 & $\overline{\mathrm{AA}-1}$ & $24 / 4$ & IWLL & 261 & 280 & 239 & 259 & 223 \\
\hline er84 & $\overline{\mathrm{AA}-1}$ & $24 / 8$ & IWLS & 545 & 590 & 480 & 543 & 381 \\
\hline er85 & $\overline{\mathrm{AA}-1}$ & $24 / 8$ & IWLL & 453 & 494 & 396 & 450 & $\overline{314}$ \\
\hline er86 & AA-1 & $24 / 12$ & IWLS & 1322 & 1418 & 1180 & 1284 & 810 \\
\hline$\overline{\text { er87 }}$ & $\overline{\mathrm{AA}-1}$ & $24 / 12$ & IWLL & 963 & 1051 & 836 & 922 & 545 \\
\hline er88 & CC-3/CC-6 & $24 / 4$ & IWLS & 729 & 723 & 730 & 746 & 851 \\
\hline er89 & $\mathrm{CC}-3 / \mathrm{CC}-6$ & $24 / 8$ & IWLS & 1414 & 1403 & 1404 & 1452 & 1599 \\
\hline er90 & $\overline{C C}-3 / \mathrm{CC}-6$ & $24 / 12$ & IWLS & 2949 & 2926 & 2950 & 3044 & 3262 \\
\hline er9l & CC-3/CC-6 & $24 / 4$ & IWLL & -757 & 753 & 756 & 775 & $\overline{875}$ \\
\hline er92 & $\mathrm{CC}-3 / \mathrm{CC}-6$ & $24 / 8$ & IWLL & 1522 & 1519 & 1498 & 1560 & 1682 \\
\hline er93 & CC-3/CC-6 & $24 / 12$ & IWLL & 3492 & 3507 & 3433 & 3574 & 3627 \\
\hline er94 & $\mathrm{CC}-3 / \mathrm{CC}-6$ & $24 / 4$ & IDLS & 248 & 249 & 252 & 245 & 253 \\
\hline er95 & $\mathrm{CC}-3 / \mathrm{CC}-6$ & $24 / 8$ & IDLS & 461 & 465 & 465 & 455 & 444 \\
\hline er96 & CC-3/CC-6 & $24 / 12$ & IDLS & 720 & 725 & 720 & 707 & 664 \\
\hline er97 & $\mathrm{CC}-3 / \mathrm{CC}-6$ & $24 / 4$ & IDLL & 256 & 258 & 260 & 252 & 259 \\
\hline er98 & $\mathrm{CC}-3 / \mathrm{CC}-6$ & $24 / 8$ & IDLL & 481 & 487 & 486 & 473 & 459 \\
\hline er99 & $\mathrm{CC}-3 / \mathrm{CC}-6$ & $24 / 12$ & IDLL & 736 & 742 & 736 & 720 & 676 \\
\hline er100 & AA-1/AA-3 & $24 / 4$ & IWLS & 493 & 506 & 477 & 495 & 484 \\
\hline er101 & AA-1/AA-3 & $24 / 8$ & IWLS & 634 & 664 & 593 & 631 & $\overline{536}$ \\
\hline
\end{tabular}


Table C.16. (contd)

\begin{tabular}{|c|c|c|c|c|c|c|c|c|}
\hline Case & Chiller & Ophrs & Storage & Nash. & Hous. & Minn. & Phoe. & San Fran. \\
\hline er102 & AA-1/AA-3 & $24 / 12$ & IWLS & 627 & 657 & .593 & 631 & 520 \\
\hline er103 & $A A-1 / A A-3$ & $24 / 4$ & IWLL & 667 & 686 & 642 & 662 & 643 \\
\hline er104 & $\mathrm{AA}-1 / \mathrm{AA}-3$ & $24 / 8$ & IWLL & 814 & 853 & 763 & 801 & 687 \\
\hline er105 & $\mathrm{AA}-1 / \mathrm{AA}-3$ & $24 / 12$ & IWLL & 801 & 840 & 763 & 801 & 659 \\
\hline er106 & AA-1/AA-3 & $24 / 4$ & IDLS & 543 & 553 & 552 & 536 & 518 \\
\hline er107 & $\mathrm{AA}-1 / \mathrm{AA}-3$ & $24 / 8$ & IDLS & 758 & 788 & 765 & 730 & 611 \\
\hline er108 & AA-1/AA-3 & $24 / 12$ & IDLS & 1094 & 1142 & 1090 & 1025 & 768 \\
\hline er109 & AA-1/AA-3 & $24 / 4$ & IDLL & 743 & 757 & 755 & 722 & 692 \\
\hline er110 & AA-1/AA-3 & $24 / 8$ & IDLL & 983 & 1022 & 996 & 928 & 777 \\
\hline erl11 & $A A-1 / A A-3$ & $24 / 12$ & IDLL & 1247 & 1293 & .1235 & 1137 & 874 \\
\hline er112 & VC-1/VC-3 & $24 / 4$ & IWLS & 236 & 239 & 231 & 235 & 239 \\
\hline er113 & $\mathrm{VC}-1 / \mathrm{VC}-3$ & $24 / 8$ & IWLS & 302 & 312 & 288 & 299 & 265 \\
\hline er114 & VC-1/VC-3 & $24 / 12$ & IWLS & 485 & 508 & 454 & 465 & 355 \\
\hline er115 & VC-1/VC-3 & $24 / 4$ & IWLL & 234 & 237 & 229 & 233 & 237 \\
\hline er116 & $\mathrm{VC}-1 / \mathrm{VC}-3$ & $24 / 8$ & IWLL & 281 & 290 & 269 & 279 & 252 \\
\hline er117 & VC-1/VC-3 & $24 / 12$ & IWLL & 387 & 406 & 364 & 373 & 298 \\
\hline er118 & $\mathrm{VC}-1 / \mathrm{VC}-3$ & $24 / 4$ & IDLS & 251 & 253 & 255 & 245 & 249 \\
\hline er119 & VC-1/VC-3 & $24 / 8$ & IDLS & 344 & 351 & 348 & 330 & 292 \\
\hline er120 & $\mathrm{VC}-1 / \mathrm{VC}-3$ & $24 / 12$ & IDLS & 487 & 496 & 484 & 457 & 372 \\
\hline er121 & VC-1/VC-3 & $24 / 4$ & IDLL & 249 & 250 & 252 & 243 & 247 \\
\hline er122 & VC-1/VC-3 & $24 / 8$ & IDLL & 314 & 320 & 317 & 302 & 271 \\
\hline er123 & $\mathrm{VC}-1 / \mathrm{VC}-3$ & $24 / 12$ & IDLL & 377 & 386 & 375 & 355 & 301 \\
\hline er124 & $\mathrm{CC}-2$ & $24 / 4$ & $\mathrm{NA}$ & 374 & 373 & 368 & 332 & 299 \\
\hline er125 & $\mathrm{CC}-2$ & $24 / 8$ & $\mathrm{NA}$ & 374 & 376 & 378 & 336 & 293 \\
\hline er126 & $\mathrm{CC}-2$ & $24 / 12$ & $\mathrm{NA}$ & 384 & 389 & 378 & 336 & 301 \\
\hline er127 & $\mathrm{CC}-2$ & $24 / 4$ & WDLS & 225 & 228 & 235 & 216 & 276 \\
\hline er128 & $\mathrm{CC}-2$ & $24 / 4$ & WDLL & 222 & 225 & 232 & 212 & 273 \\
\hline er129 & $\mathrm{CC}-2$ & $24 / 8$ & WDLS & 355 & 363 & 364 & 342 & 343 \\
\hline er130 & $\mathrm{CC}-2$ & $24 / 8$ & WDLL & 322 & 331 & 331 & 308 & 308 \\
\hline er131 & $\mathrm{CC}-2$ & $24 / 12$ & WDLS & 512 & 520 & 514 & 491 & 431 \\
\hline er132 & $\mathrm{CC}-2$ & $24 / 12$ & WDLL & 404 & 413 & 405 & 381 & 331 \\
\hline er133 & $\mathrm{CC}-1$ & $24 / 4$ & IDLS & 190 & 193 & 196 & 181 & 184 \\
\hline er134 & $\mathrm{CC}-1$ & $24 / 4$ & IDLL & 185 & 188 & 191 & 176 & 180 \\
\hline er135 & $\mathrm{CC}-1$ & $24 / 8$ & IDLS & 337 & 347 & 344 & 322 & 271 \\
\hline
\end{tabular}


Table C.16. (contd)

\begin{tabular}{|c|c|c|c|c|c|c|c|c|}
\hline Case & Chiller & Ophrs & Storage & Nash. & Hous. & Minn. & Phoe. & San Fran. \\
\hline er136 & $\mathrm{CC}-1$ & $24 / 8$ & IDLL & 294 & 304 & 301 & 279 & 233 \\
\hline er137 & $\overline{\mathrm{CC}-1}$ & $24 / 12$ & IDLS & 556 & 567 & 555 & 527 & 417 \\
\hline er138 & $\mathrm{CC}-1$ & $24 / 12$ & IDLL & 406 & 415 & 405 & 379 & 296 \\
\hline er139 & CC-2/CC-5 & $24 / 4$ & NA & 385 & 386 & 381 & 357 & 329 \\
\hline er140 & CC-2/CC-5 & $24 / 8$ & NA & 385 & 387 & 388 & 359 & 328 \\
\hline er141 & CC-2/CC-5 & $24 / 12$ & NA & 392 & 396 & 388 & 359 & 333 \\
\hline er142 & $\overline{C C-1}$ & $24 / 4$ & IWLS & 166 & 172 & 157 & 163 & 163 \\
\hline er143 & CC-1 & $24 / 4$ & IWLL & 162 & 168 & 153 & 159 & 160 \\
\hline er144 & CC-1 & $24 / 8$ & IWLS & 271 & 286 & 248 & 271 & 219 \\
\hline erl45 & $\overline{C C}-1$ & $24 / 8$ & IWLL & 239 & 253 & 219 & 239 & 194 \\
\hline$\overline{\text { er146 }}$ & $\mathrm{CC}-1$ & $24 / 12$ & IWLS & 554 & 584 & 508 & 543 & 389 \\
\hline erl47 & $\mathrm{CC}-1$ & $24 / 12$ & IWLL & 423 & 451 & 384 & 412 & 290 \\
\hline er148 & CC-1/CC-6 & $24 / 4$ & IWLS & 727 & 720 & 728 & 744 & 850 \\
\hline er149 & CC-1/CC-6 & $24 / 8$ & IWLS & 1408 & 1396 & 1399 & 1446 & 1597 \\
\hline er150 & $\mathrm{CC}-1 / \mathrm{CC}-6$ & $24 / 12$ & IWLS & 2930 & 2905 & 2934 & 3026 & 3254 \\
\hline er151 & CC-1/CC-6 & $24 / 4$ & IWLL & 744 & 738 & 744 & 762 & 867 \\
\hline er152 & CC-1/CC-6 & $24 / 8$ & IWLL & 1471 & 1462 & 1456 & 1510 & 1655 \\
\hline er153 & $\mathrm{CC}-1 / \mathrm{CC}-6$ & $24 / 12$ & IWLL & 3233 & 3221 & 3213 & 3332 & 3506 \\
\hline erl54 & $\mathrm{CC}-1 / \mathrm{CC}-6$ & $24 / 4$ & IDLS & 244 & 245 & 248 & 241 & 251 \\
\hline er155 & $\mathrm{CC}-1 / \mathrm{CC}-6$ & $24 / 8$ & IDLS & 451 & 454 & 454 & 446 & 440 \\
\hline er156 & CC-1/CC-6 & $24 / 12$ & IDLS & 698 & 702 & 699 & 688 & 654 \\
\hline er157 & $\mathrm{CC}-1 / \mathrm{CC}-6$ & $24 / 4$ & IDLL & 247 & 248 & 251 & 244 & 254 \\
\hline er158 & $\mathrm{CC}-1 / \mathrm{CC}-6$ & $24 / 8$ & IDLL & 449 & 452 & 453 & 445 & $\overline{444}$ \\
\hline er159 & $\mathrm{CC}-1 / \mathrm{CC}-6$ & $24 / 12$ & IDLL & 665 & 667 & 667 & 659 & 643 \\
\hline er160 & VC-2/CC-5 & $24 / 4$ & $\mathrm{NA}$ & 363 & 364 & 359 & 336 & 312 \\
\hline er161 & VC-2/CC-5 & $24 / 8$ & $\overline{N A}$ & 363 & 366 & 366 & 338 & 310 \\
\hline er162 & VC-2/CC-5 & $24 / 12$ & NA & 370 & 375 & 366 & 338 & 314 \\
\hline erl63 & VC-1/CC-5 & $24 / 4$ & IWLL & 236 & 238 & 233 & 237 & 249 \\
\hline er164 & VC-1/CC-5 & $24 / 8$ & IWLL & 417 & 422 & 406 & 422 & 426 \\
\hline er165 & VC-1/CC-5 & $24 / 12$ & IWLL & 663 & $\overline{676}$ & 644 & 666 & 633 \\
\hline
\end{tabular}


Table C.17. Combined-Cycle \$/kW; Evaporatively-Cooled Base; $24 \mathrm{hr} /$ day plant; $24 \mathrm{hr} /$ day cooling

\begin{tabular}{||l|l|r|r|r|r|r|r|r||}
\hline \hline Case & Chiller & Ophrs & Storage & Nash. & Hous. & Minn. & Phoe. & San Fran. \\
\hline \hline fr1 & CC-4 & $24 / 24$ & NA & 656 & 669 & 638 & 528 & 436 \\
\hline fr2 & LiBr-2 & $24 / 24$ & NA & 810 & 857 & 766 & 578 & 445 \\
\hline fr3 & AA-2 & $24 / 24$ & NA & 1797 & 1834 & 1740 & 1448 & 1150 \\
\hline fr4 & VC-2 & $24 / 24$ & NA & 345 & 352 & 339 & 299 & 264 \\
\hline fr5 & CC-4/CC-5 & $24 / 24$ & NA & 533 & 544 & 522 & 462 & 401 \\
\hline fr6 & AA-2/AA-3 & $24 / 24$ & NA & 1767 & 1815 & 1711 & 1466 & 1189 \\
\hline fr7 & VC-2/VC-3 & $24 / 24$ & NA & 349 & 354 & 344 & 317 & 291 \\
\hline fr8 & CC-2 & $24 / 24$ & NA & 384 & 389 & 378 & 336 & 301 \\
\hline fr9 & CC-2/CC-5 & $24 / 24$ & NA & 392 & 397 & 388 & 359 & 333 \\
\hline fr10 & VC-2/CC-5 & $24 / 24$ & NA & 370 & 375 & 366 & 339 & 315 \\
\hline
\end{tabular}


Table C.18. Industrial Turbine $\$ / k W$; Evaporatively-Cooled Base

\begin{tabular}{|c|c|c|c|c|c|c|c|c|}
\hline Case & Chiller & Ophrs & Storage & Nash. & Hous. & Minn. & Phoe. & San Fran. \\
\hline ir1 & AA-2 & $4 / 4$ & $\overline{\mathrm{NA}}$ & 1400 & 1407 & 1374 & 1252 & 1050 \\
\hline ir2 & AA-2 & $8 / 8$ & NA & 1400 & 1412 & 1409 & 1258 & 1062 \\
\hline ir3 & $\mathrm{CC}-2$ & $4 / 4$ & NA & 462 & 460 & 457 & 426 & 408 \\
\hline ir4 & $\mathrm{CC}-2$ & $8 / 8$ & NA & 462 & 462 & 465 & 429 & 401 \\
\hline ir5 & $\mathrm{LiBr}-1$ & $4 / 4$ & $\mathrm{NA}$ & 564 & 565 & 553 & 492 & 597 \\
\hline ir6 & $\mathrm{LiBr}-1$ & $8 / 8$ & NA & 564 & 571 & 571 & 500 & 499 \\
\hline ir7 & VC-2 & $4 / 4$ & NA & 424 & 425 & 416 & 374 & $\overline{334}$ \\
\hline ir8 & VC-2 & $8 / 8$ & $\overline{\mathrm{NA}}$ & 424 & 428 & 429 & 378 & 329 \\
\hline ir9 & VC-1 & $4 / 4$ & IWLS & 203 & 210 & 193 & 202 & 207 \\
\hline ir10 & VC-1 & $4 / 4$ & IWLL & 200 & 207 & 191 & 198 & 204 \\
\hline irl1 & VC-1 & $4 / 4$ & IDLS & 234 & 237 & 242 & 225 & 235 \\
\hline irl2 & VC-1 & $4 / 4$ & IDLL & 227 & 231 & 235 & 217 & 227 \\
\hline ir13 & VC-1 & $8 / 8$ & IWLS & 319 & 334 & 293 & 321 & 269 \\
\hline ir14 & VC-1 & $8 / 8$ & IWLL & 293 & 310 & 269 & 294 & 245 \\
\hline ir15 & VC-1 & $8 / 8$ & IDLS & 413 & 423 & 422 & 396 & 343 \\
\hline ir16 & $\mathrm{VC}-1$ & $8 / 8$ & IDLL & 357 & 368 & 365 & 340 & 291 \\
\hline ir17 & VC-2 & $4 / 4$ & WWLS & 305 & 317 & 287 & 308 & 342 \\
\hline ir18 & VC-2 & $4 / 4$ & WWLL & 298 & 311 & 281 & 301 & 334 \\
\hline ir19 & VC-2 & $4 / 4$ & WDLS & 276 & 278 & 287 & 267 & 347 \\
\hline ir20 & VC-2 & $4 / 4$ & WDLL & 269 & 272 & 281 & 259 & 338 \\
\hline ir21 & VC-2 & $8 / 8$ & WWLS & 468 & 492 & 423 & 478 & 410 \\
\hline ir22 & VC-2 & $8 / 8$ & WWLL & 428 & 454 & 385 & 437 & $\overline{372}$ \\
\hline ir23 & VC-2 & $8 / 8$ & WDLS & 430 & 438 & 440 & 416 & 425 \\
\hline ir24 & $\overline{V C-2}$ & $8 / 8$ & WDLL & 382 & 393 & 393 & 366 & 372 \\
\hline ir25 & CC-2/CC-5 & $4 / 4$ & $\mathrm{NA}$ & 474 & 472 & 472 & 459 & 462 \\
\hline ir26 & $\mathrm{CC}-2 / \mathrm{CC}-5$ & $8 / 8$ & NA & 474 & 474 & 476 & 460 & 457 \\
\hline ir27 & AA-2/AA-3 & $4 / 4$ & $\mathrm{NA}$ & 1289 & 1300 & 1270 & 1195 & 1047 \\
\hline ir28 & $\mathrm{AA}-2 / \mathrm{AA}-3$ & $8 / 8$ & $\mathrm{NA}$ & 1289 & 1303 & 1293 & 1198 & 1061 \\
\hline ir29 & $\mathrm{VC}-2 / \mathrm{VC}-3$ & $4 / 4$ & NA & 441 & 444 & 435 & 406 & 367 \\
\hline ir30 & VC-2/VC-3 & $8 / 8$ & $\overline{N A}$ & 441 & 446 & 444 & 408 & 367 \\
\hline ir31 & VC-1/VC-3 & $4 / 4$ & IWLS & 297 & 300 & 291 & 296 & $\overline{305}$ \\
\hline ir32 & VC-1/VC-3 & $8 / 8$ & IWLS & 369 & 380 & 354 & 368 & 333 \\
\hline ir33 & VC-1/VC-3 & $4 / 4$ & IWLL & 297 & 301 & 291 & 296 & 304 \\
\hline$\overline{\text { ir34 }}$ & VC-1/VC-3 & $8 / 8$ & IWLL & 357 & 368 & 341 & 355 & 323 \\
\hline
\end{tabular}


Table C.18. (contd)

\begin{tabular}{||l|c|r|c|r|r|r|r|r||}
\hline \hline Case & Chiller & Ophrs & Storage & Nash. & Hous. & Minn. & Phoe. & San Fran. \\
\hline \hline ir35 & VC-1/VC-3 & $4 / 4$ & IDLS & 316 & 318 & 321 & 310 & 318 \\
\hline ir36 & VC-1/VC-3 & $8 / 8$ & IDLS & 430 & 437 & 435 & 414 & 370 \\
\hline ir37 & VC-1/VC-3 & $4 / 4$ & IDLL & 315 & 317 & 320 & 308 & 316 \\
\hline ir38 & VC-1/VC-3 & $8 / 8$ & IDLL & 399 & 407 & 404 & 384 & 347 \\
\hline ir39 & VC-2/CC-5 & $4 / 4$ & NA & 478 & 479 & 474 & 453 & 439 \\
\hline ir40 & VC-2/CC-5 & $8 / 8$ & NA & 478 & 480 & 480 & 454 & 436 \\
\hline ir41 & VC-1/CC-5 & $4 / 4$ & IWLL & 353 & 355 & 349 & 356 & 382 \\
\hline ir42 & VC-1/CC-5 & $8 / 8$ & IWLL & 404 & 412 & 391 & 406 & 395 \\
\hline \hline
\end{tabular}


Table C.19. Aeroderivative Turbine NPV (\$M); Evaporatively-Cooled Base

\begin{tabular}{|l|l|r|c|r|r|r|r|r||}
\hline Case & Chiller & Ophrs & Storage & Nash. & Hous. & Minn. & Phoe. & San Fran. \\
\hline ar1 & AA-2 & $4 / 4$ & NA & -3.63 & -3.85 & -3.44 & -1.12 & -0.67 \\
\hline ar2 & AA-2 & $8 / 8$ & NA & -3.46 & -3.68 & -3.71 & -0.97 & -0.73 \\
\hline ar3 & CC-2 & $4 / 4$ & NA & 4.73 & 5.07 & 4.47 & 5.59 & 2.80 \\
\hline ar4 & CC-2 & $8 / 8$ & NA & 4.88 & 5.24 & 4.58 & 5.74 & 3.20 \\
\hline ar5 & LiBr-1 & $4 / 4$ & NA & 2.67 & 2.91 & 2.50 & 3.46 & 0.79 \\
\hline ar6 & LiBr-1 & $8 / 8$ & NA & 2.76 & 3.01 & 2.49 & 3.52 & 1.34 \\
\hline ar7 & VC-2 & $4 / 4$ & NA & 4.26 & 4.49 & 4.12 & 5.22 & 2.97 \\
\hline ar8 & VC-2 & $8 / 8$ & NA & 4.34 & 4.54 & 4.13 & 5.31 & 3.33 \\
\hline ar9 & VC-1 & $4 / 4$ & IWLS & 7.47 & 7.85 & 7.21 & 7.88 & 4.19 \\
\hline ar10 & VC-1 & $4 / 4$ & IWLL & 7.27 & 7.60 & 7.05 & 7.67 & 4.13 \\
\hline ar11 & VC-1 & $4 / 4$ & IDLS & 7.18 & 7.57 & 6.77 & 7.68 & 4.02 \\
\hline ar12 & VC-1 & $4 / 4$ & IDLL & 6.90 & 7.25 & 6.50 & 7.40 & 3.94 \\
\hline ar13 & VC-1 & $8 / 8$ & IWLS & 6.46 & 6.69 & 6.48 & 6.98 & 4.25 \\
\hline ar14 & VC-1 & $8 / 8$ & IWLL & 6.31 & 6.47 & 6.38 & 6.79 & 4.26 \\
\hline ar15 & VC-1 & $8 / 8$ & IDLS & 5.58 & 5.82 & 5.29 & 6.33 & 3.79 \\
\hline ar16 & VC-1 & $8 / 8$ & IDLL & 5.54 & 5.72 & 5.29 & 6.24 & 3.88 \\
\hline ar17 & VC-2 & $4 / 4$ & WWLS & 4.72 & 4.99 & 4.55 & 4.89 & 1.75 \\
\hline ar18 & VC-2 & $4 / 4$ & WWLL & 4.65 & 4.90 & 4.50 & 4.81 & 1.74 \\
\hline ar19 & VC-2 & $4 / 4$ & WDLS & 4.91 & 5.28 & 4.53 & 5.14 & 1.72 \\
\hline ar20 & VC-2 & $4 / 4$ & WDLL & 4.76 & 5.09 & 4.38 & 4.99 & 1.69 \\
\hline ar21 & VC-2 & $8 / 8$ & WWLS & 3.62 & 3.73 & 3.74 & 3.89 & 1.84 \\
\hline ar22 & VC-2 & $8 / 8$ & WWLL & 3.72 & 3.81 & 3.86 & 3.96 & 1.94 \\
\hline ar23 & VC-2 & $8 / 8$ & WDLS & 3.86 & 4.12 & 3.58 & 4.26 & 1.76 \\
\hline ar24 & VC-2 & $8 / 8$ & WDLL & 3.88 & 4.08 & 3.62 & 4.25 & 1.87 \\
\hline \hline
\end{tabular}


Table C.20. Combined-Cycle NPV (\$M); Evaporatively-Cooled Base; 12 hr/day plant; 4 or $8 \mathrm{hr} /$ day cooling

\begin{tabular}{|c|c|c|c|c|c|c|c|c|}
\hline Case & Chiller & Ophrs & $\overline{\text { Storage }}$ & Nash. & Hous. & Minn. & Phoe. & San Fran. \\
\hline crl & CC-4 & $12 / 4$ & NA & -2.49 & -2.93 & -2.11 & -0.07 & 0.70 \\
\hline $\mathrm{cr} 2$ & CC-4 & $12 / 8$ & $\mathrm{NA}$ & -2.06 & -2.75 & -2.37 & 1.34 & 0.19 \\
\hline cr3 & $\mathrm{CC}-4$ & $12 / 4$ & WDLS & 4.29 & 4.15 & 3.66 & 4.93 & 1.39 \\
\hline cr4 & $\overline{\mathrm{CC}-4}$ & $12 / 4$ & WDLL & 3.40 & 3.11 & 2.78 & 4.04 & 1.12 \\
\hline cr5 & $\mathrm{CC}-4$ & $12 / 8$ & WDLS & -6.80 & -8.17 & -7.58 & -3.15 & -3.32 \\
\hline cr6 & $\overline{C C}-4$ & $12 / 8$ & WDLL & -1.42 & -2.47 & -1.98 & 0.89 & -0.58 \\
\hline cr7 & CC-3 & $12 / 4$ & IDLS & 5.17 & 4.76 & 4.55 & 6.50 & 3.87 \\
\hline cr8 & $\begin{array}{l}\mathrm{CC}-3 \\
\end{array}$ & $12 / 4$ & IDLL & 4.41 & 3.88 & 3.83 & 5.62 & 3.65 \\
\hline cr9 & $\mathrm{CC}-3$ & $12 / 8$ & IDLS & -17.29 & -19.74 & -17.85 & -11.33 & -6.42 \\
\hline crlo & $\overline{C C}-3$ & $12 / 8$ & IDLL & -4.27 & -5.81 & -4.56 & -0.78 & -0.04 \\
\hline crl1 & $\mathrm{LiBr}-2$ & $12 / 4$ & $\overline{\mathrm{NA}}$ & -3.33 & -3.92 & -2.95 & -0.35 & -1.09 \\
\hline $\mathrm{cr} 12$ & $\mathrm{LiBr}-2$ & $12 / 8$ & $\overline{\mathrm{NA}}$ & -2.58 & -3.30 & -3.35 & 1.18 & $-\overline{-0.76}$ \\
\hline$\overline{c r 13}$ & $\mathrm{LiBr}-2$ & $12 / 4$ & WDLS & 3.87 & 3.66 & 3.25 & 4.96 & 1.49 \\
\hline crl4 & $\mathrm{LiBr}-2$ & $12 / 4$ & WDLL & 4.19 & 3.97 & 3.49 & $5: 03$ & 1.62 \\
\hline $\operatorname{crl5}$ & $\mathrm{LiBr}-2$ & $12 / 8$ & WDLS & -9.73 & -11.28 & -9.51 & -3.95 & -3.36 \\
\hline cr16 & $\mathrm{LiBr}-2$ & $12 / 8$ & WDLL & -0.19 & -1.24 & -0.93 & 2.71 & 0.33 \\
\hline crl7 & VC-2 & $12 / 4$ & $\mathrm{NA}$ & 4.27 & 4.32 & 4.38 & 5.09 & 4.97 \\
\hline cr18 & $\mathrm{VC}-2$ & $12 / 8$ & $\mathrm{NA}$ & 5.63 & 5.68 & 4.93 & 7.37 & 5.24 \\
\hline cr19 & VC-1 & $12 / 4$ & IWLS & 11.42 & 11.71 & 11.31 & 10.81 & 7.74 \\
\hline $\mathrm{cr} 20$ & $\mathrm{VC}-1$ & $12 / 4$ & IWLL & 11.17 & 11.40 & 11.11 & 10.56 & 7.68 \\
\hline $\mathrm{cr} 21$ & $\mathrm{VC}-1$ & $12 / 4$ & IDLS & 10.55 & 10.87 & 10.03 & 10.19 & 7.27 \\
\hline cr22 & $\mathrm{VC}-1$ & $12 / 4$ & IDLL & 10.26 & 10.53 & 9.75 & 9.91 & 7.22 \\
\hline cr23 & VC-1 & $12 / 8$ & IWLS & .9 .98 & 9.96 & 9.82 & 10.53 & 7.22 \\
\hline cr24 & $V C-1$ & $12 / 8$ & IWLL & 10.09 & 9.98 & 9.99 & 10.60 & 7.40 \\
\hline cr25 & $\overline{\mathrm{VC}-1}$ & $12 / 8$ & IDLS & 7.34 & 7.34 & 6.38 & 8.57 & $\overline{5.85}$ \\
\hline cr26 & $\overline{\mathrm{VC}-1}$ & $12 / 8$ & $\overline{\text { IDLL }}$ & 8.18 & 8.10 & 7.31 & 9.23 & $\overline{6.46}$ \\
\hline cr27 & $\mathrm{VC}-2$ & $12 / 4$ & WWLS & 6.59 & 6.76 & 6.61 & 5.74 & 3.50 \\
\hline cr28 & $\mathrm{VC}-2$ & $12 / 4$ & WWLL & 6.54 & 6.69 & 6.59 & 5.69 & 3.53 \\
\hline cr29 & $\overline{\mathrm{VC}-2}$ & $12 / 4$ & WDLS & 6.96 & \begin{tabular}{ll|}
7.34 \\
\end{tabular} & 6.48 & 6.27 & 3.40 \\
\hline cr30 & $\overline{\mathrm{VC}-2}$ & $12 / 4$ & WDLL & 6.80 & 7.14 & 6.32 & 6.12 & 3.40 \\
\hline cr31 & $\overline{\mathrm{VC}-2}$ & $12 / 8$ & WWLS & 4.91 & 4.76 & 4.92 & 5.16 & 2.83 \\
\hline $\operatorname{cr} 32$ & $\overline{V C}-2$ & $12 / 8$ & WWLL & 5.39 & 5.22 & 5.38 & 5.59 & 3.13 \\
\hline cr33 & $\overline{V C-2}$ & $12 / 8$ & WDLS & 5.23 & 5.40 & 4.29 & 5.86 & 2.54 \\
\hline
\end{tabular}


Table C.20. (contd)

\begin{tabular}{|c|c|c|c|c|c|c|c|c|}
\hline Case & Chiller & Ophrs & Storage & Nash. & Hous. & Minn. & Phoe. & San Fran \\
\hline cr34 & VC-2 & $12 / 8$ & WDLL & 5.74 & 5.85 & 4.84 & 6.25 & 2.97 \\
\hline cr35 & AA-2 & $12 / 4$ & NA & -24.79 & -26.75 & -23.33 & -17.76 & -8.48 \\
\hline cr36 & $A A-2$ & $12 / 8$ & $\mathrm{NA}$ & -23.97 & -26.13 & -24.37 & -16.03 & -10.04 \\
\hline cr37 & AA-2 & $12 / 4$ & WDLS & -5.78 & -7.21 & -6.66 & -3.27 & -2.61 \\
\hline $\mathrm{cr} 38$ & AA-2 & $12 / 4$ & WDLL & -2.61 & -3.69 & -3.46 & -0.79 & -1.23 \\
\hline cr39 & AA-2 & $12 / 8$ & WDLS & -47.96 & -53.71 & -48.22 & -35.65 & -18.63 \\
\hline $\mathrm{cr} 40$ & $\overline{\mathrm{AA}-2}$ & $12 / 8$ & WDLL & -13.51 & -15.91 & -14.34 & -8.50 & -5.03 \\
\hline cr41 & AA-1 & $12 / 4$ & IDLS & -8.68 & -10.55 & -9.51 & -5.23 & -2.03 \\
\hline cr42 & $\mathrm{AA}-1$ & $12 / 4$ & IDLL & -4.11 & -5.58 & -4.91 & -1.54 & 0.07 \\
\hline cr43 & $\overline{\mathrm{AA}-1}$ & $12 / 8$ & IDLS & -73.61 & -81.02 & -73.29 & -57.85 & -30.25 \\
\hline cr44 & AA-1 & $12 / 8$ & IDLL & -21.36 & -24.56 & -21.88 & -14.82 & -7.15 \\
\hline cr45 & $\mathrm{CC}-4 / \mathrm{CC}-5$ & $12 / 4$ & $\mathrm{NA}$ & -1.93 & -2.62 & -1.42 & 1.64 & 2.28 \\
\hline cr46 & CC-4/CC-5 & $12 / 8$ & $\overline{N A}$ & -1.56 & -2.57 & -1.75 & 3.16 & 1.65 \\
\hline$\overline{c r 47}$ & AA-2/AA-3 & $12 / 4$ & $\mathrm{NA}$ & -44.82 & -47.90 & -42.54 & -34.78 & -22.61 \\
\hline cr48 & AA-2/AA-3 & $12 / 8$ & NA & -43.92 & -47.40 & -43.74 & -32.74 & -24.42 \\
\hline $\operatorname{cr} 49$ & VC-2/VC-3 & $12 / 4$ & NA & 8.09 & 7.83 & 8.35 & 10.37 & 10.21 \\
\hline $\operatorname{cr} 50$ & VC-2/VC-3 & $12 / 8$ & $\mathrm{NA}$ & 10.45 & 10.09 & 9.85 & 13.81 & 11.45 \\
\hline $\operatorname{cr} 51$ & $\mathrm{CC}-3 / \mathrm{CC}-6$ & $12 / 4$ & IDLS & 12.42 & 11.79 & 11.65 & 15.18 & 11.13 \\
\hline $\operatorname{cr} 52$ & $\mathrm{CC}-3 / \mathrm{CC}-6$ & $12 / 8$ & IDLS & -20.50 & -23.50 & -21.20 & -12.54 & -8.77 \\
\hline cr53 & AA-1/AA-3 & $12 / 4$ & IDLS & -18.15 & -20.84 & -18.61 & -12.10 & -8.56 \\
\hline cr54 & AA-1/AA-3 & $12 / 8$ & IDLS & -87.80 & -96.50 & -86.67 & -68.17 & -38.19 \\
\hline cr55 & VC-1/VC-3 & $12 / 4$ & IWLS & 15.81 & 15.81 & 15.83 & 16.53 & 13.17 \\
\hline $\operatorname{cr} 56$ & VC-1/VC-3 & $12 / 8$ & IWLS & 15.21 & 14.78 & 15.20 & 17.26 & 13.62 \\
\hline cr57 & VC-1/VC-3 & $12 / 4$ & IWLL & 16.20 & 16.16 & 16.17 & 16.89 & 13.66 \\
\hline cr58 & VC-1/VC-3 & $12 / 8$ & IWLL & 16.50 & 16.00 & 16.41 & 18.50 & 14.82 \\
\hline $\operatorname{cr} 59$ & VC-1/VC-3 & $12 / 4$ & IDLS & 14.88 & 14.92 & 14.47 & 15.87 & 12.67 \\
\hline cr60 & VC-1/VC-3 & $12 / 8$ & IDLS & 12.39 & 11.97 & 11.52 & 15.18 & $\overline{12.16}$ \\
\hline cr61 & VC-1/VC-3 & $12 / 4$ & IDLL & 15.21 & 15.22 & 14.70 & 16.18 & 13.16 \\
\hline cr62 & VC-1/VC-3 & $12 / 8$ & IDLL & 14.39 & 13.87 & 13.50 & 16.95 & 13.81 \\
\hline cr63 & $\mathrm{CC}-3 / \mathrm{CC}-6$ & $12 / 4$ & IDLL & 10.82 & 10.04 & 10.11 & 13.40 & 10.15 \\
\hline cr64 & $\mathrm{CC}-3 / \mathrm{CC}-6$ & $12 / 8$ & IDLL & -7.09 & -9.14 & -7.43 & -1.92 & -2.51 \\
\hline cr65 & AA-1/AA-3 & $12 / 4$ & IDLL & -21.40 & -23.95 & -21.67 & -16.28 & -12.58 \\
\hline cr66 & AA-1/AA-3 & $12 / 8$ & IDLL & -40.02 & -44.67 & -39.77 & -30.45 & -20.17 \\
\hline cr67 & $\overline{\mathrm{CC}-2}$ & $12 / 4$ & NA & 3.04 & 3.02 & 2.95 & 4.75 & 3.12 \\
\hline
\end{tabular}

C. 43 
Table C.20. (contd)

\begin{tabular}{|l|l|r|r|r|r|r|r|r||}
\hline \hline Case & \multicolumn{1}{|c|}{ Chiller } & Ophrs & Storage & Nash. & Hous. & Minn. & Phoe. & San Fran. \\
\hline \hline cr68 & CC-2 & $12 / 8$ & NA & 4.06 & 3.97 & 3.25 & 6.70 & 3.13 \\
\hline cr69 & CC-2 & $12 / 4$ & WDLS & 5.09 & 5.14 & 4.35 & 5.62 & 1.66 \\
\hline cr70 & CC-2 & $12 / 4$ & WDLL & 5.04 & 5.05 & 4.31 & 5.50 & 1.74 \\
\hline cr71 & CC-2 & $12 / 8$ & WDLS & -3.89 & -4.76 & -4.91 & -0.74 & -2.28 \\
\hline cr72 & CC-2 & $12 / 8$ & WDLL & 2.07 & 1.65 & 1.17 & 3.98 & 0.64 \\
\hline cr73 & CC-1 & $12 / 4$ & IDLS & 6.41 & 6.23 & 5.63 & 7.55 & 4.38 \\
\hline cr74 & CC-1 & $12 / 4$ & IDLL & 6.80 & 6.62 & 6.06 & 7.77 & 4.67 \\
\hline cr75 & CC-1 & $12 / 8$ & IDLS & -12.95 & -14.80 & -13.89 & -7.71 & -4.60 \\
\hline cr76 & CC-1 & $12 / 8$ & IDLL & 0.84 & 0.02 & 0.03 & 3.74 & 2.11 \\
\hline cr77 & CC-2/CC-5 & $12 / 4$ & NA & 4.08 & 3.85 & 4.09 & 6.89 & 4.91 \\
\hline cr78 & CC-2/CC-5 & $12 / 8$ & NA & 5.10 & 4.75 & 4.37 & 8.99 & 4.84 \\
\hline cr79 & CC-1/CC-6 & $12 / 4$ & IDLS & 13.95 & 13.62 & 12.95 & 16.50 & 11.78 \\
\hline cr80 & CC-1/CC-6 & $12 / 8$ & IDLS & -15.40 & -17.67 & -16.64 & -8.27 & -6.63 \\
\hline cr81 & CC-1/CC-6 & $12 / 4$ & IDLL & 16.33 & 15.99 & 15.42 & 18.60 & 14.22 \\
\hline cr82 & CC-1/CC-6 & $12 / 8$ & IDLL & 10.09 & 9.04 & 9.11 & 14.42 & 11.69 \\
\hline cr83 & VC-2/CC-5 & $12 / 4$ & NA & 5.85 & 5.67 & 5.74 & 8.69 & 6.13 \\
\hline cr84 & VC-2/CC-5 & $12 / 8$ & NA & 7.24 & 7.01 & 6.60 & 11.15 & 7.33 \\
\hline cr85 & VC-1/CC-6 & $12 / 4$ & IWLL & 18.39 & 18.37 & 17.93 & 20.00 & 13.58 \\
\hline cr86 & VC-2/CC-6 & $12 / 8$ & IWLL & 8.66 & 8.09 & 8.58 & 11.62 & 5.59 \\
\hline \hline
\end{tabular}


Table C.21. Combined-Cycle NPV (\$M); Evaporatively-Cooled Base; 12 hr/day plant; $12 \mathrm{hr} /$ day cooling

\begin{tabular}{|c|c|c|c|c|c|c|c|c|}
\hline Case & Chiller & Ophrs & Storage & Nash. & Hous. & Minn. & Phoe. & San Fran. \\
\hline $\mathrm{drl}$ & $\mathrm{CC}-4$ & $12 / 12$ & NA & -1.66 & -2.59 & -0.18 & 1.37 & 2.07 \\
\hline $\mathrm{dr} 2$ & $\mathrm{LiBr}-2$ & $12 / 12$ & $\overline{\mathrm{NA}}$ & -2.49 & -2.86 & -1.34 & 1.54 & 1.88 \\
\hline $\mathrm{dr} 3$ & A-2 & $12 / 12$ & $\mathrm{NA}$ & -23.39 & -24.41 & -21.03 & -14.75 & -7.99 \\
\hline$\overline{\mathrm{dr} 4}$ & $\overline{C-2}$ & $12 / 12$ & NA & 9.70 & 9.96 & 9.82 & 11.65 & 8.66 \\
\hline$\overline{\mathrm{dr} 5}$ & $\overline{C-1}$ & $12 / 12$ & IWLS & 12.20 & 11.26 & 13.07 & 12.45 & 9.65 \\
\hline $\mathrm{dr} 6$ & VC-1 & $12 / 12$ & IWLL & 12.88 & 11.87 & 13.78 & 13.00 & 10.25 \\
\hline$\overline{\mathrm{dr} 7}$ & $\overline{\mathrm{VC}-1}$ & $12 / 12$ & - IDLS & 5.99 & 5.31 & 6.15 & 7.85 & 6.55 \\
\hline$\overline{\mathrm{d}} 8$ & VC-1 & $12 / 12$ & IDLL & 9.59 & 8.91 & 9.70 & 10.80 & 8.71 \\
\hline $\mathrm{dr} 9$ & VC-2 & $12 / 12$ & WWLS & 6.33 & 5.31 & 7.28 & 6.15 & 4.58 \\
\hline $\operatorname{dr} 10$ & $\bar{C}-2$ & $12 / 12$ & WWLL & 7.58 & 6.60 & 8.44 & 7.25 & 5.30 \\
\hline $\mathrm{dr} 11$ & $\overline{V C}-2$ & $12 / 12$ & WDLS & 6.13 & 5.78 & 5.99 & 6.75 & 3.88 \\
\hline $\mathrm{dr} 12$ & VC-2 & $12 / 12$ & WDLL & 7.85 & 7.48 & 7.71 & 8.15 & 5.03 \\
\hline dr13 & CC-4/CC-5 & $12 / 12$ & $\mathrm{NA}$ & -1.66 & -3.18 & 1.20 & 2.99 & 2.85 \\
\hline dr14 & $\mathrm{AA}-2 / \mathrm{AA}-3$ & $12 / 12$ & $\overline{N A}$ & -43.81 & -46.20 & -39.39 & -30.98 & -22.10 \\
\hline $\mathrm{dr} 15$ & VC-2/VC-3 & $12 / 12$ & $\overline{N A}$ & 17.59 & 17.41 & 18.43 & 21.59 & 18.34 \\
\hline $\mathrm{dr} 16$ & VC-1/VC-3 & $12 / 12$ & IWLL & 21.74 & 20.29 & 23.28 & 23.76 & 20.80 \\
\hline $\operatorname{dr} 17$ & $\mathrm{CC}-2$ & $12 / 12$ & $\mathrm{NA}$ & 6.79 & 6.65 & 7.31 & 8.60 & 6.39 \\
\hline $\mathrm{dr} 18$ & $\overline{C C}-2 / \mathrm{CC}-5$ & $12 / 12$ & $\overline{N A}$ & 7.52 & 6.86 & 9.35 & 10.86 & 7.55 \\
\hline $\operatorname{drl9}$ & VC-2/CC-5 & $12 / 12$ & $\overline{\mathrm{NA}}$ & 10.57 & 10.34 & 11.96 & 14.05 & 9.90 \\
\hline $\mathrm{dr} 20$ & $\mathrm{VC}-2 / \mathrm{CC}-5$ & $12 / 12$ & IWLL & 13.69 & 11.94 & 16.06 & 15.21 & 11.43 \\
\hline
\end{tabular}


Table C.22. Combined-Cycle NPV (\$M); Evaporatively-Cooled Base; 24 hr/day plant; 4 or 8 or $12 \mathrm{hr} /$ day cooling

\begin{tabular}{|c|c|c|c|c|c|c|c|c|}
\hline Case & Chiller & Ophrs & Storage & Nash. & Hous. & Minn. & Phoe. & San Fran. \\
\hline er1 & CC-4 & $24 / 4$ & NA & -1.10 & -1.10 & -1.48 & 2.16 & 1.79 \\
\hline er2 & $\mathrm{CC}-4$ & $24 / 8$ & NA & -0.24 & -0.02 & -1.69 & 3.88 & 2.62 \\
\hline er3 & $\mathrm{CC}-4$ & $24 / 12$ & NA & -2.47 & -4.45 & -0.63 & 0.52 & 1.93 \\
\hline$\overline{\mathrm{er} 4}$ & $\overline{\mathrm{CC}-4}$ & $24 / 4$ & WDLS & 7.51 & 8.07 & 6.22 & 8.62 & 3.11 \\
\hline er5 & $\mathrm{CC}-4$ & $24 / 4$ & WDLL & 6.72 & 7.17 & 5.40 & 7.88 & 2.80 \\
\hline er6 & $\overline{\mathrm{CC}-4}$ & $24 / 8$ & WDLS & 4.83 & 5.40 & 2.94 & 7.22 & 2.86 \\
\hline er7 & $\overline{\mathrm{CC}-4}$ & $24 / 8$ & WDLL & 4.12 & 4.52 & 2.29 & 6.50 & 2.74 \\
\hline$\overline{\mathrm{er} 8}$ & $\overline{\mathrm{CC}-4}$ & $24 / 12$ & WDLS & 2.20 & 0.47 & 3.39 & 2.79 & 3.29 \\
\hline er9 & $\overline{C C-4}$ & $24 / 12$ & WDLL & 1.41 & -0.39 & 2.68 & 1.97 & 3.28 \\
\hline er10 & $\mathrm{CC}-3$ & $24 / 4$ & IDLS & 11.30 & 11.80 & 10.00 & 12.84 & 7.22 \\
\hline erl1 & $\overline{\mathrm{CC}-3}$ & $24 / 4$ & $\overline{\text { IDLL }}$ & 10.18 & 10.56 & 8.87 & 11.76 & 6.76 \\
\hline er12. & $\overline{\mathrm{CC}-3}$ & $24 / 8$ & IDLS & 7.38 & 7.71 & 5.52 & 10.53 & 6.66 \\
\hline er13 & $\mathrm{CC}-3$ & $24 / 8$ & IDLL & 6.57 & 6.72 & 4.84 & 9.64 & 6.45 \\
\hline$\overline{\mathrm{er} 14}$ & $\mathrm{CC}-3$ & $24 / 12$ & IDLS & 0.65 & -2.09 & 2.65 & 2.70 & 4.40 \\
\hline er15 & $\mathrm{CC}-3$ & $24 / 12$ & IDLL & 0.79 & -1.87 & 2.85 & 2.47 & 4.74 \\
\hline er16 & $\mathrm{LiBr}-2$ & $24 / 4$ & $\mathrm{NA}$ & -2.40 & -2.55 & -2.73 & 1.41 & -0.44 \\
\hline er17 & $\mathrm{LiBr}-2$ & $24 / 8$ & $\overline{N A}$ & -1.66 & -1.49 & -3.51 & 2.79 & 0.80 \\
\hline$\overline{e r 18}$ & $\mathrm{LiBr}-2$ & $24 / 12$ & $\overline{N A}$ & -2.72 & -4.34 & -1.41 & 1.23 & 2.43 \\
\hline er19 & LiBr-2 & $24 / 4$ & $\overline{\text { WDLS }}$ & 7.71 & 8.28 & 6.29 & 8.88 & 3.23 \\
\hline er20 & LiBr-2 & $24 / 4$ & WDLL & 7.39 & 7.92 & 5.95 & 8.57 & 3.11 \\
\hline er21 & $\mathrm{LiBr}-2$ & $24 / 8$ & WDLS & 5.10 & 5.44 & 2.96 & 7.59 & 3.04 \\
\hline ér22 & LiBr-2 & $24 / 8$ & WDLL & 5.30 & 5.63 & 3.20 & 7.73 & 3.29 \\
\hline er23 & $\mathrm{LiBr}-2$ & $24 / 12$ & WDLS & 2.97 & 1.01 & 3.43 & 3.94 & 3.67 \\
\hline er24 & $\mathrm{LiBr}-2$ & $24 / 12$ & WDLL & 4.20 & 2.71 & 4.79 & 4.95 & 4.55 \\
\hline er25 & VC-2 & $24 / 4$ & NA & 6.15 & 6.63 & 5.20 & 8.73 & 5.43 \\
\hline er26 & VC-2 & $24 / 8$ & $\mathrm{NA}$ & 7.96 & 8.89 & 5.79 & 11.33 & 7.04 \\
\hline er27 & $\overline{V C-2}$ & $24 / 12$ & $\overline{N A}$ & 9.72 & 9.67 & 9.91 & 11.71 & 9.32 \\
\hline er28 & VC-1 & $24 / 4$ & IWLS & 13.14 & 13.80 & 12.01 & 14.31 & 8.13 \\
\hline er29 & VC-1 & $24 / 4$ & IWLL & 12.95 & 13.56 & 11.87 & 14.11 & 8.09 \\
\hline$\overline{\mathrm{er} 30}$ & VC-1 & $24 / 4$ & IDLS & 12.33 & 13.04 & 10.79 & 13.75 & 7.69 \\
\hline er31 & VC-1 & $24 / 4$ & IDLL & 12.05 & 12.71 & 10.51 & 13.46 & 7.63 \\
\hline er32 & VC-1 & $24 / 8$ & IWLS & 11.67 & 12.40 & 10.19 & 13.92 & 8.75 \\
\hline$\overline{\text { er33 }}$ & VC-1 & $24 / 8$ & IWLL & 12.18 & 12.88 & 10.72 & 14.36 & 9.11 \\
\hline
\end{tabular}


Table C.22. (contd)

\begin{tabular}{|c|c|c|c|c|c|c|c|c|}
\hline Case & Chiller & Ophrs & Storage & Nash. & Hous. & Minn. & Phoe. & San Fran. \\
\hline er34 & VC-1 & $24 / 8$ & IDLS & 9.47 & 10.27 & 7.12 & 12.36 & 7.57 \\
\hline er35 & VC-1 & $24 / 8$ & IDLL & 10.33 & 11.09 & 8.05 & 13.04 & 8.19 \\
\hline er36 & VC-1 & $24 / 12$ & IWLS & 5.73 & 4.23 & 7.53 & 7.05 & 7.80 \\
\hline er37 & VC-1 & $24 / 12$ & IWLL & 9.03 & 7.77 & 10.55 & 9.83 & 9.63 \\
\hline er38 & VC-1 & $24 / 12$ & IDLS & 5.42 & 4.63 & 5.90 & 7.34 & 6.99 \\
\hline er39 & VC-1 & $24 / 12$ & IDLL & 9.08 & 8.37 & 9.46 & 10.33 & 9.26 \\
\hline er40 & VC-2 & $24 / 4$ & WWLS & 8.04 & 8.61 & 7.04 & 8.93 & 3.55 \\
\hline er41 & $\overline{\text { VC-2 }}$ & $24 / 4$ & WWLL & 7.92 & 8.45 & 6.96 & 8.81 & 3.54 \\
\hline er42 & VC-2 & $24 / 4$ & WDLS & 8.34 & 9.10 & 6.85 & 9.39 & 3.41 \\
\hline er43 & VC-2 & $24 / 4$ & WDLL & 8.18 & 8.91 & 6.69 & 9.24 & 3.42 \\
\hline er44 & VC-2 & $24 / 8$ & WWLS & 6.42 & 7.11 & 5.06 & 8.28 & 3.85 \\
\hline er45 & VC-2 & $24 / 8$ & WWLL & 6.68 & 7.32 & 5.33 & 8.49 & 4.04 \\
\hline er46 & VC-2 & $24 / 8$ & WDLS & 6.54 & 7.52 & 4.24 & 8.78 & 3.45 \\
\hline$\overline{\mathrm{er} 47}$ & VC-2 & $24 / 8$ & WDLL & 7.06 & 8.00 & 4.80 & 9.19 & 3.88 \\
\hline er48 & $\overline{V C-2}$ & $24 / 12$ & WWLS & 3.24 & 2.14 & 4.67 & 3.73 & 4.73 \\
\hline er49 & VC-2 & $24 / 12$ & WWLL & 4.55 & 3.52 & 5.90 & 4.82 & 5.39 \\
\hline er50 & VC-2 & $24 / 12$ & WDLS & 5.87 & 5.57 & 5.93 & 6.45 & 4.66 \\
\hline er51 & VC-2 & $24 / 12$ & WDLL & 7.62 & 7.35 & 7.66 & 7.88 & 5.81 \\
\hline er52 & $A A-2$ & $24 / 4$ & NA & -23.41 & -24.92 & -22.70 & -15.53 & -7.40 \\
\hline er53 & $A A-2$ & $24 / 8$ & $\overline{\mathrm{NA}}$ & -22.15 & -23.40 & -23.69 & -13.49 & -7.62 \\
\hline er54 & $\overline{A A}$-2 & $24 / 12$ & NA & -23.86 & -26.90 & -21.26 & -15.22 & -8.51 \\
\hline er55 & $\overline{A A-2}$ & $24 / 4$ & WDLS & 3.71 & 3.76 & 2.22 & 5.47 & 1.56 \\
\hline er56 & AA-2 & $24 / 4$ & WDLL & 3.89 & 3.96 & 2.40 & 5.58 & 1.67 \\
\hline er57 & AA-2 & $24 / 8$ & WDLS & -4.82 & -5.58 & -6.97 & -0.61 & -0.84 \\
\hline er58 & AA-2 & $24 / 8$ & WDLL & -1.59 & -1.92 & -3.67 & 1.99 & 0.59 \\
\hline er59 & AA-2 & $24 / 12$ & WDLS & -16.82 & -20.50 & -15.23 & -11.97 & -3.76 \\
\hline er60 & $\overline{A A-2}$ & $24 / 12$ & WDLL & -6.39 & -8.66 & -5.13 & -3.72 & 0.53 \\
\hline er61 & $\overline{\mathrm{AA}-1}$ & $24 / 4$ & IDLS & 6.03 & 5.92 & 4.55 & 8.28 & 4.96 \\
\hline er62 & AA-1 & $24 / 4$ & IDLL & 6.13 & 6.03 & 4.65 & 8.28 & 5.04 \\
\hline er63 & $\widehat{A A-1}$ & $24 / 8$ & IDLS & -5.96 & -7.21 & -8.03 & -0.80 & 0.96 \\
\hline er64 & AA-1 & $24 / 8$ & IDLL & -1.60 & -2.36 & -3.56 & 2.82 & 3.03 \\
\hline er65 & AA-1 & $24 / 12$ & IDLS & -25.55 & -30.71 & -23.10 & -18.84 & -6.69 \\
\hline er66 & $\widehat{A A-1}$ & $24 / 12$ & IDLL & -10.57 & -13.93 & -8.49 & -6.51 & 0.14 \\
\hline er67 & CC-4/CC-5 & $24 / 4$ & NA & 0.89 & 0.69 & 0.54 & 5.39 & 4.74 \\
\hline
\end{tabular}


Table C.22. (contd)

\begin{tabular}{|c|c|c|c|c|c|c|c|c|}
\hline Case & Chiller & Ophrs & Storage & Nash. & Hous. & Minn. & Phoe. & San Fran. \\
\hline er68 & $\mathrm{CC}-4 / \mathrm{CC}-5$ & $24 / 8$ & NA & 3.69 & 3.66 & 2.13 & 9.28 & 7.38 \\
\hline er6̣ & $\mathrm{CC}-4 / \mathrm{CC}-5$ & $24 / 12$ & $\mathrm{NA}$ & -4.76 & -7.70 & -1.01 & -0.01 & $\overline{0.17}$ \\
\hline er70 & $\mathrm{AA}-2 / \mathrm{AA}-3$ & $24 / 4$ & $\mathrm{NA}$ & -41.99 & -44.59 & -40.57 & -31.03 & -20.14 \\
\hline er71 & $\mathrm{AA}-2 / \mathrm{AA}-3$ & $24 / 8$ & $\mathrm{NA}$ & -38.67 & -41.17 & -39.86 & -26.63 & -18.69 \\
\hline er72 & AA-2/AA-3 & $24 / 12$ & NA & -46.09 & -51.54 & -40.95 & -33.15 & -24.82 \\
\hline er73 & $\overline{V C}-2 / \mathrm{VC}-3$ & $24 / 4$ & $\mathrm{NA}$ & 11.42 & 11.62 & 10.50 & 15.53 & 12.05 \\
\hline er74 & VC-2/VC-3 & $24 / 8$ & NA & 16.20 & 16.80 & 13.91 & 21.34 & 16.56 \\
\hline er75 & $\mathrm{VC}-2 / \mathrm{VC}-3$ & $24 / 12$ & NA & 17.01 & 16.10 & 18.10 & 21.12 & 18.29 \\
\hline er76 & $\overline{C C}-3$ & $24 / 4$ & IWLS & 12.20 & 12.65 & 11.34 & 13.47 & 7.70 \\
\hline er77 & $\mathrm{CC}-3$ & $24 / 4$ & IWLL & 11.46 & 11.78 & 10.73 & 12.72 & 7.41 \\
\hline er78 & $\overline{\mathrm{CC}-3}$ & $24 / 8$ & IWLS & 9.81 & 10.10 & 8.90 & 12.27 & 7.93 \\
\hline er79 & $\mathrm{CC}-3$ & $24 / 8$ & IWLL & 9.17 & 9.27 & 8.48 & 11.58 & 7.74 \\
\hline er80 & $\mathrm{CC}-3$ & $24 / 12$ & IWLS & 1.07 & -2.30 & 4.59 & 2.49 & 5.25 \\
\hline er81 & $\mathrm{CC}-3$ & $24 / 12$ & IWLL & 1.16 & -2.22 & 4.74 & 2.22 & 5.53 \\
\hline er82 & $\overline{A A-1}$ & $24 / 4$ & IWLS & 8.94 & 8.82 & 8.54 & 10.46 & 6.38 \\
\hline er83 & $\overline{\mathrm{AA}-1}$ & $24 / 4$ & IWLL & 8.99 & 8.86 & 8.60 & 10.45 & 6.43 \\
\hline er84 & $\overline{A A}-1$ & $24 / 8$ & IWLS & 1.62 & 0.54 & 1.99 & 4.83 & 4.66 \\
\hline er85 & AA-1 & $24 / 8$ & IWLL & 4.28 & 3.57 & 4.32 & 7.18 & 5.83 \\
\hline er86 & AA-1 & $24 / 12$ & IWLS & -22.35 & -28.79 & -15.56 & -17.59 & -3.67 \\
\hline er87 & $\overline{\mathrm{AA}-1}$ & $24 / 12$ & IWLL & -8.83 & -13.35 & -3.96 & -6.06 & 1.99 \\
\hline er88 & $\mathrm{CC}-3 / \mathrm{CC}-6$ & $24 / 4$ & IWLS & -12.90 & -13.17 & -13.74 & -9.57 & -18.43 \\
\hline er89 & $\mathrm{CC}-3 / \mathrm{CC}-6$ & $24 / 8$ & IWLS & -55.52 & -56.71 & -56.28 & -50.01 & -59.31 \\
\hline er90 & $\mathrm{CC}-3 / \mathrm{CC}-6$ & $24 / .12$ & IWLS & -158.39 & -164.75 & -153.62 & -151.87 & -157.39 \\
\hline er91 & $\mathrm{CC}-3 / \mathrm{CC}-6$ & $24 / 4$ & IWLL & -14.11 & -14.57 & -14.77 & -10.79 & -19.07 \\
\hline er92 & $\mathrm{CC}-3 / \mathrm{CC}-6$ & $24 / 8$ & IWLL & -57.02 & -58.52 & -57.40 & -51.55 & -60.13 \\
\hline er93 & $\mathrm{CC}-3 / \mathrm{CC}-6$ & $24 / 12$ & IWLL & -160.66 & -167.41 & -155.51 & -154.65 & -159.11 \\
\hline er94 & $\mathrm{CC}-3 / \mathrm{CC}-6$ & $24 / 4$ & IDLS & 20.79 & 21.15 & 19.23 & 23.79 & 16.47 \\
\hline er95 & $\mathrm{CC}-3 / \mathrm{CC}-6$ & $24 / 8$ & IDLS & 11.17 & 11.19 & 8.92 & 16.19 & $\overline{10.16}$ \\
\hline er96 & $\mathrm{CC}-3 / \mathrm{CC}-6$ & $24 / 12$ & IDLS & -2.55 & -5.78 & -0.42 & 1.76 & 1.33 \\
\hline er97 & $\mathrm{CC}-3 / \mathrm{CC}-6$ & $24 / 4$ & IDLL & 19.18 & 19.40 & 17.61 & 22.19 & 15.57 \\
\hline er98 & $\mathrm{CC}-3 / \mathrm{CC}-6$ & $24 / 8$ & IDLL & 9.56 & 9.35 & 7.47 & 14.43 & 9.24 \\
\hline er99 & $\mathrm{CC}-3 / \mathrm{CC}-6$ & $24 / 12$ & $\overline{\mathrm{IDLL}}$ & -4.06 & -7.23 & -1.84 & -0.26 & 0.07 \\
\hline er100 & $A A-1 / A A-3$ & $24 / 4$ & IWLS & 3.05 & 1.93 & 3.17 & 6.58 & 2.49 \\
\hline er101 & AA-1/AA-3 & $.24 / 8$ & IWLS & -2.11 & -4.46 & -1.19 & 3.44 & 3.40 \\
\hline
\end{tabular}

C. 48 
Table C.22. (contd)

\begin{tabular}{|c|c|c|c|c|c|c|c|c|}
\hline Case & Chiller & Ophrs & Storage & Nash. & Hous. & Minn. & Phoe. & San Fran. \\
\hline er102 & AA-1/AA-3 & $4 / 12$ & IWLS & 3.77 & 0.42 & 7.39 & 6.35 & 8.74 \\
\hline er103 & AA-1/AA-3 & $24 / 4$ & IWLL & -5.07 & -6.39 & -4.72 & -1.49 & -3.77 \\
\hline er104 & AA-1/AA-3 & $24 / 8$ & IWLL & -7.66 & -9.83 & -6.88 & -2.26 & -1.98 \\
\hline er105 & AA-1/AA-3 & $24 / 12$ & IWLL & -6.74 & -10.15 & -3.31 & -4.25 & -0.34 \\
\hline er106 & A-1/AA-3 & $24 / 4$ & IDLS & -0.40 & -1.39 & -1.84 & 3.92 & 0.56 \\
\hline er107 & $\mathrm{AA}-1 / \mathrm{AA}-3$ & $24 / 8$ & IDLS & -10.54 & -13.17 & -12.62 & -2.95 & -0.95 \\
\hline er108 & $\mathrm{AA}-1 / \mathrm{AA}-3$ & $24 / 12$ & $\overline{\text { IDLS }}$ & -33.83 & -41.74 & -29.45 & -24.05 & -10.82 \\
\hline erl09 & $A-1 / A A-3$ & $24 / 4$ & $\overline{I D L L}$ & -8.47 & -9.63 & -9.72 & -4.14 & -5.63 \\
\hline er 110 & $A-1 / A A-3$ & $24 / 8$ & IDLL & -14.26 & -16.56 & -16.06 & -7.26 & -5.28 \\
\hline erl11 & $\mathrm{AA}-1 / \mathrm{AA}-3$ & $24 / 12$ & IDLL & -30.78 & -36.90 & -26.35 & -23.24 & -14.21 \\
\hline erl12 & $\mathrm{C}-1 / \mathrm{VC}-3$ & $24 / 4$ & IWLS & 18.96 & 19.37 & 17.85 & 21.53 & 14.94 \\
\hline er113 & C-1/VC-3 & $24 / 8$ & IWLS & 20.28 & 20.66 & 18.73 & 24.19 & 18.44 \\
\hline er114 & $\bar{C}-1 / V C-3$ & $24 / 12$ & IWLS & 12.88 & 10.43 & 15.71 & 16.25 & 16.78 \\
\hline er115. & VC-1/VC-3 & $24 / 4$ & IWLL & 19.24 & 19.61 & 18.11 & 21.80 & 15.31 \\
\hline er116 & $\mathrm{C}-1 / \mathrm{VC}-3$ & $24 / 8$ & IWLL & 21.62 & 21.97 & 19.99 & 25.46 & 19.50 \\
\hline er1 17 & VC-1/VC-3 & $24 / 12$ & IWLL & 16.31 & 14.10 & 18.86 & 19.12 & 18.67 \\
\hline er118 & $-1 / V C-3$ & $24 / 4$ & IDLS & 18.10 & 18.56 & 16.55 & 20.94 & 14.46 \\
\hline er119 & $C-1 / V C-3$ & $24 / 8$ & IDLS & 17.93 & 18.39 & 15.45 & 22.52 & 17.18 \\
\hline er120 & $\mathrm{C}-1 / \mathrm{VC}-3$ & $24 / 12$ & IDLS & 12.55 & 10.83 & 13.94 & 16.55 & 15.92 \\
\hline er121 & $\mathrm{C}-1 / \mathrm{VC}-3$ & $24 / 4$ & IDLL & 18.27 & 18.70 & 16.64 & 21.10 & 14.82 \\
\hline er122 & $\mathrm{C}-1 / \mathrm{VC}-3$ & $24 / 8$ & IDLL & 19.66 & 20.06 & 17.16 & 24.06 & 18.58 \\
\hline erl23 & $\mathrm{C}-1 / \mathrm{VC}-3$ & $24 / 12$ & IDLL & 16.34 & 14.71 & 17.64 & 19.65 & 18.27 \\
\hline er124 & $C-2$ & $24 / 4$ & $\overline{N A}$ & 4.42 & 4.84 & 3.58 & 6.97 & 4.20 \\
\hline er125 & $C-2$ & $24 / 8$ & $\mathrm{NA}$ & 6.38 & 7.18 & 4.44 & 10.65 & $\overline{5.91}$ \\
\hline er126 & $\mathrm{C}-2$ & $24 / 12$ & $\mathrm{NA}$ & 6.46 & 5.87 & 7.17 & 8.26 & 6.74 \\
\hline er127 & $\overline{\mathrm{CC}}-2$ & $24 / 4$ & WDLS & 7.99 & 8.70 & 6.58 & 9.05 & 3.25 \\
\hline er128 & $\overline{C-2}$ & $24 / 4$ & WDLL & 7.66 & 8.31 & 6.23 & 8.73 & 3.14 \\
\hline er129 & $\mathrm{CC}-2$ & $24 / 8$ & WDLS & 6.43 & 7.28 & 4.29 & 9.59 & 3.55 \\
\hline er130 & $\mathrm{CC}-2$ & $24 / 8$ & WDLL & 6.58 & 7.39 & 4.49 & 9.65 & 3.76 \\
\hline er131 & $\mathrm{CC}-2$ & $24 / 12$ & WDLS & 4.63 & 3.83 & 5.14 & 5.06 & 4.09 \\
\hline er132 & $\mathrm{CC}-2$ & $24 / 12$ & WDLL & 5.58 & 4.86 & 6.08 & 5.75 & 4.77 \\
\hline er133 & $\overline{\mathrm{CC}-1}$ & $24 / 4$ & IDLS & 12.05 & 12.72 & 10.59 & 13.48 & 7.53 \\
\hline er134 & $\overline{C C-1}$ & $24 / 4$ & IDLL & 11.57 & 12.19 & 10.11 & 13.00 & 7.34 \\
\hline erl35 & $\overline{C C-1}$ & $24 / 8$ & $\overline{\text { IDLS }}$ & 9.56 & 10.24 & 7.37 & 13.38 & 7.72 \\
\hline
\end{tabular}


Table C.22. (contd)

\begin{tabular}{|c|c|c|c|c|c|c|c|c|}
\hline Case & Chiller & Ophrs & Storage & Nash. & Hous. & Minn. & Phoe. & San Fran. \\
\hline er136 & $\mathrm{CC}-1$ & $24 / 8$ & IDLL & 9.95 & 10.61 & 7.84 & 13.61 & 8.03 \\
\hline er137 & CC-1 & $24 / 12$ & IDLS & 4.49 & 3.07 & 5.46 & 6.21 & 6.35 \\
\hline er138 & $\mathrm{CC}-1$ & $24 / 12$ & IDLL & 7.02 & 5.84 & 7.95 & 8.16 & 7.77 \\
\hline er139 & $\mathrm{CC}-2 / \mathrm{CC}-5$ & $24 / 4$ & NA & 6.91 & 7.16 & 6.05 & 10.63 & 7.38 \\
\hline er140 & $\mathrm{CC}-2 / \mathrm{CC}-5$ & $24 / 8$ & NA & 10.85 & 11.46 & 8.75 & 16.52 & 10.94 \\
\hline er141 & $\mathrm{CC}-2 / \mathrm{CC}-5$ & $24 / 12$ & NA & 4.96 & 3.51 & 7.47 & 8.41 & 5.41 \\
\hline er142 & $\overline{\mathrm{CC}-1}$ & $24 / 4$ & IWLS & 12.83 & 13.46 & 11.78 & 14.02 & 7.95 \\
\hline er143 & $\mathrm{CC}-1$ & $24 / 4$ & IWLL & 12.51 & 13.08 & 11.52 & 13.69 & 7.84 \\
\hline er144 & $\overline{C C}-1$ & $24 / 8$ & IWLS & 11.69 & 12.32 & 10.37 & 14.89 & 8.85 \\
\hline er145 & $\mathrm{CC}-1$ & $24 / 8$ & IWLL & 11.86 & 12.46 & 10.59 & 14.99 & 9.00 \\
\hline er146 & $\mathrm{CC}-1$ & $24 / 12$ & IWLS & 4.72 & 2.70 & 7.06 & 5.91 & 7.05 \\
\hline er147 & $\mathrm{CC}-1$ & $24 / 12$ & IWLL & 6.96 & 5.20 & 9.05 & 7.67 & 8.21 \\
\hline er148 & $\mathrm{CC}-1 / \mathrm{CC}-6$ & $24 / 4$ & IWLS & -12.17 & -12.25 & -13.24 & -8.93 & -18.13 \\
\hline er149 & $\mathrm{CC}-1 / \mathrm{CC}-6$ & $24 / 8$ & IWLS & -53.43 & -54.24 & -54.67 & -47.21 & -58.29 \\
\hline er150 & $\mathrm{CC}-1 / \mathrm{CC}-6$ & $24 / 12$ & IWLS & -154.24 & -159.03 & -150.82 & -147.97 & -155.30 \\
\hline er151 & $\mathrm{CC}-1 / \mathrm{CC}-6$ & $24 / 4$ & IWLL & -12.96 & -13.16 & -13.91 & -9.73 & -18.60 \\
\hline er152 & $\mathrm{CC}-1 / \mathrm{CC}-6$ & $24 / 8$ & IWLL & -54.13 & -55.09 & -55.15 & -47.97 & -58.79 \\
\hline er153 & $\mathrm{CC}-1 / \mathrm{CC}-6$ & $24 / 12$ & IWLL & -154.36 & -159.35 & -150.82 & -148.72 & -156.20 \\
\hline er154 & $\mathrm{CC}-1 / \mathrm{CC}-6$ & $24 / 4$ & IDLS & 21.60 & 22.15 & 19.87 & 24.49 & 16.80 \\
\hline er155 & $\mathrm{CC}-1 / \mathrm{CC}-6$ & $24 / 8$ & IDLS & 13.51 & 13.90 & 10.89 & 19.16 & 11.29 \\
\hline er156 & $\mathrm{CC}-1 / \mathrm{CC}-6$ & $24 / 12$ & IDLS & 1.62 & -0.16 & 2.64 & 5.58 & 3.44 \\
\hline er157 & $\mathrm{CC}-1 / \mathrm{CC}-6$ & $24 / 4$ & IDLL & 20.69 & 21.18 & 18.95 & 23.55 & 16.21 \\
\hline er158 & $\mathrm{CC}-1 / \mathrm{CC}-6$ & $24 / 8$ & IDLL & 13.19 & 13.53 & 10.69 & 18.62 & 10.92 \\
\hline er159 & $\mathrm{CC}-1 / \mathrm{CC}-6$ & $24 / 12$ & IDLL & 2.71 & 1.15 & 3.70 & 5.93 & 3.37 \\
\hline er160 & VC-2/CC-5 & $24 / 4$ & NA & 8.68 & 8.98 & 7.70 & 12.43 & 8.60 \\
\hline er161 & $\mathrm{VC}-2 / \mathrm{CC}-5$ & $24 / 8$ & $\mathrm{NA}$ & 13.00 & 13.73 & 10.66 & 18.68 & 12.43 \\
\hline er162 & VC-2/CC-5 & $24 / 12$ & NA & 8.38 & 7.53 & 10.34 & 12.05 & 8.09 \\
\hline er163 & $\mathrm{VC}-1 / \mathrm{CC}-5$ & $24 / 4$ & IWLL & 21.98 & 22.46 & 20.65 & 24.54 & 16.81 \\
\hline er164 & VC-1/CC-5 & $24 / 8$ & IWLL & 15.97 & 16.34 & 14.17 & 20.79 & 12.28 \\
\hline er165 & VC-1/CC-5 & $24 / 12$ & IWLL & 4.75 & 3.12 & 6.38 & 7.60 & 5.21 \\
\hline
\end{tabular}


Table C.23. Combined-Cycle NPV (\$M); Evaporatively-Cooled Base; 24 hr/day plant; $24 \mathrm{hr} /$ day cooling

\begin{tabular}{|l|l|l|r|r|r|r|r|r||}
\hline Case & Chiller & Ophrs & Storage & Nash. & Hous. & Minn. & Phoe. & San Fran. \\
\hline \hline fr1 & CC-4 & $24 / 24$ & NA & -5.17 & -9.02 & -2.15 & -1.94 & 0.68 \\
\hline fr2 & LiBr-2 & $24 / 24$ & NA & -3.64 & -6.09 & -1.89 & 0.16 & 2.17 \\
\hline fr3 & AA-2 & $24 / 24$ & NA & -25.58 & -29.88 & -22.21 & -16.76 & -9.23 \\
\hline fr4 & VC-2 & $24 / 24$ & NA & 9.42 & 8.99 & 9.78 & 11.50 & 9.36 \\
\hline fr5 & CC-4/CC-5 & $24 / 24$ & NA & -14.31 & -20.27 & -7.55 & -9.18 & -8.60 \\
\hline fr6 & AA-2/AA-3 & $24 / 24$ & NA & -52.90 & -61.27 & -45.24 & -39.48 & -30.57 \\
\hline fr7 & VC-2/VC-3 & $24 / 24$ & NA & 15.61 & 13.43 & 17.57 & 20.04 & 17.41 \\
\hline fr8 & CC-2 & $24 / 24$ & NA & 5.14 & 3.61 & 6.43 & 7.05 & 6.16 \\
\hline fr9 & CC-2/CC-5 & $24 / 24$ & NA & -3.10 & -6.55 & 1.78 & 0.60 & -2.64 \\
\hline fr10 & VC-2/CC-5 & $24 / 24$ & NA & 1.43 & -0.81 & 5.31 & 5.31 & 0.72 \\
\hline
\end{tabular}


Table C.24. Industrial Turbine NPV (\$M); Evaporatively-Cooled Base

\begin{tabular}{|c|c|c|c|c|c|c|c|c|}
\hline Case & Chiller & Ophrs & Storage & Nash. & Hous. & Minn. & Phoe. & San Fran. \\
\hline$\overline{\text { ir1 }}$ & $\overline{\mathrm{AA}-2}$ & $4 / 4$ & $\overline{\mathrm{NA}}$ & -17.03 & -18.19 & -16.22 & -12.33 & $-\overline{-6.62}$ \\
\hline ir2 & $\mathrm{AA}-2$ & $8 / 8$ & $\mathrm{NA}$. & -16.62 & -17.76 & -16.97 & -12.00 & 33.30 \\
\hline ir3 & $\mathrm{CC}-2$ & $4 / 4$ & NA & 0.76 & 0.78 & 0.64 & 1.98 & 0.78 \\
\hline ir4 & $\mathrm{CC}-2$ & $8 / 8$ & NA & 1.13 & 1.22 & 0.66 & 2.32 & 41.66 \\
\hline$\overline{\text { ir5 }}$ & $\mathrm{LiBr}-1$ & $4 / 4$ & $\overline{N A}$ & -0.95 & -1.05 & -0.93 & 0.49 & -0.81 \\
\hline ir6 & $\mathrm{LiBr}-1$ & $8 / 8$ & $\mathrm{NA}$ & -0.71 & -0.77 & -1.14 & 0.64 & 40.33 \\
\hline$\overline{\text { ir7 }}$ & VC-2 & $4 / 4$ & $\mathrm{NA}$ & 1.08 & 0.99 & 1.10 & 2.34 & 1.49 \\
\hline ir8 & VC-2 & $8 / 8$ & $\overline{N A}$ & 1.27 & 1.15 & 1.03 & 2.55 & 42.37 \\
\hline irg & $\mathrm{VC}-1$ & $4 / 4$ & IWLS & 6.10 & 6.17 & 5.96 & 6.35 & 3.43 \\
\hline irlo & VC-1 & $4 / 4$ & IWLL & 5.92 & 5.95 & 5.82 & 6.17 & 3.39 \\
\hline irl1 & VC-1 & $4 / 4$ & IDLS & 5.48 & 5.59 & 5.05 & 5.91 & 3.10 \\
\hline irl2 & VC-1 & $4 / 4$ & IDLL & 5.29 & 5.35 & 4.86 & 5.72 & $\overline{3.06}$ \\
\hline ir13 & $\overline{V C-1}$ & $8 / 8$ & IWLS & 4.25 & 4.07 & 4.41 & 4.69 & 43.73 \\
\hline ir14 & VC-1 & $8 / 8$ & IWLL & 4.35 & 4.11 & 4.55 & 4.76 & $\overline{43.86}$ \\
\hline ir15 & $\overline{\mathrm{V} C}-1$ & $8 / 8$ & IDLS & 2.40 & 2.24 & 1.97 & 3.32 & $\overline{42.76}$ \\
\hline ir16 & VC-1 & $8 / 8$ & IDLL & 3.02 & 2.81 & 2.66 & 3.82 & 43.21 \\
\hline ir17 & VC-2 & $4 / 4$ & WWLS & 3.26 & 3.25 & 3.22 & 3.37 & 1.07 \\
\hline ir18 & VC-2 & $4 / 4$ & WWLL & 3.24 & 3.21 & 3.21 & 3.35 & 1.10 \\
\hline ir19 & VC-2 & $4 / 4$ & WDLS & 3.56 & 3.71 & 3.14 & 3.79 & 1.00 \\
\hline ir20 & VC-2 & $4 / 4$ & WDLL & 3.47 & 3.58 & 3.05 & 3.70 & 1.01 \\
\hline ir21 & $\mathrm{VC}-2$ & $8 / 8$ & WWLS & 1.36 & 1.08 & 1.64 & 1.63 & 41.43 \\
\hline ir22 & VC-2 & $8 / 8$ & WWLL & 1.75 & 1.47 & 2.02 & 1.98 & 41.66 \\
\hline ir23 & VC-2 & $8 / 8$ & WDLS & 1.68 & 1.64 & 1.23 & 2.21 & 41.24 \\
\hline ir24 & VC-2 & $8 / 8$ & WDLL & 2.09 & 2.02 & 1.68 & 2.54 & 41.57 \\
\hline ir25 & $\mathrm{CC}-2 / \mathrm{CC}-5$ & $4 / 4$ & $\overline{N A}$ & $1: 48$ & 1.37 & 1.28 & 3.51 & 1.05 \\
\hline ir26 & $\mathrm{CC}-2 / \mathrm{CC}-5$ & $8 / 8$ & NA & 2.54 & 2.49 & 1.93 & 4.61 & 42.56 \\
\hline ir27 & $\mathrm{AA}-2 / \mathrm{AA}-3$ & $4 / 4$ & $\overline{\mathrm{NA}}$ & -30.70 & -32.48 & -29.64 & -24.11 & -17.99 \\
\hline ir28 & AA-2/AA-3 & $8 / 8$ & $\overline{\mathrm{NA}}$ & -29.59 & -31.34 & \begin{tabular}{|l|}
-29.97 \\
\end{tabular} & -23.00 & 22.27 \\
\hline ir29 & VC-2/VC-3 & $4 / 4$ & $\overline{N A}$ & 1.20 & 0.86 & 1.36 & 3.38 & 2.59 \\
\hline ir 30 & $\mathrm{VC}-2 / \mathrm{VC}-3$ & $8 / 8$ & $\mathrm{NA}$ & 1.26 & 0.78 & 1.16 & 3.59 & 43.33 \\
\hline ir31 & VC-1/VC-3 & $4 / 4$ & IWLS & 6.60 & 6.43 & 6.60 & 7.69 & 4.66 \\
\hline ir32 & VC-1/VC-3 & $8 / 8$ & IWLS & 4.52 & 3.99 & 4.85 & 5.94 & 44.80 \\
\hline ir33 & VC-1/VC-3 & $4 / 4$ & IWLL & 6.92 & 6.73 & 6.87 & 7.98 & 5.04 \\
\hline ir34 & VC-1/VC-3 & $8 / 8$ & IWLL & 5.52 & 4.95 & 5.77 & \begin{tabular}{l|l|}
6.89 \\
\end{tabular} & 45.72 \\
\hline
\end{tabular}


Table C.24. (contd)

\begin{tabular}{|l|c|r|c|r|r|r|r|r||}
\hline \hline Case & Chiller & Ophrs & Storage & Nash. & Hous. & Minn. & Phoe. & San Fran. \\
\hline \hline ir35 & VC-1/VC-3 & $4 / 4$ & IDLS & 5.96 & 5.82 & 5.64 & 7.24 & 4.31 \\
\hline ir36 & VC-1/VC-3 & $8 / 8$ & IDLS & 2.55 & 2.03 & 2.26 & 4.49 & 43.78 \\
\hline ir37 & VC-1/VC-3 & $4 / 4$ & IDLL & 6.23 & 6.08 & 5.84 & 7.49 & 4.69 \\
\hline ir38 & VC-1/VC-3 & $8 / 8$ & IDLL & 4.05 & 3.48 & 3.73 & 5.82 & 45.02 \\
\hline ir39 & VC-2/CC-5 & $4 / 4$ & NA & 1.08 & 0.79 & 1.08 & 3.30 & 1.66 \\
\hline ir40 & VC-2/CC-5 & $8 / 8$ & NA & 1.87 & 1.53 & 1.51 & 4.18 & 43.05 \\
\hline ir41 & VC-1/CC-5 & $4 / 4$ & IWLL & 6.27 & 6.11 & 6.14 & 7.41 & 3.67 \\
\hline ir42 & VC-1/CC-5 & $8 / 8$ & IWLL & 5.18 & 4.72 & 5.29 & 6.56 & 44.63 \\
\hline
\end{tabular}





\section{Distribution}

No. of

Copies

\section{OFFSITE}

2 DOE/Office of Scientific and Technical Information

G. Albrecht

Westinghouse Electric Corporation

Energy Center

4400 Alafaya Trail, MC 550

Orlando, FL 32826

C. Dorgan

Thermal Energy Storage Applications

Research Center

University of Wisconsin

150 East Gilman

Room 2200

Madison, WI 53703-1441

R. Dracker

Bechtel

50 Beale Street

San Francisco, CA 94105-1895

J. Ebeling

Burns and McDonnell Engineering

Company

4800 East 63rd Street

Kansas City, MO 64130

A. F. Ellis

Southern Company Services, Inc.

P.O. Box 2625

Birmingham, AL 35202

D. Erickson

Energy Concepts Company

627 Ridgely Avenue

Annapolis, MD 21401
No. of

Copies.

K. Gainer

Business Communications Company, Inc.

25 Van Zant Street

Suite No. 13

Norwalk, CT 06855-1713

J. Kimball

Gas Research Institute

8600 West Bryn Manor Avenue

Chicago, IL 60631-3562

D. Knebel

12830 Link Drive

Shakapee, MN 55379

C. Kohlenberger

Kohlenberger Associates

Consulting Engineers, Inc.

611 South Euclid Street

Fullerton, CA 92635

C. Landry

Turbo Refrigerating

1815 Shady Oaks Drive

Denton, TX 76205

J. McNamara

Resorcon, Inc.

701 Rodi Road

Suite 102

Pittsburgh, PA 15235

I. Ondryas

Fluor Daniel, Inc.

3333 Michelson Drive

Irvine, CA 92730

T. Ramisch

Pacific Power

920 SW 6th Avenue

Portland, OR 97204

Distr.1 
.No. of

Copies

P. Sarkisian

Rocky Research

P.O. Box 61800

Boulder City, NV 89006-1800

B. Silvetti

Calmac Manufacturing Corp.

$101 \mathrm{~W}$. Sheffield Ave.

Englewood, NJ 07631-480.4

D. Sopocy

Sargent \& Lundy

20th Floor

55 East Monroe Street

Chicago, IL 60603

5 U.S. Department of Energy

Office of Energy Efficiency and

Renewable Energy

1000 Independence Avenue, S.W.

Washington, D.C. 20585

ATTN: S. Blazewecz

R. Eaton

D. Knowles

EE-221

EE-142

EE-221

B. Parks

EE-221

N. Rossmeissl

EE-142
No. of

Copies

G. Weidinger

U.S. Generating Company

7500 Old Georgetown Road

Bethesda, MD 20814

P. Winters

CBI - Walker

1245 Corporate Blvd

Suite 102

Aurora, IL 60504

\section{ONSITE}

DOE Richland Operations Office

50 Pacific Northwest National Laboratory

S. J. Arey (20)

K5-20

D. R. Brown (20)

K8-17

S. Katipamula

K5-16

J. H. Konynenbelt

P7-41

S. Somasundaram

K5-20

Information Release Office (7) 